\title{
INTERNET Y POBREZA
}

\author{
Bernardo Sorj \\ Luis Eduardo Guedes
}




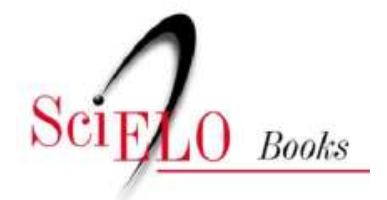

\title{
Internet y pobreza
}

\author{
Bernardo Sorj \\ Luis Eduardo Guedes
}

SORJ, B., and GUEDES, LE. Internet y pobreza [online]. Rio de Janeiro: Centro Edelstein de Pesquisa Social, 2008. 173 p. ISBN 978-85-99662-49-6. Available from SciELO Books <http://books.scielo.org>.

\section{(1)(9)(2)}

All the contents of this chapter, except where otherwise noted, is licensed under a Creative Commons Attribution-Non Commercial-ShareAlike 3.0 Unported.

Todo o conteúdo deste capítulo, exceto quando houver ressalva, é publicado sob a licença Creative Commons Atribuição Uso Não Comercial - Partilha nos Mesmos Termos 3.0 Não adaptada.

Todo el contenido de este capítulo, excepto donde se indique lo contrario, está bajo licencia de la licencia Creative Commons Reconocimento-NoComercial-CompartirIgual 3.0 Unported. 
Esta publicación es parte de la Biblioteca Virtual de Ciencias Humanas del Centro Edelstein de investigaciones Sociales - www.bvce.org

Copyright (C) 2008, Bernardo Sorj y Luís Eduardo Guedes Copyright (c) 2008 de esta edición on-line: Centro Edelstein de Pesquisas Sociais

Traducción del portugués por Patricia Rivero: Internet na favela, Rio de Janeiro, Gramma, 2005.

Ninguna parte de esta publicación puede ser reproducida o transmitida por cualquier medio de comunicación para uso comercial sin el permiso escrito de los propietarios de los derechos de autor. La publicación en su conjunto o en parte puede ser reproducida para fines no comerciales a condición de que el origen de la publicación y autor sea debidamente reconocida.

ISBN 978-85-99662-49-6

Centro Edelstein de Investigaciones Sociales www.centroedelstein.org.br/espanol/index.asp Rua Visconde de Pirajá, 330/1205

Ipanema - Rio de Janeiro - RJ

CEP: 22410-000. Brasil

Contacto: bvce@centroedelstein.org.br 


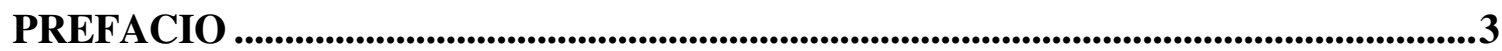

1 - INTRODUCCIÓN ...........................................................................................................4

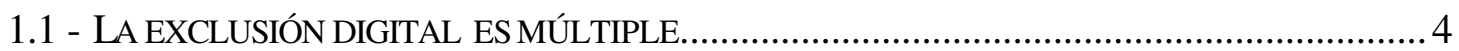

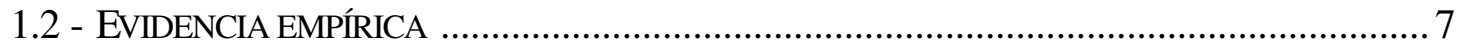

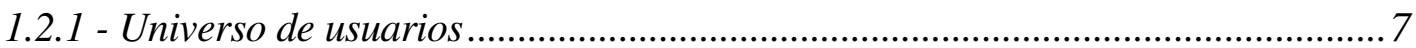

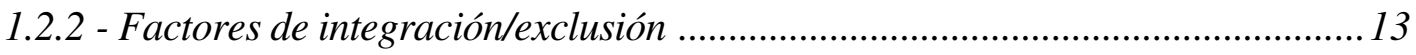

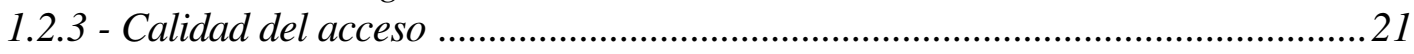

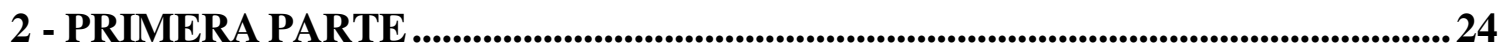

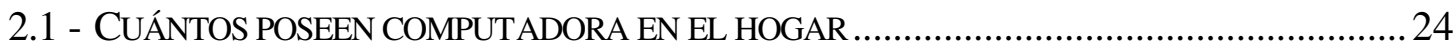

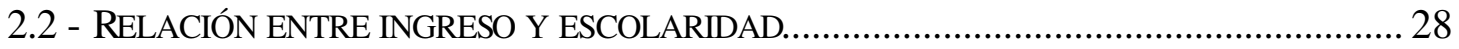

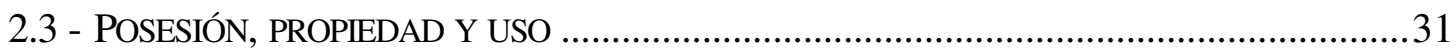

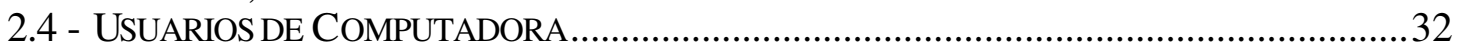

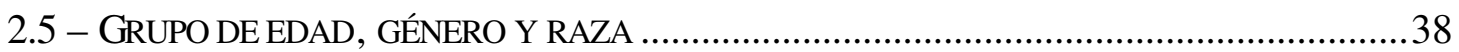

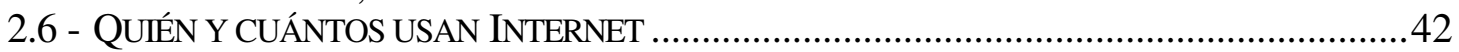

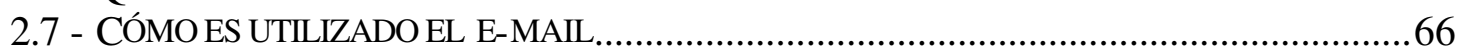

2.8 - TELECENTROS: EL CASO DE LAS ESTACIONES FUTURO............................................. 71

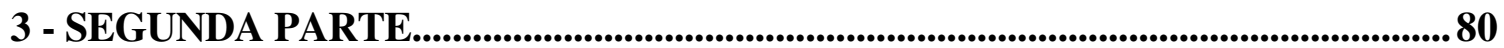

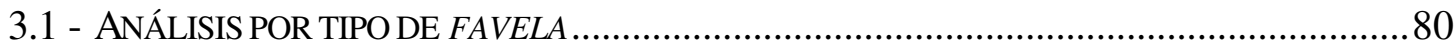

3.2 - ANÁLISIS DETALLADO DE LOS USUARIOS DEINFORMÁTICA E INTERNET .....................87

3.3 - DIFERENCIAS DE ACUERDO AL GÉNERO ................................................................ 108

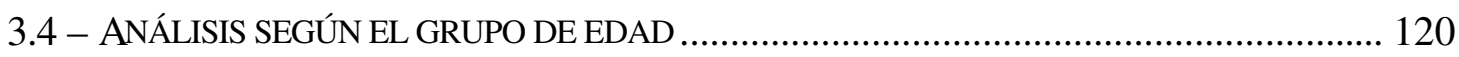

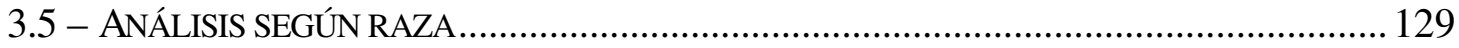

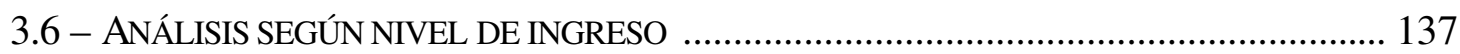

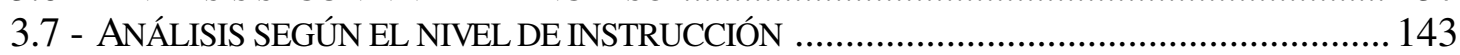

3.8 - ANÁLISIS SEGÚN TIPO DE INSTITUCIÓN DE ENSEÑANZA ............................................. 152

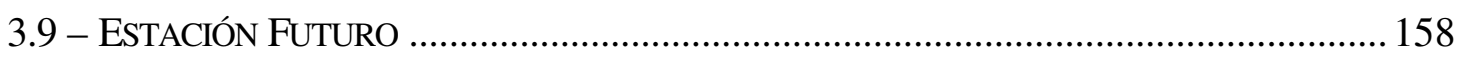

4 - CONCLUSIONES: POLÍTICAS PÚBLICAS E INCLUSIÓN DIGITAL ............ 165

ANEXO 1: REPRESENTATIVIDAD DEL UNIVERSO DE INVESTIGACIÓN ..... 169 


\section{Prefacio}

Este trabajo intenta avanzar en la elaboración de políticas públicas a partir del análisis empírico de la dinámica de inclusión/exclusión digital en los sectores más pobres de la población, teniendo como base una amplia investigación cuantitativa y cualitativa en los barrios de bajos ingresos del municipio de Rio de Janeiro. La encuesta fue realizada en dos etapas, en el segundo semestre de 2003 en Rio de Janeiro. Cada una de estas etapas contó con 1.510 entrevistas, representando un universo de cerca de un millón doscientos mil individuos. La investigación fue complementada por la realización de reuniones con ocho grupos motivacionales con muestras de las diferentes grupos de edad y de género. ${ }^{3}$

La discusión sobre inclusión digital como instrumento de lucha contra la pobreza y la desigualdad social está entrando en una nueva fase, fundada en evidencias empíricas. Estos estud ios permitirán ir más allá de las generalizaciones que dominaron el debate, que osciló entre aquellos que vendían la inclusión digital como una panacea para los males de bs países en desarrollo y los que la denunciaban como retórica vacía o al servicio de intereses comerciales de bs países del primer mundo. En ambos casos eran movilizados ejemplos anecdóticos de éxito o fracaso sin representatividad y retirados del contexto social más amplio.

Agradecemos al ICA (Institute for Connectivy Americas)/IDRC e a la Unesco por el apoyo para la realización de esta investigación. Este trabajo no habría sido posible sin los comentarios de Rubem César Fernand es, Franklin Coelho y la dedicación del equipo del Núcleo de Investigaciones Favela, Opinión y Mercado del ISER/Viva Rio

\footnotetext{
${ }^{3}$ En la primera encuesta fue realizado un levantamiento con el universo represent ativo del conjunto de los habitantes de las favelas. En la segunda, fueron investigadas, utilizando un cuestionario más detallado, seis favelas, dos con el promedio de ingresos más altos, dos con el promedio de ingresos intermedios y ds con el promedio de ingresos bajos. Mientras en la primera encuesta fue incluida la población con más de 15 años que utiliza o no micro-computadores, en la segunda fueron incluidos niños a partir de 10 años de edad, y todos los entrevistados deberían usar micro-computador, con la intención de profundizar el conocimiento de este universo.
} 


\section{1 - Introducción}

\section{1 - La exclusión digital es múltiple ${ }^{4}$}

En este estudio la exclusión digital se refiere a las consecuencias sociales, económicas y culturales de la distribución desigual al acceso a computadoras e Internet, excluyendo por lo tanto el acceso a la telefonía. Aunque el teléfono pertenece al mismo grupo de productos de IC (Informática y Comunicación), inclusive compartiendo la misma infraestructura, desde una perspectiva sociológica, posee características bastante diferentes. Los teléfonos son parte de la familia de productos "inclusivos para analfabetos" - esto significa, productos que pueden ser utilizados por personas técnicamente sin escolaridad -, mientras las computadoras e Internet exigen un nivel educacional mínimo. Si la futura convergencia de tecnologías llevase al uso de teléfonos celulares para la transmisión de lectura de mensajes escritos, posiblemente tendríamos nuevas formas de desigualdad entre los usuarios de teléfonos.

Este artículo focalizará sobre el acceso individual a computadoras e Internet, tema que está relacionado - pero no debe ser confundido - con el uso de las Tecnologías de Información y de Comunicación (TIC) como un instrumento de desarrollo y crecimiento económico. Aunque la mayoría de la bibliografía sobre exclusión digital producida por las organizaciones internacionales enfatiza el potencial de las TICs para reducir la pobreza y la desigualdad, la dinámica social en la práctica funciona en sentido contrario: la introducción de nuevas TICs aumenta la exclusión y la desigualdad social. La universalización del

\footnotetext{
${ }^{4}$ La bibliografía sobre exclusión digital actualmente es bastante consensual sobre la necesidad de tener en cuenta la diversidad de situaciones de acceso y uso. Ver, por ejemplo, "Digital Divides: Past, Present and Future", IT\&Society, Vol. 1, Issue 5, Summer 2003 y Mark Warschauer, "Reconceptualizing the Digital Divide", First Monday, Vol. 7, no. 7, 2002. Asimismo existen pocos estudios cuantitativos detallados sobretipos de accesos y usos de Internet. Entre los más completos ver "The UCInternet Report - Surveying the Digital Future, Year Three", UCLA Center for Communication Policy, February 2003 (www.ccp.ucla.edu). En relación a Europa ver el estud io realizado por la Eurostat "ICT usage in household and by individuals", 2004. (http://europa.eu.int/information_society/activities/statistics/index_en.htm). Sólo cuando tengamos estudios más profundosy detallados de los tipos de acceso y uso dentro de cada realidad nacional será posible realizar comparaciones internaciona les más precisas sobre el impacto efectivo del acceso a las tecnologías de lacomunicación.
} 
acceso es sobre todo un instrumento para disminuir los daños sociales, desde el punto de vista de la lucha contra la desigualdad. ¿Por qué?:

a) La pobreza no es un fenómeno aislado. Cómo la pobreza es definida y percibida, depende del nivel de desarrollo cultural/tecnológico/político de cada sociedad. La introducción de nuevos productos que pasan a ser indicativos de la condición de vida “civilizada" (ya sea el teléfono, la electricidad, la heladera, la radio o la TV) aumenta el nivel límite de bienes considerados necesarios, por debajo del cual una persona o familia es considerada pobre. Como el ciclo de acceso a nuevos productos comienza con los riesgos para que se extiendan a los pobres, después de pasado un tiempo más o menos largo (el ciclo muchas veces no se completa), la introducción de nuevos productos esenciales aumenta la desigu aldad.

b) Como los ricos son los primeros a alcanzar los beneficios del uso e/o dominio de los nuevos productos, ellos aumentan sus ventajas competitivas, mientras que la carencia de estos bienes aumenta las desventajas de los grupos excluidos.

En ambos casos, nuevos productos TICs, en principio, aumentan la pobreza y la exclusión digital. Las políticas públicas pueden aprovechar las nuevas tecnologías para mejorar las condiciones de vida del conjunto de la población y de los más pobres, pero la lucha contra la exclusión digital es en primer lugar la lucha para encontrar caminos que disminuyan el impacto negativo de éstas sobre la distribución de la riqueza y las oportunidades de vida.

Los estudios que más profundizan sobre la exclusión digital, generalmente están concentrados en pequeñas comunidades o experiencias locales, cuyo valor es limitado, pues en general presentan poca o ninguna interfase con los estudios basados en datos cuantitativos $^{5}$. Por otro lado, los estudios estadísticos, particularmente los relativos a los países en desarrollo, tienen como parámetro principal, y generalmente único, la división entre los que tienen y los que no tienen acceso a la informática y a Internet en el hogar. A pesar de ser una forma de medir importante, resulta insuficiente para entender la dinámica

\footnotetext{
${ }^{5}$ Se reproduce una oposición bastante común entre los estudios cuantitativos realizados generalmente por los economistas y los trabajos cualitativos, realizados por sociólogos y antropólogos.
} 
social de la exclusión digital y definir políticas de universalización de acceso, pues presenta tres grandes limitaciones:

a) No identifica la calidad del acceso, ya sea en términos de velocidad de la conexión o
del costo/tiempo disponible de conexión, en particular para los grupos más pobres
de la población.
b) Cuando los estudios cuantitativos diferencian sectores socio-económicos suponen
que el universo de usuarios es el de aquellos que poseen computador en el hogar.
c) Éstos no dan pistas sobre la diversidad de usos y la relevancia de la inclusión digital
para los usuarios. Este último punto, a pesar de ser central, no será objeto de esta
presentación y será tratado detalladamente en la segunda parte del libro.

La exclusión digital no se refiere a un fenómeno sencillo, que trata de los que tienen y de los que no tienen acceso a la computadora y a Internet, de los incluidos y de los excluidos, una polaridad que a pesar de ser real a veces disfraza los múltiples aspectos de la exclusión digital. El motivo de esto es simple, la oposición acceso/no acceso es una generalización entendible cuando se trata de servicios públicos o de bienes de consumo intermedios tradicionales (a pesar de que el tipo de TV, heladera o automóvil pueden ser mejores o peores, y para la población pobre el costo de la llamada limita enormemente el uso del teléfono o el costo de la gasolina limita el uso del automóvil).

El número de propietarios de computadoras o personas con acceso a Internet es una forma demasiado primitiva para medir la exclusión digital. ¿Por qué? a) porque la cantidad de tiempo disponible y la calidad del acceso afectan decisivamente el uso de Internet, b) porque las tecnologías de la información y de la comunicación (desde ahora en adelante telemática) son muy dinámicas y obligan a una constante actualización de hardware y software y de los sistemas de acceso, exigiendo una inversión constante por parte del usuario para no quedar obsoleto, c) porque su potencial de utilización depende de la 
capacidad de lectura y de la interpretación de la información por parte del usuario (en el caso de Internet) y de la red social (en el caso del e-mail).

A continuación presentamos algunos de los principales resultados de la investigación y sus implicaciones para la elaboración de políticas y proyectos sociales de inclusión digital. Debemos destacar que en este trabajo enfatizamos en la inclusión digital de los individuos. Otros aspectos también deberán ser considerados. En ciertos contextos, la inclusión digital de instituciones comunitarias puede mejorar la calidad de vida de las poblaciones pobres, en particular de aquellas que están espacialmente aisladas, ofreciendo servicios e informaciones de valor cultural, económico y social.

\section{2 - Evidencia empírica}

\subsection{1 - Universo de usuarios}

La inclusión digital en un país generalmente se define a través del porcentaje de personas en el total de la población, con acceso a computador e/o Internet en el domicilio. ${ }^{6}$ Para identificar las personas incluidas, el criterio generalmente utilizado es el número de computadoras por domicilio y/o de computadoras por domicilio con conexión a Internet. Esta metodología ya fue objeto de críticas, pues en ciertos países, con un número relevante de puntos de acceso colectivo (comúnmente denominados de tele-centros o ciber-cafés), el número de personas que entran a Internet por computadora es mucho mayor que el promedio de entrada por hogar. Se argumenta también que las familias de clase media generalmente poseen más de una computadora por hogar, lo que no sucede en familias pobres, y significaría un mayor número de usuarios por computadora en las familias pobres y un número menor en las familias de clase media.

En el caso brasileño, el impacto estadístico de los tele-centros es secundario, debido a que su número a escala nacional todavía es relativamente pequeño, aunque, como veremos, está lejos de ser insignificante para los barrios donde se localizan. Por su parte, la expectativa de 
un mayor número de usuarios por computadora en el hogar, en el caso de las familias pobres, debe ser calificada, ya que, como lo indica nuestra investigación, en la mayor parte de los casos, son pocos los miembros de familias pobres que usan computadora.

Como lo muestran los datos a continuación, la cuantificación de la inclusión digital a partir del número de computadoras por hogar produce una visión totalmente equivocada sobre el acceso a la informática y a Internet de los sectores más pobres de la población. Esto sucede porque solamente la mitad de los que poseen computadora tienen conexión a Internet en el hogar, y sobre todo, porque para los usuarios de informática y de Internet en las favelas $^{7}$, el local de trabajo y la casa de terceros constituyen el principal lugar de entrada. Veamos las estadísticas:

De acuerdo con la investigación, 9\% de los hogares localizados en las favelas poseen computadora.

Gráfico 1.2.2.1: Posesión de computadora en el hogar, en los barrios del municipio de Rio de Janeiro

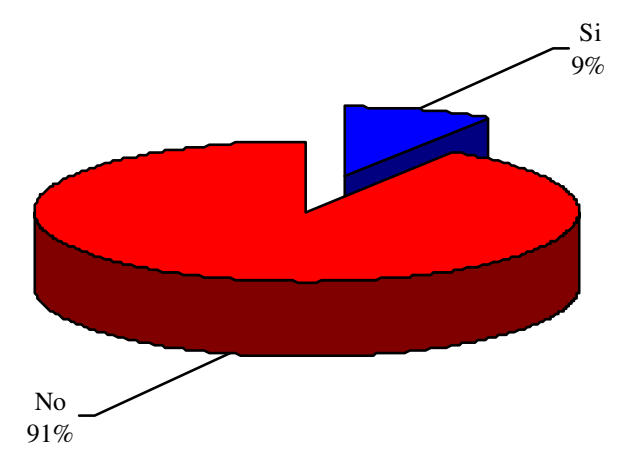

\footnotetext{
${ }^{6}$ Como lo hace, por ejemplo, el Mapa de la Exclusión Digital de la Fundación Getulio Vargas: http://www2.fgv.br/ibre/cps/mapa_exclusao/apresentacao/apresentacao.htm

${ }^{7}$ Las favelas son barrios formados en tierras públicas o privadas, sin planificación urbana, con servicios públicos precarios, habitados, mayoritariamente, por segmentos pobres de la población y muchas veces bajo el control de grupos armados asociados al trafico de drogas.
} 
El acceso a informática en las favelas, incluso, es superior al promedio de muchas capitales del Norte y del Nordeste del país. Si posesión de computadora en las favelas de Rio de Janeiro está cerca del promedio nacional, ésta es $30 \%$ inferior al promedio del estado y presenta, en relación a su ambiente directo (el Municipio de Rio de Janeiro), una relación de 1 computadora para 2.6 computadoras (y comparado con los barrios más ricos, la distancia es alrededor de 1 para 6).

Gráfico 1.2.2.2: Comparación entre las tasas de inclusión digital de los barrios de bajos ingresos del municipio de Rio de Janeiro y algunas capitales

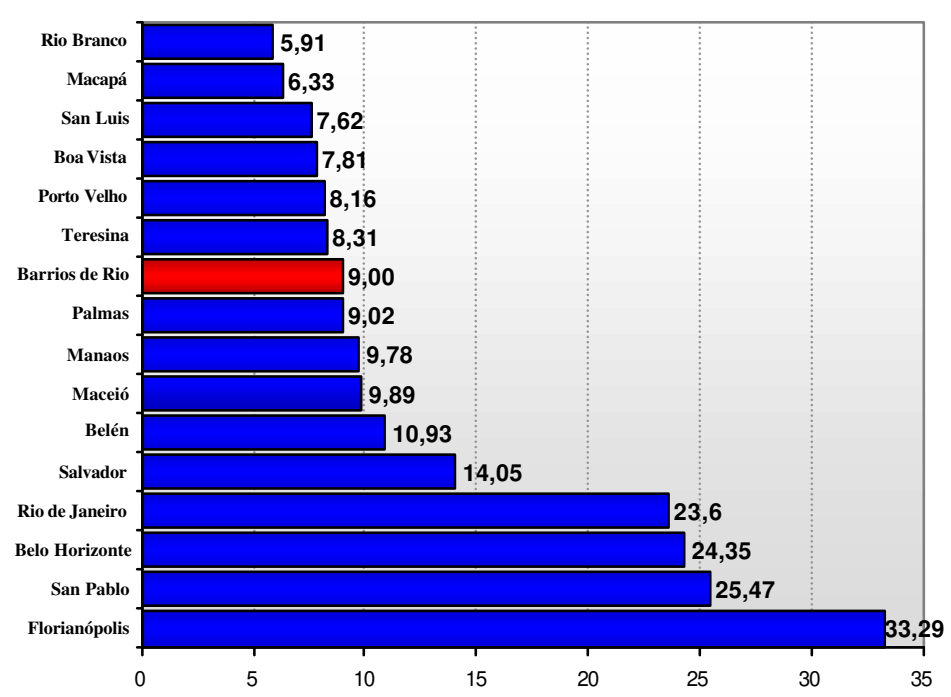

Nota: Inclusión Digital, en este caso, se refiere al porcentaje de computadoras en el total de hogares.

El proceso desigual de difusión de la computadora entre ł población de las diferentes ciudades de Brasil refleja, sin duda, el nivel desigual de riqueza y de escolaridad entre las diferentes regiones y ciudades del país, particularmente de las poblaciones pobres de la región Norte y Nordeste en relación al Centro-Sur. Pero la posesión de computadora está también relacionada a un componente no tangible: la difusión de una cultura de valorización de la informática asociada particularmente a la noción de que su dominio es condición de empleo y éxito en la educación. En otros términos, a medida que el sistema productivo se informatiza, la noción de que es necesario dominar este instrumento para 
asegurar mayores posibilidades de trabajo se "infiltra" rápidamente entre los diversos sectores sociales, pues el uso de la informática pasa a ser visto como condición de obtención de trabajo y de éxito educativo. De hecho, la única pregunta para la cual encontramos una respuesta de consenso, independientemente del nivel educacional, ingreso, raza o género, es en relación a la importancia que el conocimiento de informática tiene para la obtención de empleo: casi todos los entrevistados señalaron que ésta ayuda a conseguir trabajo. Por lo tanto, si la difusión de la computadora tiene una correlación obvia con el nivel de ingreso y de escolaridad, también está asociada a los patrones culturales más amplios de informatización de la sociedad.

La exclusión digital se da también dentro de los grupos pobres, entre géneros, razas y grupos de edad, así como entre diferentes barrios. La mención a los barrios pobres puede dar una visión homogénea de éstos, pero en el interior de cada barrio pobre como entre ellos, la desigualdad en la posesión de computadora es muy marcada:

\section{Gráfico 1.2.1.3: Comparación entre las tasas de inclusión digital de barrios de bajos ingresos del municipio de Rio de Janeiro y algunos municipios del estado}

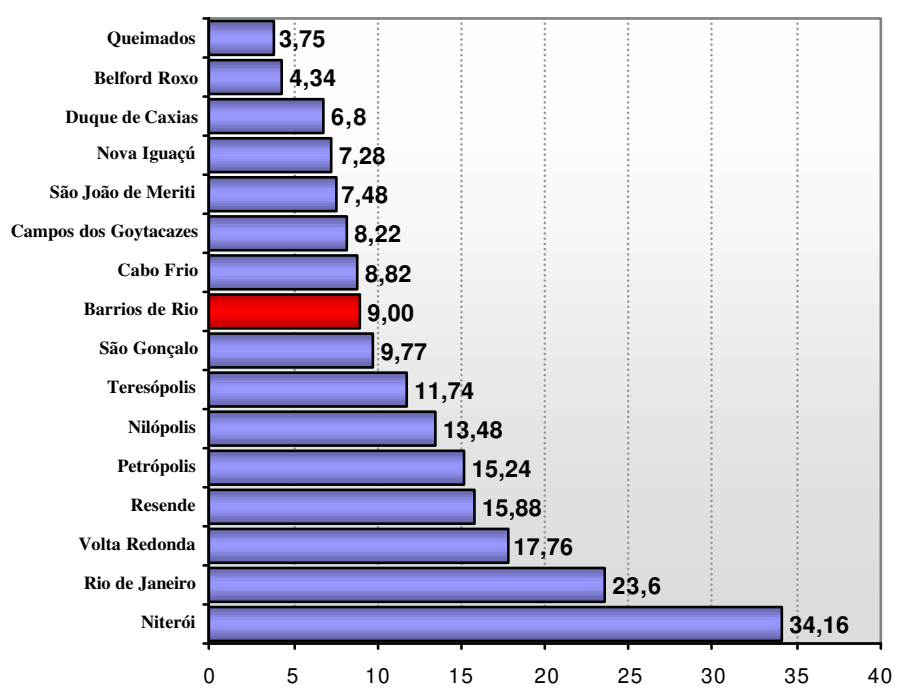

Nota: Inclusión Digital, en este caso, se refiere al porcentaje de hogares con computadora.

Sin embargo, el número de personas con computadora en el hogar no define el número de usuarios, que es el doble de los que lo poseen: 
Gráfico 1.2.1.4: Porcentaje de personas que poseen y que utilizan computadoras en los barrios de bajos ingresos del municipio de Rio de Janeiro

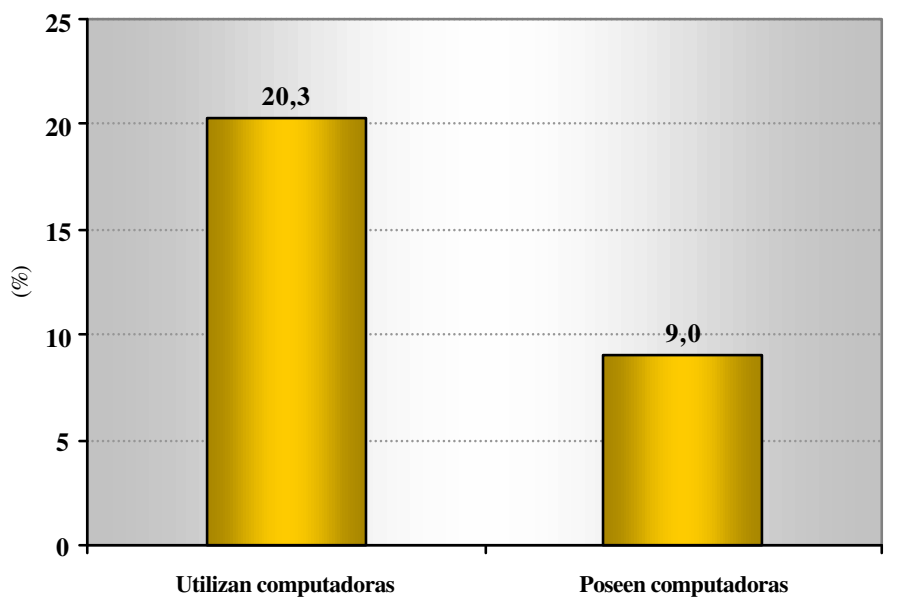

Una posible explicación de que el número de usuarios de computadora sea mayor que el número de hogares con computadora, es que cada computadora sería utilizada por varios miembros de la familia. Pero esta explicación es insuficiente, pues solamente $27.6 \%$ de los entrevistados señalaron al hogar como principal local de uso de la computadora. Incluso los entrevistados y las entrevistas de los grupos motivacionales indican que la computadora generalmente es vista como un bien de consumo personal, aunque posesión y propiedad no estén claramente definidas. Muchos, en particular los jóvenes, definen la computadora como "suya", aunque haya sido comprada por los padres. La cuestión de la posesión está directamente relacionada a la utilización, pues, en general, es quien la utiliza que define la computadora como suya. La tendencia a la individualización de la propiedad de la computadora está asociada tanto al hecho de que muchos miembros de la familia no usan computador como a la voluntad de afirmar la posesión, debido al conflicto sobre los horarios de su utilización, tema que fue indicado en los grupos motivacionales como productor de tensiones dentro de la familia.

El mayor número de usuarios en relación a los propietarios es consecuencia, principalmente, de que en las favelas el hogar no es el principal local de acceso a la computadora: 
Gráfico 1.2.1.5: Principal local de utilización de la computadora en los barrios de bajos ingresos del municipio de Rio de Janeiro

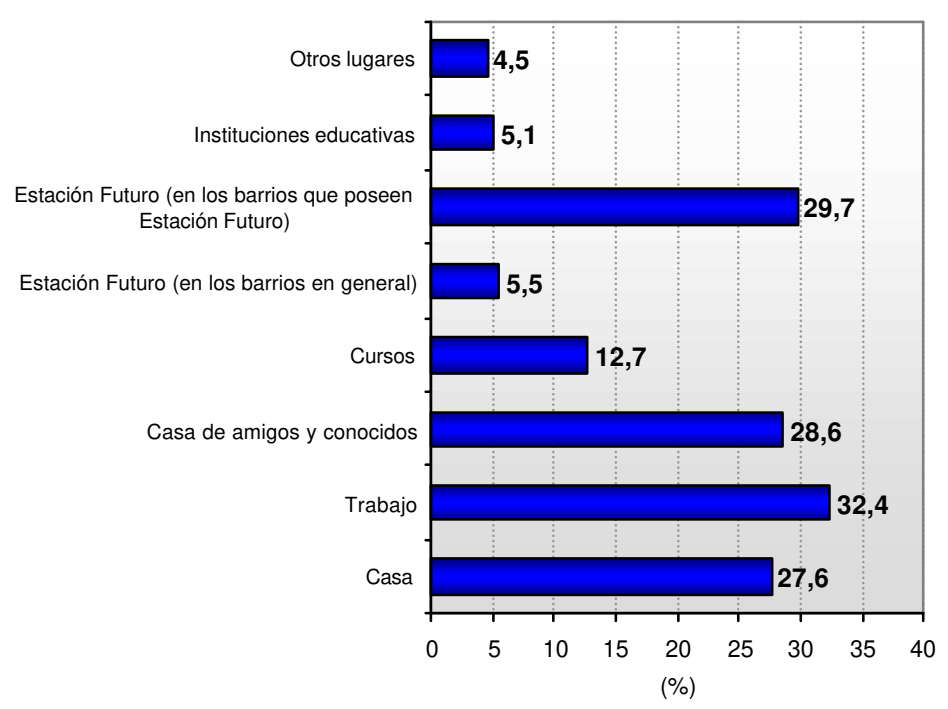

El trabajo (no el hogar), representa para los habitantes de la favela el principal local de utilización de la computadora, seguido por la casa de amigos y conocidos, quedando en tercer lugar el hogar. En las favelas donde existen Estaciones Futuro (tele-centros) de la ONG Viva Rio, éstas son el segundo local de acceso para casi $\mathbf{3 0 \%}$ de los usuarios de informática. Estos datos contradicen la expectativa de que entre los sectores más pobres de la población el número de usuarios por computadora en el hogar es alto, pues, en general, son pocos los miembros de la familia que utilizan computadora, generalmente son los dependientes y menores de edad.

Este fenómeno de disociación, entre posesión de computadora y usuarios, se reproduce en relación a Internet. Aunque solamente la mitad de los que poseen computadora en el domicilio tienen acceso a Internet, el número de usuarios de Internet es más del triple de aquellos que tienen acceso en el domicilio: 
Gráfico 1.2.1.6: Porcentaje de personas que poseen y que utilizan computadoras e Internet en los barrios de bajos ingresos del municipio de Rio de Janeiro

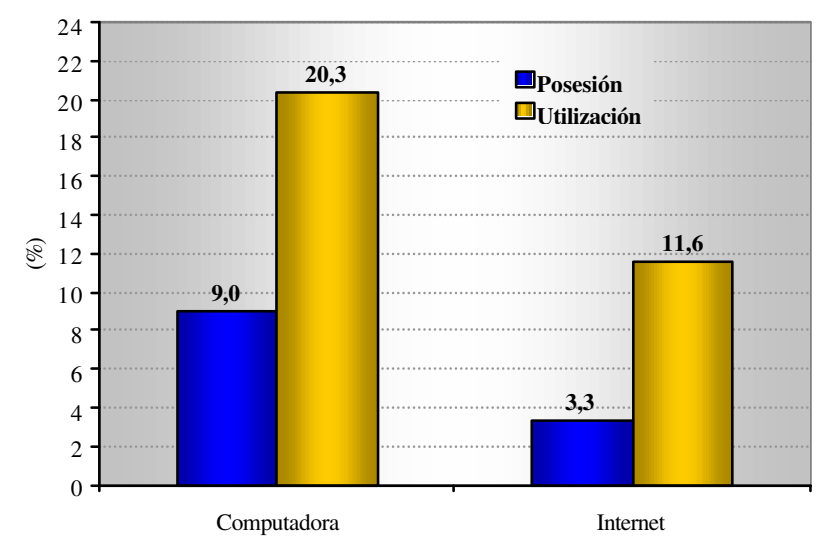

Nota: Los porcentajes se refieren al total de la muestra

\subsection{2 - Factores de integración/exclusión}

Entre los usuarios de informática existe en la favela, como en el conjunto de la población en general, una tendencia decreciente al uso de la informática a medida en que se avanza en el grupo de edad. En la favela, sin embargo, esta tendencia se acentúa, debido a los menores niveles de escolaridad entre los más ancianos y menores posibilidades de aprendizaje en el empleo:

Gráfico 1.2.2.1: Porcentaje de utilización de la computadora, según el grupo de edad

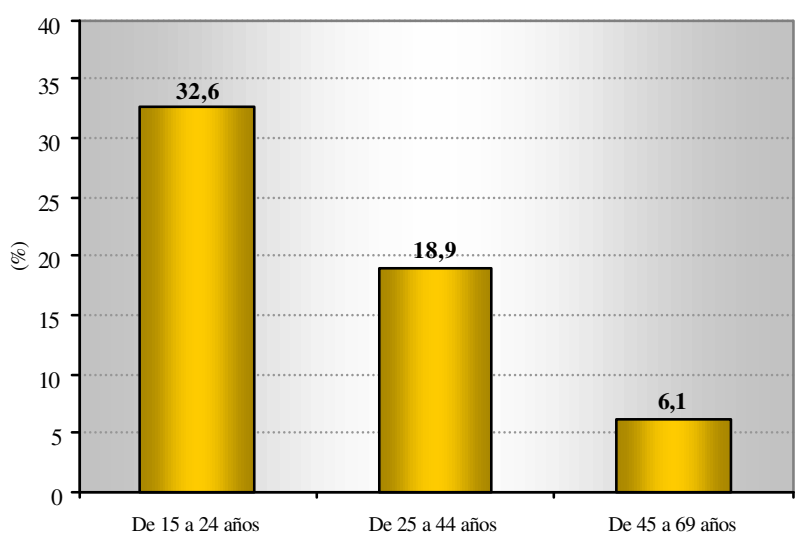

Nota: Los porcentajes fueron calculados en relación al propio grupo. 
Como se preveía, los gráficos a continuación indican que existe una correlación clara entre el nivel de ingreso y de educación y la posesión de computadora. El nivel de educación es fundamental: entre aquellos de 1 a 3 años de estudio encontramos 2 computadoras por cada 100 hogares, en el grupo de personas con más de 15 años de estudio la posesión de la computadora llega a 48.9 por cada 100 hogares:

Gráfico 1.2.2.2: Ingreso individual y familiar per capita promedio, según la posesión de computadora en las favelas del municipio de Rio de Janeiro

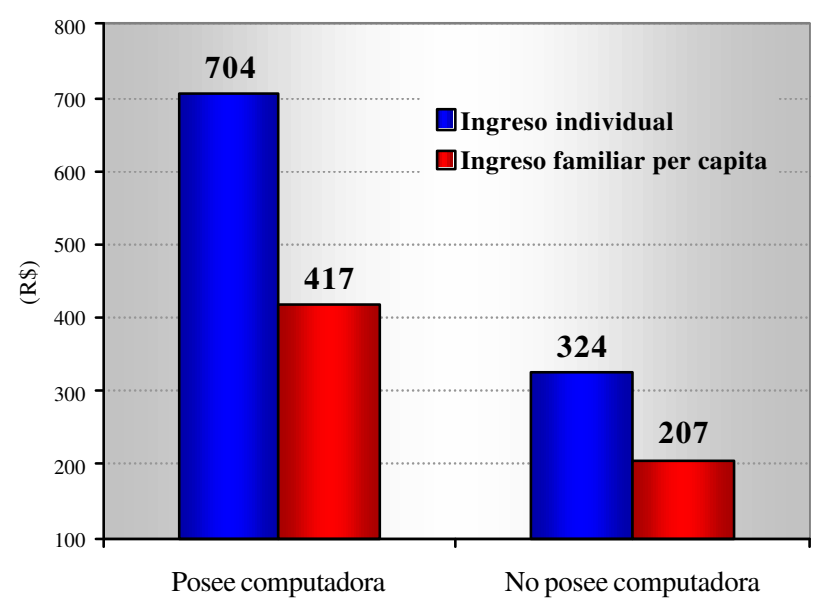

Gráfico 1.2.2.3: Porcentaje de personas que poseen computadora en el hogar por grupo de años de estudio en las favelas del municipio de Rio de Janeiro

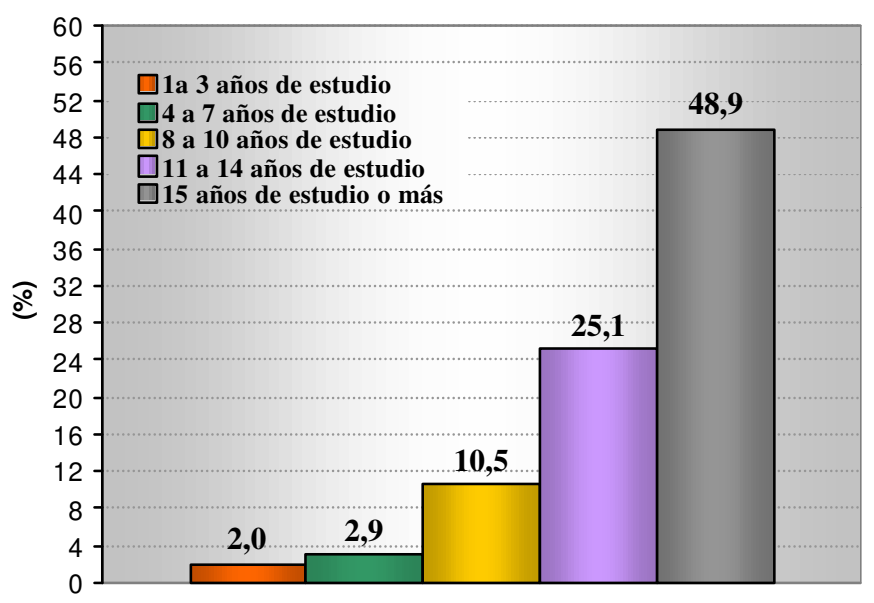


Pero el hecho de que la principal base de acceso (y de aprendizaje y motivación de uso) de la computadora y de Internet, sea el local de trabajo y no el hogar, cambia sustancialmente el número de personas incluidas así como también el perfil de los usuarios.

Como veremos a continuación, hs mujeres, por el tipo de trabajo que realizan- en general empleadas domésticas o en servicios de limpieza, son las más perjudicadas y presentan un nivel de exclusión digital mucho más alto que los hombres entre los sectores pobres de la población. Por otro lado, la población negra masculina, que presenta un promedio de posesión de computadora por hogar bastante inferior a la población blanca de la favela, encuentra en el trabajo un mecanismo de equiparación social. Así, el acceso a la informática fuera del domicilio tiene un impacto general democratizador, aunque es desigual, permitiendo el ingreso en el mundo de la informática a personas con ingreso medio y nivel educacional más bajo.

Entre los usuarios de computadora, dentro o fuera del hogar, el padrón que asocia ingreso con uso de informática se mantiene, pero la distancia tiende a disminuir, lo que indica que las personas de menos educación encuentran en las computadoras fuera del domicilio un mecanismo de igualación social:

Gráfico 1.2.2.4: Porcentaje de personas que poseen y utilizan computadora, por grupo de años de estudio, en los barrios del municipio de Rio de Janeiro

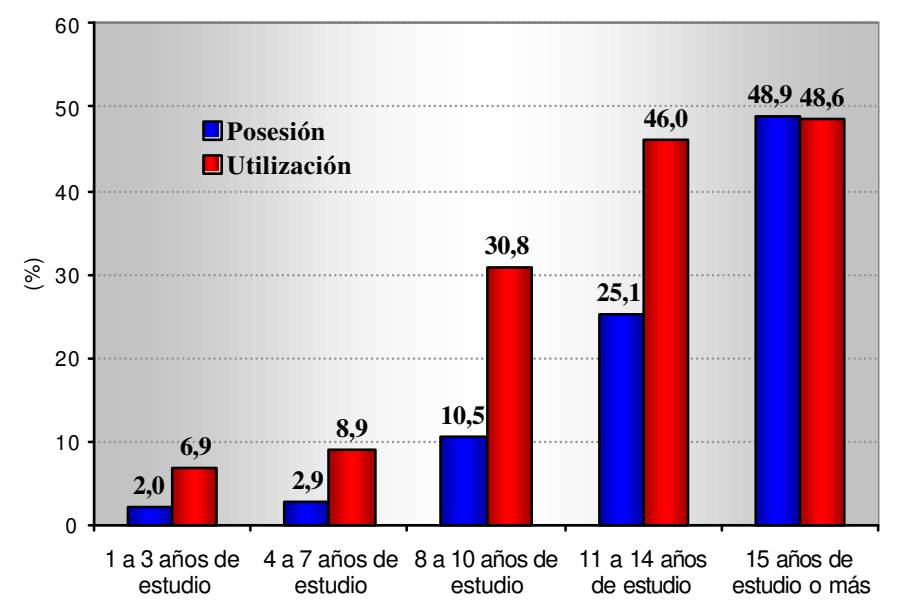

Nota: Los porcentajes fueron calculados en relación al propio grupo. 
Esto es válido para el nivel de ingresos:

Gráfico 1.2.2.5: Ingreso familiar per capita según la posesión y utilización de computadora

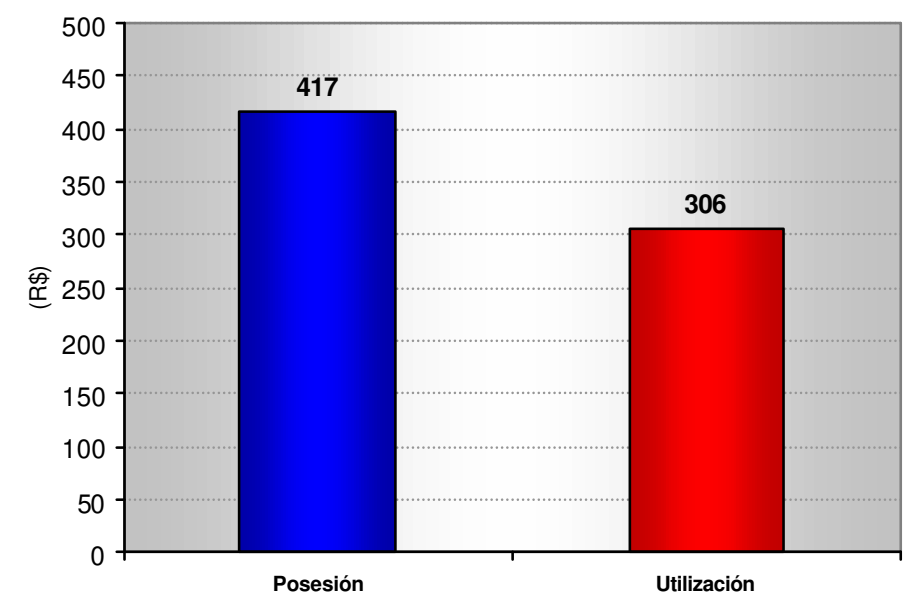

Como muestra el gráfico 12, mientras el porcentaje de personas blancas con propiedad de computadora supera el promedio (9.0\%), y los pardos lo igualan, la población negra presenta un nivel de posesión equivalente a la mitad del promedio.

Gráfico 1.2.2.6: Porcentaje de personas que posee computadora en su hogar por raza, en los barrios del municipio de Rio de Janeiro

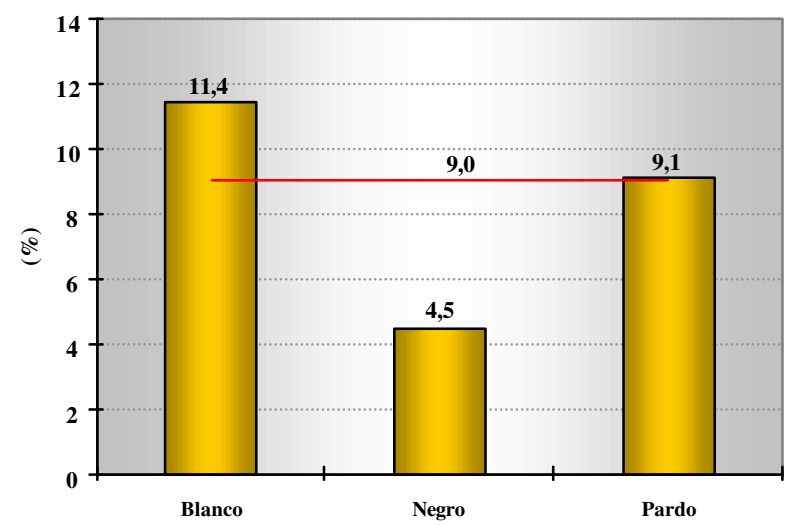

Nota: Los porcentajes fueron calculados en relación al propio grupo. 
Como lo indica el gráfico 13, esta situación refleja la doble posición desfavorecida de la población negra en términos de ingreso y educación:

Gráfico 1.2.2.7: Comparación de las medias de ingreso familiar per cápita y años de estudio

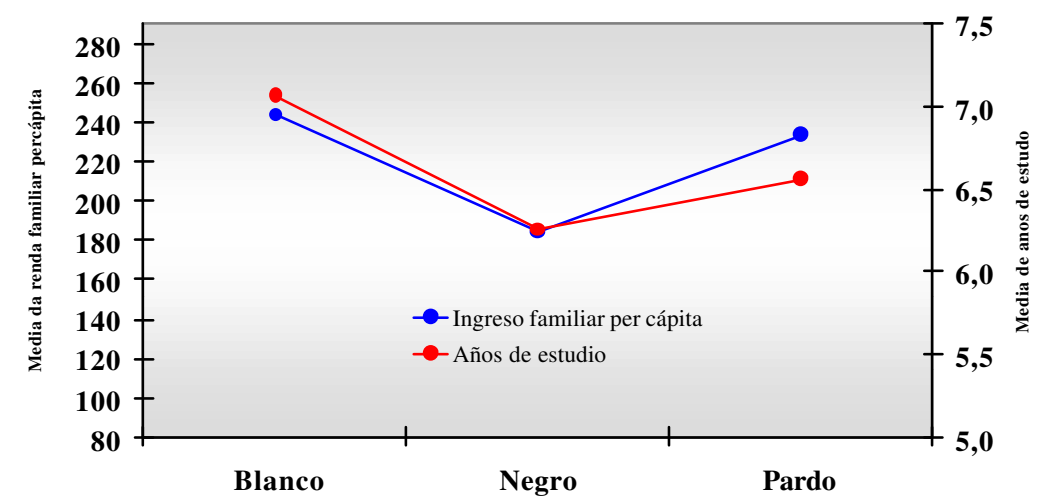

Sin embargo, en términos de usuarios de informática esta diferencia tiende a disminuir debido a otros accesos fuera del domicilio:

Gráfico 1.2.2.8: Porcentajes de posesión y utilización de computadora según raza

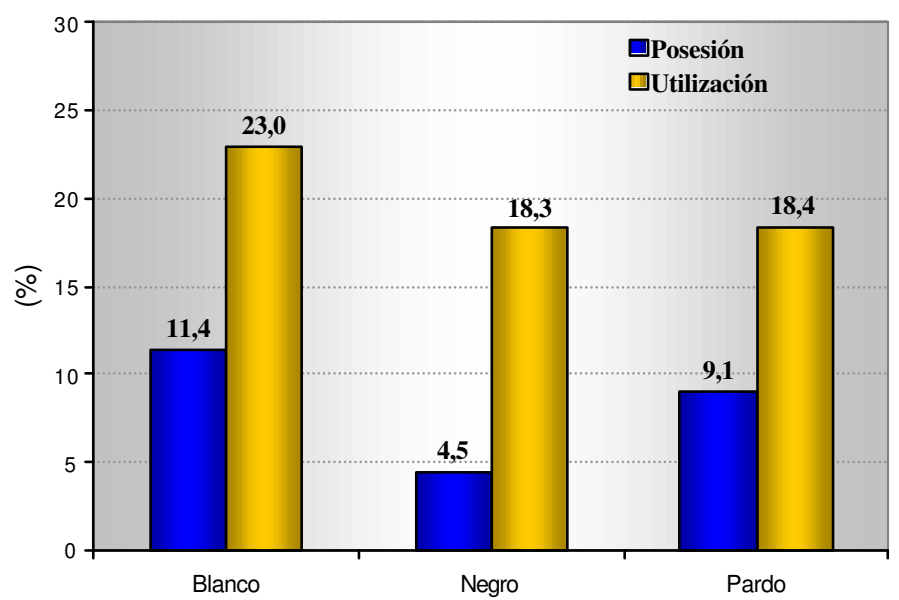

Nota 1: Los porcentajes fueron calculados en relación al propio grupo.

Nota 2: Para utilización fue usado el universo: los que utilizan el computador ( 20,3\% de la población).

O sea, el acceso fuera del domicilio funciona como un factor de creación de oportunidades para la población negra. Con la población femenina sucede lo contrario: 


\section{Gráfico 1.2.2.9: Utilización de computadoras según el sexo en los barrios}

del municipio de Rio de Janeiro

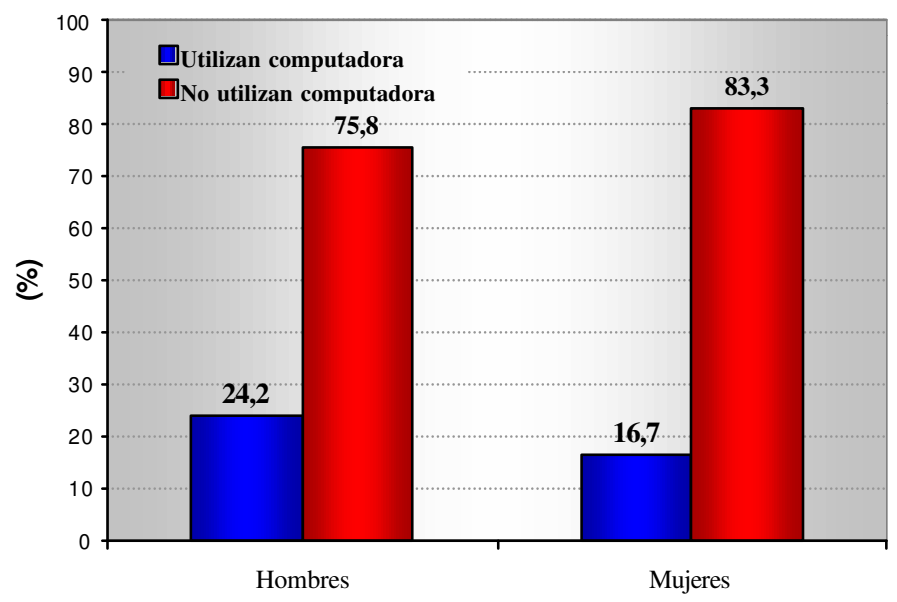

¿Qué es lo que ocurre en ambos casos: bajo acceso de las mujeres e incremento del porcentaje de la población negra de usuarios? El trabajo actúa como factor de exclusión digital en el caso de las mujeres y de igualación social en el caso de los negros. La mayoría de las mujeres trabaja en servicios de limpieza o como empleadas domésticas y no tiene oportunidad de utilizar computadora, mientras que una mayor cantidad de hombres, incluso muchos que trabajan como cadetes, terminan conviviendo en ambientes que incentivan y a veces permiten el conocimiento de los usos básicos de la computadora.

Las tendencias en relación al uso de computadoras se reproducen e inclusive se acentúan en relación a Internet. Del total de los que poseen computadora, solamente un tercio tienen acceso a Internet, de forma tal que, del total de usuarios de Internet, un poco más de un $25 \%$ lo hacen en el domicilio, reproduciendo los padrones de uso de la computadora mencionados anteriormente, lo que significa que la principal fuente de acceso se encuentra fuera del hogar. 
Gráfico 1.2.2.10: Locales de conexión a Internet más utilizados en los barrios del municipio de Rio de Janeiro

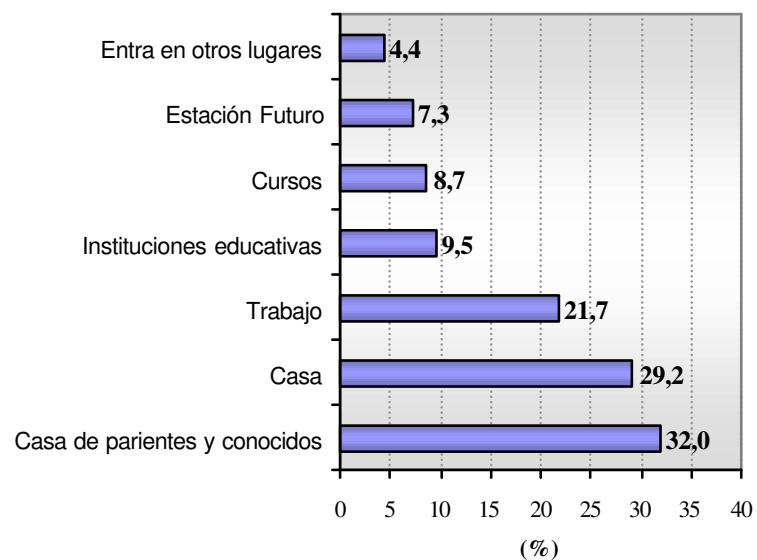

Universo: los que usan internet (11,6\% de la población)

En relación al uso de Internet, el grupo de edad es más decisivo, ya que su importancia aumenta entre los sectores más jóvenes:

Gráfico 1.2.2.11: Porcentaje de utilización de Internet y computadora según edad

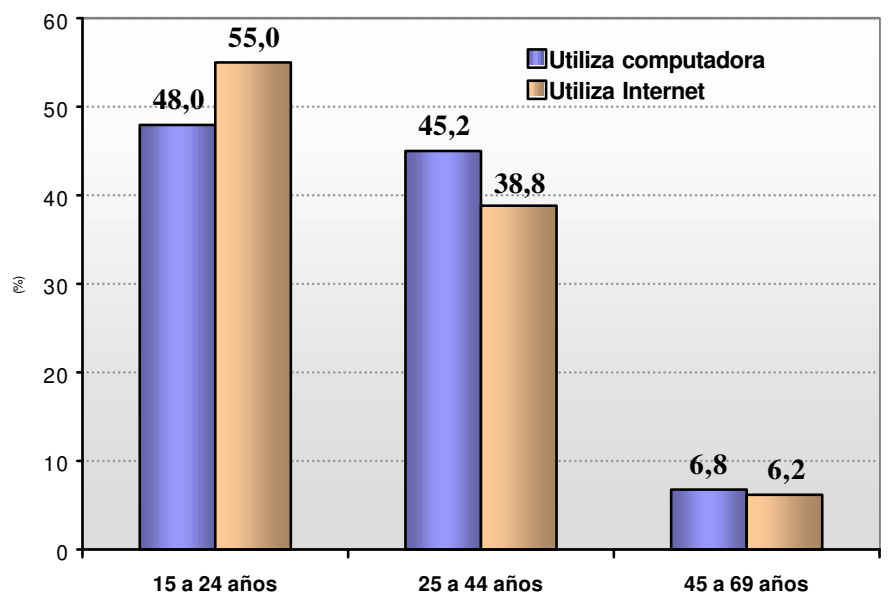

Nota: los porcentajes fueron calculados en relación al propio grupo.

La distancia entre el menor y mayor ingreso aumenta visiblemente cuando pasamos de los usuarios de computadora para los usuarios de Internet, lo que debe estar relacionado al costo y a la dificultad de acceso a Internet: 


\section{Gráfico 1.2.2.12: Ingreso del hogar per capita e ingreso individual según el nivel de inclusión digital}

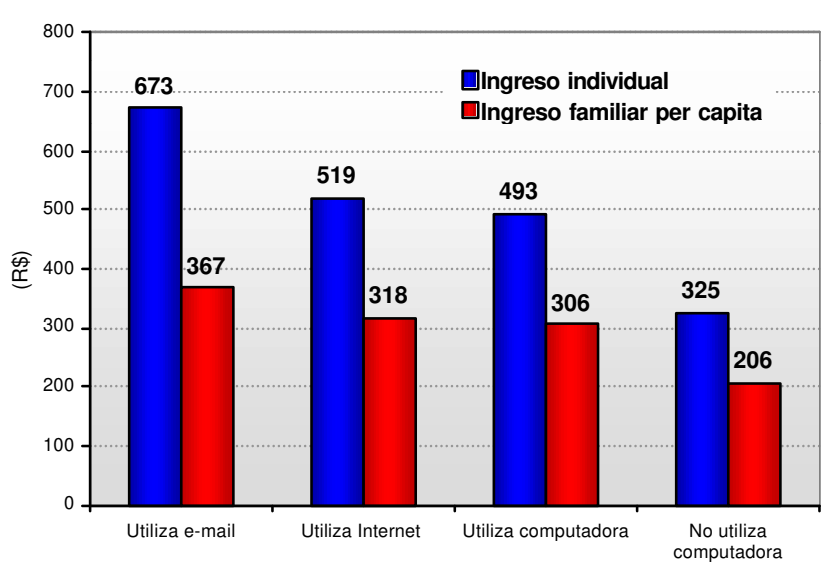

Finalmente, aunque en esta presentación no se incluya una discusión sobre los usos de Internet, no podemos dejar de señalar un dato que muestra los límites del uso de la telemática por las capas populares:

Gráfico 1.2.2.13: Porcentaje de uso de e-mail en relación a la utilización de computadoras e Internet en el total de la población de las favelas

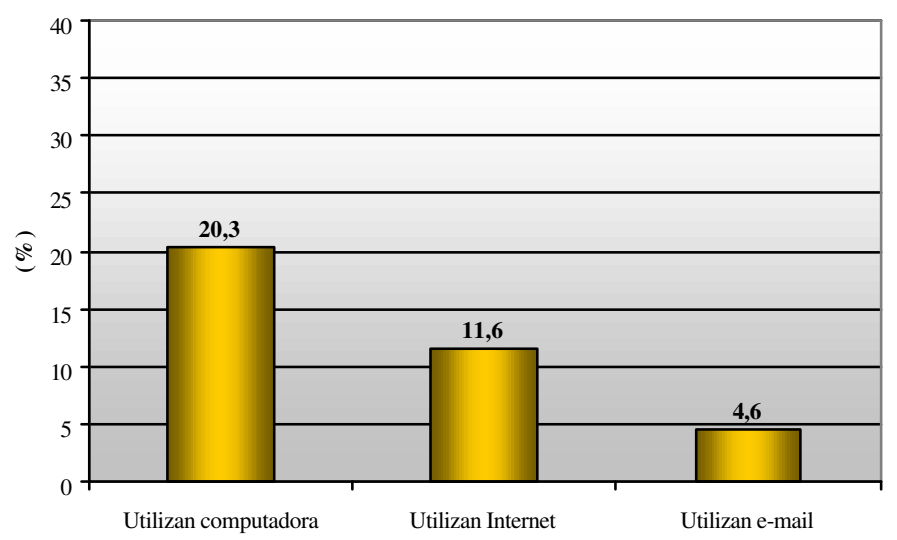

O sea, menos de la mitad de los usuarios de Internet usan e-mail. Como la gran mayoría del ambiente social del habitante de la favela no usa Internet, las oportunidades de utilidad del e-mail decrecen mucho. 
Menos de la mitad de los usuarios de Internet son usuarios de e-mail. Se trata de un porcentaje muy bajo de usuarios, producto del contexto social de los habitantes de las favelas, donde gran parte de la red social no utiliza Internet, resultando el e-mail un instrumento de comunicación menos útil.

\subsection{3 - Calidad del acceso}

Si los datos anteriores indican que los caminos para utilizar la computadora y entrar en Internet son múltiples, todos coinciden en indicar las limitaciones del tiempo disponible y de la calidad del acceso del usuario de bajos ingresos:

1) Aquellos que poseen computadora y conexión a Internet en su casa, están limitados por la calidad del acceso (prácticamente sin conexión a banda larga) y el tiempo en que pueden permanecer conectados (ya que utilizan conexión discada, donde se paga por tiempo de permanencia en la línea). Esto da como resultado una baja frecuencia de uso:

La imposibilidad de conexión a Internet rápida con un valor mensual fijo, independientemente del tiempo de uso, tiene doble consecuencia: la información demora más tiempo para ser ingresada, mientras el tiempo disponible para permanecer en Internet es menor, ya que el usuario paga por el tiempo en que permanece conectado.

Como lo muestra el siguiente gráfico, la intensidad de uso de Internet entre los habitantes de las favelas todavía es bastante baja. En el estudio sobre exclusión digital, por lo tanto, debe ser considerado no solamente el número de usuarios y no-usuarios, sino también la intensidad de uso, tanto en la calidad de la conexión (baja y alta velocidad) como el tiempo efectivamente disponible. 
Gráfico 1.2.3.1: Frecuencia de conexión a Internet, en los barrios del municipio de Rio de Janeiro

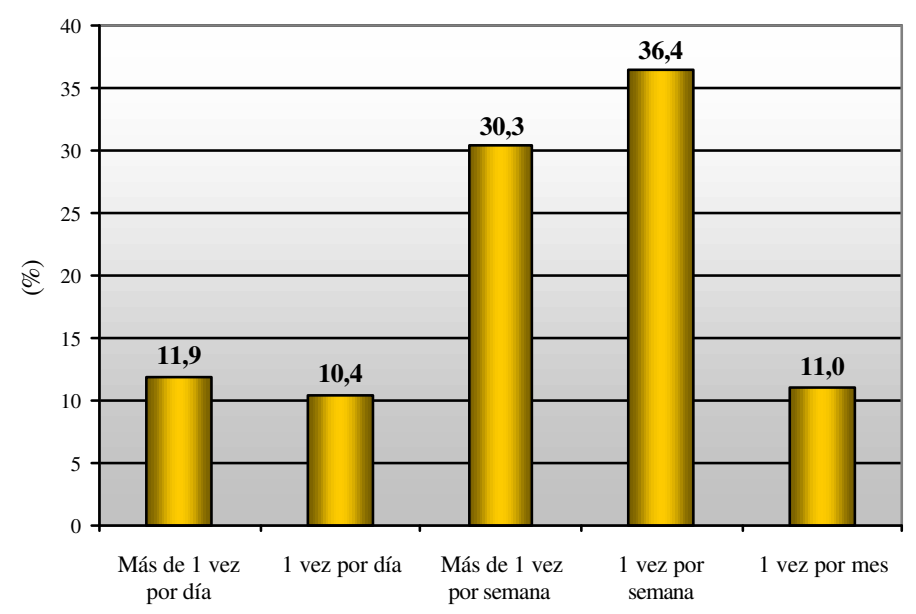

Universo: los que usan internet (11,6\% de la población)

2) Los que acceden a la informática y a la computadora en el trabajo pueden utilizar estos instrumentos dentro de los límites que le imponen sus obligaciones y de sus horarios de trabajo.

3) Aquellos que utilizan los tele-centros dependen de la existencia de los tele-centros más cercanos, de recursos para pagar el servicio y de disponibilidad de computadoras en el telecentro en el horario que les queda conveniente.

4) Aquellos que tienen acceso en casa de amigos o familiares enfrentan igualmente dificultades de disponibilidad limitadas de estos instrumentos.

5) Finalmente, los usuarios de las Estaciones Futuro (tele-centros de la ONG Viva Rio) con acceso a precios más bajos presentan el mismo perfil educacional y de ingreso que el usuario típico de computadora e Internet en la favela. 


\section{Gráfico 1.2.3.2: Ingreso del hogar per capita e ingreso individual} según la utilización de Estación Futuro

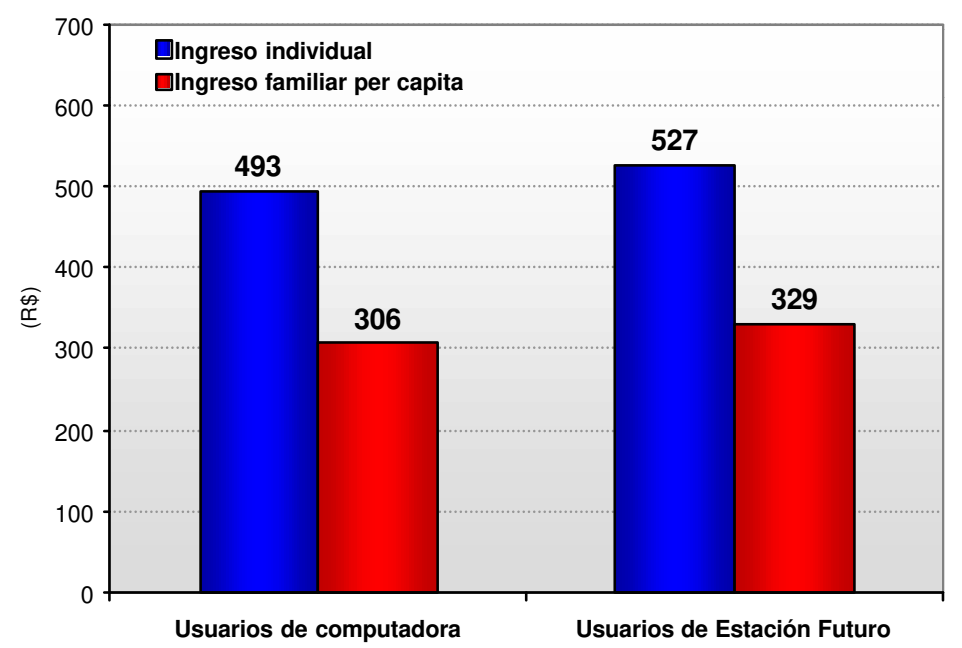

De todas formas, los tele-centros aumentan la base de usuarios y proveen a los habitantes de la favela, inclusive a aquellos que poseen conexión en casa, con mejor calidad de servicios, infraestructura y apoyo ${ }^{8}$.

\footnotetext{
${ }^{8}$ Uno de los pocos estudios cuantitativos sobre el uso de Internet por la población pobre, en Lima, que es considerado como un caso ejemplar de expansión de tele-centros en los barrios populares, presenta el mismo tipo de perfil de usuario: predominancia de los mayores niveles de escolaridad e ingresos. Cf. Francisco J. Proenza, Roberto Bastidas -Buch, Gullermo Montero, "Tele-centros para el desarrollo socioeconómico y rural en América Latina y el Caribe”, FAO/UIT/BID, 2001 (www.iadb.org/regions/telecentros/index.htm).
} 


\section{2 - Primera Parte}

\section{1 - Cuántos poseen computadora en el hogar}

Según los datos de esta investigación, 9\% de los hogares localizados en las favelas poseen computadora. Aunque no tengamos datos cuantitativos sobre la compra, en los grupos motivacionales, entre el $50 \%$ de las personas que poseían computadora, la mayoría adquirió equipamientos nuevos, de los cuales la mitad fue comprado al contado.

\section{Gráfico 2.1.1: Posesión de computadora en el hogar, en los barrios} del municipio de Rio de Janeiro

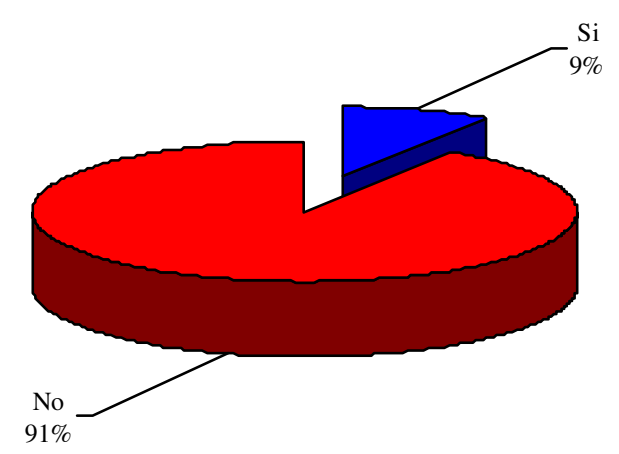

Este dato, comparado con la situación nacional, muestra resultados bastante interesantes: 


\section{Gráfico 2.1.2: Comparación entre las tasas de posesión de computadora de los}

barrios de bajos ingresos de Rio, Brasil, Estado y Municipio de Rio de Janeiro

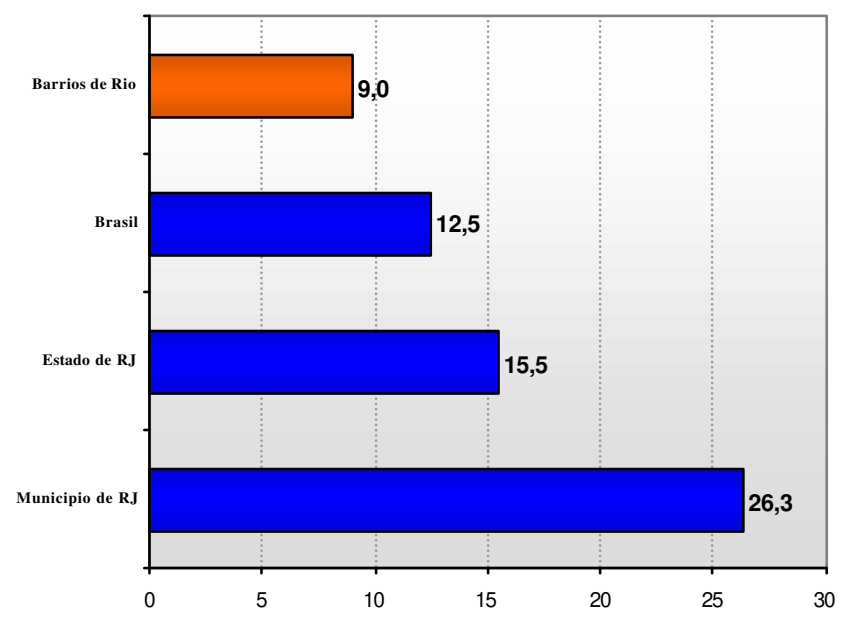

Nota: Inclusión Digital, en este caso, se refiere al porcentaje de computadoras en el total de hogares.

Aunque la posesión de computadora en las favelas de Rio de Janeiro esté cerca del promedio nacional, es 30\% menor que la media del estado y presenta, en relación a su ambiente directo, el Municipio de Rio de Janeiro, una relación de 1 computadora por 2.6 computadoras (comparado con los barrios más ricos, la diferencia es cerca de 1 por 6). Asimismo, aunque la desigualdad de acceso sea importante, impresiona la cantidad de propietarios de computadoras en barrios pobres, lo que indica el comienzo de un proceso de masificación de uso.

Inclusive el acceso a la informática en las favelas es superior al promedio de muchas capitales del Norte y Nordeste del país. 
Gráfico 2.1.3: Comparación entre las tasas de posesión de computadora de los barrios de bajos ingresos del municipio de Rio de Janeiro y de algunas capitales

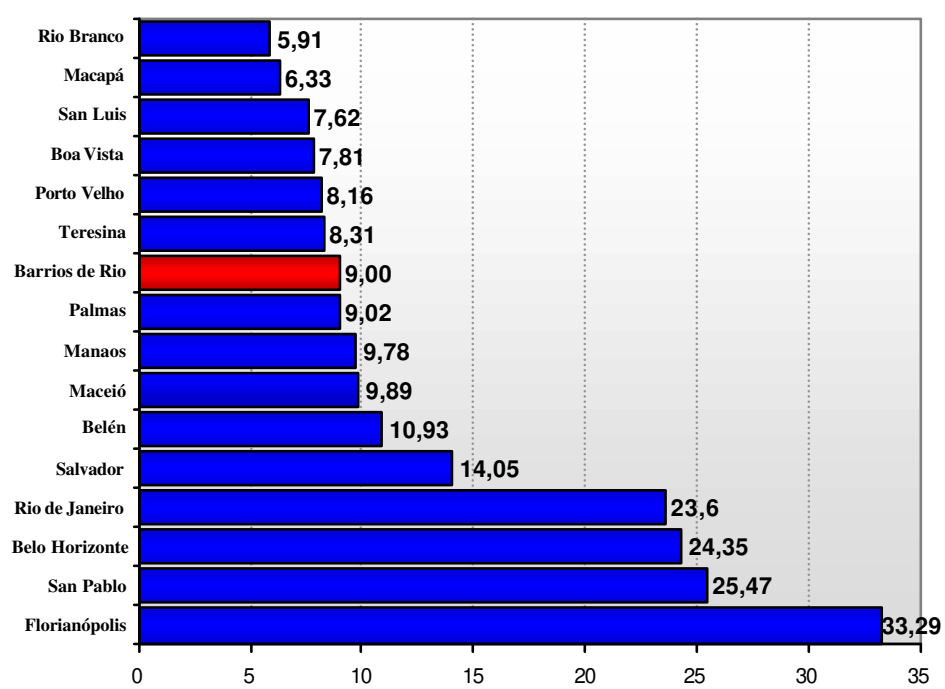

Nota: Inclusión Digital, en este caso, se refiere al porcentaje de computadoras en el total de hogares.

La explicación de este fenómeno puede ser encontrada en la bibliografía internacional sobre la difusión de la computadora: se trata de un fenómeno predominantemente urbano, fundamentalmente de las grandes metrópolis, y su uso está asociado a la difusión en el conjunto de la sociedad local y, como veremos, en el ambiente de trabajo.

El proceso desigual de difusión de la computadora entre la población de diferentes ciudades de Brasil refleja, sin duda, el desigual nivel de riqueza y educación entre diferentes regiones y ciudades del país, particularmente de las poblaciones pobres de la región Norte y Nordeste en relación al Centro-Sur. Sin embargo, la posesión de computadora está también asociada a un componente intangible: la difusión de una cultura de valorización de la informática asociada particularmente a la noción de que su dominio es condición de empleo y de éxito educacional. En otras palabras, a medida que el sistema productivo se informatiza, la noción de que es necesario dominar este instrumento para asegurar posibilidades de trabajo, se "infiltra" rápidamente entre los diversos sectores sociales. Algo similar sucede con el uso de computadora por los niños. A medida que los padres invierten en la educación de sus hijos (una prioridad de la población pobre urbana, a pesar de sus limitados recursos), la informática pasa a ser vista como condición de éxito escolar. La 
difusión de la computadora tiene, por lo tanto, una obvia correlación con el ingreso y el nivel de escolaridad, pero también está asociada a los padrones culturales más amplios de informatización de la sociedad.

Finalmente, si la posesión de computadora en el conjunto de los municipios pobres de la región metropolitana de Rio de Janeiro es relativamente alta, la desigualdad en el interior de este conjunto es muy profunda:

Gráfico 2.1.4: Comparación entre las tasas de posesión de computadora de los barrios de bajos ingresos del municipio de Rio de Janeiro y de algunos municipios del estado

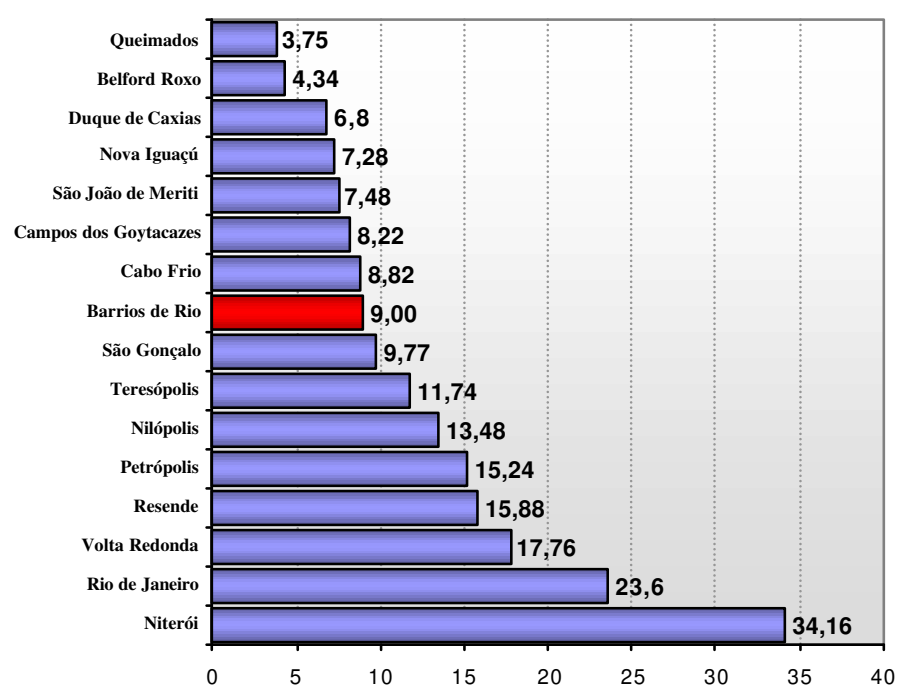

\begin{tabular}{|l} 
Reparos de la computadora \\
El mantenimiento de la computadora es hecho normalmente por conocidos o amigos de la \\
propio barrio. Miembros de la familia que trabajan con computadoras son también \\
requeridos para hacer aarreglos. Pocos buscan servicios autorizados. Uno de los \\
entrevistados (hombre de 22 a 35 años) declaró que el hecho de haber elegido a una \\
persona del barrio se debe al precio más barato de los servicios prestados dentro del \\
barrio, más allá de que muchos técnicos de fuera no quieren entrar en la favela por \\
considerarla área de riesgo. Sin embargo, uno de los habitantes de la favela Rocinha, \\
hombre de 22 a 35 años, no tiene confianza en el trabajo hecho por las personas del \\
barrio, debido a una mala experiencia con el arreglo de la computadora que él tenía. Con \\
esto, en caso de que él no pueda tratar el problema en la computadora, prefiere hacer el \\
mantenimiento en la empresa en que trabajó, especializada en telecomunicaciones. Él
\end{tabular}


$\left|\begin{array}{l}\text { resalta que una de las ventajas de hacer el servicio fuera del barrio es la garantía ofrecida, } \\ \text { mientras en una tienda en Rocinha le ofrecieron un teclado para comprar sin garantía. } \\ \text { Los que poseen algún conocimiento intentaron inicialmente resolver el problema por sí } \\ \text { mismos y solamente cuando no pueden o cuando es necesario un conocimiento más } \\ \text { especializado buscan al técnico del barrio. }\end{array}\right|$

\section{2 - Relación entre ingreso y escolaridad}

La posesión de computadora está asociada en primer lugar al nivel de ingresos y de escolaridad:

Gráfico 2.2.1: Ingreso Individual y Familiar per capita promedio, según posesión de computadora en las favelas del municipio de Rio de Janeiro

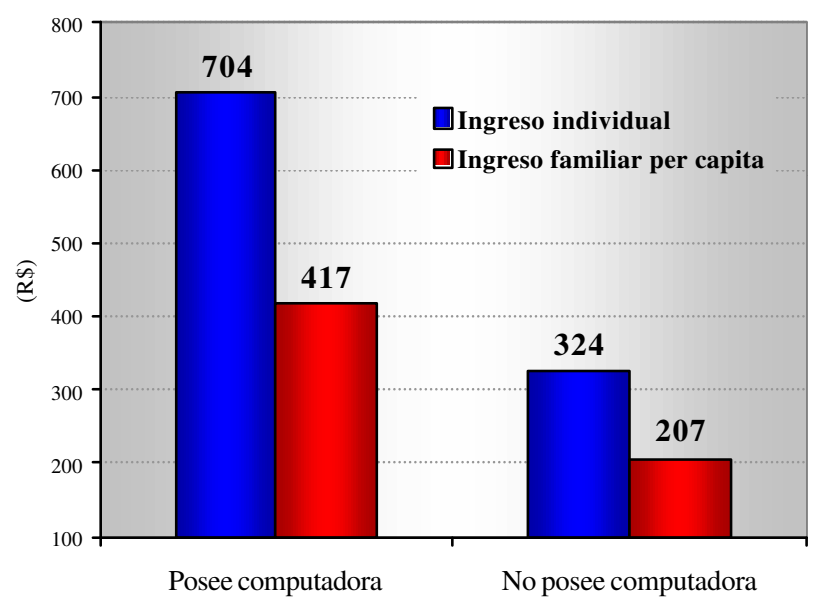




\section{Gráfico 2.2.2: Porcentaje de personas que poseen computadora en el hogar por grupo de años de estudio en las favelas del municipio de Rio de Janeiro}

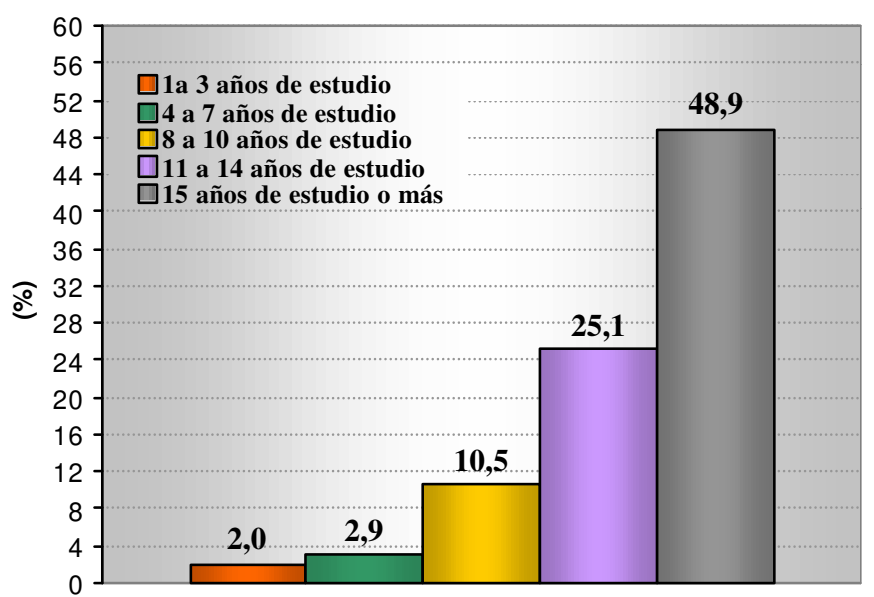

Los datos indican una clara correlación entre posesión de computadora e ingresos: los que poseen computadora disponen de un ingreso promedio, tanto individual como familiar, superior al doble del ingreso de los que no poseen. El factor escolaridad tiene, sin embargo, una incidencia todavía más grande: mientras en el grupo con 1 a 3 años de estudio encontramos 2 computadoras por cada 100 hogares, entre el grupo de individuos con más de 15 años de estudio la posesión de computadora llega a 48.9 por cada 100 hogares.

Indudablemente hay una correlación entre ingreso y años de estudio, pero la posesión de computadora entre los grupos con escolaridad más alta en relación a los de escolaridad más baja presenta un diferencial de 25 a 1 , mientras que el diferencial de ingresos entre estos grupos no llega a ser de 4 a 1. 
Gráfico 2.2.3: Ingreso familiar per cápita por grupo de años de estudio en los barrios del municipio de Rio de Janeiro

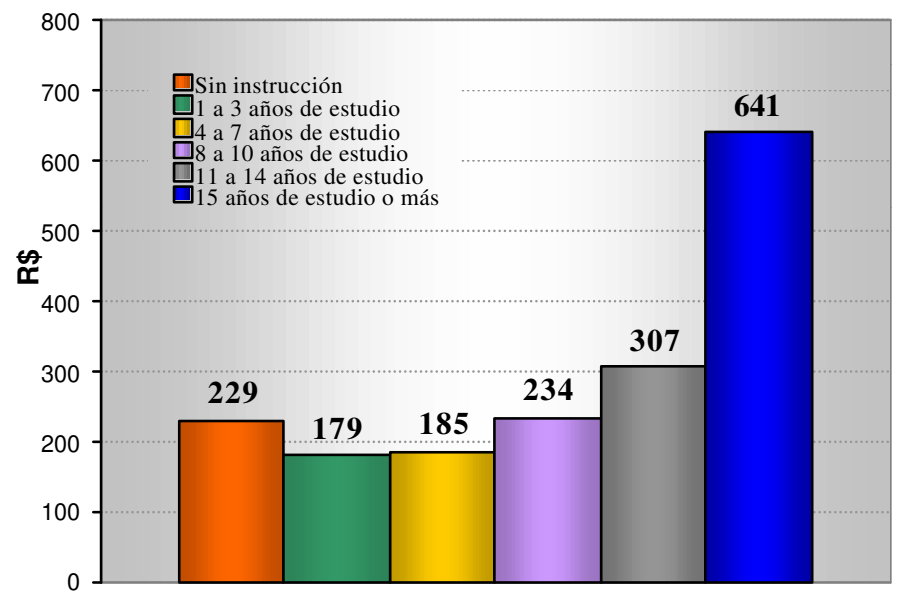

Nota: En relación al gráfico 7, que indica un ingreso superior de los "sin instrucción" en relación al grupo de "1 a 7 años de estudio", la explicación puede ser encontrada posiblemente en el hecho de que muchos de los que están en el grupo de 1 a 7 años de estudio son jóvenes y no trabajan, lo que disminuye el ingreso familiar per capita .

Como lo muestra el gráfico 2.2.4, mientras el porcentaje de personas blancas que tienen computadora supera al promedio $(9.0 \%)$, y los pardos lo igualan, la población negra presenta un nivel de posesión equivalente a la mitad del promedio.

Gráfico 2.2.4: Porcentaje de personas que poseen computadora en su hogar por raza, en los barrios del municipio de Rio de Janeiro

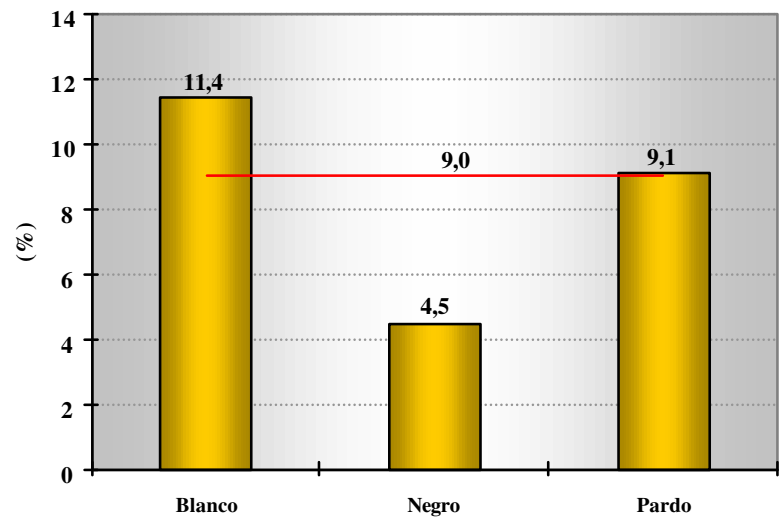

Nota: Los porcentuajes fueron calculados en relación al propio grupo. 
Como lo indica el gráfico 2.2.5, esta situación refleja la doble posición desfavorecida de la población negra, en términos de ingreso y educación:

Gráfico 2.2.5: Comparación de las medias de ingreso familiar per cápita y años de estudio

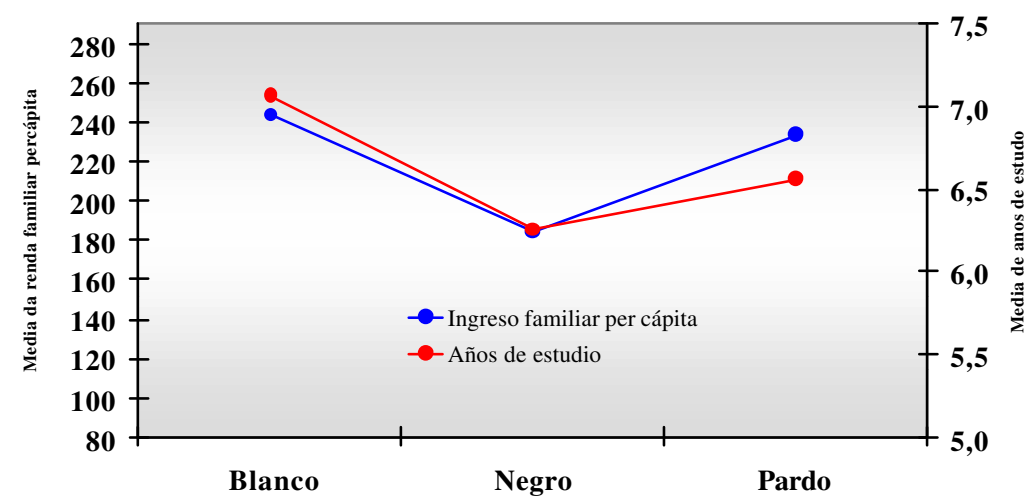

\section{3 - Posesión, propiedad y uso}

Una cuestión sociológica importante en el análisis de las relaciones entre posesión y uso de computadora se refiere a cómo la computadora es concebida: ¿cómo un bien de consumo familiar (como el refrigerador, el teléfono fijo y la TV) - su propiedad y uso es percibida como de un bien de consumo colectivo - o cómo de un bien de consumo individual (como es el caso del automóvil o, cada vez más, del grabador) en que la propiedad, la posesión y el uso son considerados personales? Como lo indican las respuestas en los grupos motivacionales, la computadora generalmente es vista como un bien de consumo personal, aunque la posesión y la propiedad no queden claramente definidas. Muchos, en particular los jóvenes, definen las computadoras como "suyas", aunque hayan sido compradas por sus padres. La cuestión de la posesión está asociada directamente a la utilización, pues, generalmente, es el utilizador quien define la computadora como suya. La tendencia a individualizar la propiedad de la computadora está asociada tanto al hecho de que muchos miembros de la familia no usan computadora como a la voluntad de afirmar la posesión, 
dado el conflicto sobre los horarios de utilización, tema que fue indicado en los grupos motivacionales como generador de tensiones en la familia.

Uso de la computadora en el hogar
La mayoría de los participantes de los grupos motivacionales que poseían computadora
indicaron que utilizan la computadora de forma exclusiva. En algunos casos, la
computadora pertenece a más de una persona, como hijos, cónyuges, hermanos u otro
pariente próximo. Los hijos normalmente la utilizan para los trabajos escolares. Es común
entre los que dividen el equipamiento con otra persona que haya problemas para conciliar
el horario de utilización.

\section{4 - Usuarios de Computadora}

El número de usuarios de computadora en las favelas es el doble de los que la poseen:

Gráfico 2.4.1: Porcentaje de personas que poseen y que utilizan comput adoras en los barrios de bajos ingresos del municipio de Rio de Janeiro

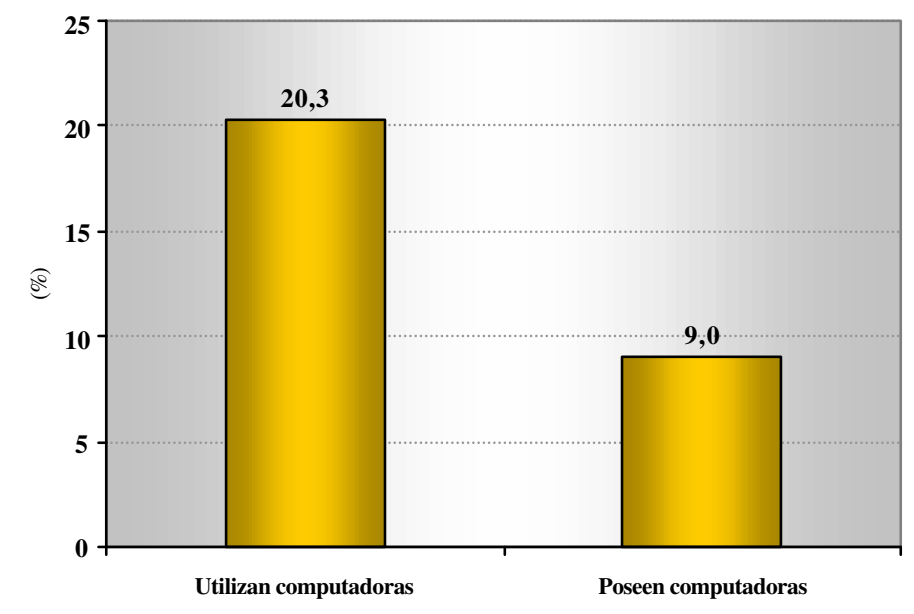

La explicación de que el número de usuarios de computadora es mayor que el número de computadoras por hogar sería producto de que cada computadora estaría siendo utilizada por varios miembros de la familia, es insuficiente, inclusive porque solamente $27.6 \%$ de los 
entrevistados indicaron al hogar como el principal local do uso de la computadora. El número superior de usuarios en relación al de propietarios es consecuencia principalmente de que en las favelas el hogar no es el principal local de acceso a la computadora:

Gráfico 2.4.2: Principal local de utilización de la computadora en los barrios de bajos ingresos del municipio de Rio de Janeiro

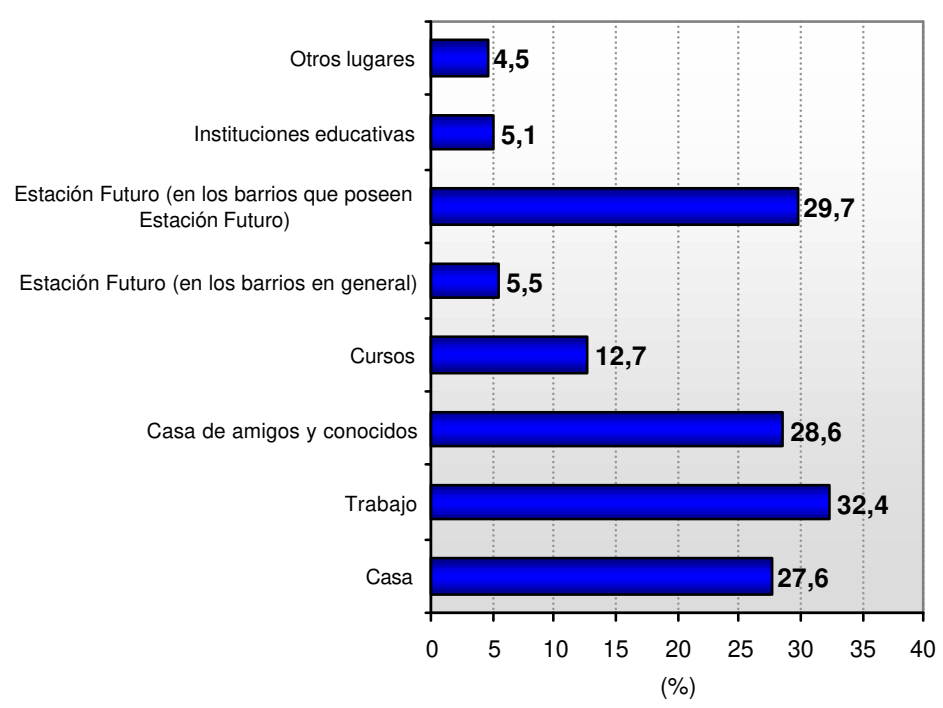

El trabajo (no el hogar), representa para los habitantes de la favela el principal local de utilización de la computadora, seguido por la casa de amigos y conocidos, quedando en tercer lugar el hogar. En las favelas donde existen Estaciones Futuro (tele-centros) de la ONG Viva Rio, éstos son el segundo local de acceso para casi $\mathbf{3 0 \%}$ de los usuarios de informática. Estos datos contradicen la expectativa de que en los sectores más pobres de la población el número de usuarios por computadora en el domicilio es alto, pues, en general, son pocos los miembros de la familia que utilizan computadora (generalmente dependientes y menores de edad).

La poca utilización de computadora por hogar se confirma en el próximo gráfico, que indica que más de un tercio de los habitantes no utilizan la computadora y sólo 31,4\% utilizan la computadora con cierta frecuencia. 


\section{Gráfico 2.4.3: Frecuencia de la utilización de computadora en los}

barrios del municipio de Rio de Janeiro

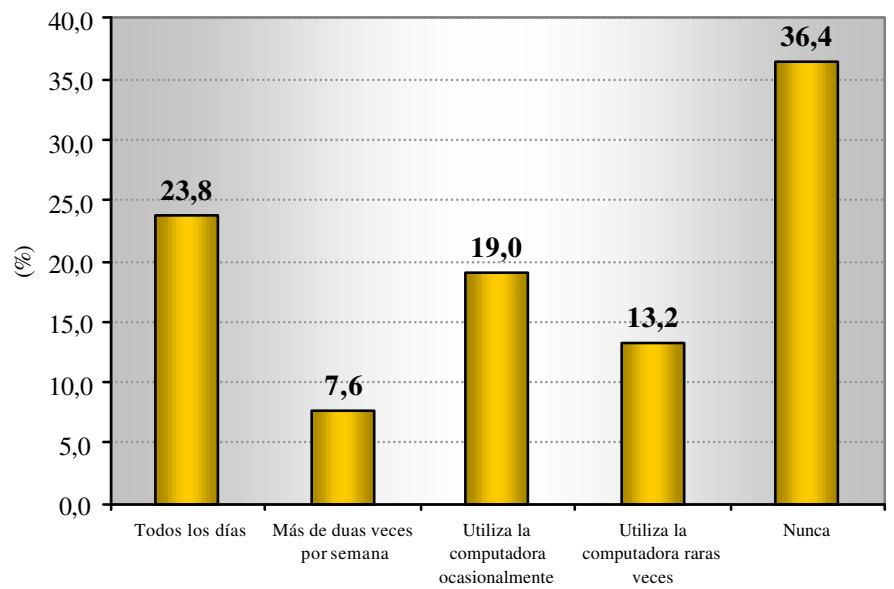

Universo: quien posee computadora en el hogar ( $9 \%$ de la población)

Entre los usuarios de computadora (dentro o fuera del hogar) el padrón que asocia ingreso y educación con uso de informática se mantiene, pero la distancia tiende a disminuir, lo que indica que las personas de menor ingreso y escolaridad encuentran en las computadoras fuera del hogar un mecanismo de igualación social.

Gráfico 2.4.4: Porcentaje de individuos que utilizan computadora por grupo de años de estudio, en los barrios del municipio de Rio de Janeiro

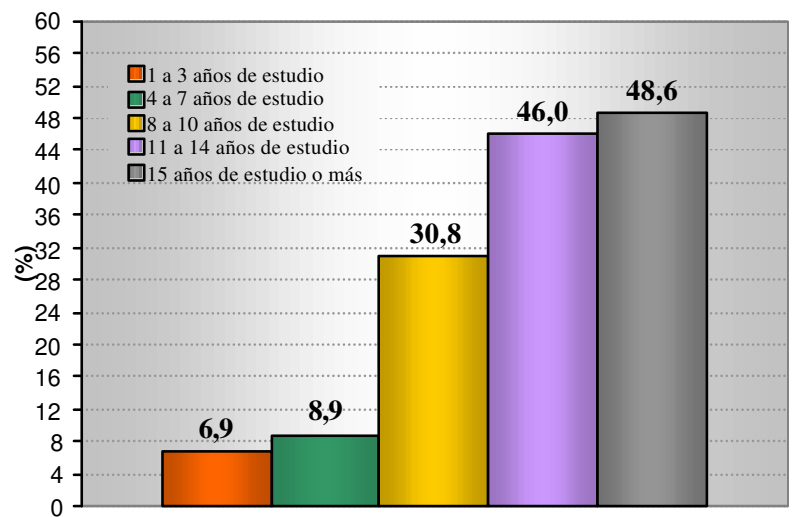

Nota: Los porcentajes fueron calculados en relación al propio grupo. 


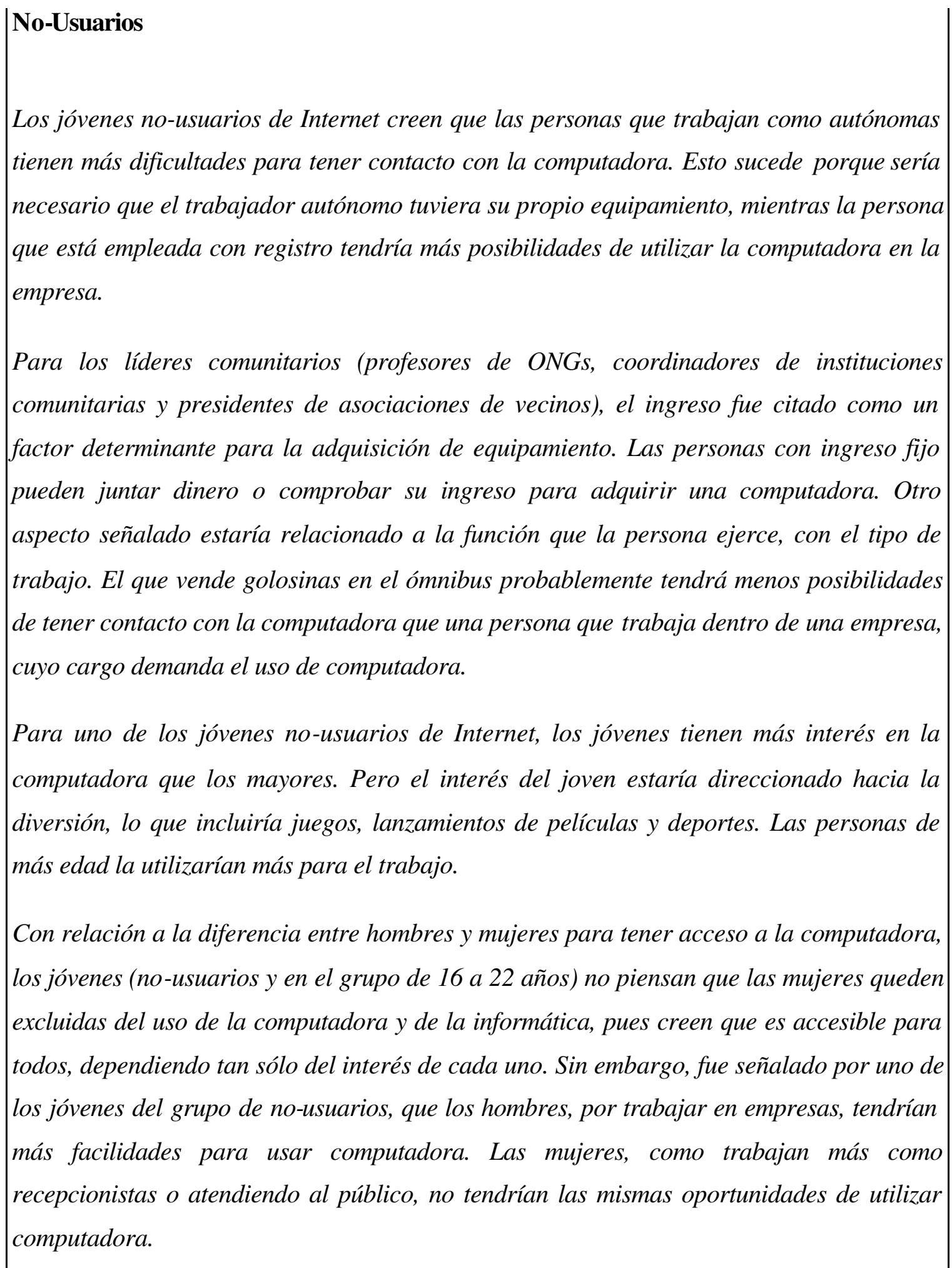


Sin embargo, no todos están de acuerdo con la igualdad entre hombres y mujeres, pues hay una cuestión cultural relacionada, que hasta puede llegar a ser modificada. El presidente de una asociación de vecinos señala que, además del aspecto cultural, también existe el individual, que va a depender de cada persona y de las inversiones que ésta se propone hacer.

Cuando son interrogados acerca de los motivos para no haber entrado a Internet, uno de los chicos dijo que no se quiere "enviciar", lo cual probablemente sucedería, ya que tendría acceso a otro mundo y conocería nuevas personas. Los demás afirmaron que nunca entraron en Internet por no tener computadora.

Dos de los motivos alegados para la no utilización de un punto de entrada se refieren a la falta de dinero y al desconocimiento sobre cómo proceder para navegar en Internet. Además de esto, una de las chicas dijo que no tenía motivos para entrar, pues iría a "quedarse conectado a Internet para nada", ya que no era necesario para ella. Otros participantes piensan que Internet tendría algo para ofrecer, como ayudar en la búsqueda de empleo y brindar informaciones sobre concursos, además de la posibilidad de conocer personas y lugares. Uno de ellos confesó que no puede ni imaginarse los beneficios que Internet le podría traer, dado su total desconocimiento sobre esta herramienta.

Muchos protestan por la dificultad que tienen para entrar, ya que los cursos del barrio no ofrecen Internet. Uno de ellos dijo que le gustaría tener más conocimiento, pues sería más fácil conseguir un empleo. El hecho de no tener computadora o no entrar a Internet hace que uno de los chicos se sienta un poco constreñido cuando las personas comienzan a hacer algún tipo de comentario sobre informática.

Según el grupo de líderes comunitarios, no poseer computadora lleva a una exclusión de ciertos grupos. Uno de los líderes, que es profesor de una ONG, relató que, cuando todavía no había computadora, quedaba totalmente fuera de las cosas que sucedían, porque todos los profesores se correspondían por email. Tenía que pedirle a algunas personas que enviaran los e-mails por él. Un coordinador de la institución comunitaria también protestó sobre cierta exigencia de que los trabajos y pruebas de la facultad que cursaba fueran realizados en computadora; no se consideraba si la persona poseía equipamiento o no. 


\section{Frecuencia y usos de computadora}

Con relación a la frecuencia de uso de la computadora, normalmente aquellos que la utilizan constantemente son los que poseen el equipamiento en el domicilio y los que necesitan de computadora para el trabajo. El grupo de hombres de más de 35 años, de Maré, la utiliza constantemente. La mayoría entra en la computadora diariamente o por lo menos tres veces por semana. Los que la utilizan con menor frecuencia son los que tienen dificultades de acceso al equipamiento. Dos de los chicos, por ejemplo, usaban la computadora diariamente en el trabajo. Sin embargo, como no tenían computadora en el hogar, la frecuencia de uso diminuyó cuando quedaron desempleados y pasaron a depender de amigos para tener acceso a la computadora.

Los jóvenes de hasta 16 años y los hombres de 22 a 35 años de Rocinha también utilizan frecuentemente la computadora. La mayoría la utiliza diariamente y el resto la utiliza por lo menos una vez por semana. Los jóvenes (hasta los 16 años) la utilizan normalmente en su casa y en la institución de enseñanza y los hombres (de 22 a 35 años) la usan en el trabajo y en casa. La casa de parientes o amigos, así como la Estación Futuro, son opciones para los que no tienen acceso más facilitado a la computadora. De la misma forma, la mayor parte de los hombres y mujeres entre 16 y 22 años de Maré usan diariamente la computadora. Dos de ellos, inclusive, trabajan con la computadora. Otros dos, a pesar de hacer uso frecuente, no están entrando en la computadora en casa, pues, recientemente, el equipamiento tuvo problemas. A pesar de esto, la institución de enseñanza en que estudian les permite el acceso al laboratorio y usan constantemente la computadora en la institución. Sin embargo, en la institución de enseñanza el uso de computadora e Internet está limitado a investigaciones o trabajos académicos

Contrariamente a lo observado en el caso de los jóvenes y hombres, las mujeres con más de 35 años (Rocinha) usan muy poco los programas de computadora, utilizando básicamente Internet y sólo cuando es necesario. Dos de ellos utilizan la computadora con más frecuencia debido a las obligaciones del trabajo. La mayoría la utiliza eventualmente en la Estación Futuro o en casa de parientes. 
La utilización que hacen las mujeres de 22 a 35 años (Rocinha) es todavía más limitada de la que hacen las mujeres de más edad. El uso de la computadora es realizado básicamente 1 vez por semana y tan sólo una de ellas hace un uso diario debido a la necesidad impuesta por el trabajo. La mayoría hace un uso de la computadora en la propia Estación Futuro e inclusive la que tiene computadora en casa procura entrar en Internet en la Estación debido al costo más bajo.

Los no usuarios de Internet utilizan raramente la computadora. La mayoría sólo usó la computadora en el curso básico y no la utiliza más. Uno de ellos la utilizaba en el trabajo, pero actualmente está desempleado. Sólo dos chicos la utilizan más frecuentemente, uno en casa de parientes y el otro en una tienda, pero tan sólo para jugar.

Entre los líderes comunitarios (profesor de ONGs, coordinadores de instituciones comunitarias y presidente de la asociación de vecinos), la mitad utiliza diariamente la computadora en casa o en el trabajo y el resto o no la utiliza o lo hace tan sólo cuando es necesario para la institución, utilizando normalmente la Estación Futuro.

En general, los programas más utilizados son el Word, Excel, Power Point e Internet, objetivando, principalmente, la realización de trabajos escolares y profesionales (digitación de trabajos, currículum, investigación escolar, búsqueda de empleo). El Word es el programa más utilizado por todos los grupos. Los no usuarios de Internet son los que más utilizan juegos, seguidos por los jóvenes de 16 a 22 años y mujeres con más de 35. Las mujeres mayores de 35 años utilizan bastante la computadora para hacer investigación escolar para sus hijos.

\section{5 - Grupo de edad, género y raza}

Entre los usuarios de informática, existe en la favela, como en el conjunto de la población, una tendencia decreciente al uso de la informática a medida que se avanza en el grupo de edad. En la favela, sin embargo, esta tendencia se acentúa, debido a los menores niveles de escolaridad entre los más ancianos y menores oportunidades de aprendizaje en el trabajo: 
Gráfico 2.5.1: Porcentaje de utilización de computadora según el grupo de edad

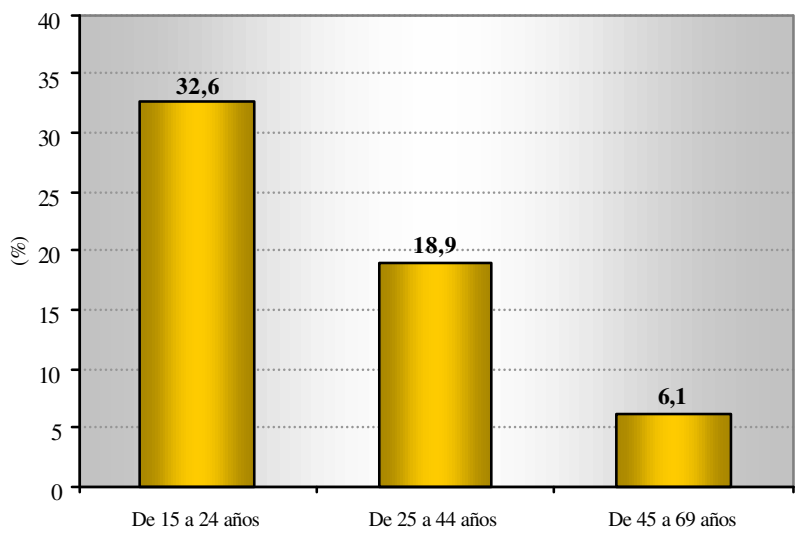

Nota: los porcentajes fueran calculados en relación al propio grupo.

La población de usuarios de informática es mayoritariamente masculina - entre los hombres cerca de un cuarto del total, entre las mujeres no llega a un sexto:

Gráfico 2.5.2: Utilización de computadoras según sexo en los barrios del municipio de Rio de Janeiro

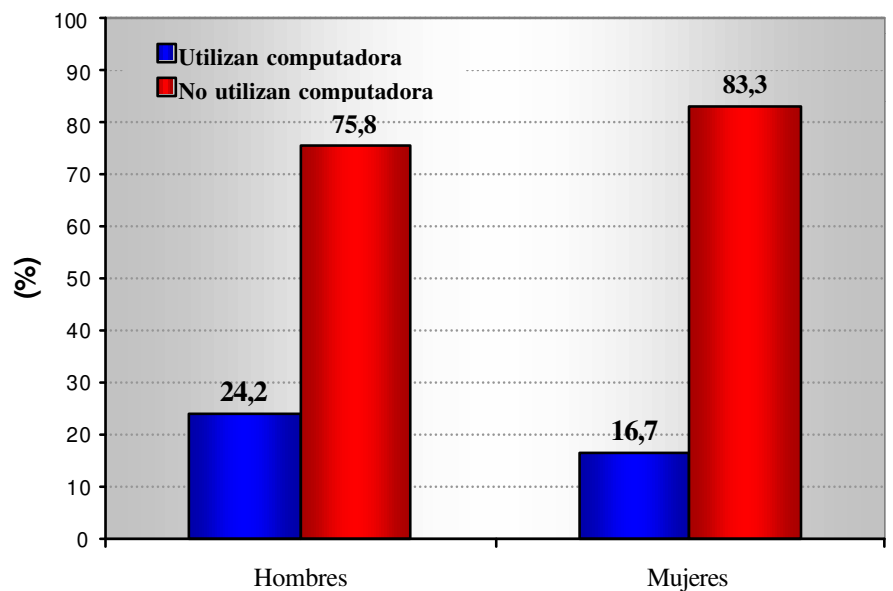

Si comparamos el número de usuarios de la población negra que usa computadora con aquellos que poseen computadora, nos sorprende que la desigualdad detectada entre los propietarios tiende a disminuir radicalmente: 
Gráfico 2.5.3: Porcentaje de utilización de Internet y posesión de computadoras según raza

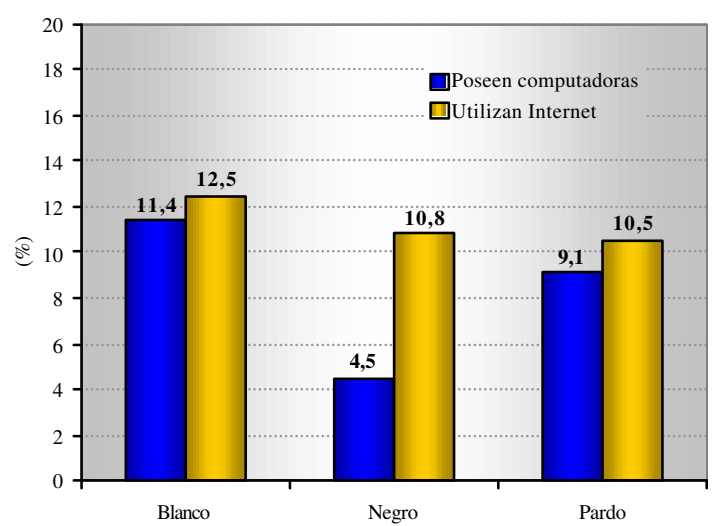

Nota: Los porcentajes fueron calculados en relación al propio grupo.

¿Qué es lo que sucede en ambos casos (de bajo acceso de las mujeres e incremento del porcentaje de población negra usuaria)? El trabajo actúa como factor de exclusión digital en el caso de las mujeres y de igualación social en el caso de los negros. La mayor parte de las mujeres trabaja en servicios de limpieza o como empleadas domésticas y no tienen oportunidad de utilizar computadora, en tanto que los hombres, inclusive muchos que trabajan como cadetes, terminan conviviendo en ambientes que incentivan y a veces permiten el conocimiento de usos básicos de la computadora.

Gráfico 2.5.4: Porcentaje de personas que trabajan por sexo

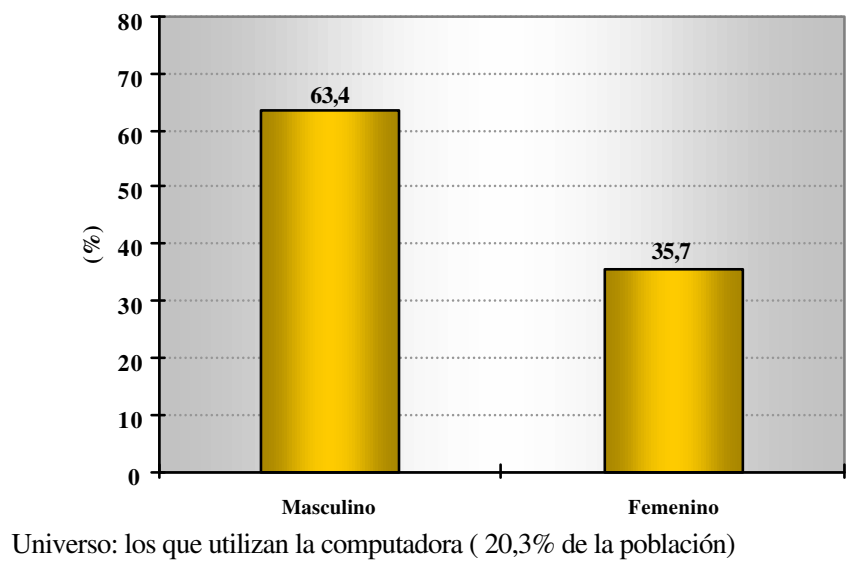

En las familias de clase media, la socialización con la computadora es un fenómeno casi natural, y los niños, incluso los adultos, aprenden por ósmosis dentro del núcleo familiar o 
en el trabajo. Este no es el caso de las poblaciones más pobres, donde más de la mitad (la mayor parte sin computadora en casa), depende de los cursos de especialización pagos:

\section{Gráfico 2.5.5: Cómo aprendió a usar la computadora en los barrios} del municipio de Rio de Janeiro

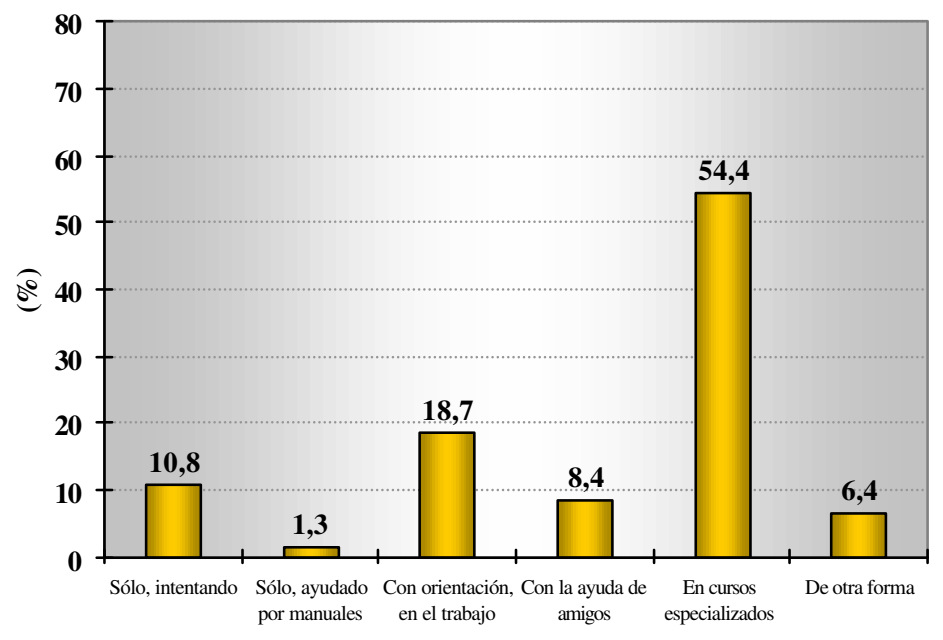

Universo: los que utilizan computadora ( 20,3\% de la población)

\begin{tabular}{|l|}
\hline Aprendiendo a usar la computadora \\
La mayoría de las personas aprendió a utilizar la computadora a través de cursos. Los \\
cursos realizados por los habitantes normalmente incluyen los aspectos más elementales \\
del uso de la computadora. Un número menor, aunque significativo, aprendió en el propio \\
trabajo, por la demanda del cargo. También es común, incluso entre los que hicieron \\
cursos, que la persona perfeccione su aprendizaje sola, utilizando la computadora, con \\
alguna orientación hecha por alguien con más experiencia. En realidad, no hay sólo una \\
forma de aprender, sino que hay un conjunto de prácticas que favorecen la utilización de \\
la computadora. \\
El uso de manuales es muy raro entre los entrevistados. Entre los hombres con más de 35 \\
años, sólo uno declaró haber aprendido sólo a través de manuales. Sin embargo, en este \\
grupo, el aprendizaje fue sobre todo a través de cursos pagos y por el trabajo. Uno de ellos \\
fue a jugar fútbol a Alemania y le fue exigido entrar en Internet para que tomara \\
conocimiento de las reglas del fútbol y del campeonato. Era brindada, incluso, asistencia
\end{tabular} \mid


técnica y había profesores pagos para enseñar al jugador a utilizar la computadora. Posteriormente, éste pasó por una experiencia similar en Venezuela. Otro ejemplo puede ser encontrado en el grupo de las mujeres de más de 35 años. Una de ellas aprendió a usar la computadora cuando trabajó como recepcionista en una clínica, registrando clientes y con la orientación de una compañera de trabajo con más antigüedad.

\section{6 - Quién y cuántos usan Internet}

En las favelas, $11.6 \%$ de la población con más de quince años usa Internet, por lo tanto, el número de usuarios de Internet llega a cerca de la mitad del total de usuarios de computadora:

Gráfico 2.6.1: Porcentaje de personas que utilizan computadoras e Internet en los barrios de bajos ingresos del municipio de Rio de Janeiro

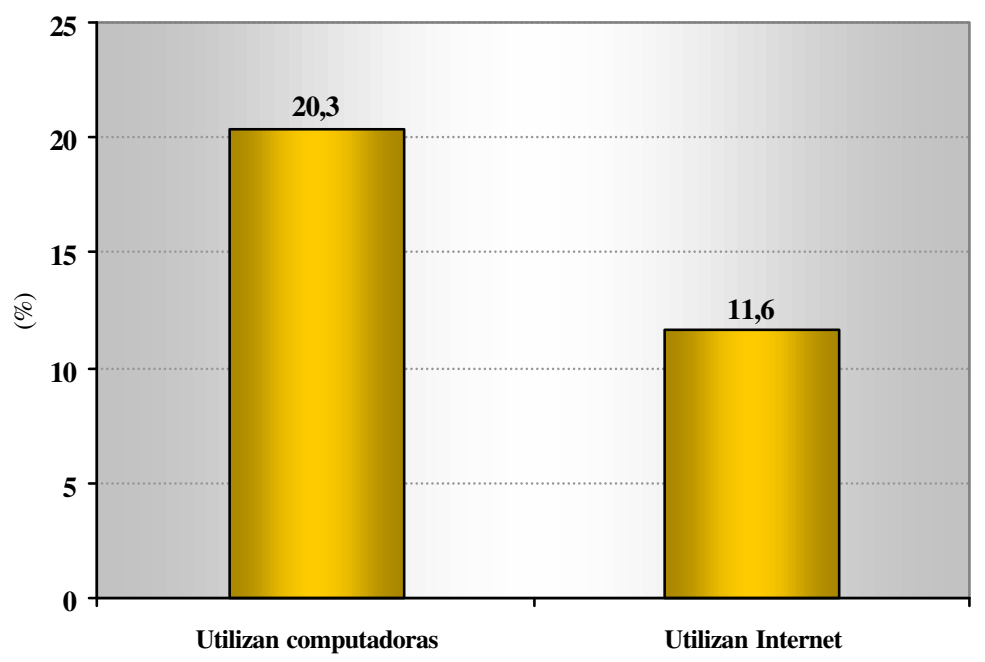

Del total de los que poseen computadora, solamente un tercio tiene acceso a Internet, de modo que, del total de usuarios de Internet, un poco más del $25 \%$ entran en el domicilio, reproduciendo los padrones de uso de computadora mencionados anteriormente, esto es, la principal fuente de acceso se encuentra fuera del domicilio. 


\section{Gráfico 2.6.2: Porcentaje de utilización de internet y computadora}

en los barrios del municipio de Rio de Janeiro

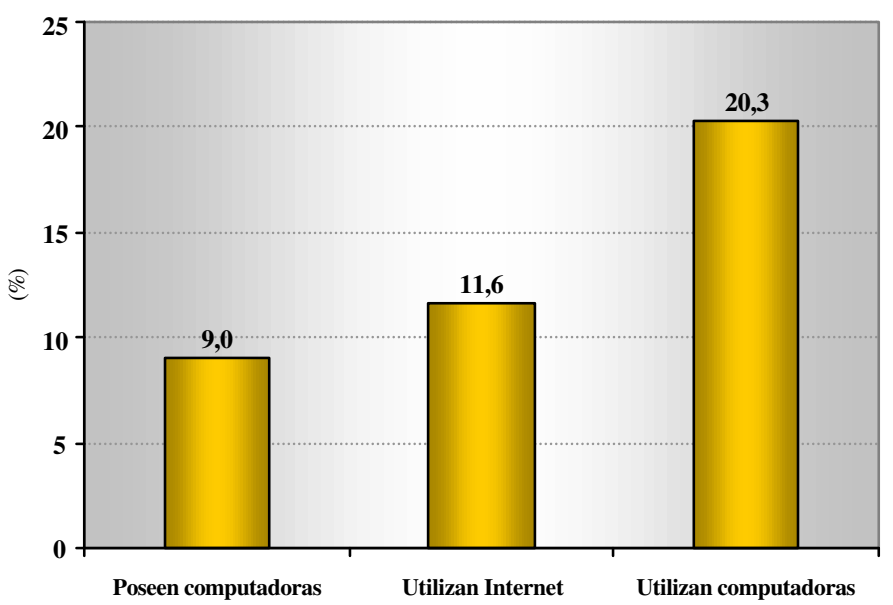

Prácticamente todos los usuarios que entran en el hogar utilizan conexión telefónica de baja velocidad, siendo que dos tercios utiliza proveedores gratuitos.

\section{Gráfico 2.6.3: Tipo de proveedor utilizado en los barrios del municipio de Rio de Janeiro}

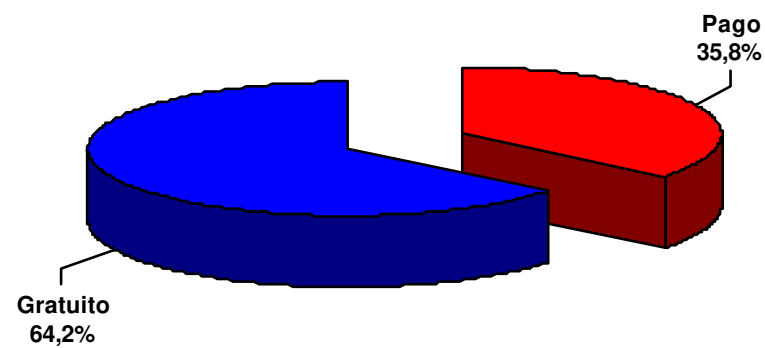

Universo: los que usan internet ( 11,6\% de la población)

La no entrada en Internet rápida con un valor mensual fijo, independientemente del tiempo de uso, tiene una doble consecuencia: la información demora más tiempo para ser ingresada, mientras que el tiempo disponible para permanecer en Internet es menor, ya que el usuario paga por el tiempo en que permanece conectado. 
Como lo muestra del gráfico a seguir, la intensidad de uso de Internet entre los habitantes de las favelas todavía es bastante baja. En el estudio de la exclusión digital, por lo tanto, debe ser considerado no solamente el número de usuarios y no usuarios, sino también la intensidad de su uso, tanto en la calidad de la conexión (baja y alta velocidad) como el tiempo efectivamente disponible.

\section{Gráfico 2.6.4: Frecuencia de conexión a Internet, en los barrios del municipio de Rio de Janeiro}

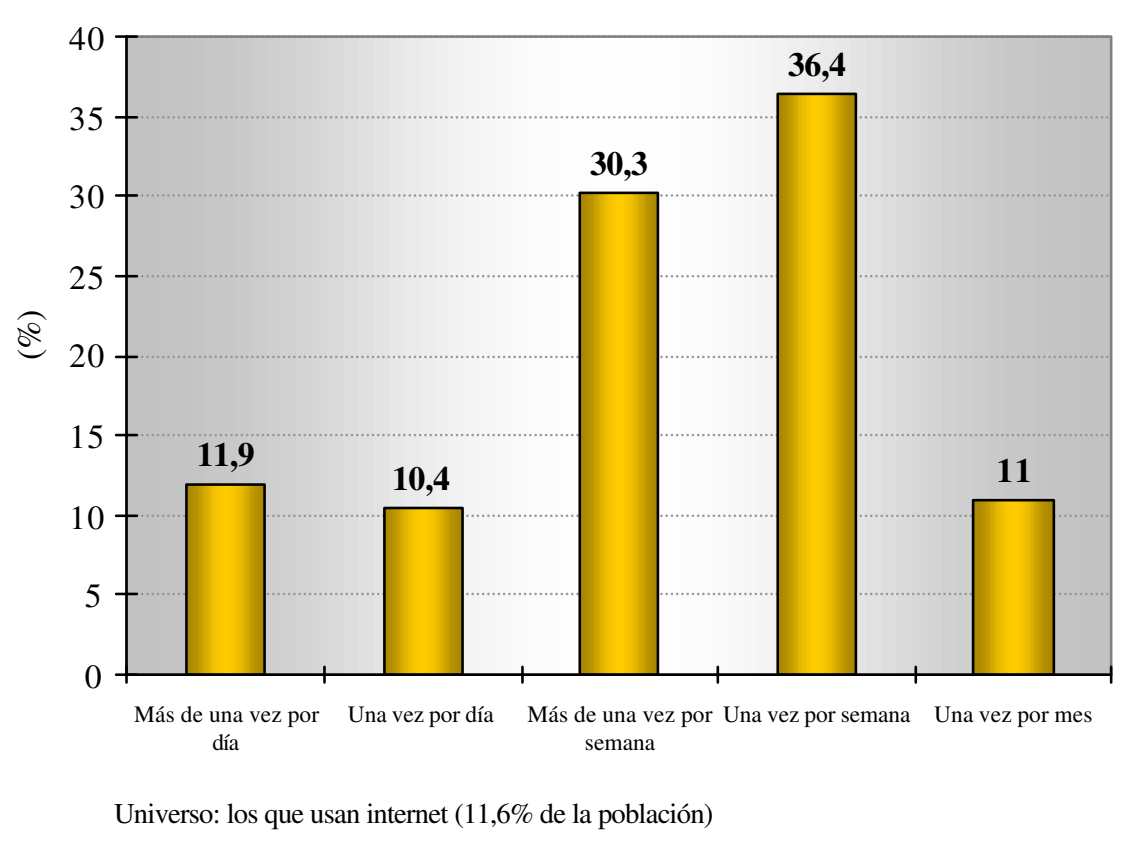

En el caso de Internet, se repite, en líneas generales, el mismo fenómeno que para el uso de la computadora. La mayoría de los usuarios se conecta fuera del hogar, aunque la importancia de la conexión en el hogar y en casa de amigos y conocidos presente un ligero aumento, en particular en el último caso: 
Gráfico 2.6.5: Locales de conexión a Internet más utilizados en los barrios del municipio de Rio de Janeiro

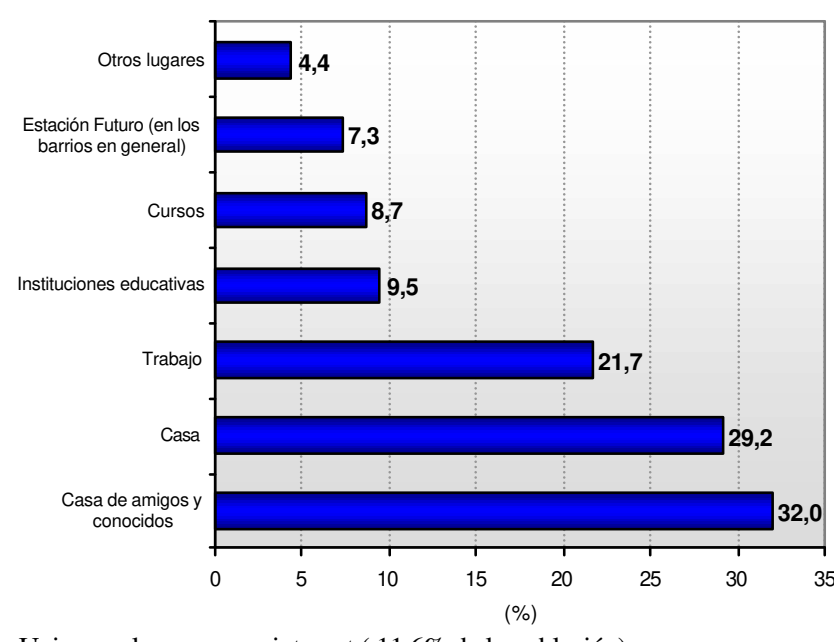

Universo: los que usan internet ( $11,6 \%$ de la población)

En el uso de Internet, el grupo de edad es más decisivo, ya que su importancia aumenta en los sectores más jóvenes:

Gráfico 2.6.6: Porcentaje de utilización de Internet y posesión de computadora según edad

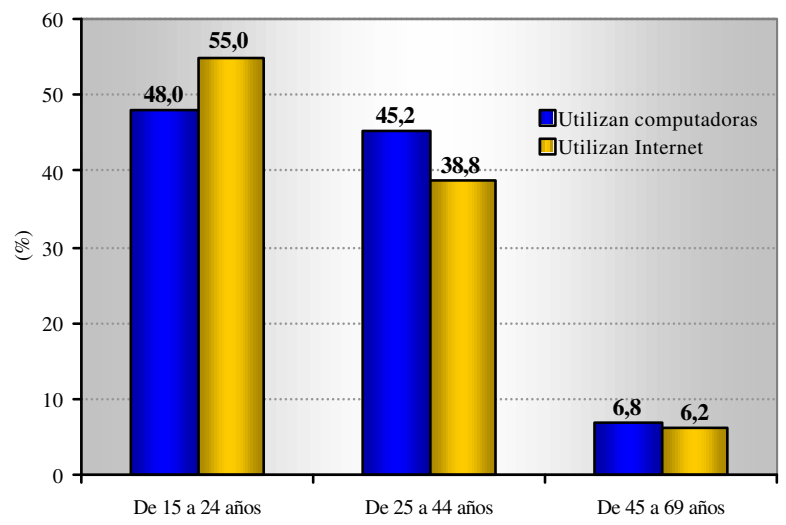

Nota: los porcentajes fueran calculados en relación al propio grupo.

Para el uso de Internet, se repite el mismo padrón que fue encontrado para el uso de la computadora en relación al ingreso y el mismo efecto de exclusión en relación a la población femenina: 
Gráfico 2.6.7: Ingreso indvidual y familiar per cápita promedio según la utilización de Internet

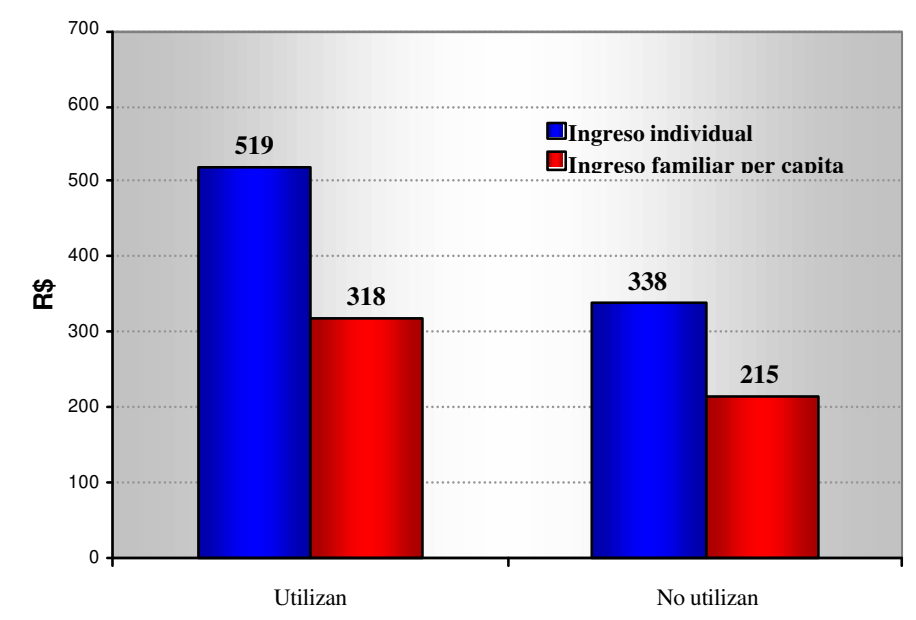

Gráfico 2.6.8: Porcentaje de utilización de Internet y posesión de computadora según sexo

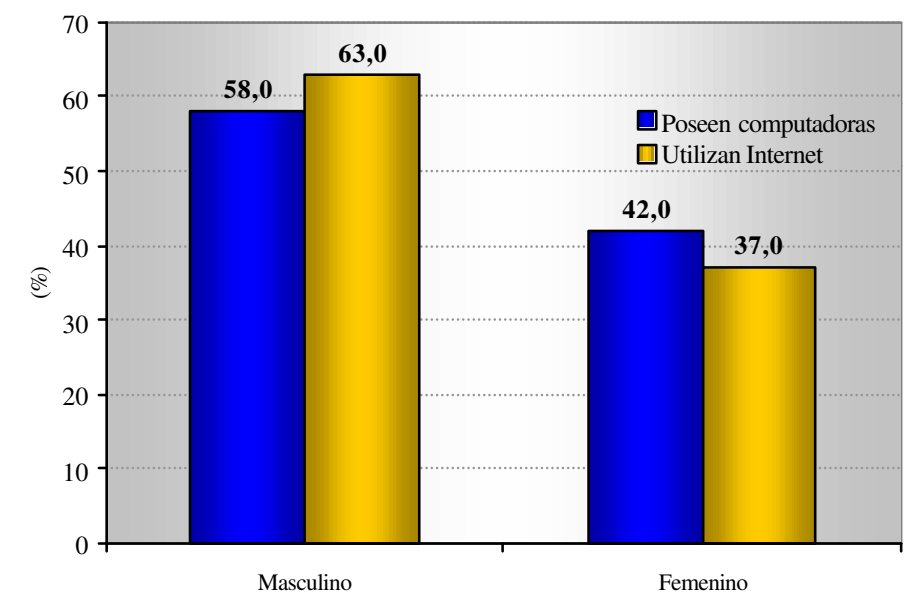

Nota: los porcentajes fueron calculados en rel ación al propio grupo.

El hecho de que aumente la distancia entre los usuarios del género masculino y femenino de acuerdo a la edad, confirma la hipótesis de que entre los adultos el trabajo realizado es un factor importante de exclusión digital. 


\section{Gráfi co 2.6.9: Porcentaje de utilización de Internet por}

sexo y grupo de edad

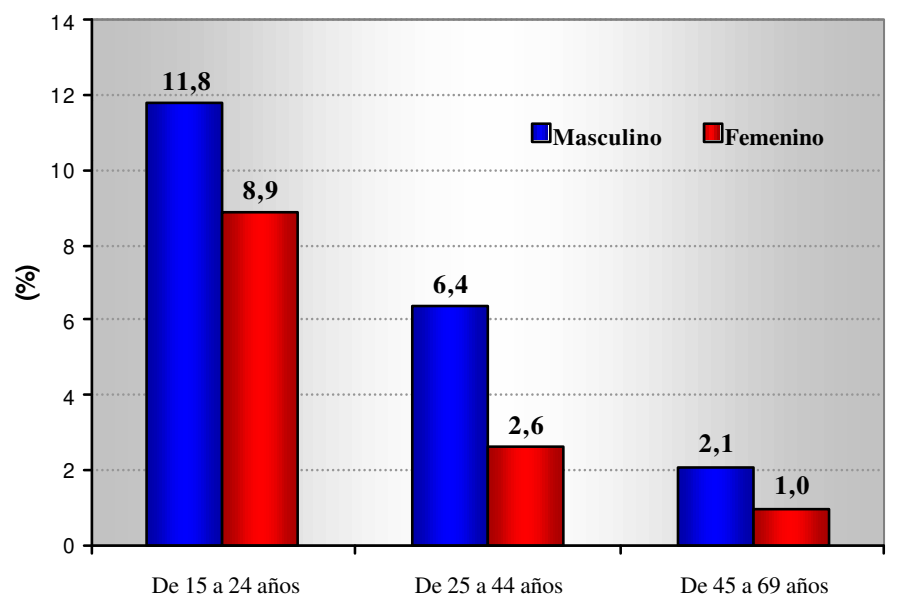

Tal como con en el uso de la informática, el trabajo funciona como un nivelador social en relación a la raza:

Gráfico 2.6.10: Porcentaje de utilización de Internet, de e-mail y posesión de computadoras según raza

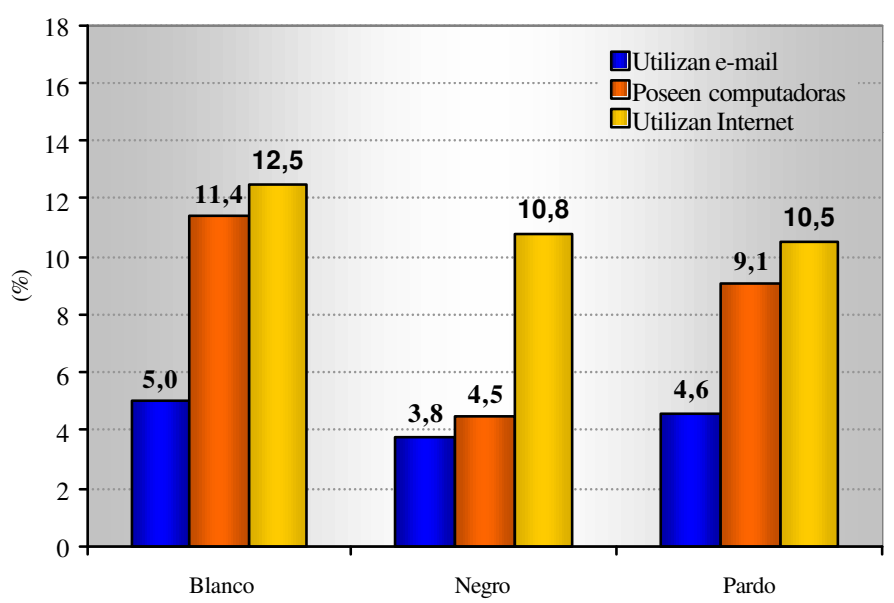

Nota: los porcentajes fueron calculados en relación al propio grupo.

La mayor entrada en Internet de acuerdo al nivel de escolaridad se mantiene: 
Gráfico 2.6.11: Porcentaje de personas que utilizan Internet por grupo de años de estudio en los barrios del municipio de Rio de Janeiro

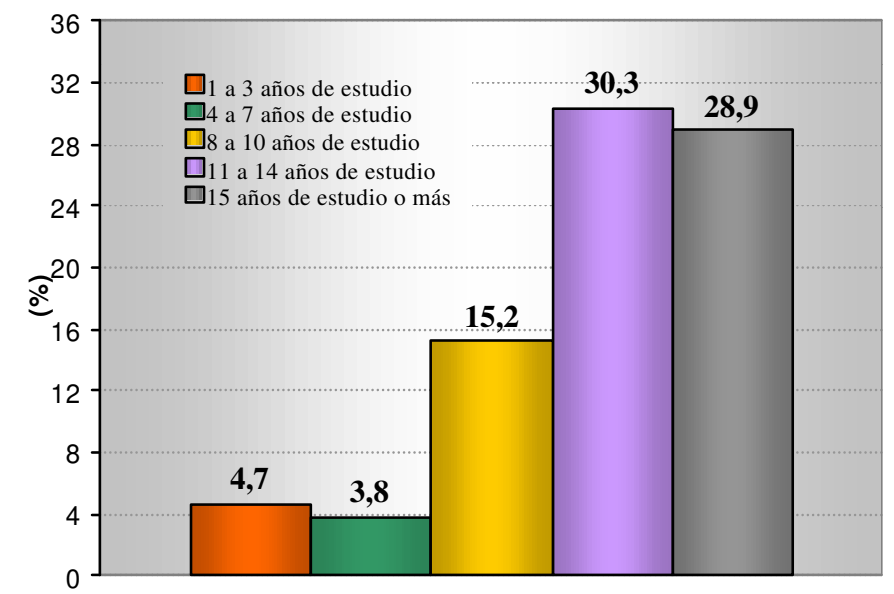

Nota: los porcentajes fueron calculados en relación al propio grupo

La distancia entre el ingreso más alto y el más bajo aumenta visiblemente cuando pasamos de usuarios de computadora para usuarios de Internet, lo cual debe de estar relacionado al costo y a la dificultad de acceso a Internet:

Gráfico 2.6.12: Ingreso del hogar per cápita e ingreso i ndividual según el nivel de inclusión digital

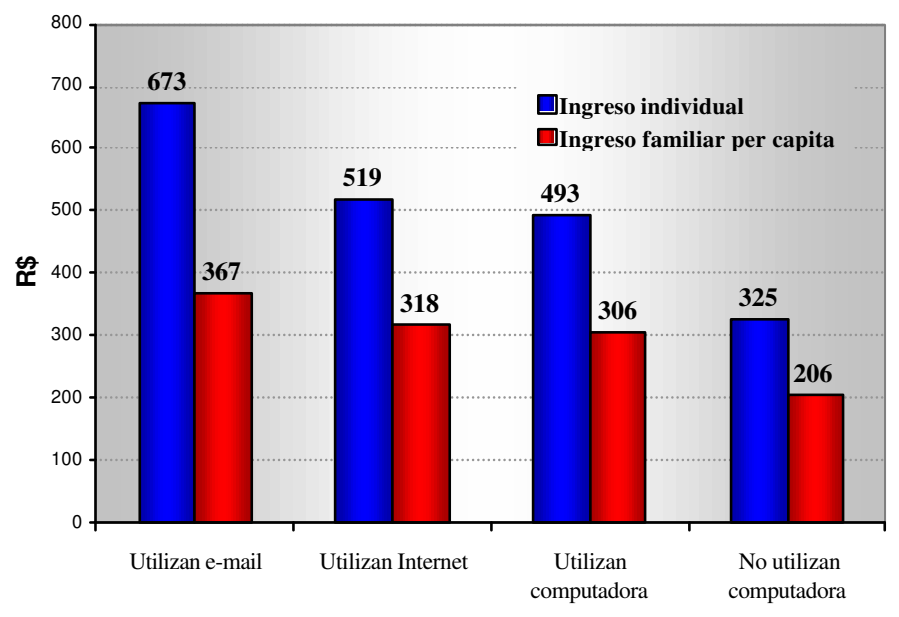


Esta hipótesis se confirma en el gráfico siguiente, en que el motivo indicado para no conectarse a Internet por más de la mitad, es la falta de local, y $14.6 \%$ señala el costo.

Gráfico 2.6.13: Motivos para no conectarse a Internet en los barrios del municipio de Rio de Janeiro

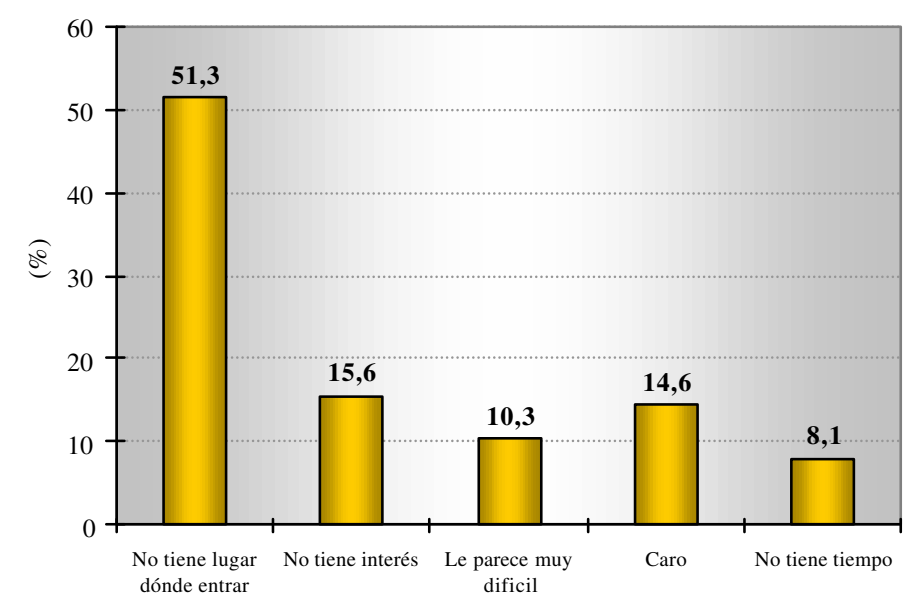

Universo: los que utilizan computadoras pero no se conectan a Internet ( $8,7 \%$ de la población)

\begin{tabular}{|l} 
Intensidad y tipos de uso \\
La mayoría de los participantes de los grupos motivacionales utiliza Internet por lo menos \\
una vez por semana y se conectan de dos a tres horas, más o menos. La entrada se hace \\
normalmente en casa, en el trabajo o en la Estación Futuro. Generalmente, el grupo de \\
hombres de más de 35 años es el grupo de los líderes comunitarios, principalmente \\
algunos de los coordinadores de instituciones comunitarias, son los que se conectan a \\
internet con más frecuencia. La mitad de los hombres de más de 35 años se conecta a \\
Internet como mínimo tres veces por semana, normalmente por el trabajo o en busca de \\
información relacionada al trabajo, por ejemplo, al IPVA, financiamiento de la Caja \\
Económica o registro de CPF. Los que se conectan con menor frecuencia, normalmente lo \\
hacen rápidamente, para buscar información específica (sobre concursos o consulta de \\
saldo en el banco, por ejemplo). \\
Todos los líderes comunitarios (el profesor de ONG y algunos de los coordinadores de \\
instituciones comunitarias) que tienen acceso a Internet, la utilizan diariamente. Algunos
\end{tabular} \mid


|llegan a quedarse conectados todo el día. La entrada a Internet está normalmente vinculada al trabajo, a la comunicación con compañeros, al envio de proyectos y documentos, a la divulgación de seminarios y captación de recursos. Algunos también entran para leer algún diario o para investigar algo para la facultad.

A los jóvenes que tienen entre 16 y 22 años, les gusta conectarse a sitios que básicamente están vinculados a la diversión, especialmente los de música y de chismes. Uno de ellos es vicepresidente del club de admiradores de Vanessa Jackson y está siempre buscando saber todo lo que es divulgado en relación a ella. Otro chico entra toda las noches para entretenerse, después de pasar todo el día trabajando con la computadora. A veces la utiliza para mandar informes para los clientes y también para buscar información sobre economía, además de visitar espacios para charla, ICQ y sitios con noticias y chismes. Internet también es utilizada por algunos de este grupo y por la mayoría de los jóvenes con hasta 16 años para la realización de trabajos escolares, a través de investigación en sitios de búsqueda. Generalmente, los principales puntos que los participantes indicaron que deberían ser mejorados en Internet son la velocidad, la seguridad, la facilidad de conexión y el costo. El costo de la conexión fue bastante enfatizado por los hombres de más 35 años. Para uno de ellos, la propaganda debería ser la que financia Internet. El usuario debería pagar sólo por el costo de la electricidad, y los patrocinadores pagarían el costo de Internet. Según él, esta sería la forma más racional para globalizar realmente Internet y terminar un poco con la exclusión.

El grupo de jóvenes entre 16 y 22 años se mostró preocupado con el uso continuo de Internet, ya que todo puede ser hecho a partir de la computadora, desde pagar las cuentas hasta encontrarse con amigos y divertirse. Para ellos, esto llevaría a un aislamiento, un distanciamiento entre las personas, pues Internet es muy impersonal. El grupo de líderes comunitarias también piensa que la computadora genera un cierto aislamiento de aquellos que la utilizan. Las personas se aprisionan a la computadora o a Internet y se olvidan de conversar. El profesor de la ONG comparó la computadora con la televisión: las personas se aprisionan a determinado programa en determinada hora. Sin embargo, Internet da la 
$\begin{aligned} & \text { posibilidad de interacción, pero se trata de una relación fria porque no hay un contacto } \\ & \text { personal. }\end{aligned} \mid$

\section{Tipos de sitios visitados y contenidos de los mismos}

La calidad de la conexión y la necesidad de traducción para los sitios extranjeros, fueron señaladas por las mujeres de 22 a 35 años, como aspectos importantes a ser mejorados. De forma general, los jóvenes de 16 años no esperan nada más de Internet, tan sólo más organización. El exceso de la propaganda divulgada también molesta a este grupo.

Con respecto a los sitios extranjeros, son pocos los que visitan sitios en otras lenguas. Los que buscan este tipo de sitio, normalmente lo hacen por los cursos de idiomas o por trabajo profesional. Un joven de 16 a 22 visita sitios en inglés por alguna demanda del curso y le da preferencia a los sitios de música, chismes y noticias. No tiene dificultades con el idioma. Un hombre de más de 35 años visita un sitio de la BBC, cuya propuesta es enseñar inglés, lo que hace que su contenido sea más comprensible.

En el grupo de hombres de 22 a 35 años, uno de ellos ya visitó sitios gays en cantonés, tailandés, chino. Pero él no busca el sitio por el contenido, que incluso no comprende, sino por las imágenes, pues trabaja con diseño y webdesigner. Otro, que trabaja con deportes, visitó algunas veces un sitio de Inglaterra sobre fútbol y pudo comprender el contenido con ayuda del traductor de texto.

Pocas mujeres entre 22 y 35 años y con más de 35, visitan sitios en otros idiomas. Las que entran no tienen dificultad con el contenido, pues ya hicieron cursos. Algunos de los jóvenes visitan sitios de grupos de música y buscan leer la historia del grupo cuando hay alguna traducción. Si no la hay, ellos no se preocupan con el texto e intentan entender el contenido del sitio por las imágenes. 
A todos los participantes les gustaría tener contacto con barrios de otros países. A la mayoría le gustaría conocer sobre la cultura, las costumbres y las creencias de otros pueblos. Uno de los jóvenes entre 16 y 22 años se interesa específicamente por la parte negra de los Estados Unidos en lo relativo al tipo de música. Para los chicos que tienen hasta 16 años, el tema sería “mujeres”. Para uno de los hombres de más de 35 años, que es músico, la posibilidad de divulgación de su trabalho en portugués sería muy interesante.

A la mayoría le pareció interesante la idea de conocer los barrios pobres de otros países y de tener acceso al estilo de vida. Se dio énfasis al intercambio de informaciones con el objetivo de mejorar la vida en los barrios, a partir de experiencias en que alguna dificultad haya sido superada, y el sufrimiento de las personas haya sido minimizado. Otros sugirieron sólo una comparación entre estilos de vida. A una de las mujeres de 22 a 35 años, le gustaría ver la diferencia entre una "favela del primer mundo y una de tercer mundo”.

Algunos participantes relataron que conocieron personas por Internet, excepto las integrantes del grupo de mujeres de más de 35 años. Dos de los jóvenes de 16 a 22 años hicieron algunos amigos en la sala de charla e, inclusive, ya se ennoviaron con algunas de las chicas que conocieron por Internet. Sin embargo, uno de ellos declaró que le pareció peligroso marcar encuentros a través de salas de charla y evita dar informaciones sobre su vida a las personas que no conoce.

En el grupo de hombres con más de 35 años, uno de ellos organizó algunos encuentros entre varios internautas en el Norte Shopping.com, con los cuales todavía mantienen contacto por e-mail y por teléfono. Estas personas están siempre intercambiando informaciones y esto ayudó a emplear a dos de ellos en el área de seguridad. Otro se hizo amigo de un argentino en una sala de charla, pero no lo llegó a conocer personalmente.

Algunas mujeres entre 22 y 35 años relataron que conocieron hombres por Internet, llegando a encontrarlos personalmente. Una de ellas puso sus datos en un sitio de Internet y conoció muchas personas, llegando a ir a citas marcados por internet. Una de las personas que conoció hasta arregló su computadora, y otro, que era abogado, la ayudó con su separación. En el grupo de hombres de 22 a 35 años, uno de ellos conoció una 


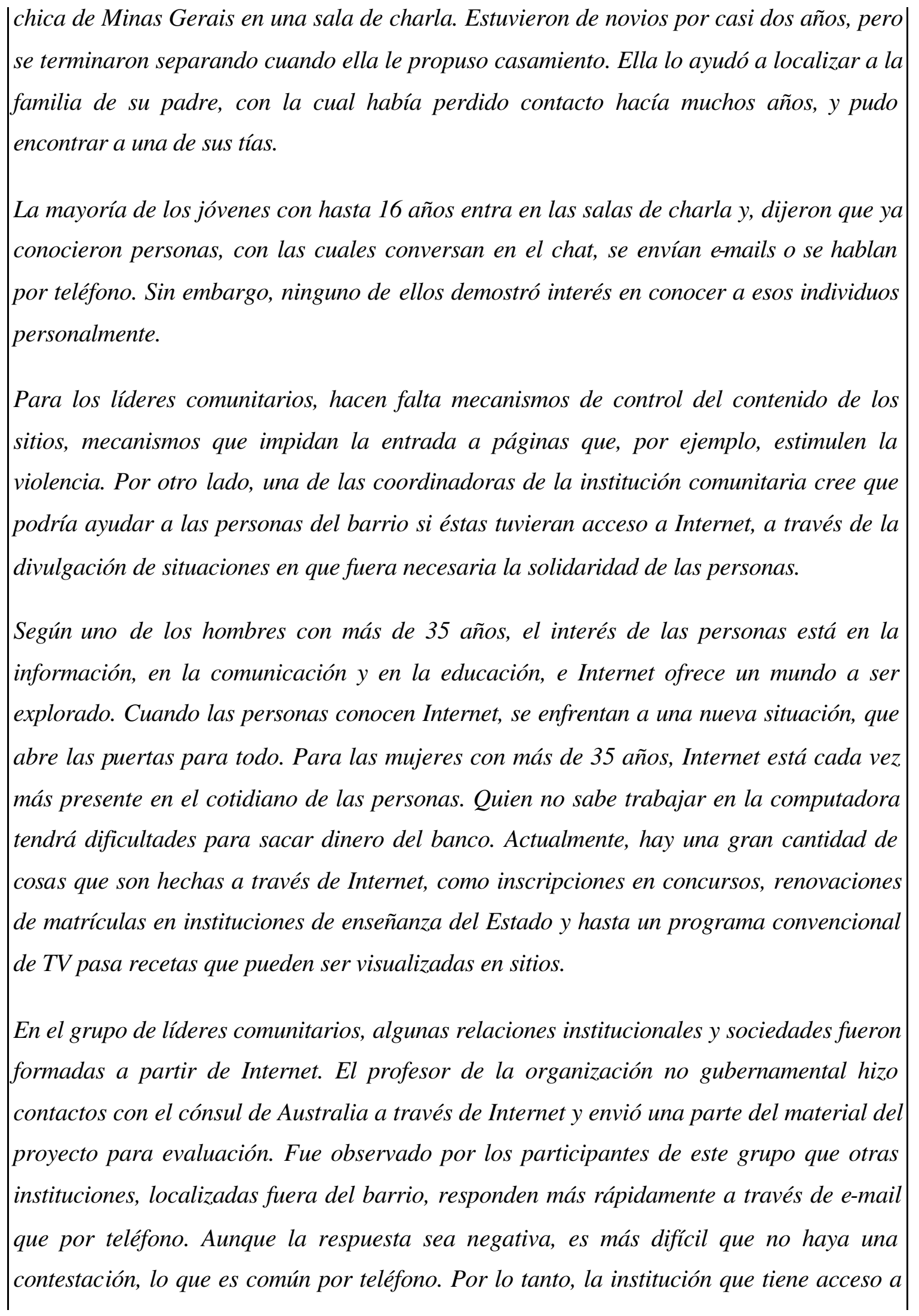




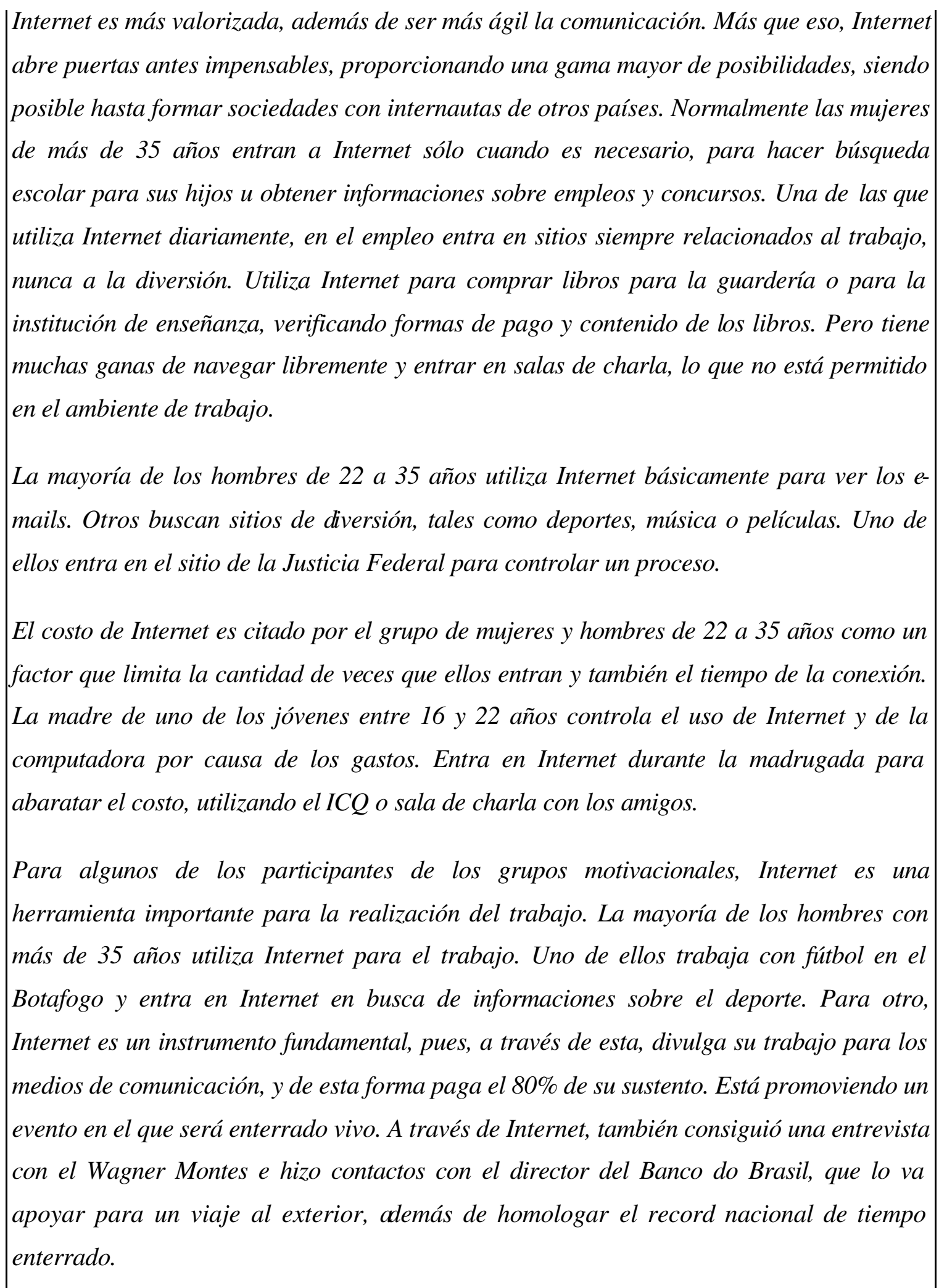


Una de las mujeres con más de 35 años vendía videos y libros por Internet. Poseía un lista de e-mails, donde eran anexadas las propagandas a ser enviadas. Otra también ganaba dinero con Internet cuando trabajaba con servicios gráficos. Algunas personas pagaban una tasa mensual para que ella verificara sus e-mails, pues no tenían tiempo para hacerlo ellas mismas. Entre las mujeres del grupo de 22 a 35 años, una tuvo que aprender a utilizar Internet por obligación en el trabajo, ya que era necesario el acceso a sitios específicos, de la Receita Federal y de la Caixa Econômica. También en el grupo de hombres de 22 a 35 años, el técnico de fútbol se asoció con una ONG de Italia, a través de la cual varias familias en la Rocinha van a recibir ayuda económica para que sus hijos puedan participar del cuadro.

El proveedor utilizado por los que tienen computadora en casa normalmente es gratuito, (IBEST o IG, en la mayor parte de los casos). Sólo en el grupo de los jóvenes de hasta 16 años, la mitad utiliza proveedor pago.

Los sitios en los que más entran las mujeres de 22 a 35 años son los relacionados al empleo (CAT) o a concursos. Una de ellas tuvo respuesta, y fue llamada para participar de la selección para un puesto como auxiliar contable. Sin embargo, lo rechazó pues estaba realizando un trabajo como autónoma en el que pagaban mejor. Las mujeres con más de 35 años también suelen enviar currículum y hacer inscripciones para concursos por Internet.

Sólo uno de los jóvenes de 16 a 22 años ya buscó empleo a través de Internet. Él, está registrado en el SIEA (Sitio de Inmigración del Ambiente Escolar) y está constantemente verificando si hay alguna posibilidad de pasantía, y ya consiguió un trabajo a través de este sitio.

Una de las personas del grupo de líderes comunitarios también ya buscó empleo por Internet. Pasó por el proceso de selección de la empresa Vale do Rio Doce, haciendo varias entrevistas. Al final no fue llamada y tuvo la impresión de que la empresa sólo estaba formando un banco de datos. 


\section{Tipos de portales visitados y contenidos de los mismos}

Generalmente, los puntos principales que los participantes indicaron que debían ser mejorados en Internet son la velocidad, la seguridad, la facilidad de ent rada y el costo. El costo de la entrada fue bastante enfatizado por los hombres con más de 35 años. Para uno de ellos, la propaganda debería de ser la que financia Internet. El usuario debería pagar sólo el costo de la electricidad y los patrocinadores pagarían el costo de Internet. Según él, esta sería la forma más racional para globalizar realmente Internet y terminar un poco con la exclusión.

El grupo de jóvenes de 16 a 22 años se mostró preocupado con el uso continuo de Internet, en el cual todo sería hecho a partir de la computadora, desde el pago de cuentas hasta los encuentros con amigos y la diversión. Para ellos, esto llevaría a un aislamiento, un alejamiento entre las personas, pues Internet es muy impersonal. El grupo de líderes comunitarios también cree que la computadora lleva a cierto aislamiento de parte de quienes la utilizan. Las personas se aprisionan a la computadora o a Internet, olvidándose de conversar. El profesor de la ONG comparó la computadora con la televisión, pues las personas se aprisionan a determinado programa en determinada hora. Sin embargo, Internet da la posibilidad de interacción, pero es una relación fria porque no hay un contacto personal.

La calidad de la conexión y la necesidad de traducción para los sitios extranjeros también fueron indicadas, por las mujeres entre 22 y 35 años, como aspectos importantes a ser mejorados. Generalmente, los jóvenes de 16 años no esperan nada más de Internet, sino tan sólo más organización. El exceso de la propaganda que es divulgada también molesta a este grupo.

La mayoría opina que el ideal sería que todos tuvieran condiciones de tener una computadora y acceso a Internet. Internet también tiene el papel de educador pues favorece el acceso a la información y a la educación.

Con respecto a los sitios extranjeros, son pocos los que entran en sitios en otros idiomas. Los que buscan este tipo de sitio normalmente lo hacen por el curso de idiomas o por su 
profesión. Un joven de 16 a 22 entra en sitios en inglés por una demanda del curso y le da preferencia a los sitios de música, chismes y noticias. No tiene dificultades con el idioma. Uno de los hombres de más de 35 años entra en un sitio de la BBC, que tiene como propuesta enseñar inglés, lo que hace que su contenido sea más comprensible.

En el grupo de hombres de los 22 a los 35 años, uno de ellos ya entró en sitios gays en cantonés, tailandés y chino. Pero no entraba por el contenido del sitio, que inclusive no comprende, sino por las imágenes, pues trabaja con diseño y webdesigner. Otro, que trabaja con deportes, entró algunas veces a un sitio de Inglaterra sobre fútbol y pudo comprender el contenido con ayuda del traductor de texto.

Pocas mujeres entre 22 y 35 años y con más de 35 entran en sitios en otros idiomas. Las que lo hacen no tienen dificultades con el contenido pues ya hicieron cursos. Algunos jóvenes entran en sitios de grupos de música y buscan leer la historia del grupo cuando hay alguna traducción. Por el contrario, no se preocupan con el texto, e intentan entender el contenido del sitio por las imágenes.

A todos los participantes les gustaría tener contacto con barrios de otros países. A la mayoría le gustaría saber más sobre la cultura, las costumbres y las creencias de otros pueblos. Uno de los jóvenes entre 16 y 22 años está interesado específicamente en la parte negra de los Estados Unidos en relación al tipo de música. Para los chicos de hasta 16 años, el tema serían "las mujeres". La posibilidad de divulgación de su trabajo en portugués sería muy interesante para uno de los hombres con más de 35 años, que es músico.

A la mayoría de las personas también le pareció interesante la idea de conocer personas de barrios pobres de otros países y tener acceso al estilo de vida. Fue enfatizado el intercambio de informaciones con el objeto de mejorar la vida en los barrios, a partir de experiencias en que alguna dificultad haya sido superada y el sufrimiento de las personas haya sido disminuido. Otros sugirieron sólo una comparación entre estilos de vida. A una de las mujeres con entre 22 y 35 años le gustaría ver la diferencia entre una favela del primer mundo y una de tercer mundo. 
Algunos participantes relataron que conocieron personas por Internet, excepto las mujeres con más de 35 años. Dos de los jóvenes de 16 a 22 años hicieron varias amistades en salas de conversación e, inclusive, ya se pusieron de novio con algunas chicas que conocieron en Internet. Sin embargo, uno de ellos declaró que le parecía peligroso marcar encuentros a través de salas de charla y evita dar informaciones sobre su vida para personas que no conoce.

Uno de los integrantes del grupo de hombres de más de 35 años, organizó algunos encuentros entre varios internautas en el Norte Shopping.com, que todavía mantienen contacto por e-mail y por teléfono. Estas personas están siempre intercambiando informaciones y él ayudó a dos de ellos a conseguir empleo en el área de seguridad. Otro hizo amistad con un argentino en una sala de charla, pero no llegó a conocerlo personalmente.

Algunas de las mujeres entre 22 y 35 años relataron que conocieron hombres por Internet, y llegaron a encontrarlos personalmente. Una de ellas colocó sus datos en un sitio de Internet y conoció muchas personas, llegando a ir a citas marcados con los internautas. Una de las personas que ella conoció le arregló la computadora y el otro, que era abogado, la ayudó con su separación. En el grupo de hombres de 22 a 35 años, uno de ellos conoció a una chica de Minas Gerais en un chat. Ellos fueron novios por casi dos años, pero se terminaron separando cuando ella le propuso casamiento. Ella lo ayudó a localizar la familia de su padre, con la cual él había perdido contacto hace muchos años, y pudo encontrarse con una de sus tías.

La mayoría de los jóvenes de hasta 16 años entra en salas de conversación y dijeron que y a conocieron personas, con las cuales conversan en el chat, se envían e-mails o se hablan por teléfono. Sin embargo, ninguno de ellos demostró tener interés en conocerlas personalmente.

Computación, educación y cursos por Internet

Los padres del grupo de jóvenes de 16 a 22 años demuestran que prefieren que los hijos se queden en casa, utilizando la computadora, y no en la calle, sujetos a cualquier tipo de 
situaciones, especialmente a las relacionadas con la violencia. Otro joven del grupo de no usuarios de Internet también percibe este movimiento por parte de un tio, que facilita el acceso a la computadora para evitar que se quede en la calle metiéndose en problemas. Este estímulo al uso de la computadora pasa por una tentativa de protección y ofrecimiento de más seguridad a los hijos. A pesar de reconocer esto, los jóvenes señalan la importancia de mantener otras actividades, como el contacto personal, además del trabajo, el estudio y el deporte.

Algunos jóvenes de 16 a 22 años también observan que los padres incentivan el uso de la computadora con vistas a abrirles puertas en la vida profesional, para ayudarlos a conseguir un mejor empleo. Otro relata que el padre no sólo lo estimula por el lado profesional, sino también para que pueda ayudarlo con los aparatos electrónicos, los cuales el padre no sabe manejar.

La computadora también sería una opción mejor que la televisión. Con la TV, la persona no puede interactuar y se olvida de lo que hay a su alrededor, separándose, inclusive, de la lectura. Por el contrario, la computadora por lo menos permite que la persona practique su escritura y lectura (jóvenes de 16 a 22 años)

Otros líderes comunitarios, entre los cuales está el presidente de la asociación de vecinos, el profesor de la ONG y los coordinadores de las instituciones comunitarias, también creen que la computadora puede ayudar a sacar al joven de la criminalidad. Sin embargo, sólo eso no sería suficiente, siendo necesario otro tipo de iniciativas para que los jóvenes tengan para dónde ir después de hacer el curso. Según ellos, es necesario que haya más recursos y asociación con otras instituciones de enseñanza o con empresarios y con la sociedad civil. Fue también observada la necesidad de invertir en el ser humano para generar cambio. El foco debería estar en la educación y en la generación de ingresos y empleos. Fue destacada la importancia de reclamar del Estado, que tiene responsabilidades con esas personas. El papel de estas instituciones no sería el de hacer el trabajo del Estado.

En cuanto a la posibilidad de utilizar la computadora en las instituciones de enseñanza, está limitada a la red de instituciones particulares. Prácticamente ninguna de las 
|instituciones de enseñanza públicas posee acceso a la computadora. Dos mujeres de 22 a 35 años estudian en la enseñanza pública, donde hay computadora para uso exclusivo de los funcionarios; no existe la posibilidad de acceso para los alumnos. En el grupo de hombres y mujeres de hasta 16 años, los alumnos de la institución de enseñanza particular tienen acceso a la computadora y, en algunos casos, también a Internet, pero con el uso dirigido a la investigación escolar. Algunos profesores piden a sus alumnos que hagan búsqueda en Internet, pero de forma optativa.

En el grupo de jóvenes de 16 a 22 años, una de las chicas es estudiante de facultad particular y puede utilizar la computadora y entrar a Internet en el laboratorio, que es abierto a todos los alumnos. Ellos pueden, inclusive, entrar por cuestiones personales, no vinculadas a la actividad académica. Uno de los chicos del mismo grupo de edad está participando de un proyecto para la implementación de un laboratorio para los alumnos de la institución de enseñanza estadual en la que estudia. Esto fue posible debido a una donación de computadoras Pentium II, hecha por la Petrobras. El laboratorio ya está prácticamente listo; él y un compañero darán clases para los otros estudiantes.

En lo referido a la realización de cursos por Internet, la mayoría de los hombres de más de 35 años mostraron interés, y la opinión de las mujeres con más de 35 años está bastante dividida. Las mujeres entre 22 y 35 años y los jóvenes de hasta 16 años no harían ningún tipo de curso por Internet.

La principal objeción de los grupos con respecto a los cursos via Internet, está referida a la necesidad de un profesor para aclarar las dudas. Para uno de los vecinos con más de 35 años, la interacción con el profesor es fundamental para la enseñanza, de forma tal que aunque exista un servicio de apoyo para aclarar las dudas, no sustituiría el contacto personal. Para las mujeres de 22 a 35 años, la interacción es esencial para que el alumno aprenda y resuelva sus dudas. Algunas mujeres de más de 35 años piensan que Internet aislaría a la persona. Para ellas, las relaciones establecidas personalmente y el intercambio de conocimientos son muy importantes, junto con la oportunidad de conocer nuevas personas. La gran ventaja de los cursos ofrecidos via Internet sería la economía de tiempo, especialmente porque evita dislocaciones innecesarias. 
Otras objeciones fueron levantadas por los grupos. Para uno de los hombres entre 22 y 35 años, el curso por Internet sería muy básico, en función de los pocos recursos disponibles para un buen aprendizaje. Otra dificultad se refiere a la entrada en Internet, que sería muy lenta si fuera en el domicilio (hombre de más de 35 años). Fue señalada la necesidad de la banda larga, vía radio, con más velocidad para entrar. No sería posible hacer el curso con una conexión lenta, que cae a cualquier momento. El costo fue citado por el grupo de hombres entre 22 y 35 años, que creen que sería muy caro realizar un curso por Internet. Por eso, uno de ellos sólo lo haría si fuera posible recibir el material por e-mail.

Algunas mujeres con más de 35 años harían un curso de educación superior por Internet, pues sería una oportunidad para aquellos que no llegaron a la Universidad. Sin embargo, una de ellas considera que el curso de educación superior es muy serio para ser hecho por Internet, pues sería necesario un espacio de discusión que no fuera superficial, lo que probablemente sucedería con Internet. Un hombre de más de 35 años declaró que sólo haría un curso de perfeccionamiento dentro de la propia área en que trabaja, porque ya posee algún conocimiento. Pero no haría un curso para el cual no tenga ninguna base, porque estaría limitado a informaciones teóricas sin la posibilidad de aplicar el conocimiento en la práctica. Además de esto, algunos cursos serían muy difíciles de ser hechos por Internet, como los que necesitan la utilización de herramientas u otros, como medicina e ingeniería. Serían viables los cursos relacionados al manejo de la computadora y de algunos softwares, e incluso, cursos superiores, dependiendo del área.

Otro aspecto relevante se refiere a las diferencias en la valorización del curso hecho por Internet en relación a los cursos tradicionales realizados en la sala de aula. Según la opinión de uno de los habitantes (hombre con más de 35 años), los cursos realizados on line no serían reconocidos por ninguna empresa y, por lo tanto, sería una pérdida de tiempo y dinero realizarlos. Entre los hombres del grupo de los 22 a los 35 años, también está el miedo de que el curso no sea reconocido. 


\section{Empleo, negocios y transacciones por Internet}

El conocimiento de informática fue considerado unánimemente, por todos los participantes, como favorecedor de la contratación de personal, por mejorar el currículum del candidato al cargo. La exigencia de aumentar la especialización es sentida por todos los entrevistados. En el grupo de los hombres y mujeres de 16 a 22 años, la informática y el conocimiento de algún idioma fueron señalados como esenciales para conseguir un empleo. Además de esto, dos de los chicos (16 a 22 años) necesitaron tener conocimientos de informática para conseguir ascenso profesional. Uno de ellos trabaja con ventas y fue promovido para telemarketing, pero si no tuviera conocimiento de computación no ocuparía el cargo. Otro trabaja haciendo el mantenimiento de computadoras, incluyendo limpieza, instalación de programas, etc. Para este grupo, la presentación de certificados no sería una garantía de contratación, pues sería necesaria una demostración práctica de conocimientos.

Sin embargo, uno de los hombres mayor de 35 años perdió una oportunidad de trabajo por no haber hecho cursos de informática, a pesar de poseer conocimiento en el área. La empresa exigía que presentara certificados. Según uno de los entrevistados, el mercado de trabajo, principalmente para quien tiene más de 30 años, está cada vez más dificil. Él sugiere más flexibilidad de la empresa, en el sentido de verificar el interés del candidato y la posibilidad de ascender en el cargo, y no sólo de querer un funcionario que ya esté preparado. Otro hizo una queja en relación a las oportunidades que son ofrecidas a la población carente. En una institución de enseñanza pública actualmente no hay una sala con laboratorio de informática para los alumnos. Para él, Brasil no tiene y no ofrece estructura para que el usuario se perfeccione y adquiera conocimiento.

Entre las mujeres con más de 35 años, el conocimiento de informática favoreció la obtención de empleo. Una de ellas explica que no sólo la ayudó a conseguir un trabajo, sino también a descubrir su vocación. Ella ganó una beca para el curso de informática y fue invitada por el profesor como asistente en las clases. A partir de esto, descubrió que 


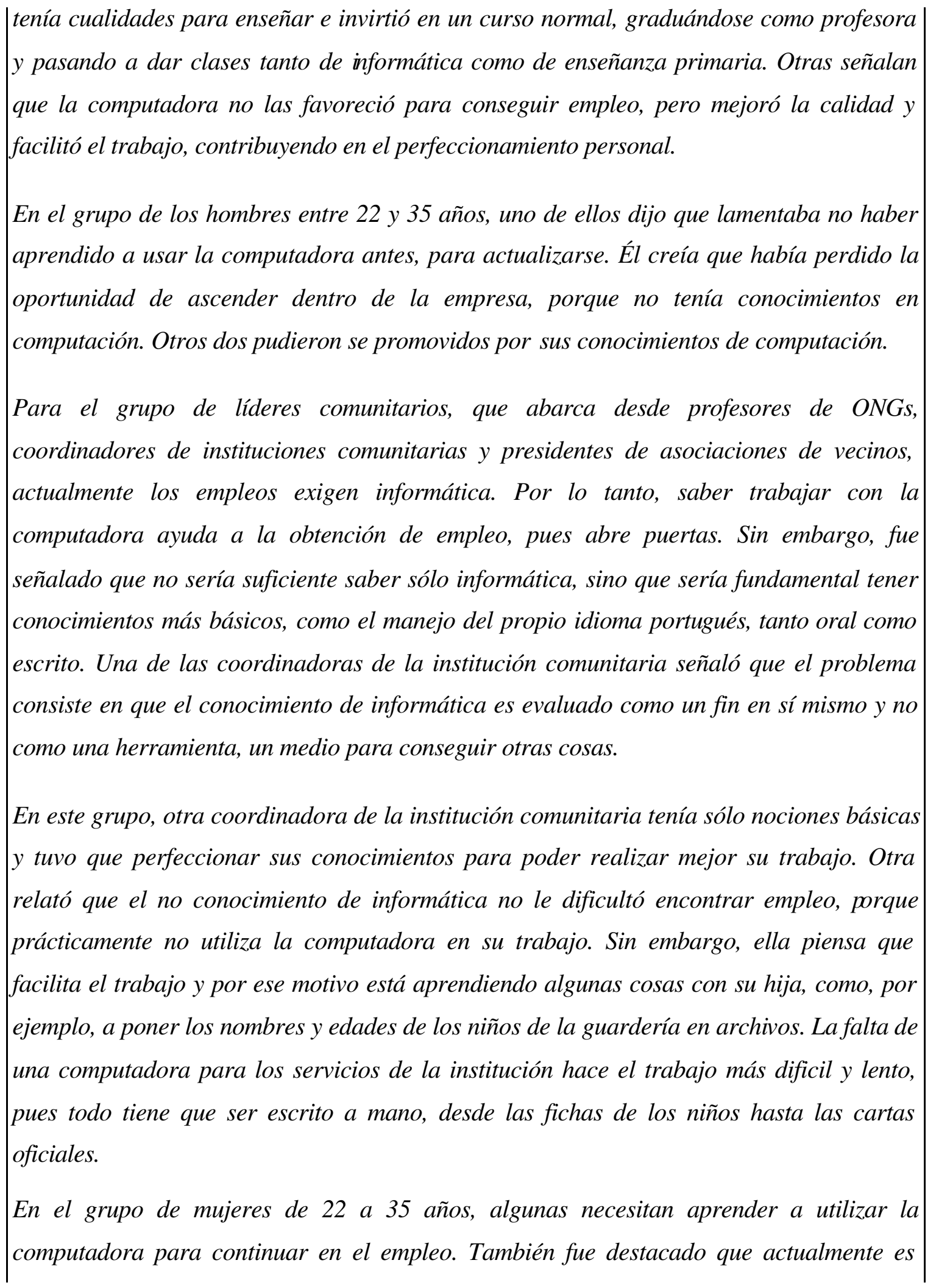


necesario que la persona sepa por lo menos prender la computadora, porque en las empresas marcar tarjeta ya es una operación electrónica.

Un chico del grupo de 16 a 22 años (Maré) gana dinero con la computadora y demuestra un amplio conocimiento en el área de informática. Él hace sistemas (recientemente hizo uno para SERVAS), edición de imágenes y videos, animación 3D, sitios, currículos, ediciones de cartas, slogans, designer y, en Internet, sabe programar el HTML. Otro chico, del grupo de 22 a 35 (Rocinha) también utiliza la computadora para ganar dinero, especialmente con recursos audiovisuales y trabajos administrativos. Él hace logomarcas, tarjetas personales, crea los diseños que utiliza, hace marcas personalizadas. Para esto, usa, por ejemplo, el photoshop. Uno de ellos es un hombre mayor de 35 años que actualmente trabaja con PhotoShop y Corel Drawn. Él es músico y diseñó la tapa de su propio $C D$, que, a través de un personaje roquero, habla del cotidiano y de las dificultades de los barrios pobres. Su trabajo es divulgado por Internet.

Para ellas, el uso de la informática va más allá de la utilización en el empleo. Hasta en el banco es necesario saber alguna cosa sobre informática para poder manejar los cajeros automáticos y hacer pagamentos, saques o digitar la seña.

Con relación a la utilización de Internet para hacer negocios, generalmente, los participantes de los grupos motivacionales no consideran que sea un espacio seguro para este tipo de uso. La mayoría no haría compras, ni transacciones bancarias que implicaran movimientos de dinero. Muchos utilizan Internet sólo para comparar precios, consultar el saldo, imprimir $2^{a}$ vía para el pago de cuentas y registro de CPF. Uno de los jóvenes de 16 a 22 años cree que entrar al banco por Internet es peligroso y que por más protecciones que el sistema tenga es siempre posible alguna invasión. La mayor parte de los hombres de 22 a 35 años no confía en Internet y no la utilizaría para pagar cuentas.

Los que ya realizaron transacciones bancarias o compras continúan inseguros con respecto a Internet. Una de las mujeres de 22 a 35 años ya hizo transferencia de dinero de un banco para otro. Ella piensa que es más práctico este tipo de procedimiento por Internet. Sin embargo, por problemas de seguridad, prefiere ir personalmente al banco. 
Dar el número de tarjeta de crédito es visto, por las mujeres con más de 35 años, como el procedimiento más peligroso cuando se trata de compras por Internet. Otro habitante (hombre 22 a 35 años) entra en sitios del banco sólo para ver el saldo y sólo hace compras por Internet a través del la boleta bancaria.

La necesidad de examinar el producto para ver si es realmente lo que se desea adquirir, también fue señalada como uno de los problemas para hacer compras por Internet. Uno de los hombres con más de 35 años desistió de hacer un negocio porque había que pagar sin tener el producto en la mano. Un joven de 16 a 22 años también prefiere ver el producto antes de realizar la compra, más allá de tener el nombre de quien lo atendió para después poder tener alguien a quien buscar. Sin embargo, Internet no ofrece esa facilidad. Uno de los chicos de hasta 16 años compró un instrumento por Internet cuyo auricular estaba roto. Perdió mucho tiempo para hacer la reclamación y, por esto, no compraría nuevamente. Otro intentó comprar, pero había muchos formularios a ser llenados y terminó desistiendo.

Sitios de tiendas conocidas, como Lojas Americanas o Shoptime, dejan a los usuarios más tranquilos para adquirir algún producto. Algunos hombres de más de 35 años harían compras por Internet, si conocieran la tienda.

Una de las mujeres con más de 35 años ya realizó varias transacciones bancarias y se siente completamente segura, pues piensa que el que arca con las consecuencias, en el caso de que haya algún problema, es el propio banco. Otras mujeres de este grupo de edad harían compras por Internet, a pesar de que nunca lo hayan hecho anteriormente. Lo que las limita es el precio de los productos, que son considerados más caros, y también la imposibilidad de hacer compras con tarjeta o cheque.

Por curiosidad, uno de los participantes (hombre con más de 35 años) hizo contactos con un grupo en el cual él podría aprender a ser un hácker. Para esto, él tendría que hacer un depósito y recibiría informaciones sobre cómo tener acceso a las conversaciones de los otros en teléfonos móviles. Él prefirió no completar la operación. 


\section{7 - Cómo es utilizado el e-mail}

Solamente $4.6 \%$ de los habitantes de la favela usan e-mail, o sea, menos de la mitad de los usuarios de Internet y un cuarto de los usuarios de computadora:

Gráfico 2.7.1: Porcentaje de uso de e-mail en relación a la utilización de computadoras e Internet

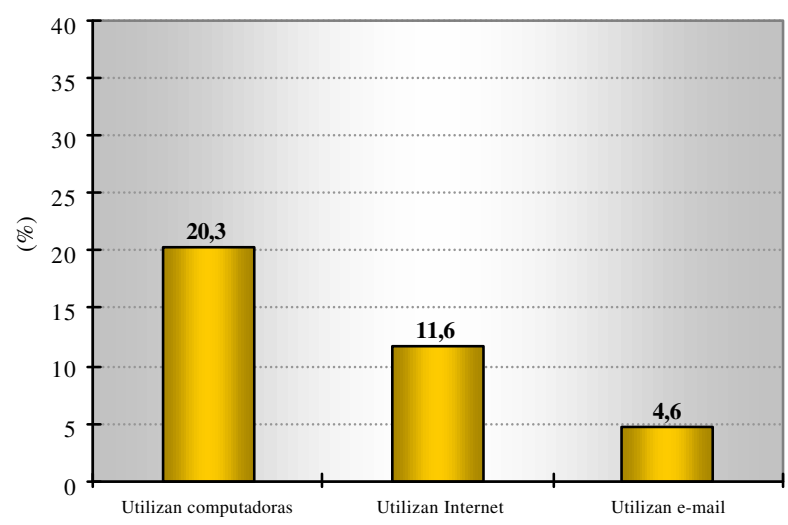

La relación entre el usuario de e-mail por grupo de edad indica una tendencia inesperada: aunque sea todavía preponderante el uso de e-mail entre el grupo más joven de la población, la distancia en el uso de e-mail entre los grupos de edad, comparados con la distancia entre los grupos de edad en el uso de la computadora e Internet, tiende a disminuir:

Gráfico 2.7.2: Porcentaje de utilización del e-mail según el grupo de edad en los barrios de bajos ingresos del municipio de Rio de Janeiro

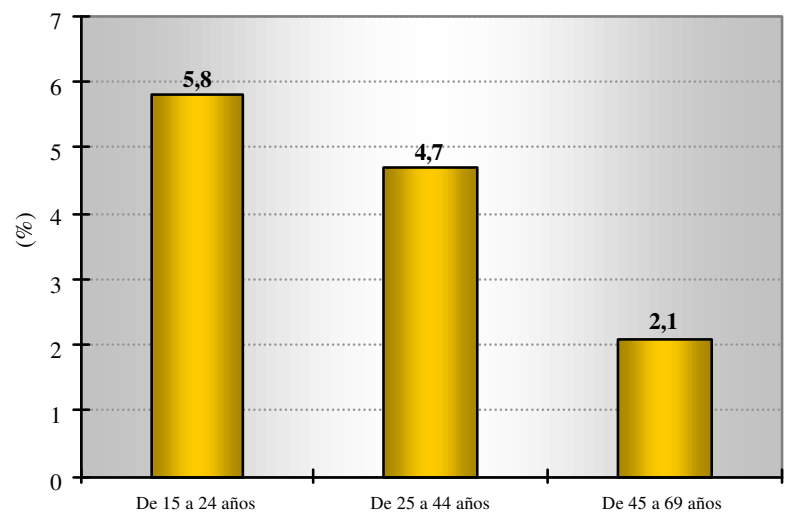

Nota: los porcentajes fueron calculados en relación al propio grupo. 
En la utilización del e-mail se reproduce nuevamente el fenómeno de exclusión femenina:

Gráfico 2.7.3: Utilización de e-mail según sexo en los barrios de bajos ingresos del municipio de Rio de Janeiro

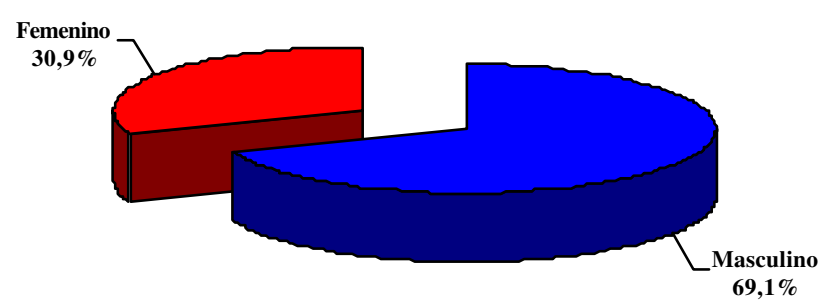

Universo: los que utilizan E-mail ( 4,6\% de la población)

En relación a la raza, constatamos que el diferencial relativo entre blancos, negros y pardos es relativamente bajo, comparado con las diferencias de ingreso, escolaridad y posesión de computadora. Este bajo diferencial posiblemente está asociado al fenómeno ya mencionado de acceso a través del trabajo:

Gráfico 2.7.4: Porcentaje de utilización de e-mail según raza en los barrios de bajos ingresos del municipio de Rio de Janeiro

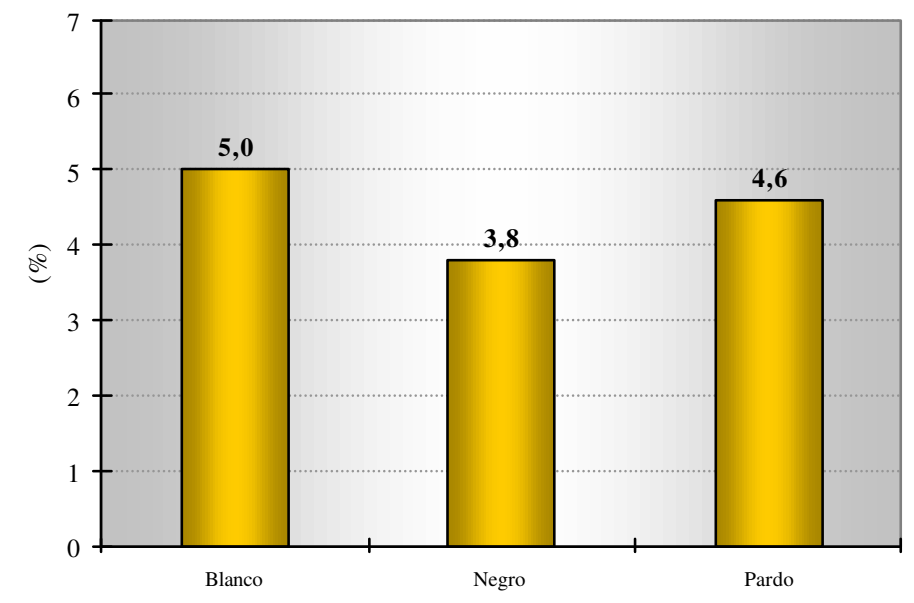

Nota: los porcentajes fueron calculados en relación al propio grupo. 
En el nivel de escolaridad, sin embargo, la distancia en el uso de e-mail adquiere más importancia (la disminución del porcentaje de usuarios de e mail entre los grupos de escolaridad más alta en relación al nivel inmediatamente inferior debe ser referida, posiblemente, al margen del error técnico producido por el pequeño número de entrevistados con escolaridad superior a 15 años):

\section{Gráfico 2.7.5: Porcentaje de utilización del e-mail según el nivel educacional} en los barrios de bajos ingresos del municipio de Rio de Janeiro

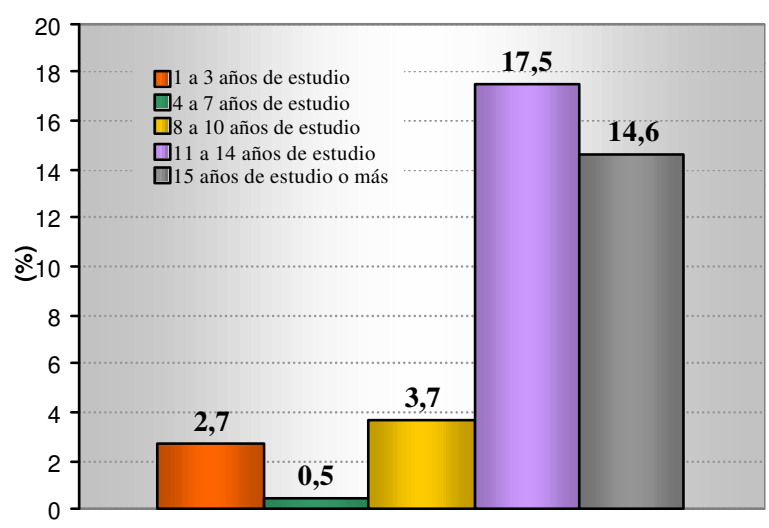

Nota: los porcentajes fueron calculados en relación al propio grupo.

El diferencial en el nivel de ingreso reproduce porcentajes similares a los del uso de Internet y computadora:

Gráfico 2.7.6: Ingreso individual y familiar per cápita medio según la utilización de e-mail en los barrios de bajos ingresos del municipio de Rio de Janeiro

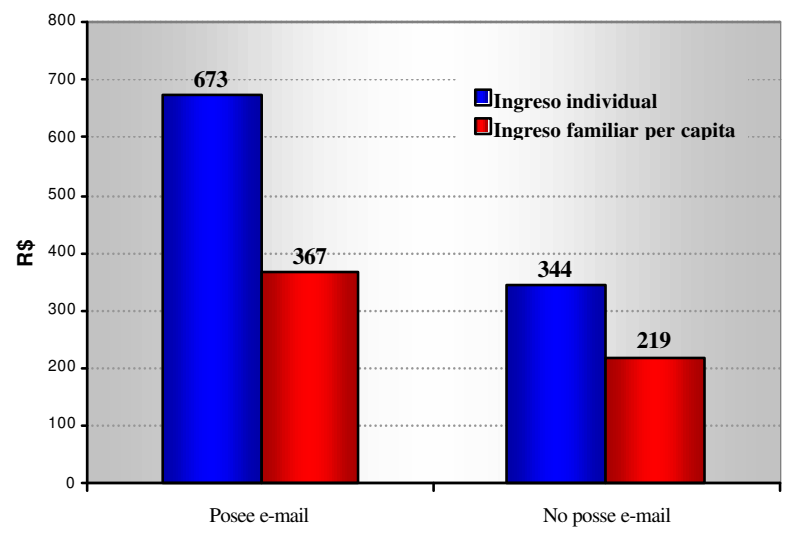


La intensidad en el uso del e-mail es indicada en el gráfico siguiente:

Gráfico 2.7.7: Frecuencia de utilización de e-mails en los barrios del municipio de Rio de Janeiro

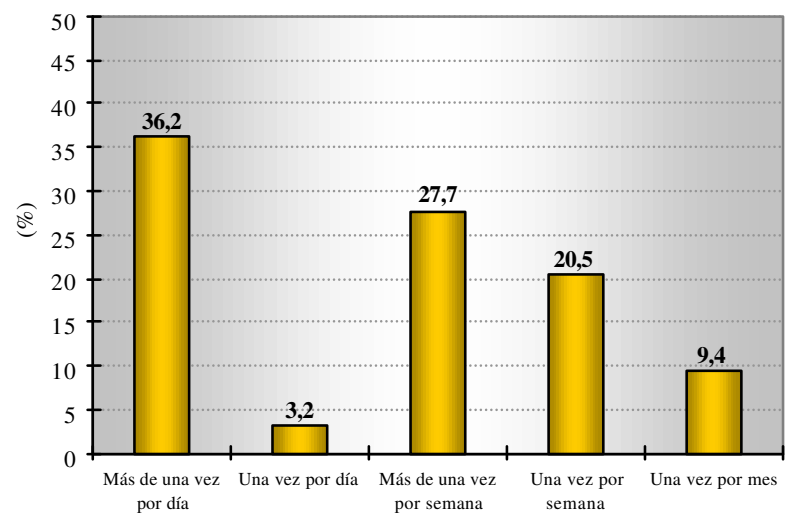

Universo: los que usan e-mail ( 4,6\% de la población)

El uso de e-mail es fundamentalmente para amigos y parientes. Su uso profesional todavía es limitado, lo que puede ser explicado según el tipo de ocupación ejercida por el usuario de e-mail en favela, así como por su sociabilidad, pues gran parte de su entorno social no tiene acceso a Internet y al e-mail.

Gráfico 2.7.8: Principales remitentes y destinatarios de e-mails en los barrios de bajos ingresos del municipio de Rio de Janeiro

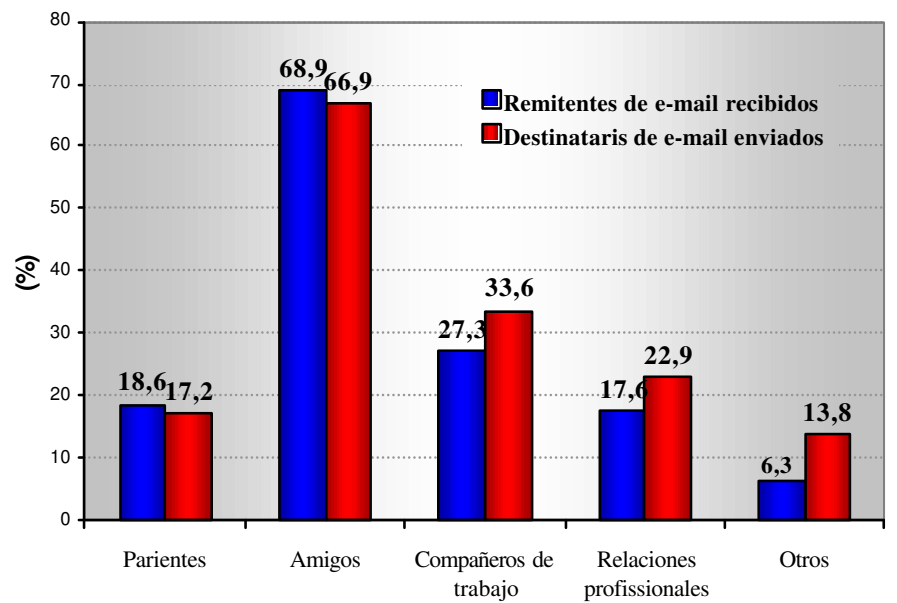




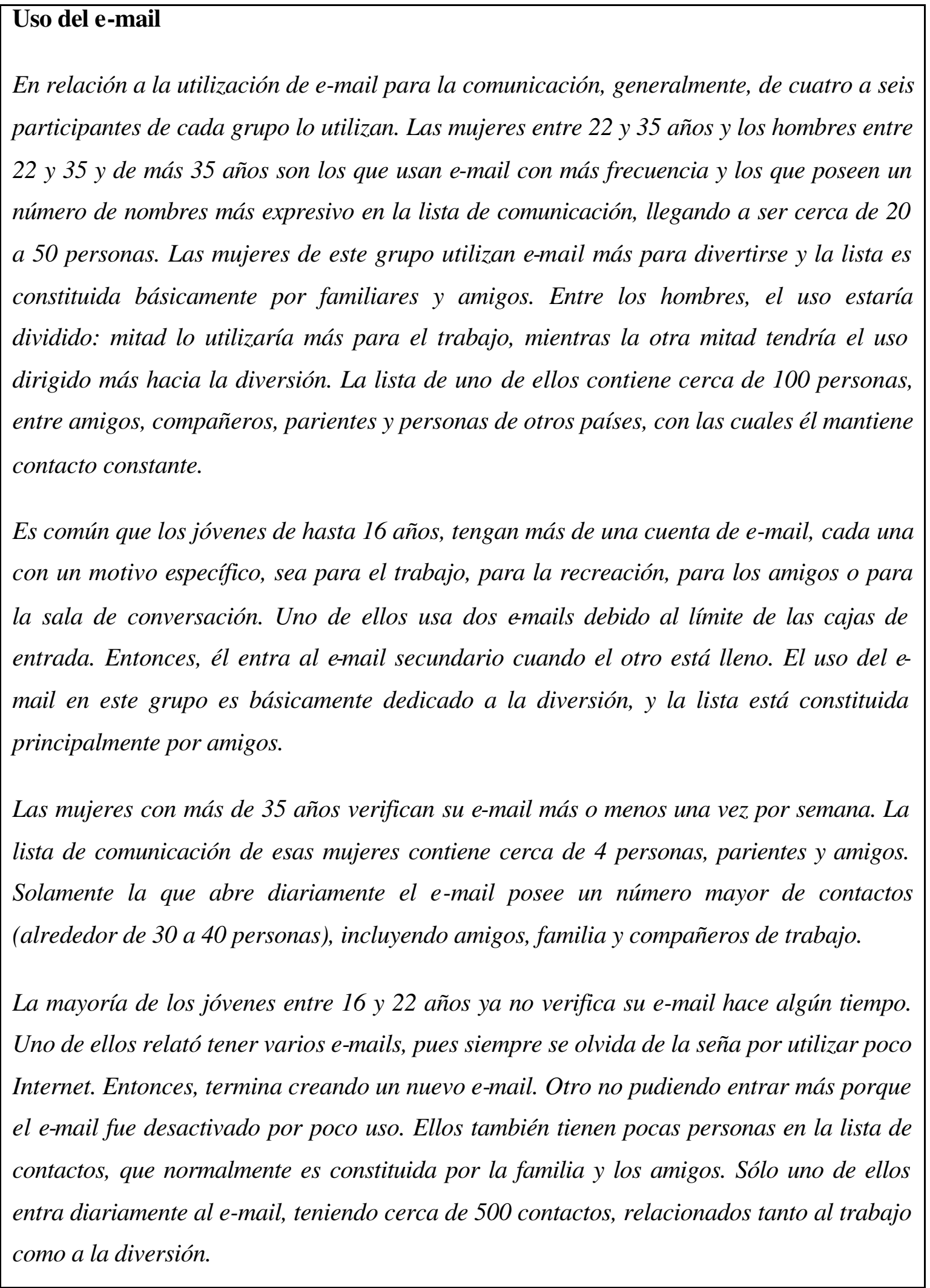


La mayoría de los líderes comunitarios (profesor de ONG, coordinadores de instituciones comunitarias y presidente de la asociación de vecinos) tienen e-mail y lo utliizan diariamente para hacer contactos de trabajo y también con amigos. El presidente de una asociación de vecinos tiene e-mail, pero sin embargo este es usado por los hijos, ya que él no sabe cómo usarlo.

\section{8 - Telecentros: el caso de las Estaciones Futuro}

Las Estaciones Futuro, que actualmente llegan a 12, son telecentros de la ONG Viva Rio, establecidos en Campo Grande, Cesarão, Itararé, Macaé, Maré, Rocinha, Santa Cruz, São Cristóvão, Urucânia, Itaguaí e a Barraca da Feira de São Cristóvão. ${ }^{9}$ Del total de la población de las favelas, las 12 Estaciones Futuro son indicadas por 7.3\% de los usuarios como el principal local de entrada, y, en las favelas en que existe una Estación, este porcentaje sube para $30 \%$ del total de los usuarios. El impacto en los barrios puede ser medido en los gráficos 40, 41 y 42 .

Gráfico 2.8.1: Porcentaje de uso de computadoras según el tipo de barrio

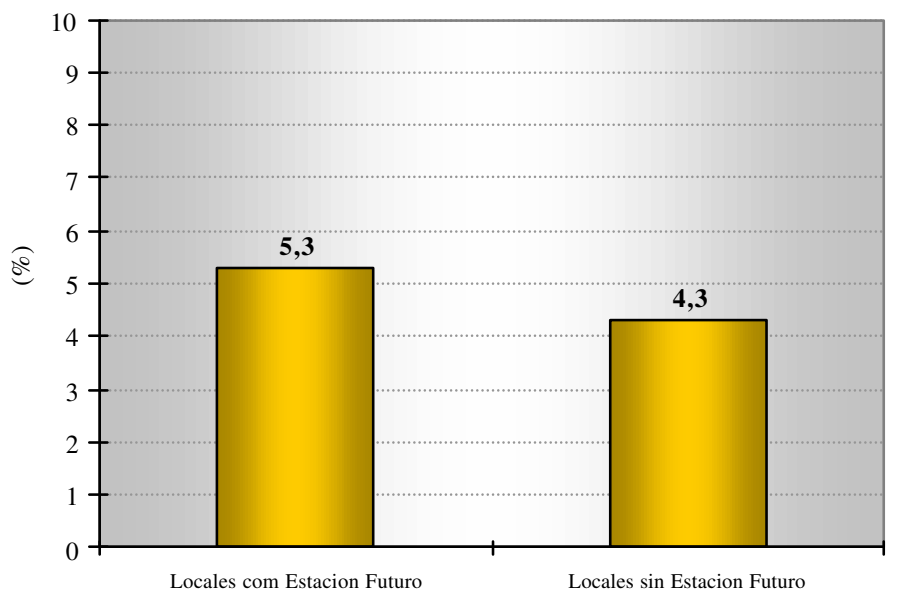


Gráfico 2.8.2: Porcentaje de uso de Internet según el tipo de barrio

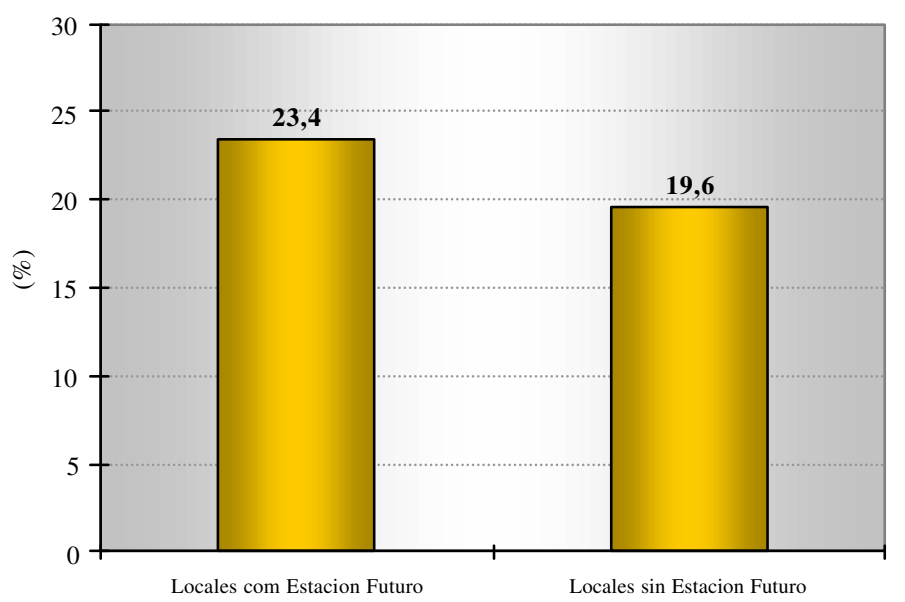

Gráfico 2.8.3: Porcentaje de uso del e-mail según el tipo de barrio

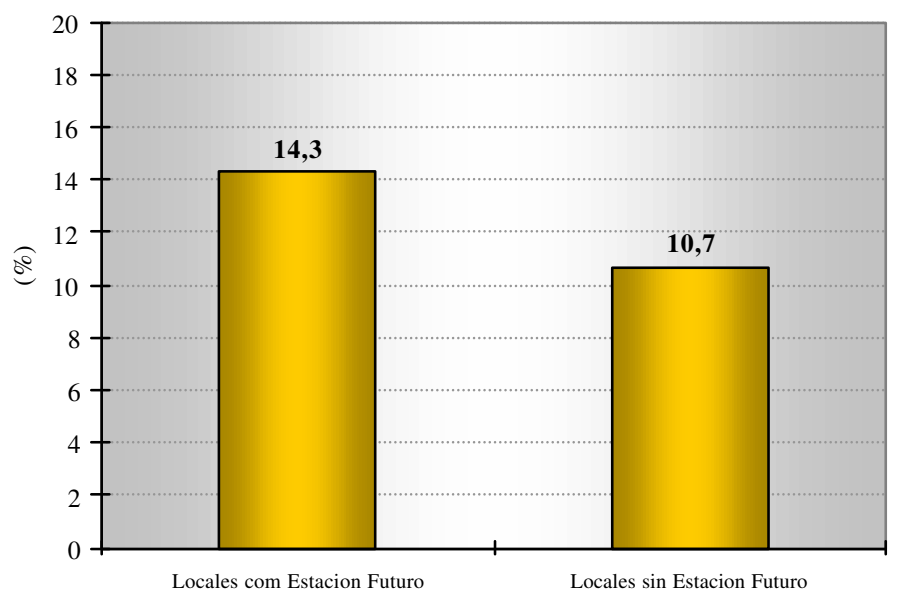

En todos los casos la presencia de la Estación Futuro indica un impacto positivo en el aumento del acceso a la informática y a Internet. En relación a los padrones generales analizados anteriormente, las Estaciones Futuro muestran (como lo veremos en el último capítulo a partir del análisis de datos más refinados sobre las favelas donde existe Estación

\footnotetext{
${ }^{9}$ En otro trabajo, Sorj, B., brasil@ povo.com - La lucha contra la desigualdad en la Sociedad de la Información, Rio Janeiro, Jorge Zahar, 2003, analizamos detalladamente las Estaciones Futuro.
} 
Futuro), que la distancia entre los sexos se mantiene, así como también en relación a los negros:

Gráfico 2.8.4: Utilización de Internet y Estación Futuro según la raza

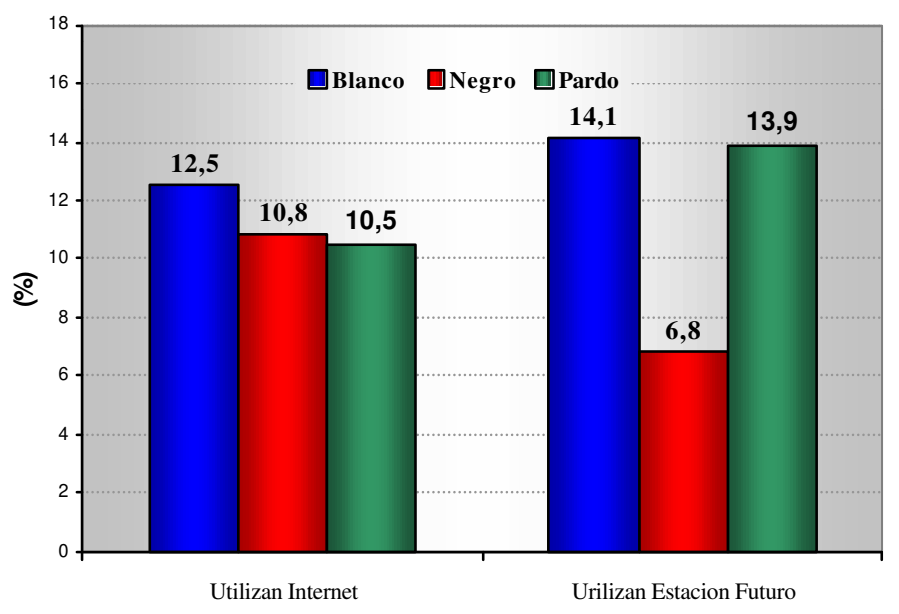

La conexión a Internet en las Estaciones Futuro tiene un precio inferior al cobrado por los Cybercafés privados, por lo tanto los usuarios tienden a pertenecer a los sectores de más poder adquisitivo de la favela, factor éste que es neutro en relación al género, pero desfavorece a la población negra, que, en general, se sitúa en los grupos de ingresos inferiores.

Gráfico 2.8.5: Ingreso individual y familiar per cápita medio según la utilización de Internet

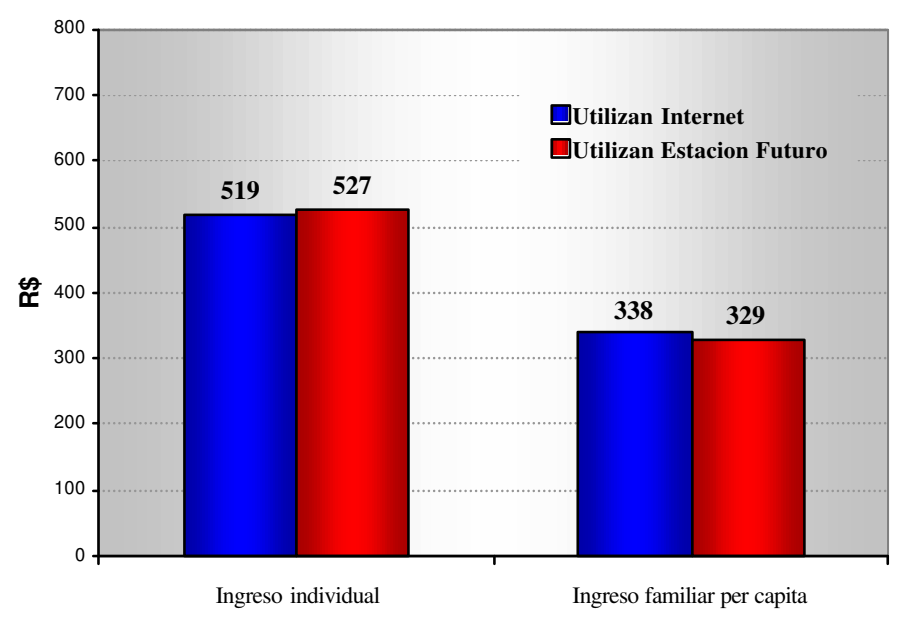


Las Estaciones Futuro son un factor nivelador en términos del grupo de edad, ya que su público tiene un promedio de edad más alto que los usuarios de Internet. Una explicación posible para esto puede ser encontrada en el apoyo que las Estaciones Futuro ofrecen al usuario, como los servicios de búsqueda de empleo, así como la mayor disponibilidad de ingreso de las personas de más edad en relación al público juvenil.

\section{Gráfico 2.8.6: Utilización de Internet y Estación Futuro según el} grupo de edad

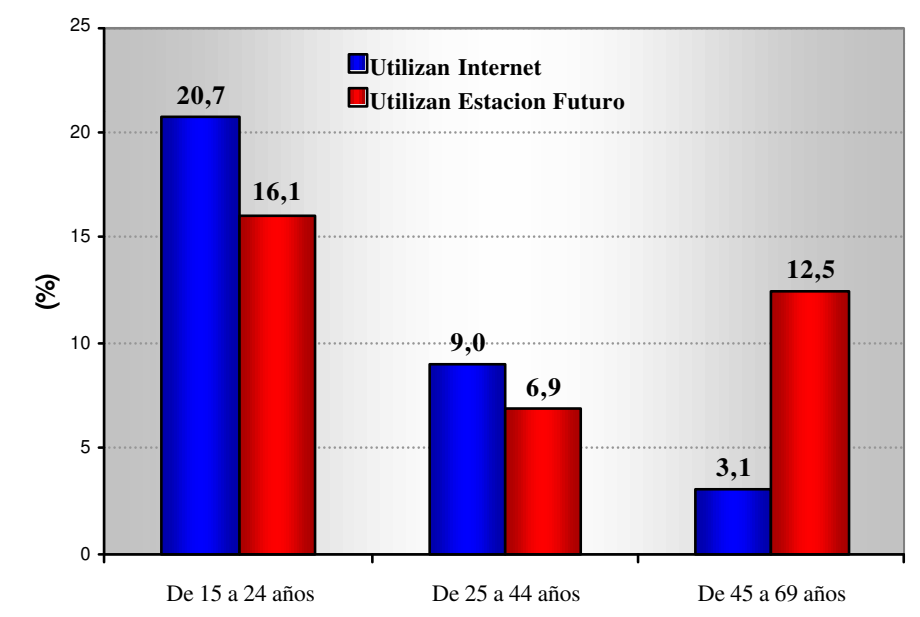

\begin{tabular}{|l|}
\hline Estación Futuro \\
La mayoría de los participantes de los grupos ya utilizó o todavía utiliza la Estación \\
Futuro, excepto el grupo de los no usuarios de Internet. Sólo hubo un chico del grupo de \\
hasta 16 años que declaró que nunca fue a la Estación por no tener mucho interés y que \\
utiliza la computadora en la casa de parientes sólo para trabajos escolares. Pero los \\
jóvenes de hasta 16 años que todavía utilizan la Estación, lo hacen con cierta regularidad, \\
y la frecuentan alrededor de una vez por semana. En el grupo de mujeres con más de 35 \\
años, una de los principales motivos para la utilización de la Estación Futuro es la mejor \\
conexión a Internet. De forma similar, las mujeres de 22 a 35 años prefieren entrar a \\
Internet en la Estación Futuro, inclusive aquellas que poseen computadora en el domicilio, \\
pues es más barato que entrar en la casa.
\end{tabular}


Todos los que representaban a los líderes comunitarios (profesor de ONG, coordinadores de la institución comunitaria y presidente de la asociación de vecinos) conocen las actividades de la Estación Futuro. Aquellos que no poseen computadora en la institución o en la casa, utilizan la Estación Futuro con cierta regularidad. Una de las instituciones comunitarias de la Rocinha, que funciona principalmente como guardería, utiliza la Estación para hacer informes, oficios, cartas. Dependiendo de la necesidad, la frecuencia para ir a la Estación es alrededor de una a dos veces por semana. Una de las coordinadoras de la institución comunitaria también contó que utiliza la Estación Futuro cuando hay necesidad de hacer un oficio con mejor presentación, pero generalmente utiliza el mimeógrafo. En realidad, ella la utiliza con más frecuencia para asuntos personales, pues tiene una amiga en Francia que está siempre enviándole e-mails. Generalmente es la hija quien va hasta allá y le trae los mensajes impresos.

El motivo más comúnmente aludido para no utilizar la Estación es la posesión de la computadora en el domicilio. Incluso en este caso, los jóvenes de 16 a 22 años van a la Estación Futuro cuando no pueden conectarse a Internet en la casa. También los jóvenes de hasta 16 años que poseen computadora, cuando la conexión con Internet es dificil en el domicilio, van hasta la Estación para entrar en Internet. Algunos líderes comunitarios, especialmente aquellos que trabajan en la coordinación de la institución comunitaria, frecuentan la Estación Futuro sólo cuando hay algún problema con Internet o con la computadora.

Solamente uno de los participantes del grupo de los no usuarios conocía la Estación Futuro. La descubrió cuando estaba pasando en frente y vio carteles indicando los precios para el uso. Pensó que era una buena iniciativa, pues favorece a aquellos que no tienen dónde entrar a Internet. Sin embargo, le pareció que el espacio físico era muy chico (un quiosco en el Piscinão), además de ser poco confortable.

A pesar de que existen otros lugares de entrada a Internet en Rocinha, la Estación Futuro es considerada la mejor, por los participantes del grupo de jóvenes (hasta 16 años). Uno de los problemas señalados se refiere a la velocidad de las máquinas en la Estación Futuro, las cuales deberían ser más rápidas. La falta de auriculares para escuchar música 
y la cantidad de computadoras disponibles, también fueron señalados como aspectos que | podrían ser mejorados.

En relación a la velocidad de entrada a los sitios en Internet, los hombres y mujeres de 22 a 35 años, también piensan que es muy lenta. Sin embargo, el grupo de jóvenes de 16 a 22 años considera que, a pesar de que algunas computadoras demoren un poco más, de forma general no podría considerarse que la entrada sea lenta.

El número de máquinas disponibles también fue uno de los puntos abordados por las mujeres con entre 22 y 35 años y por las de más de 35. Dependiendo del horario, es necesario quedarse esperando que la otra persona termine para poder entrar. Por esto, sería interesante que hubiera un número mayor de computadoras para usar. Una de las mujeres con más de 35 años sugirió que fuera hecha una promoción para un horario específico, exactamente cuando la sala es menos utilizada.

En relación al espacio físico, todos los participantes lo consideran bueno y confortable, excepto las mujeres de 22 a 35 años (Rocinha). Para ellas, la Estación Futuro fue más cómoda y ahora el espacio es muy pequeño. El aire acondicionado, a pesar de ser central, parece no funcionar, porque la sala está siempre con una temperatura inadecuada.

El grupo de jóvenes entre 16 y 22 años sólo elogió el trabajo realizado en la Estación Futuro. Sin embargo, el grupo de hombres de 35 años piensa que la recepción no debería ser parte de la sala de computadoras, por el gran barullo. Además, todo el tiempo se conversa mucho, lo que dificulta a los que están allí para trabajar y necesitan concentrarse.

Las mujeres de 22 a 35 años también protestaron por el barullo. Además de esto, la falta de privacidad fue señalada como uno de los problemas de la Estación. Una de ellas se siente constreñida cuando un hombre se sienta a su lado para entrar en el sitio de la Playboy, y a otras les gustaría sentirse más cómodas cuando tienen que hacer sus trabajos o navegar por Internet. Para evitar tales situaciones, se sugirió la utilización de cabinas privadas. 
La mayor parte de los grupos considera que la atención es buena, pues las funcionarias están siempre dispuestas a elucidar las dudas. Sin embargo, dos de los hombres de 22 a 35 años protestaron por la mala atención. Las funcionarias no atendieron sus dudas. Por esto, debería haber una mejor preparación del personal para trabajar con el público. Uno de ellos intentó conectarse en otro local y fue mejor atendido.

Con relación al costo para la utilización de la Estación Futuro, sólo en el grupo de hombres con más 35 años hubo quejas acerca de los precios cobrados. Uno de ellos contó que posee pocos recursos, lo que dificulta e incluso imposibilita la utilización constante de computadora. Él entra poco en Internet porque, aunque sea barato, no posee un salario fijo y muchas veces tiene que comprar comida, y no puede pasar 4 o 5 horas en Internet o en Viva Rio entrando en Internet. Por esto, tiene que entrar siempre rápidamente, sabiendo lo que va a mandar y no puede quedarse navegando. Como el caso del músico, que a veces necesita mandar una música en MP3, pero en la Estación Futuro hay que bajar el mídia player por Internet, lo que lleva mucho tiempo. Por ser de un barrio pobre, sugiere que se haga una encuesta para verificar quién realmente es pobre y necesita Internet, para que sea realizado, por ejemplo, un sorteo de algunas horas por mes para esas personas.

Otro hombre de este mismo grupo sugirió que se separara el uso del computador de la conexión a Internet. La idea es no cobrar el mismo valor para quien va a digitar un texto que para los que usen Internet. Debería haber un costo diferenciado para los servicios. También fue recomendado que las mejores computadoras deberían ser usadas exclusivamente para entrar en Internet y las otras, con menos recursos, para trabajos más simples. En el grupo de jóvenes de 16 a 22 años, fue sugerido que se cobre una tasa mensual que daría derecho a un cierto número de horas de utilización.

\section{Organizaciones localizadas en las favelas y uso de informática}

Una de las instituciones participantes del grupo focal es una ONG dirigida principalmente para el área de educación, que actúa en instituciones de enseñanza a partir de convenios (con la Petrobras, por ejemplo) y funcionando como institución de enseñanza preparatoria, 
ofreciendo diversos cursos para el barrio, desde enseñanza primaria hasta el examen de ingreso a la Universidad. Esta institución posee dos laboratorios de Informática, uno de ellos atiende al barrio y el otro atiende a los alumnos. Además, existen computadoras que pertenecen a otros proyectos. En el curso de informática se ofrece un paquete básico (Windows, Excel, Power Point) y se cobra una tasa para material de apoyo, que no cubre el gasto con personal, pero cubre el gasto del material didáctico. Internet, sin embargo, es de uso sólo de los funcionarios, pues todavía se está esperando la aprobación de recursos de un proyecto para la compra de material de estructura para proveer el mantenimiento. En la institución todo funciona a partir del uso de la computadora, incluyendo la elaboración de documentos.

En el centro deportivo, cultural y educacional de la prefectura, que está localizado en Maré, hay computadoras en el sector administrativo y también un laboratorio de informática que ofrece cursos gratuitos, desde el básico al avanzado, de todos los programas. La mayor parte de las computadoras fue donada por socios y sólo fueron compradas como máximo dos computadoras. Como la búsqueda es muy grande, se prepara una lista de espera. Sólo después de la construcción, que ya está prevista, desde la segunda sala será posible atender mejor a la demanda del barrio. La conexión a Internet es limitada a los funcionarios de la administración, pues todavía no se consiguió ningún socio para la instalación de Internet.

Una institución comunitaria, que ofrece guardería y cursos dirigidos a la educación, como el de alfabetización para jóvenes y adultos, posee computadoras que son de uso de la Secretaria, pero pueden ser eventualmente utilizados para trabajos de los alumnos. Las computadoras, que fueron donadas, agilizan una serie de informaciones, y también aumentan la flexibilidad en el trabajo cotidiano de la institución.

Otra institución funciona básicamente como guardería, ofreciendo también cursos de artesanía para mujeres desempleadas del barrio. Hay sólo una computadora que no tiene conexión con Internet. La coordinadora de esta institución declaró que le gustaría tener más 
computadoras para capacitar jóvenes. Este trabajo sería realizado por otros jóvenes que saben trabajar con computadora y que están disponibles para el curso. Ella cree que, al traer jóvenes para la institución, estará ayudando a sacarlos de la calle y de la violencia. Sin embargo, espera que haya alguna donación, ya que no puede comprar las computadoras. 


\section{3 - Segunda Parte}

\section{1 - Análisis por tipo de favela}

La Segunda parte de este libro está basada en otra encuesta realizada en los meses de octubre y noviembre de 2003, centrada únicamente en usuarios de computación e Internet. Nuestro objetivo fue de profundizar el conocimiento específico de los usuarios en las favelas de Rio de Janeiro. Considerando la heterogeneidad del universo de las favelas, decidimos investigar una favela de mayor nivel de ingreso (Rocinha), tres favelas de ingreso medio (Maré, Rio das Pedras y Dona Marta) y dos favelas de bajo ingreso (Jacaré y Jacarezinho). Esta diferenciación entre favelas, sin embargo, debe ser calificada, ya que todas las favelas tienen un importante nivel de heterogeneidad interna, que inclusive se expresa en una segmentación espacial. Este es el caso principalmente de la favela de Maré, en la práctica un conglomerado de favelas, ocho grandes barrios que en el proceso de expansión crearon una continuidad habitacional.

A continuación presentaremos el perfil de las favelas del municipio de Rio de Janeiro, tomando como referencia los datos de la primera investigación, representativa de los adultos mayores de 15 años, del conjunto de los barrios del municipio de Rio de Janeiro. En esta investigación fueron seleccionadas dos favelas que poseen Estación Futuro: Favela de Rocinha y de Maré, representada por ocho grandes barrios (Parque Maré, Nova Holanda, Baixa do Sapateiro, Parque União, Rubens Vaz, Morro do Timbau, Praia de Ramos, Roquete Pinto) y dieciocho favelas que no tienen Estaciones Futuro: Alto da Bela Vista, Canal do Anil, Mangueira, Fazenda Coqueiro, Formiga, Favela do Jacaré (Santíssimo), Jacarezinho, Joaquim Queiroz, Morro da União, Nova Brasília, Parque Alegria, Parque Royal, Parque São Jorge, Pavão-Pavãozinho, Vila Cruzeiro, Vila Rica de Irajá, Vila São Jorge, Vila Vintém.

Como lo indica el siguiente gráfico, el ingreso promedio per capita, tomando como referencia los salarios de las personas con declaración de fuente de renta, es de $6.5 \%$ entre favelas de ingresos altas y medios y de $16 \%$ entre favelas de ingresos medios y bajos. 
Gráfico 3.1.1: Ingreso promedio individual por tipo de favela

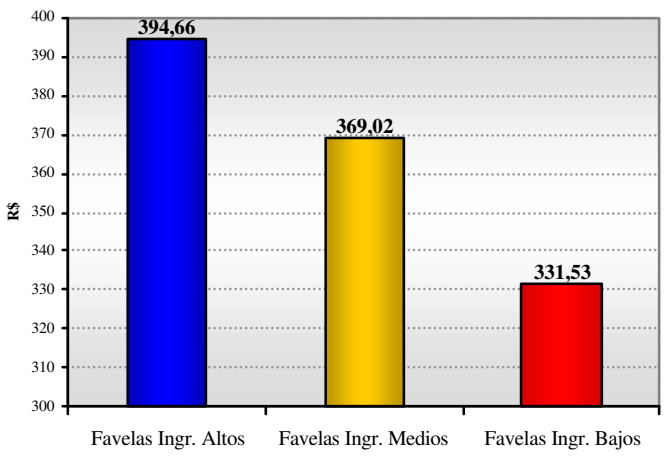

Gráfico 3.1.2: Diferencial de ingreso individual según tipo de favela

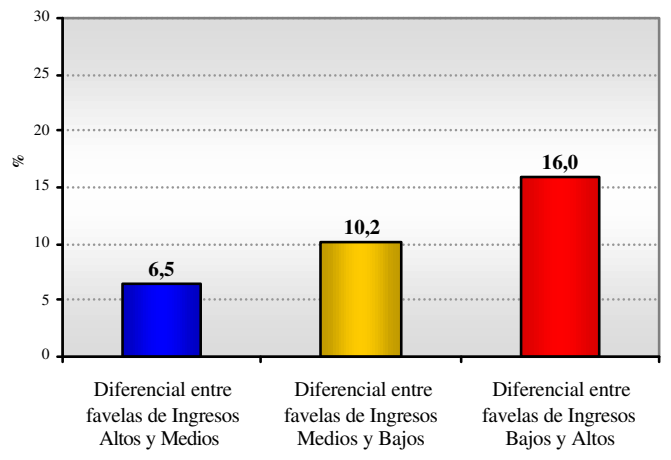

Este diferencial se modifica cuando analizamos el ingreso promedio familiar, manteniendo el diferencial entre las favelas de ingreso medio y alto y aumentando la desigualdad en relación a las favelas de bajos ingresos. Como vermos más adelante, los factores que posiblmente explican este diferencial se relacionan al mayor número de hijos, distribución de la población por raza y al menor nivel educacional de las favelas de bajos ingresos.

Gráfico 3.1.3: Ingreso promedio familiar por tipo de favela

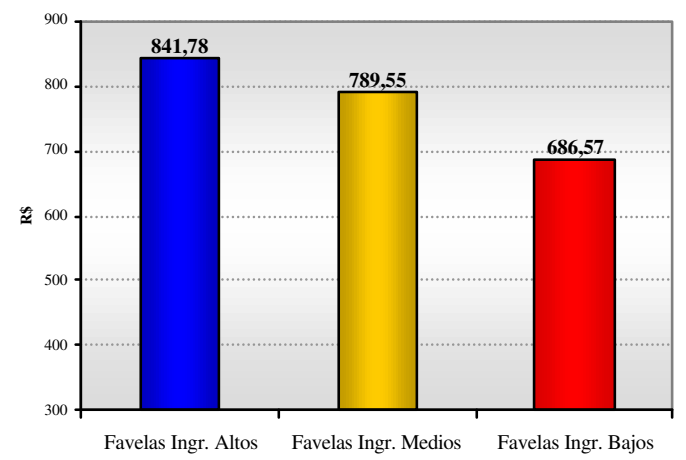


Gráfico 3.1.4: Diferencial del ingreso familiar según tipo de favela

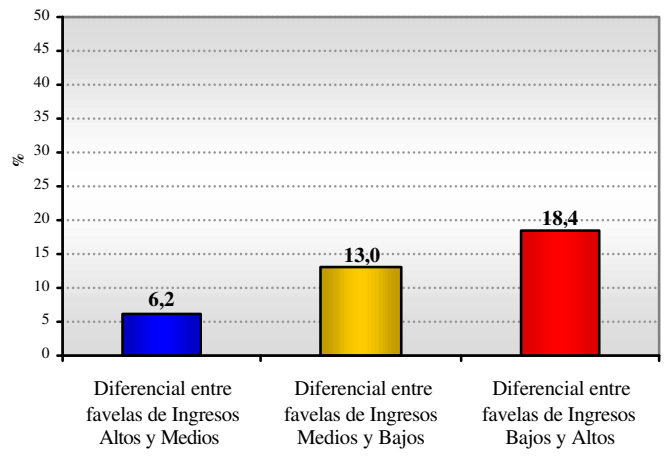

Esta hipótesis se confirma en los gráficos siguientes donde se presenta el diferencial de años de estudio y números de hijos:

Gráfico 3.1.5: Promedio de años de estudio por tipo de favela

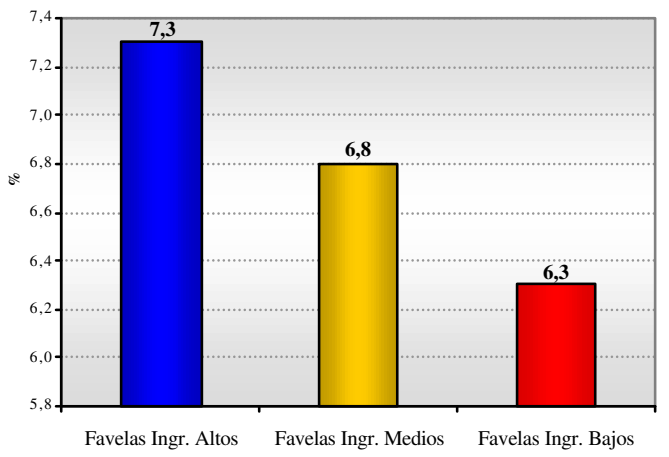

Gráfico 3.1.6: Media del número de hijos por tipo de favela

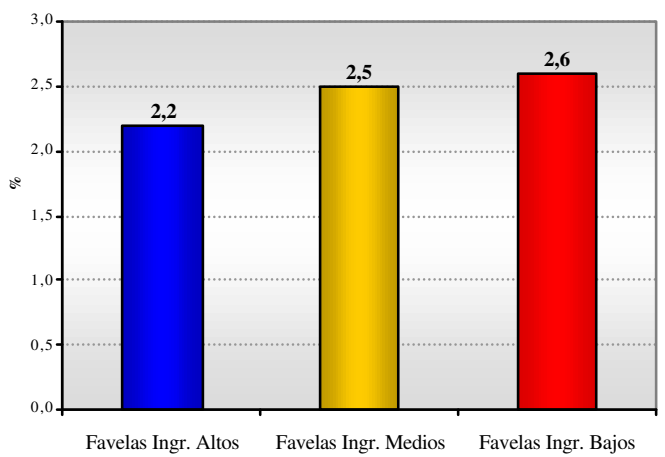


La distribución de sexo por favelas muestra generalmente un porcentaje mayor de población femenina, reflejando una proporción encontrada en el conjunto de la población brasileña.

\section{Gráfico 3.1.7: Distribución del sexo por tipo de favela}

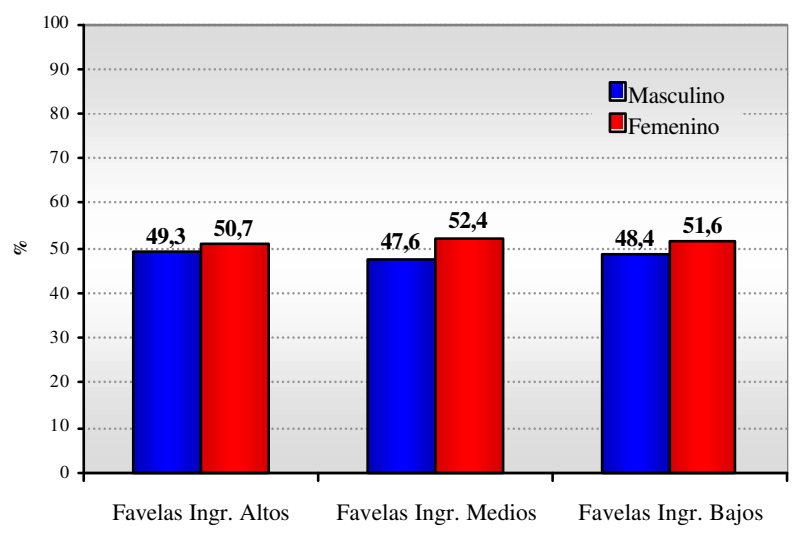

La distribución por edad en las favelas no presenta grandes diferenciales, a no ser por una leve preponderancia de la población joven a medida que se pasa de las favelas de ingresos altos para las de menores ingresos, producto natural de la mayor cantidad de hijos.

\section{Gráfico 3.1.8: Distribución del grupo de edad por tipo de favela}

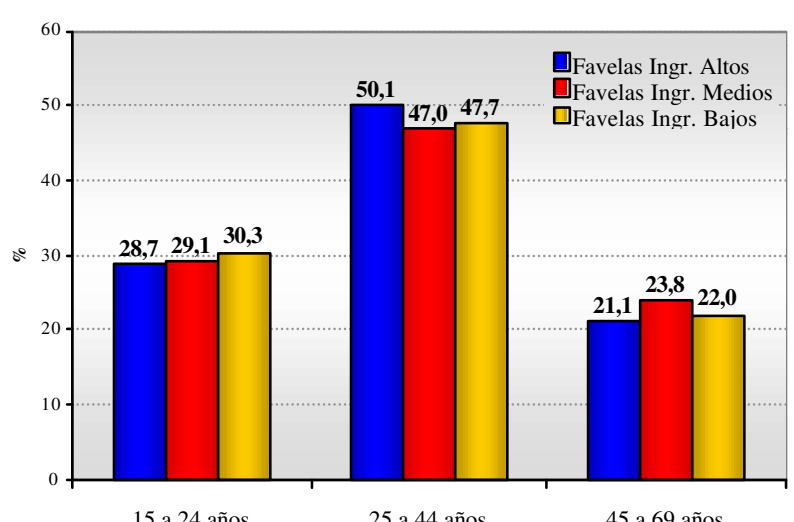

La distribución por raza (autodefinida) entre los diferentes tipos de favelas, presenta una nítida separación entre las favelas de altos ingresos y las otras. Mientras que en las favelas de altos ingresos existe un claro predominio de blancos, en las favelas de ingresos medios y 
bajos predomina la población parda. Uno de los factores que explican los ingresos más altos de algunas favelas, es que el ingreso promedio de los pardos se aproxima más al ingreso promedio de los negros que al de los blancos.

\section{Gráfico 3.1.9: Distribución de raza por tipo de favela}

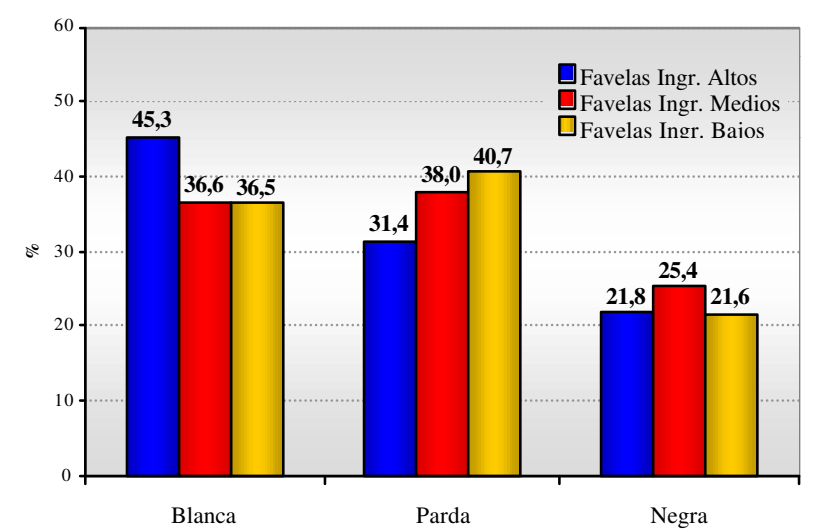

Como lo muestra el siguiente gráfico, la población blanca tiene un ingreso familiar superior al de la población parda y negra.

\section{Gráfico 3.1.10: Promedio de ingreso familiar per cápita}

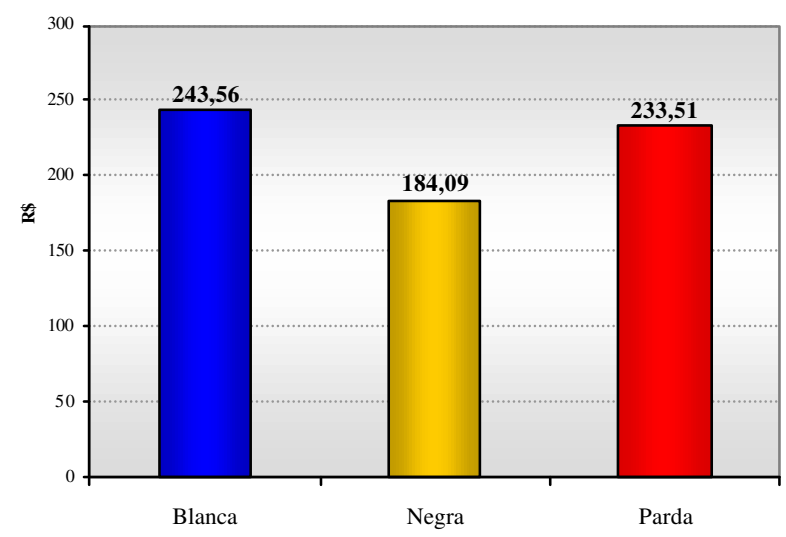

Lo que sucede es que el ingresso de las familias pardas y negras es diferente según el tipo de favela. 
Tabela 3.1.1: Media de ingreso familiar per cápita por raza según la clasificación por tipo de favela

\begin{tabular}{|c|c|c|c|}
\hline Raza & $\begin{array}{l}\text { Favelas } \\
\text { Ingr. Altos }\end{array}$ & $\begin{array}{c}\text { Favelas } \\
\text { Ingr. Medios }\end{array}$ & $\begin{array}{c}\text { Favelas } \\
\text { Ingr. Bajos }\end{array}$ \\
\hline Blanca & 268,75 & 234,49 & 235,97 \\
\hline Parda & 233,28 & 204,20 & 137,03 \\
\hline Negra & 265,37 & 274,65 & 186,57 \\
\hline
\end{tabular}

El número de habitaciones en las casas por tipo de favela es inverso al ingreso. Uno de los motivos es el costo del alquiler o la compra, que es menor en las favelas de bajos ingresos. Otro factor, como lo muestra el siguiente gráfico, es que el número de personas por domicilio va aumentando a medida que el ingreso disminuye.

Gráfico 3.1.11: Media de habitaciones utilizadas como dormitorios por tipo de favela

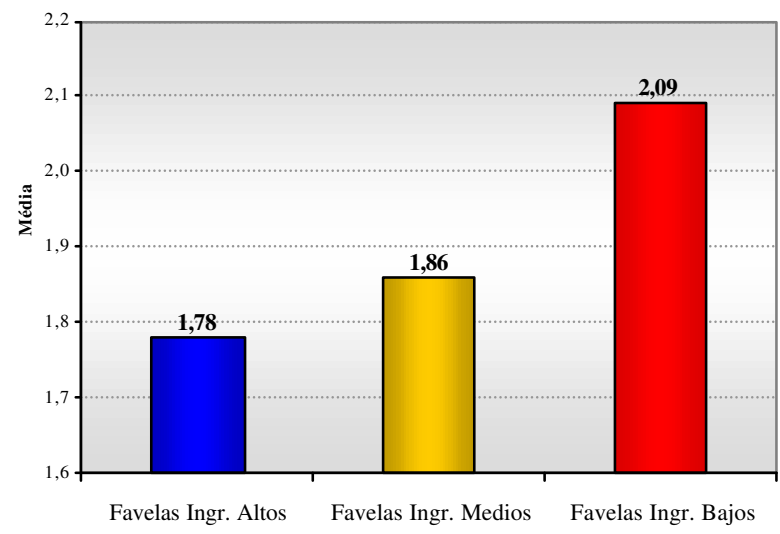

Gráfico 3.1.12: Media de personas que viven en el domicilio por tipo de favela

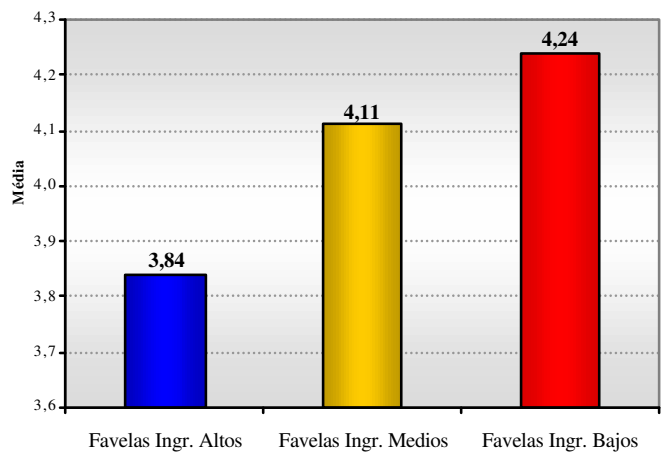

Como lo muestra el gráfico siguiente, la posesión de computadoras acompaña el nivel de ingresos de las favelas. 
Gráfico 3.1.13: Distribución según la posesión de computadora por tipo de favela

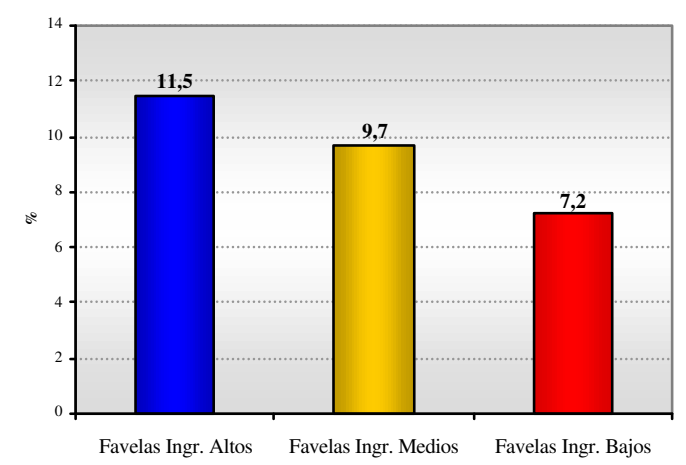

El diferencial entre utilizadores de computadora tiende a disminuir en relación a la posesión, entre habitantes de favelas de bajos ingresos y de ingresos medios. La explicación puede ser encontrada en la primera parte de este trabajo donde mostramos que la mayoría de los usuarios tiene acceso a la informática fuera del hogar. Como lo muestra el gráfico, el acceso fuera del hogar aumenta a medida que el ingreso disminuye, ya que las posibilidades de poseer una computadora en el domicilio disminuye:

Gráfico 3.1.14: Distribución según la utilización de computadora, según el tipo de favela

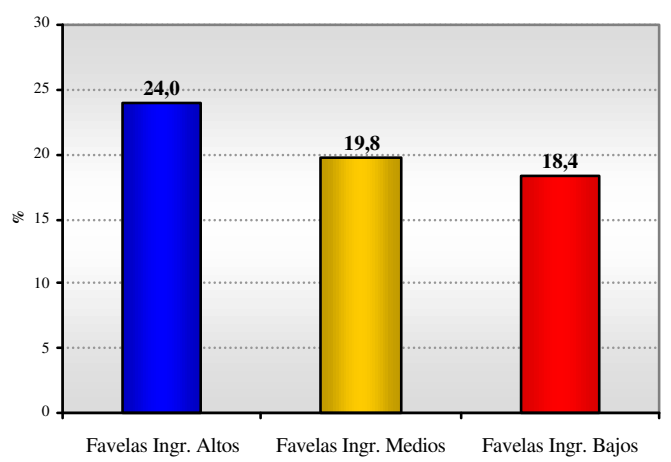




\section{2 - Análisis detallado de los usuarios de informática e Internet}

En este capítulo analizaremos solamente el universo de usuarios. Por lo tanto, todos los gráficos tienen como referencia solamente este universo. En la primera parte, indicamos que el porcentaje de usuarios del sexo masculino es superior a los usuarios de sexo femenino. Como lo vemos en el gráfico siguiente, esta tendencia es constante, independientemente del tipo de favela:

\section{Gráfico 3.2.1: Utilización de computadora por tipo de favela según sexo}

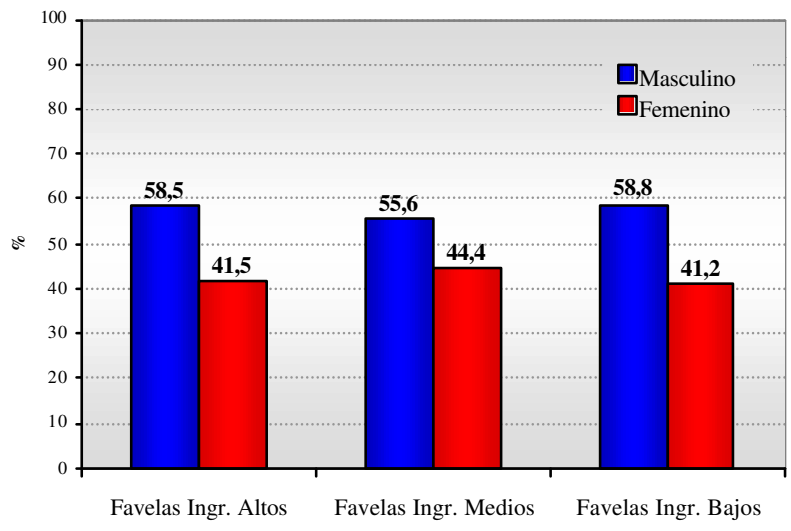

La distribución de usuarios según raza indica que mientras en las favelas de bajos ingresos la distribución según este criterio acompaña los porcentajes relativos de estos grupos en el total de la población, en las favelas de altos ingresos y de ingresos medios, el número de usuarios blancos es superior al total de usuarios blancos en el total de la población de favela. En el caso de la población parda en las favelas de ingresos altos, el porcentaje de usuarios es superior al total de este grupo en el total de la población, mientras que en las favelas de ingresos medios y bajos, es un poco inferior. 
Gráfico 3.2.2: Utilización de computadora por tipo de favela según la raza

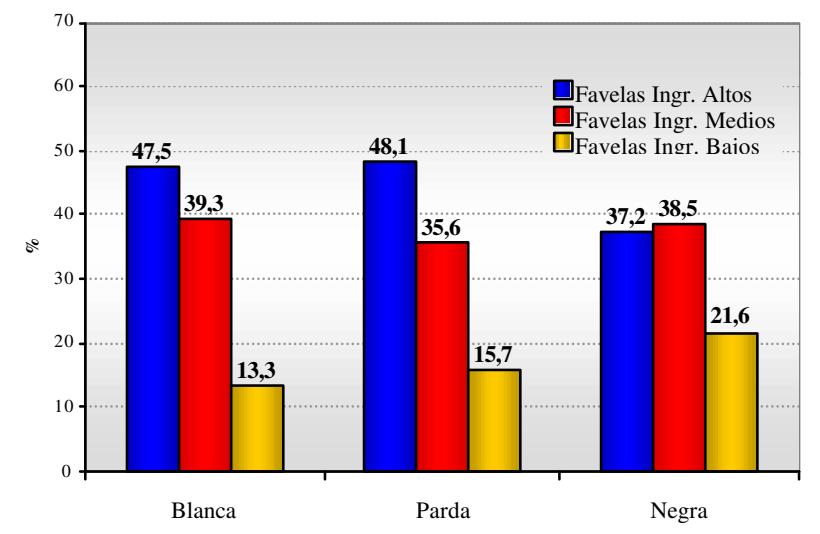

Gráfico 3.2.3: Distribución de raza por tipo defavela

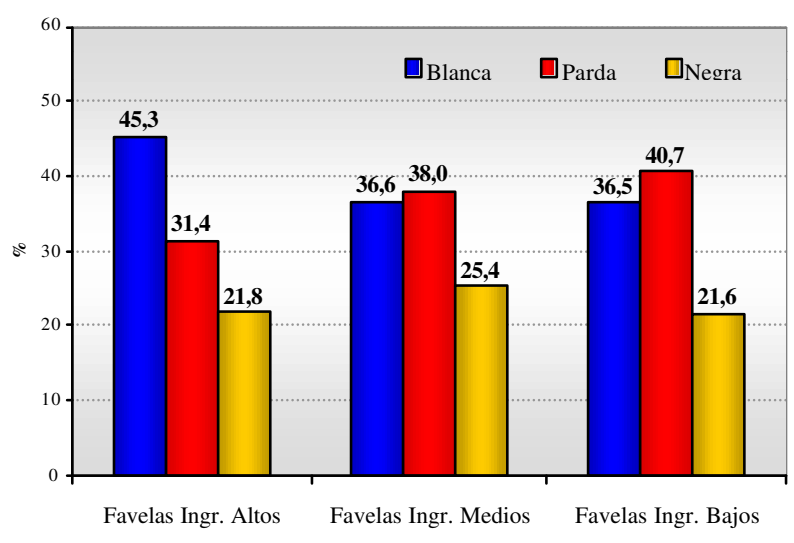

La distribución por religión de los usuarios de computadora generalmente acompaña al porcentaje de cada religión en el total de la población, excepto las favelas de altos ingresos, donde los sin religión presentan un porcentaje superior importante y en las favelas de bajos ingresos, donde los evangélicos presentan un porcentaje bastante superior a su participación en la población. 


\section{Gráfico 3.2.4: Utilización de computadora por tipo de favela según religión}

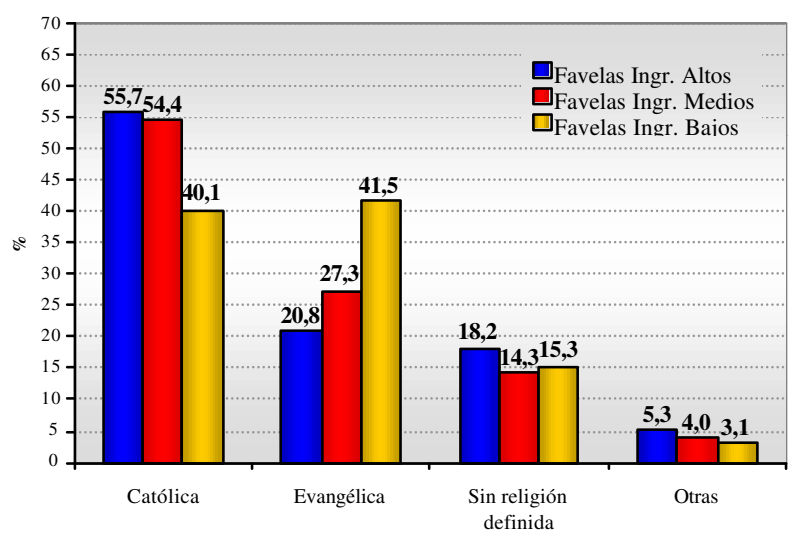

Gráfico 3.2.5:. Distribución de la religión por tipo de favela

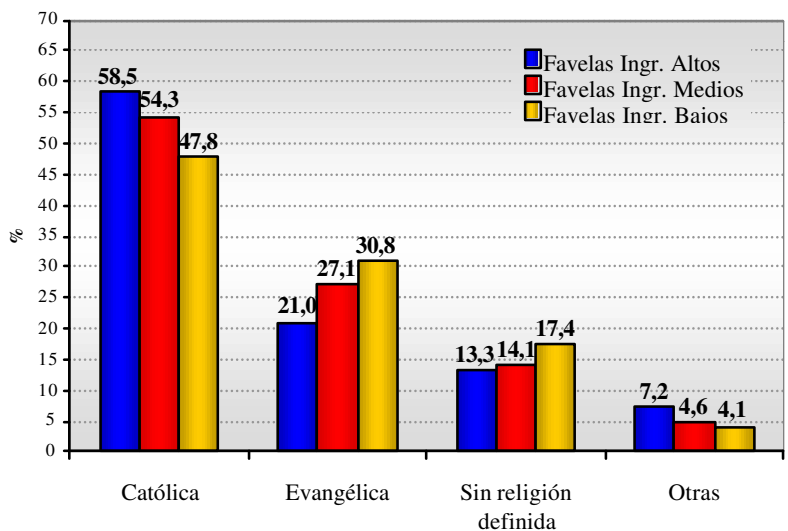

En términos del ingreso individual, el gráfico 3.2.6 indica que:

a) La mayoría de los usuarios que no tiene ingresos, generalmente ocupan la posición de hijos en el núcleo familiar y todavía son estudiantes.

b) Él número de los sin ingresos aumenta en las favelas de ingresos medios y bajos, donde el número de hijos es mayor que en las favelas de altos ingresos. Aunque en las favelas de bajos ingresos el número de hijos es también alto, la disminución de usuarios está relacionada al menor nivel de ingresos y escolaridad de las familias. 
c) La principal diferencia de ingresos entre las favelas se concentra en las personas con más de 2.400 reales de ingreso, lo que llega al 3.7 en las favelas de altos ingresos, en contraposición al $0.7 \%$ y $0.5 \%$ en las favelas de ingresos medios y bajos.

\section{Gráfico 3.2.6: Distribución según el grupo de ingreso me nsual de los habitantes que utilizan computadora por tipo de favela}

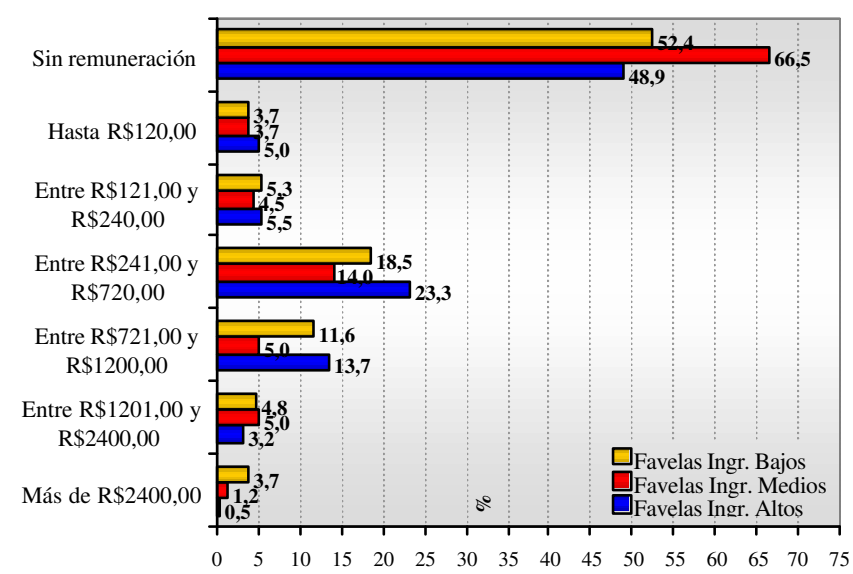

La distribución de ingresos de los usuarios se modifica cuando se trata del ingreso familiar, el cual tiende a aumentar relativamente en las favelas de ingresos medios y bajos, como resultado del mayor número de hijos.

Gráfico 3.2.7: Distribución según el grupo de ingreso familiar mensual de los habitantes que utilizan computadora por tipo de favela

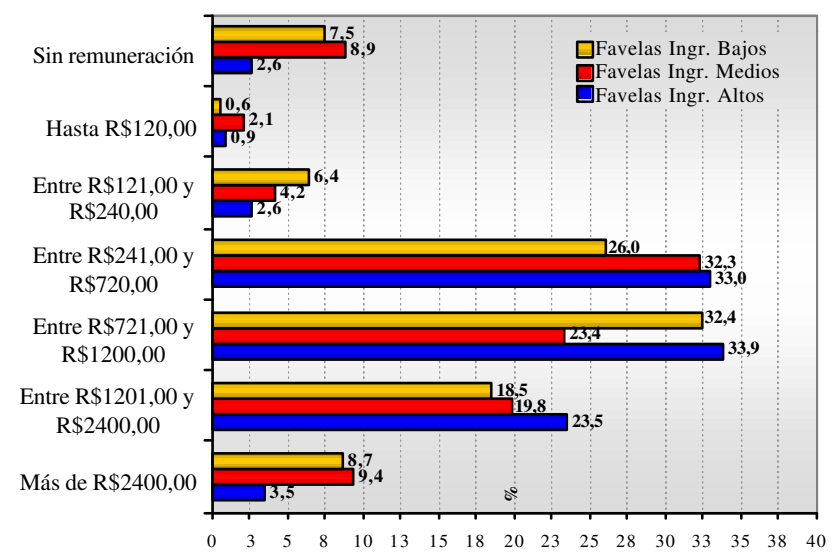


Como lo muestran los gráficos a continuación, los que en el momento están estudiando, llegan a casi la mitad de los usuarios, y en general son niños y jóvenes. A medida que pasamos de las favelas de altos ingresos para las de bajos ingresos, vemos que, mientras en las primeras todos los usuarios de 7 a 14 años están estudiando, en las favelas de ingresos medios $4.6 \%$ dejaron de estudiar, y, en las de ingresos bajos, $8.3 \%$ no están estudiando.

\section{Gráfico 3.2.8: Utilización de computadora por tipo de favela según esté estudiando actualmente}

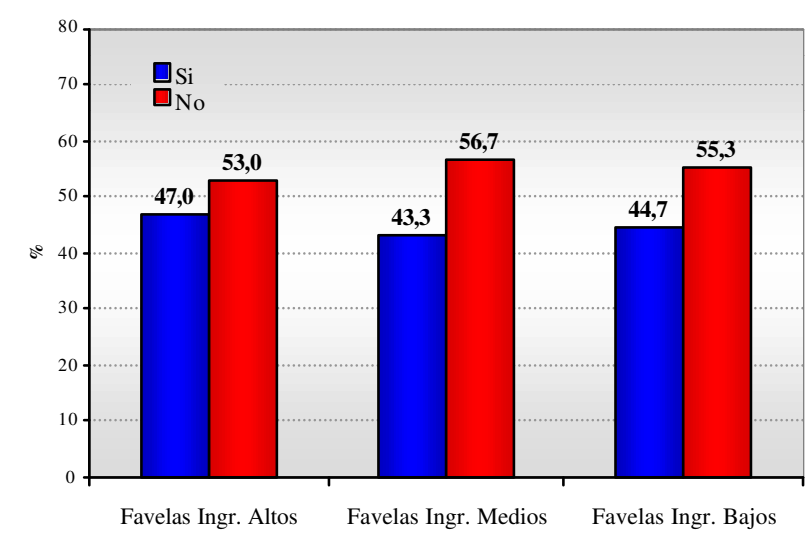

Gráfico 3.2.9: Utilización de computadora según tipo de favela según esté estudiando actualmente (entre 07 y 14 años de edad)

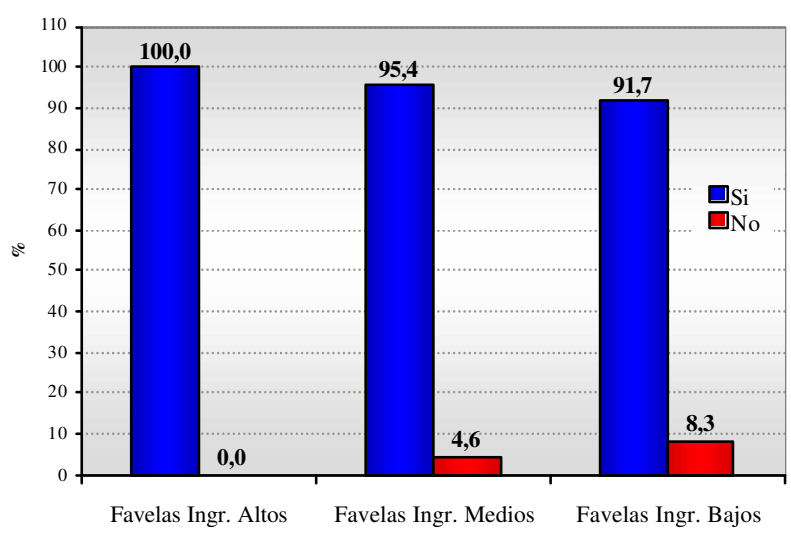

El siguiente gráfico muestra el drama de los habitantes de las favelas: cuanto más pobre es la favela, mayor es el porcentaje de estudiantes en instituciones de enseñanza privadas. El 
motivo para esto está relacionado al hecho de que en las favelas de mayores ingresos, tanto por la mayor antiguiedad como por la localización, se benefician de una red de servicios públicos de enseñanza más adecuados. Un factor adicional es que en las favelas de menores ingresos el número de personas que buscan cursos privados complementarios para compensar el atraso escolar o realizar cursos técnicos especializados, es mayor, como lo indica el próximo gráfico.

\section{Gráfico 3.2.10: Utilización de computadora según tipo de favela según el tipo de institución de enseñanza que frecuentó}

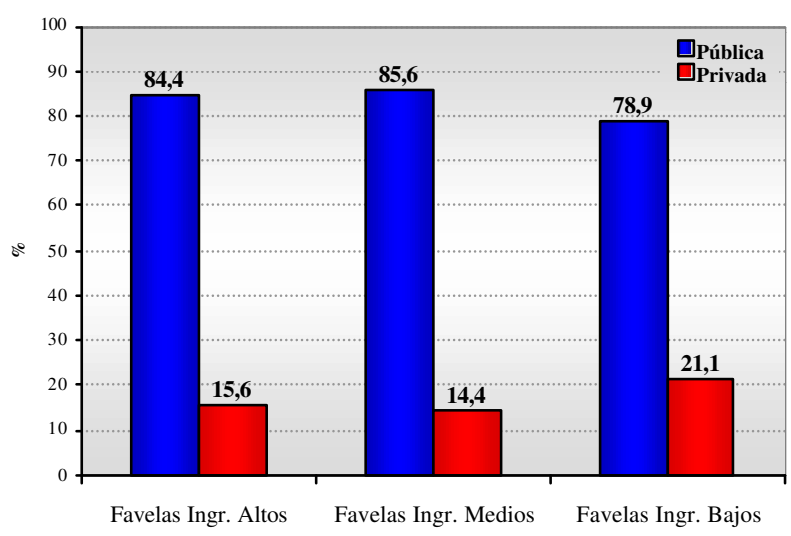

Gráfico 3.2.11: Utilización de computadora según tipo de favela según el tipo de enseñanza que cursa o cursó

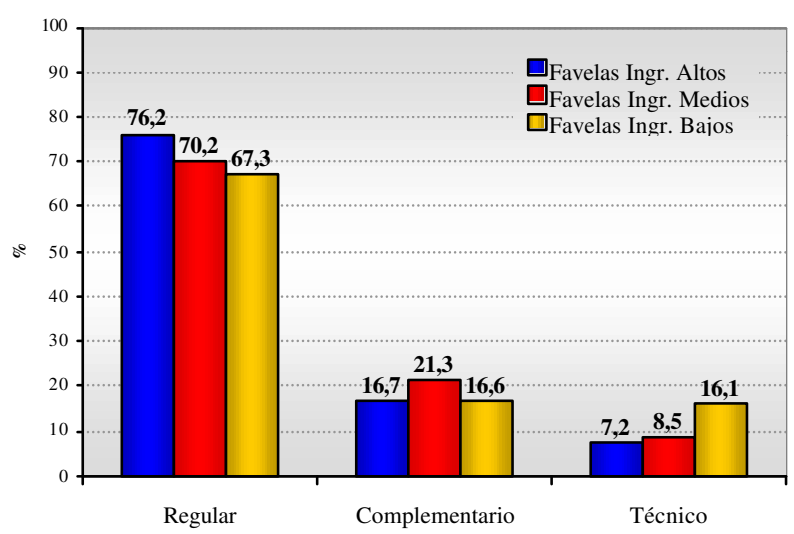

Cerca de cuatro quintos de las instituciones de enseñanza en que estudian los alumnos usuarios de computadora, poseen computadora. Pero menos de la mitad de los alumnos pueden utilizarla, excepto los de las favelas de bajos ingresos, donde el porcentaje es un 
poco mayor de 50\%, lo que debe corresponder al hecho de que en estas favelas es más alto el porcentaje de personas en instituciones de enseñanza privadas, donde generalmente hay computadoras.????

Gráfico 3.2.12: Utilización de computadora según tipo de favela según tenencia de computadora en la institución de enseñanza

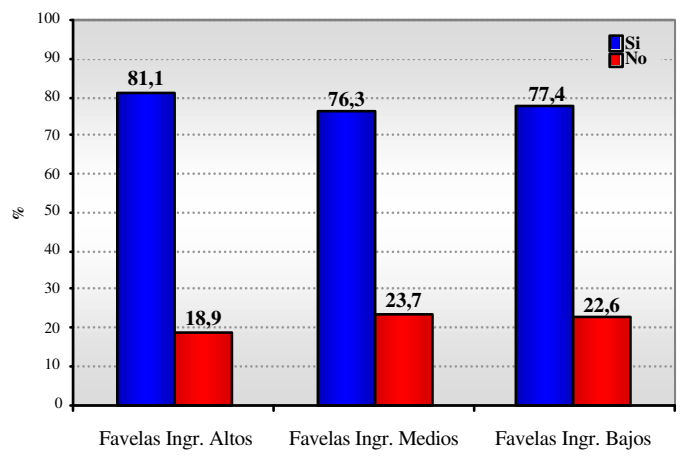

Gráfico 3.2.14: Utilización de computadora según tipo de favela según posibilidad de uso de computadora en la institución de enseñanza

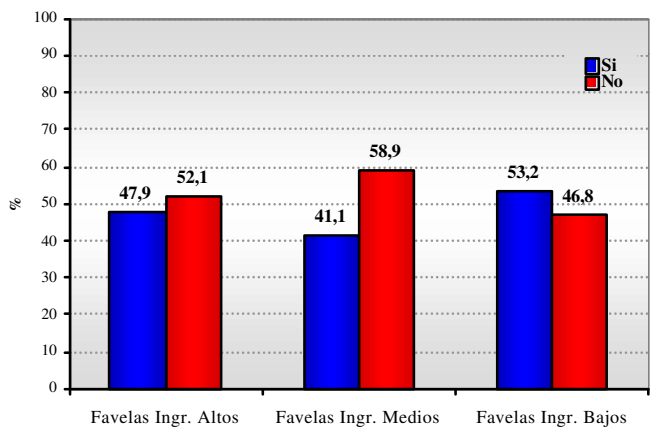

Gráfico 3.2.13: Utilización de computadora según tipo defavela según presencia de Intemet en la institución de enseñanza

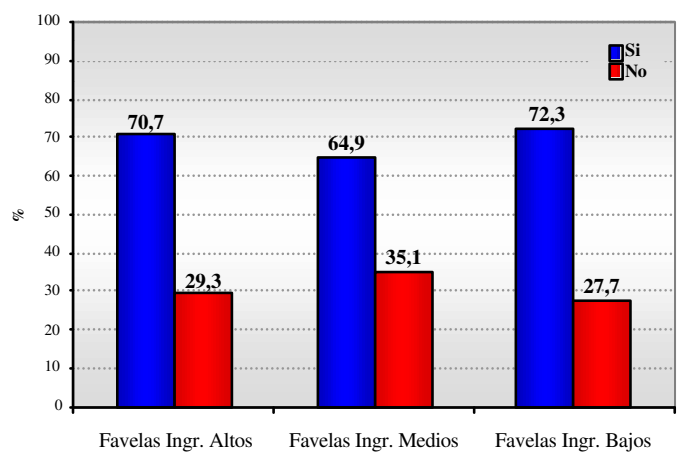


Gráfico 3.2.15: Utilización de computadora según tipo de favela según posibilidad de uso de Internet en la institución de enseñanza

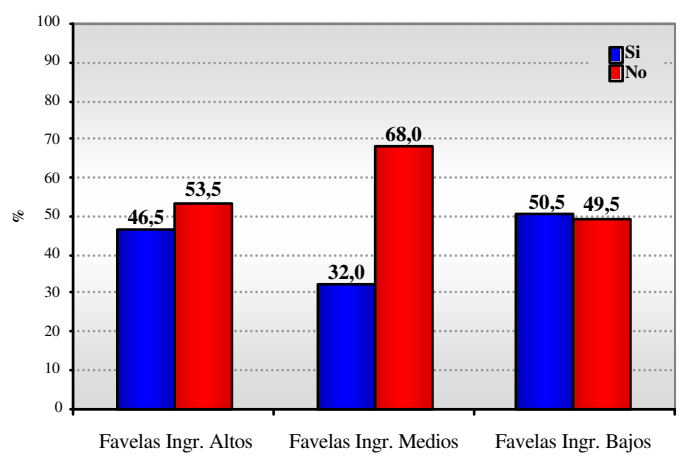

La frecuencia de uso de la computadora no se modifica sustancialmente de acuerdo al tipo de favela. Los que utilizan la computadora diariamente son alrededor de $30 \%$ de los usuarios, y más de 30\% la utilizan por lo menos una vez por semana.

Gráfico 3.2.16: Utilización de computadora según tipo de favela según frecuencia de utilización de la computadora

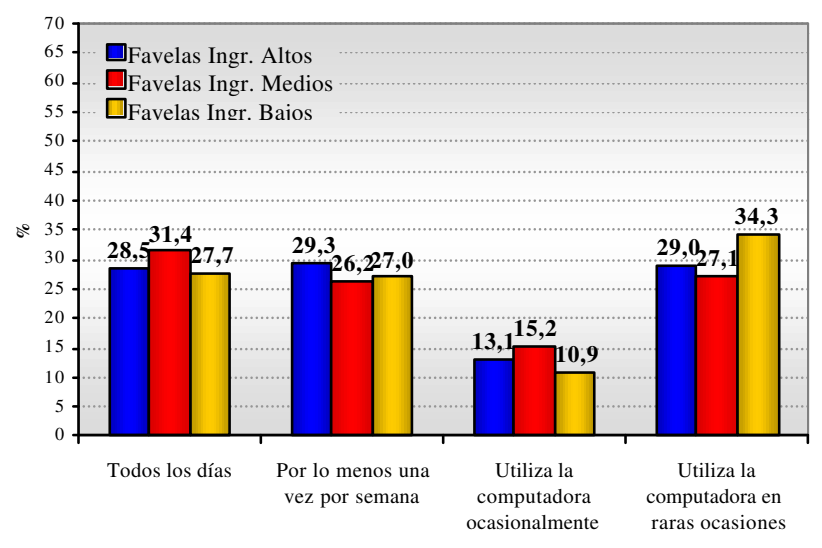

Como lo muestra el gráfico siguiente, en todas las favelas la principal forma de aprendizaje es a través de cursos especializados, una tendencia que aumenta en las favelas bajas, donde la posibilidad de aprender computación en casa de amigos es menor: 
Cuadro 3.2.1: Forma de aprender a usar la computadora según tipo de favela

\begin{tabular}{|c|c|c|c|}
\hline & Favelas Ingr. Altos & Favelas Ingr. Medios & Favelas Ingr. Bajos \\
\hline \multicolumn{4}{|l|}{ Forma de aprendizaje } \\
\hline Sólo, intentando & 17,0 & 15,5 & 12,8 \\
\hline Sólo, ayudado por manuales & 1,8 & 1,1 & 2,9 \\
\hline Con orientación, en el trabajo & 6,6 & 7,1 & 8,4 \\
\hline Con la ayuda de amigos & 15,7 & 13,0 & 7,5 \\
\hline En cursos especializados & 55,2 & 60,7 & 61,7 \\
\hline \multirow[t]{2}{*}{ De otra forma } & 3,8 & 2,6 & 6,6 \\
\hline & 100 & 100 & 100 \\
\hline
\end{tabular}

El procesador de texto es el programa más utilizado, seguido por los juegos y las planillas electrónicas.

Cuadro 3.2.2: Tipos de programas más utilizados según tipo de favela

\begin{tabular}{|c|c|c|c|}
\hline & Favelas Ingr. Altos & Favelas Ingr. Medios & Favelas Ingr. Bajos \\
\hline \multicolumn{4}{|l|}{ Tipo de programa } \\
\hline Procesadores de texto & 74,9 & 75,2 & 83,9 \\
\hline Planillas electrónicas & 48,5 & 40,4 & 61,2 \\
\hline Programas de presentación gráfica & 27,2 & 26,4 & 41,3 \\
\hline Lenguaje de programación & 3,8 & 3,7 & 8,7 \\
\hline Juegos & 54,6 & 45,2 & 66,1 \\
\hline Otro & 4,6 & 5,9 & 5,1 \\
\hline
\end{tabular}

Más de un tercio de los usuarios de Internet en todas las favelas pretenden hacer cursos a través de Internet. 
Gráfico 3.2.17: Predisposición para realizar cursos por Internet entre los habitantes que utilizan computadora según tipo de favela

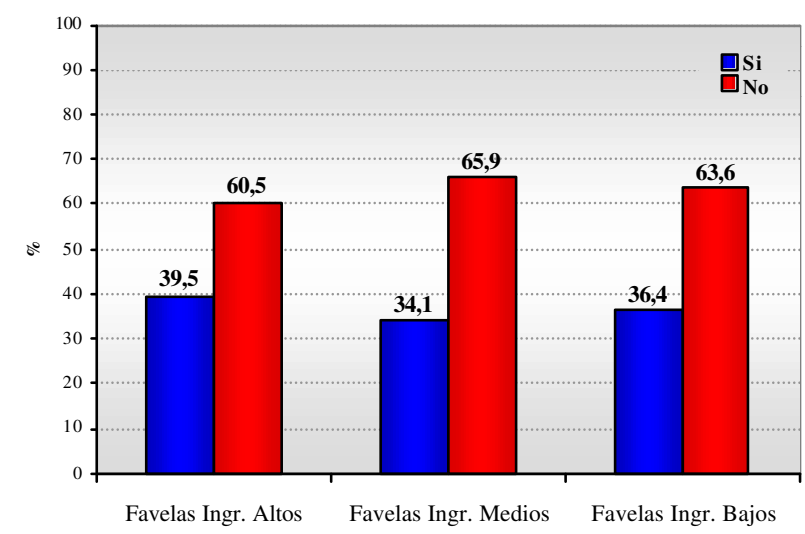

A medida que el ingreso disminuye, cambia la forma en que la computadora fue adquirida entre los que la poseen o la tienen en sus hogares. En las favelas de ingresos promedio más bajos, los índices de compras en cuotas y donaciones son mayores. Entre los que compraron, el perfil tiende a ser bastante similar en los diversos tipos de favela: $70 \%$ compró computadora nueva y $30 \%$ usado.

Gráfico 3.2.18: Tipo de adquisición de la computadora del hogar según tipo de favela

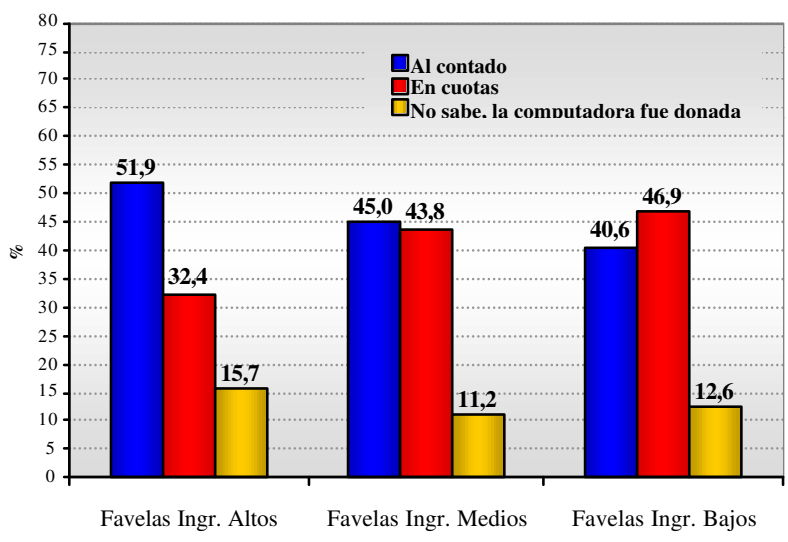


Gráfico 3.2.19: Estado en que la computadora del domicilio fue adquirida según tipo de favela

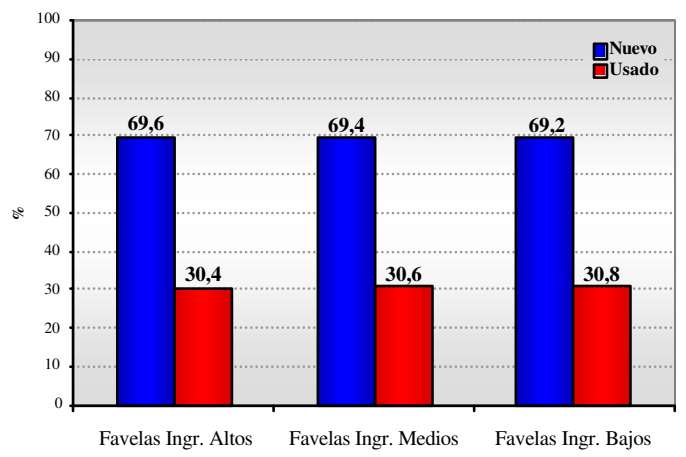

Las formas de mantenimiento/ arreglo, son bastante diversificadas. En las favelas de ingresos bajos, el mayor porcentaje de usuarios de servicios fuera de la favela posiblemente esté relacionado al menor número de servicios técnicos disponibles dentro de la favela.

Cuadro 3.2.3: Local de mantenimiento /arreglo de la computadora según tipo de favela

\begin{tabular}{|c|c|c|c|}
\hline \multirow{2}{*}{\multicolumn{4}{|c|}{ Favelas Ingr. Medios }} \\
\hline & & & \\
\hline Locales especializados fuera del barrio & 10,6 & 7,2 & 20,3 \\
\hline Locales especializados dentro del barrio & 20,4 & 10,6 & 4,9 \\
\hline $\begin{array}{l}\text { Mantenimiento pago con parientes e/o } \\
\text { amigos }\end{array}$ & 17,7 & 13,9 & 18,9 \\
\hline $\begin{array}{l}\text { Mantenimiento gratuito con parientes } \\
\text { e/o amigos }\end{array}$ & 23,0 & 30,0 & 21,0 \\
\hline $\begin{array}{l}\text { Yo mismo hago el mantenimiento de mi } \\
\text { computadora }\end{array}$ & 15,0 & 22,8 & 19,6 \\
\hline No hago mantenimiento & 13,3 & 15,6 & 15,4 \\
\hline Total & 100 & 100 & 100 \\
\hline
\end{tabular}

El siguiente gráfico, en el cual fue posible indicar más de una alternativa, muestra que los principales usuarios de computadoras son los hijos, en particular en las favelas de bajos ingresos, y muestra la importancia del no residente en el hogar entre los usuarios de computadora. 
Cuadro 3.2.4: Relación del principal usuario de computadora con el jefe de hogar

\begin{tabular}{|c|c|c|c|}
\hline & Favelas Ingr. Altos & Favelas Ingr. Medios & Favelas Ingr. Bajos \\
\hline \multicolumn{4}{|l|}{ Tipo de programa } \\
\hline Jefe del hogar & 26,8 & 25,1 & 30,9 \\
\hline Cónyuge & 7,1 & 12,0 & 8,7 \\
\hline Hijos & 37,5 & 30,1 & 62,4 \\
\hline Otros parientes que viven en el hogar & 7,1 & 12,6 & 7,4 \\
\hline Otros parientes que no viven en el hogar & - & 1,6 & - \\
\hline Otros & 31,3 & 25,1 & 2,7 \\
\hline
\end{tabular}

Entre los usuarios de computadora en las favelas de altos ingresos, 67.7\% utiliza Internet, bajando a $56.2 \%$ el porcentaje en las favelas de ingresos medios y situándose en $59.3 \%$ el porcentaje que lo hace en las favelas de bajos ingresos.

Gráfico 3.2.20: Utilización de Internet entre los usuarios de computadora según tipo de favela

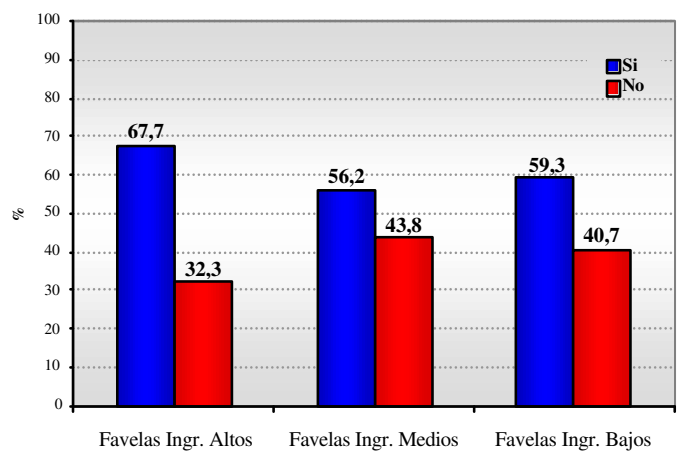

La frecuencia en el uso de Internet cambia significativamente según el tipo de favela. Los que utilizan Internet diariamente, en las favelas de altos ingresos, son alrededor del $26 \%$ de los usuarios, mientras que en las favelas de ingresos medios, este número llega a aproximadamente $47 \%$. En las favelas de bajos ingreesos la frecuencia de utilización diaria llega a cerca del $18 \%$ de los usuarios. No encontramos una explicación clara para este fenómeno. 


\section{Gráfico 3.2.21: Frecuencia de utilización de Internet según tipo de favela}

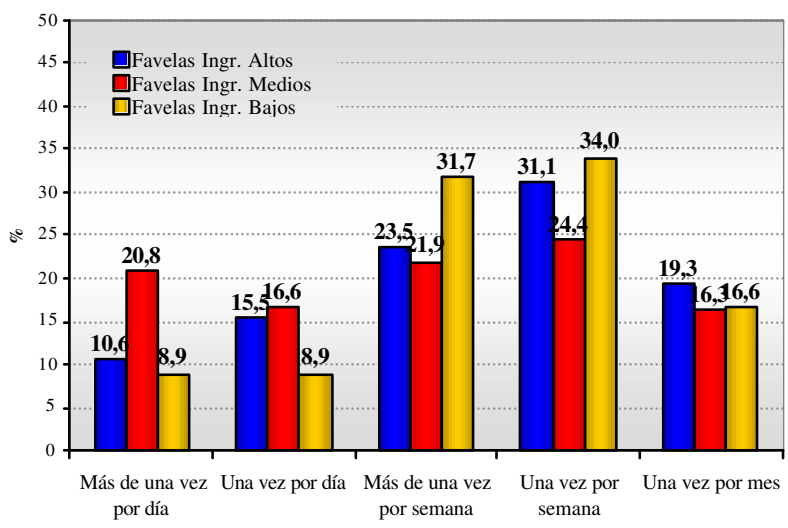

El gráfico siguiente indica varios motivos aducidos por los usuarios de computadora para no usar Internet. El principal es el de no poseer local para conectarse. En las favelas de bajos ingresos el costo y la falta de tiempo son el segundo motivo. En las favelas de bajos y altos ingresos, la falta de interés y el hecho de pensar que es muy complicado, ocupan el segundo lugar.

Cuadro 3.2.5: Motivos para la no utilización de Internet según tipo de favela

\begin{tabular}{|c|c|c|c|}
\hline & Favelas Ingr. Altos & Favelas Ingr. Medios & Favelas Ingr. Bajos \\
\hline \multicolumn{4}{|l|}{ Motivo } \\
\hline No tiene lugar dónde entrar & 66,1 & 63,4 & 61,5 \\
\hline No tiene interés & 11,8 & 11,8 & 9,5 \\
\hline Le parece muy dificil & 8,7 & 11,5 & 5,0 \\
\hline Caro & 3,9 & 5,4 & 11,2 \\
\hline No tiene tiempo & 9,4 & 7,9 & 12,8 \\
\hline Total & 100 & 100 & 100 \\
\hline
\end{tabular}

En el próximo gráfico aparecen los tipos de sitios de conexión. Las variaciones entre los sitios es relativamente pequeña, predominando, en primer lugar, los de búsqueda/investigación, seguidos de sitios de música, proveedores, diarios, webmail, deporte y utilidad pública (no fue incluida la pornografía en el conjunto de opciones, quedando implícita a partir de las otras). 
Cuadro 3.2.6: Tipos de sitios más visitados según tipo de favela

\begin{tabular}{lccc}
\hline \hline \multirow{2}{*}{ Tipos de sitios } & Favelas Ingr. Altos & Favelas Ingr. Medios & Favelas Ingr. Bajos \\
\cline { 2 - 3 } Webmail & 38,8 & 36,9 & 37,0 \\
Cybercafés & 14,4 & 11,5 & 12,3 \\
Sitios de los proveedores & 49,4 & 52,5 & 49,0 \\
Sitios de búsqueda/ investigación & 74,1 & 63,9 & 68,5 \\
Sitios de revistas & 33,1 & 31,7 & 30,1 \\
Sitios de diarios & 38,8 & 39,3 & 39,1 \\
Utilidad pública & 20,2 & 27,9 & 29,5 \\
Sitios de empresas & 17,5 & 20,5 & 21,1 \\
Sitios de música & 55,5 & 47,0 & 49,5 \\
Sitios de deportes & 39,5 & 35,8 & 35,3 \\
Sitios infantiles & 8,7 & 8,5 & 8,2 \\
Otro tipo de sitios (específicos) & 11,8 & 17,8 & 12,1 \\
\hline
\end{tabular}

El gráfico que sigue a continuación, aparentemente, es difícil de explicar: mientras en las favelas de ingresos altos y bajos el número de usuarios de Internet utilizan $29.2 \%$ y $25.9 \%$ de los proveedores pagos, este número sube a $50.8 \%$ en las favelas de ingresos medios. Una explicación puede estar dada por el hecho de que la muestra de los usuarios de Internet en el hogar es muy baja, y el margen de error técnico aumenta mucho. Otro factor puede ser la utilización de "gatos" (conexiones ilegales) de servicios de TV a cable, en los cuales un pago por el "mantenimiento" es realizado al responsable por el "gato".

Gráfico 3.2.22: Tipo de proveedor utilizado por los habitantes que poseen computadora según tipo de favela

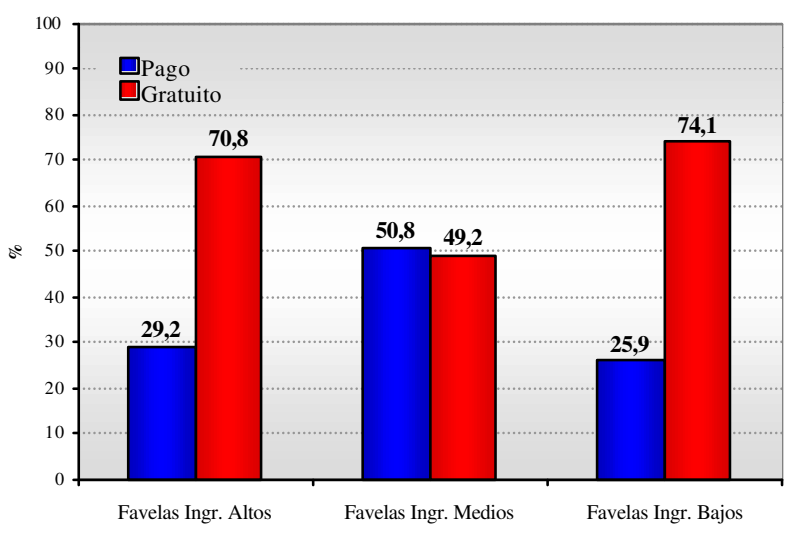


La utilización de Internet para realizar cualquier tipo de negocio es superior en las favelas de altos ingresos que en las de ingresos medios, y es todavía menor en las de más bajos ingresos:

Gráfico 3.2.23: Utilización de Internet para hacer negocios entre los habitantes que utilizan computadora según tipo de favela

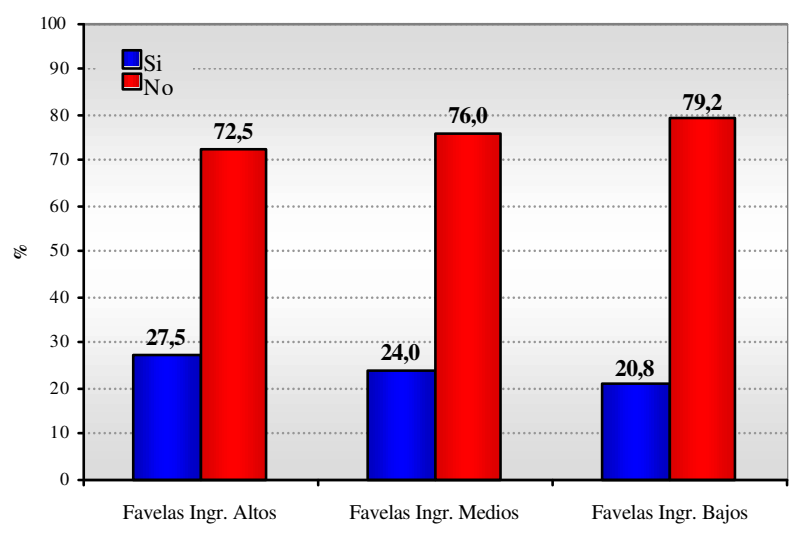

Aunque el uniiverso de usuarios sea muy bajo y por lo tanto los siguientes valores posiblemente no sean estadísticamente representativos, presentamos el gráfico para tener una noción de los tipos de transacciones realizadas.

Cuadro 3.2.7: Tipo de negocio realizado en Internet según tipo de favela

\begin{tabular}{|c|c|c|c|}
\hline & Favelas Ingr. Altos & Favelas Ingr. Medios & Favelas Ingr. Bajos \\
\hline \multicolumn{4}{|l|}{ Tipo de operación } \\
\hline Compra & 28,8 & 45,3 & 48,2 \\
\hline Venta & 4,1 & 7,0 & 12,5 \\
\hline Información de precios & 27,4 & 12,8 & 16,1 \\
\hline Pago de cuentas & 13,7 & 46,3 & 10,7 \\
\hline Operaciones financieras & 6,8 & 14,0 & 5,4 \\
\hline Otros & 19,2 & 4,7 & 7,1 \\
\hline Total & 100 & 100 & 100 \\
\hline
\end{tabular}

En las favelas de altos ingresos la entrada en sitios en otros idiomas es mayor que en las favelas medias y bajas, reflejando el nivel de escolaridad más alto de los usuarios. 
Gráfico 3.2.24: Visita de sitios de texto en otros idiomas entre los habitantes que utilizan computadora según tipo de favela

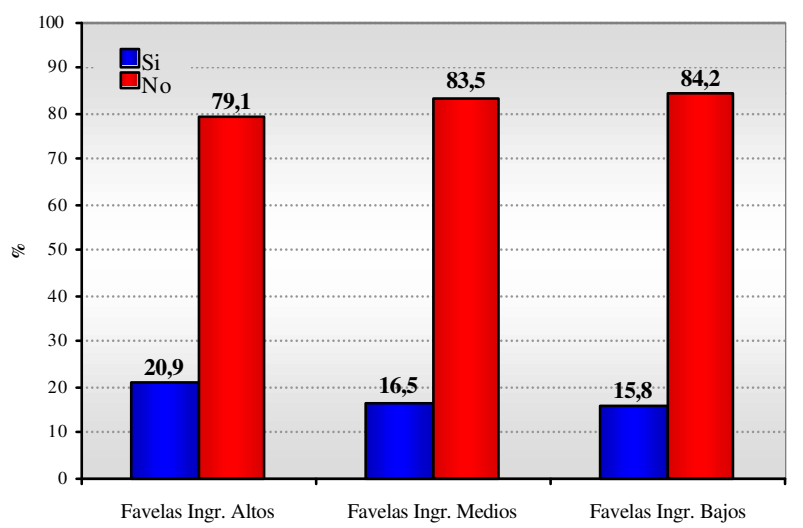

Aunque el universo de usuarios sea muy bajo y por lo tanto los valores a continuación posiblemente no sean estadísticamente representativos, presentamos el gráfico, que brinda una noción del aprendizaje de idiomas por parte de los usuarios de Internet en las favelas.

Cuadro 3.2.8: Local donde aprendió otros idiomas según el tipo de favela

\begin{tabular}{lccc}
\hline \hline \multirow{2}{*}{ Local } & Favelas Ingr. Altos & Favelas Ingr. Medios & Favelas Ingr. Bajos \\
\cline { 2 - 3 } Curso & 39,6 & 54,7 & 31,6 \\
Institución de enseñanza & 41,7 & 18,9 & 44,7 \\
Sólo & 8,3 & 11,3 & 15,8 \\
En Internet & 4,2 & 7,5 & 2,6 \\
De otra forma & 6,3 & 7,5 & 5,3 \\
\hline Total & $\mathbf{1 0 0}$ & $\mathbf{1 0 0}$ & $\mathbf{1 0 0}$ \\
\hline
\end{tabular}

A la pregunta de si la persona tendría interés de contratar por Internet personas de otros países, la respuesta es mayoritariamente positiva. 
Gráfico 3.2.25: Interés en tener contacto con otros países entre habitantes que utilizan computadora según tipo de favela

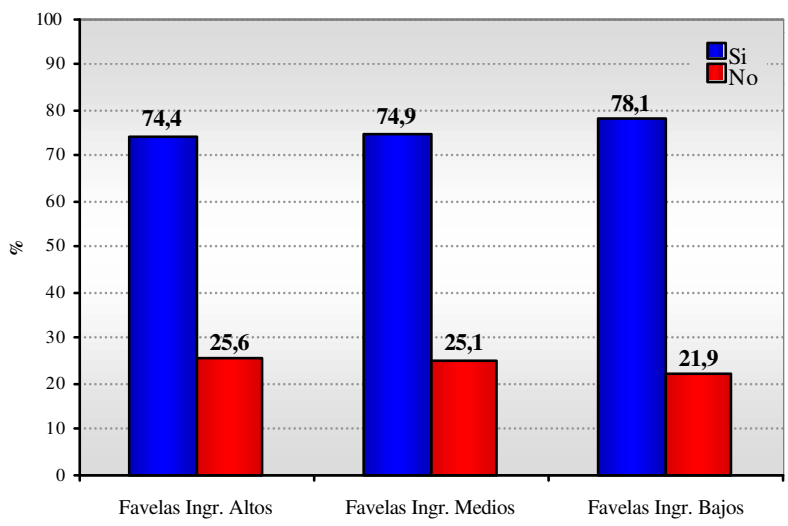

Es más alta la proporción de usuarios de e-mails en las favelas de ingresos medios y bajos que en las favelas de ingresos altos. Esto sucede posiblemente por la existencia de una base mayor de usuarios de Internet en las favelas de altos ingresos.

Gráfico 3.2.26: Utilización de e-mail entre los habitantes que utilizan Internet según tipo de favela

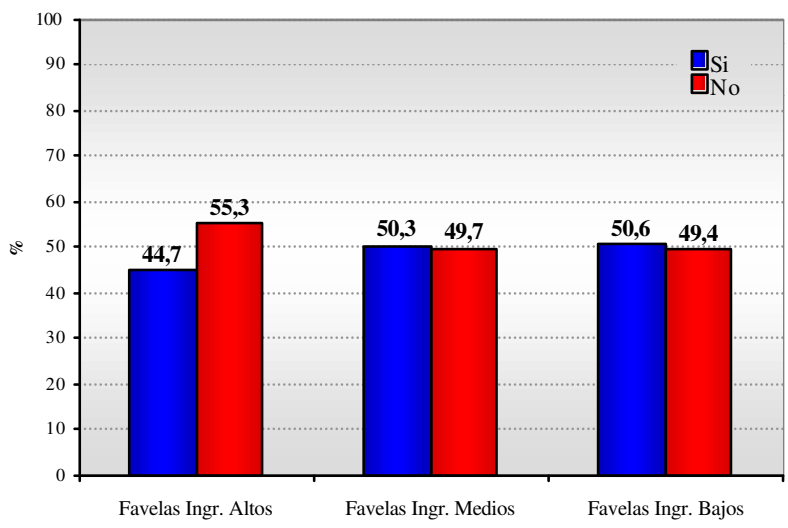


La frecuencia con la que las personas abren el e mail es bastante similar entre los tres grupos de favelas, con menor frecuencia en las favelas de ingresos bajos. Llama la atención la alta frecuencia de usuarios de una vez por día, en las favelas de ingresos medios.

Cuadro 3.2.8: Frecuencia con que abre el e-mail según tipo de favela

\begin{tabular}{|c|c|c|c|}
\hline & Favelas Ingr. Altos & Favelas Ingr. Medios & Favelas Ingr. Baios \\
\hline \multicolumn{4}{|l|}{ Frecuencia } \\
\hline Más de una vez por día & 16,1 & 20,1 & 8,3 \\
\hline $\begin{array}{l}\text { Una vez por día } \\
\text { Más de una vez por semana }\end{array}$ & $\begin{array}{l}17,8 \\
21,2\end{array}$ & $\begin{array}{l}29,3 \\
17,4\end{array}$ & $\begin{array}{l}15,8 \\
28,6\end{array}$ \\
\hline Una vez por semana & 28,0 & 19,0 & 32,3 \\
\hline Una vez por mes & 11,0 & 9,2 & 9,8 \\
\hline Nunca & 5,9 & 4,9 & 5,3 \\
\hline Total & 100 & 100 & 100 \\
\hline
\end{tabular}

El número de personas que hacen parte de la lista de e-mails del usuario es de $25.1 \%$ en las favelas de altos ingresos, descendiendo a $20.2 \%$ en las favelas de ingresos medios y a $18.9 \%$ en las favelas bajos ingresos. A medida que el porcentaje de usuarios de Internet en el barrio disminuye, es natural que el universo de personas conocidas por el usuario con acceso a Internet también caiga.

Gráfico 3.2.27: Número medio de personas que son parte de la lista de usuarios según tipo de favela

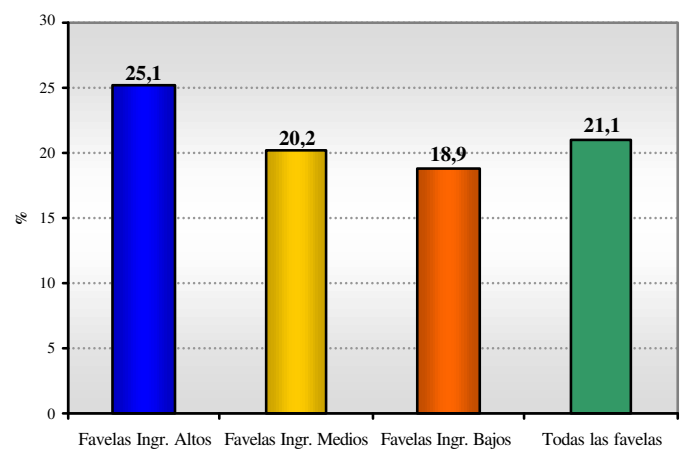


Entre los usuarios de e-mail, cerca de la mitad señaló que conoció nuevas personas por Internet, siendo que este porcentaje disminuye a medida que pasamos de las favelas de altos ingresos para las de ingresos bajos.

\section{Gráfico 3.2.28: Conocimiento de personas por Internet en relación a los} habitantes que utilizan computadora según tipo de favela

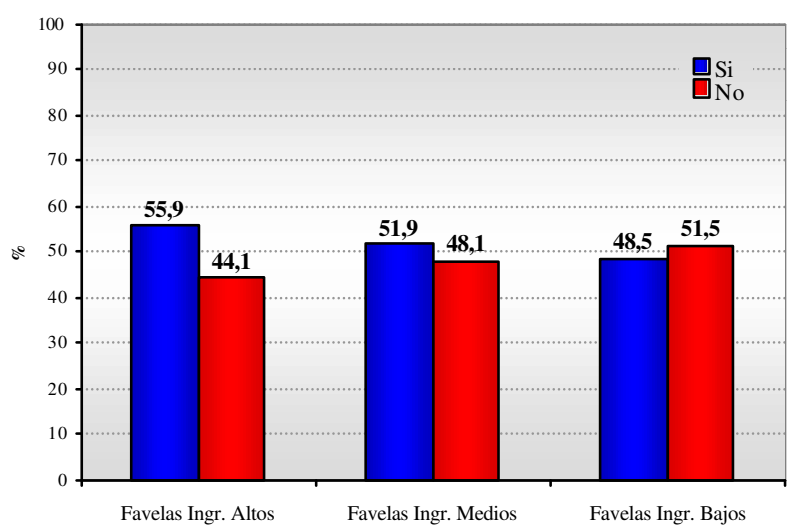

El relacionamiento a través de Internet permite entrar en contacto con personas de nivel socioeconómico superior (prácticamente la mitad) o el equivalente (la otra mitad). El contacto con personas de nivel más bajo es casi inexistente.

Gráficos 3.2.29: Nivel socioeconómico de las personas que conoció por Internet entre habitantes que utilizan computadora según tipo de favela

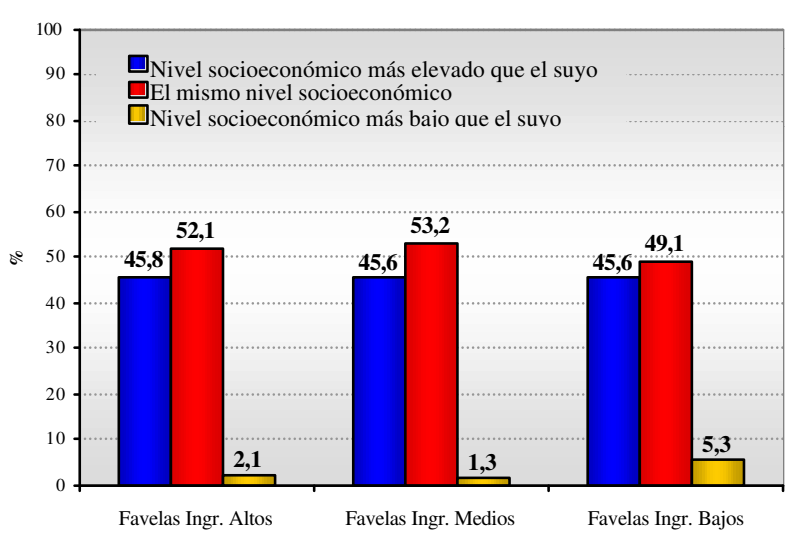


Los contactos hechos por Internet fueron en primer lugar relevantes para la obtención de informaciones relativas a la propia Internet y en segundo lugar para contactos de trabajo. Para cerca de la mitad de los entrevistados estos contactos no fueron de utilidad.

Cuadro 3.2.9: De qué forma las personas que usted conoció por Internet lo ayudaron

\begin{tabular}{lccc}
\hline \hline & & & \\
Tipo de ayuda & Favelas Ingr. Altos & Favelas Ingr. Medios & Favelas Ingr. Bajos \\
Recomendación de trabajo & & & \\
No obtiene informaciones, no hay temas que le interesen & 6,3 & 10,6 & 8,9 \\
Estas personas me ayudaron en otras cosas & 38,1 & 27,7 & 44,6 \\
$\quad$ Estas personas no me ayudaron & 7,9 & 7,4 & 5,4 \\
Total & 47,6 & 54,3 & 41,1 \\
\hline
\end{tabular}

La participación en sitios de chateo es relativamente común entre los usuarios de Internet, llegando al $46.7 \%$ en las favelas de ingresos medios y bajando a $28.8 \%$ en las favelas de bajos ingresos.

Gráfico 3.2.30: Participación en chateos entre habitantes que utilizan Internet según tipo de favela

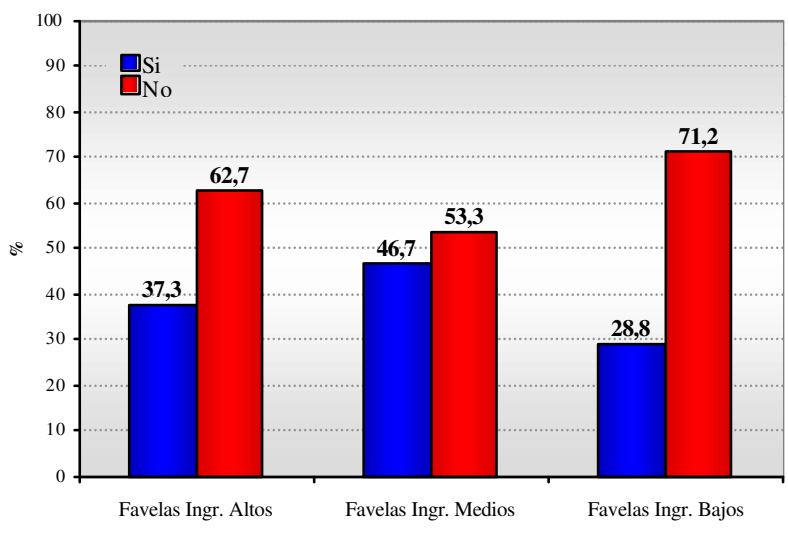


Mientras en las favelas de altos ingresos los usuarios que utilizan el e-mail para trabajar (incluído el trabajo escolar) y para recreación, superan el 50\%, en las favelas de ingresos medios y bajos este porcentaje desciende a poco más del 40\%. La utilización sólo para trabajo es más alta en las favelas de ingresos medios, sin embargo, si sumamos "sólo para trabajo" y "más para trabajo que para recreación", en las favelas de bajos ingresos este total es de $40.8 \%$ y cerca de $30 \%$ en las favelas de ingresos medios y altos.

Cuadro 3.2.10: Objetivo de la utilización del e-mail según tipo de favela

\begin{tabular}{|c|c|c|c|}
\hline & Favelas Ingr. Altos & Favelas Ingr. Medios & Favelas Ingr. Bajos \\
\hline \multicolumn{4}{|l|}{ Motivo } \\
\hline Sólo para trabajar & 15,5 & 11,9 & 21,4 \\
\hline Más para trabajar que para divertirse & 14,1 & 20,6 & 19,4 \\
\hline Mitad para trabajar, mitad para divertirse & 52,1 & 14,3 & 40,8 \\
\hline Más para divertirse que para trabajar & 18,3 & 26,2 & 18,4 \\
\hline Total & 100 & 100 & 100 \\
\hline
\end{tabular}

Prácticamente todos los usuarios de informatica consideran que saber computación ayuda a encontrar empleo.

Gráfico 3.2.31: Opinión sobre el efecto del conocimiento de informática en la obtención de empleo entre habitantes que utilizan computadora según tipo de favela

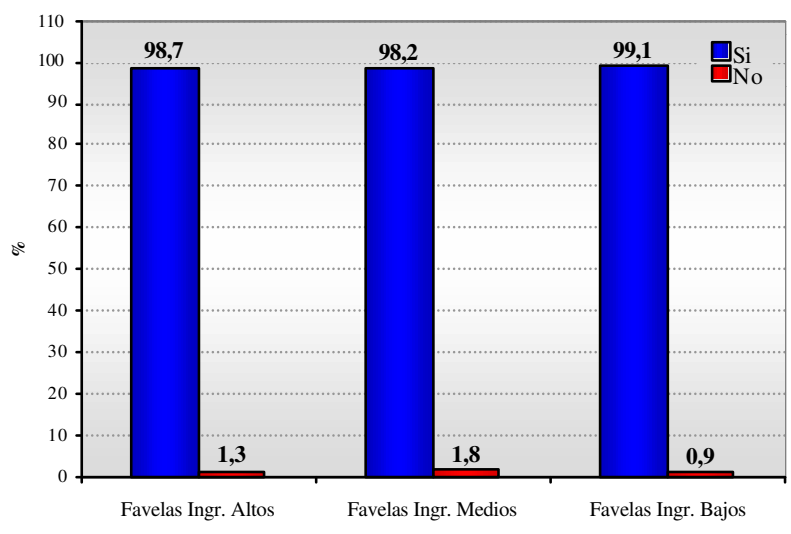


Entre los que encontraron empleo con ayuda de la informática (cerca de un tercio de los usuarios de computadora), más de la mitad señaló que el conocimiento de informática era una condición para la obtención del empleo; una proporción importante, de $18.4 \%$ en las favelas de ingresos medios y $32.7 \%$ en las favelas de ingresos bajos señaló que ayudó en el momento de la entrevista, o sea, no era condición de empleo pero aumentaba el interés del empleador (entre $16.9 \%$ en las favelas altos ingresos y $12.3 \%$ en las favelas de bajos ingresos, obtuvieron información sobre empleo por Internet).

Cuadro 3.2.11: Cómo la computación ayudó a encontrar empleo, según tipo de favela

\begin{tabular}{cccc}
\hline \hline & & & \\
Contribución de computación & Favelas Ingr. Altos & Favelas Ingr. Medios & Favelas Ingr. Baios \\
A través de información & 16,9 & 14,7 & 12,3 \\
En el momento de la entrevista & 22,9 & 18,4 & 32,7 \\
Para cumplir, en el trabajo & 58,5 & 64,5 & 51,2 \\
Otros motivos & 1,7 & 2,3 & 3,7 \\
\hline
\end{tabular}

\section{3 - Diferencias de acuerdo al género ${ }^{10}$}

Como lo vimos anteriormente, el porcentaje de población femenina que usa computadora es inferior al masculino. No sólo los números absolutos de acceso desfavorecen al género femenino, sino también la intensidad del uso. La desigualdad entre los géneros sólo disminuye en las favelas de baja remuneración, y posiblemente se debe al peso que tiene la población escolar usuaria de computadora, en donde se encuentran grandes diferencias entre los géneros.

\footnotetext{
$\overline{10}$ Todas los cuadros de esta sección se muestran en porcentajes relativos a los propios grupos
} 
Cuadro 3.3.1: Frecuencia de utilización de la computadora según tipo de favela y sexo

\begin{tabular}{|c|c|c|c|c|c|c|}
\hline & \multicolumn{2}{|c|}{ Favelas Inar. Altos } & \multicolumn{2}{|c|}{ Favelas Inar. Medios } & \multicolumn{2}{|c|}{ Favelas Inar. Baios } \\
\hline & Masculino & Femenino & Masculino & Femenino & Masculino & Femenino \\
\hline Todos los días & 29,0 & 28,0 & 28,0 & 22,9 & 29,5 & 25,4 \\
\hline Por lo menos una vez por semana & 32,5 & 24,4 & 24,9 & 28,1 & 26,7 & 27,1 \\
\hline Utiliza la computadora ocasionalmente & 13,0 & 13,4 & 15,0 & 15,6 & 12,8 & 8,3 \\
\hline Utiliza la computadora raras veces & 25,5 & 34,1 & 22,2 & 33,3 & 31,0 & 39,2 \\
\hline Total & 100 & 100 & 100 & 100 & 100 & 100 \\
\hline
\end{tabular}

Como lo indicamos anteriormente, en los sectores pobres de la población, el aprendizaje por "ósmosis" (esto significa ver a los padres usando o tan sólo jugando con la computadora), típico de las clases medias, es bastante reducido. Los cursos especializados en general son la principal vía de aprendizaje, particularmente para las usuarias del género femenino. El aprendizaje a través de amigos o solo, es mucho más importante para los usuarios masculinos. El trabajo, aunque sea un importante local de acceso, tiene una importancia bastante menor como local de aprendizaje.

Cuadro 3.3.2: Forma cómo aprendió a usar la computadora, según tipo de favela y sexo

\begin{tabular}{|c|c|c|c|c|c|c|}
\hline \multirow[b]{3}{*}{ Sólo, intentando } & \multicolumn{2}{|c|}{ Favelas Inar. Altos } & \multicolumn{2}{|c|}{ Favelas Inar. Medios } & \multicolumn{2}{|c|}{ Favelas Inar. Baios } \\
\hline & Masculino & $\overline{\text { Femenino }}$ & Masculino & $\overline{\text { Femenino }}$ & Masculino & $\overline{\text { Femenino }}$ \\
\hline & 18,7 & 14,6 & 18,4 & 11,9 & 15,0 & 9,7 \\
\hline Sólo, ayudado por manuales & 2,6 & 0,6 & 1,4 & 0,7 & 3,8 & 1,6 \\
\hline Con orientación, en el trabajo & 5,7 & 7,9 & 7,5 & 6,7 & 12,0 & 3,2 \\
\hline $\begin{array}{l}\text { Con la ayuda de amigos } \\
\text { En cursos especializados }\end{array}$ & $\begin{array}{l}18,7 \\
49,6\end{array}$ & $\begin{array}{l}11,6 \\
62,8\end{array}$ & $\begin{array}{l}17,3 \\
53,2\end{array}$ & $\begin{array}{c}7,4 \\
70,2\end{array}$ & $\begin{array}{c}9,0 \\
53,4\end{array}$ & $\begin{array}{c}5,4 \\
73,5\end{array}$ \\
\hline De otra forma & 4,8 & 2,4 & 2,2 & 3,2 & 6,8 & 6,5 \\
\hline Total & 100 & 100 & 100 & 100 & 100 & 100 \\
\hline
\end{tabular}

La principal diferencia en la utilización de programas de Internet entre los géneros se refiere a juegos, más utilizados por el público masculino, particularmente en las favelas de remuneraciones altas y medias. 
Cuadro 3.3.3: Tipos de programas más utilizados por sexo y tipo de favela

\begin{tabular}{|c|c|c|c|c|c|c|}
\hline \multirow{4}{*}{$\begin{array}{l}\text { Procesadores de texto } \\
\text { Planillas electrónicas }\end{array}$} & \multicolumn{2}{|c|}{ Favelas Inar. Altos } & \multicolumn{2}{|c|}{ Favelas Inar. Medios } & \multicolumn{2}{|c|}{ Favelas Inar. Baios } \\
\hline & Masculino & Femenino & Masculino & Femenino & Masculino & Femenino \\
\hline & 74,6 & 75,2 & 70,0 & 81,4 & 77,7 & 93,4 \\
\hline & 48,2 & 49,1 & 37,8 & 44,2 & 60,0 & 63,2 \\
\hline Programas de presentación gráfica & 26,3 & 28,6 & 27,8 & 24,9 & 42,6 & 39,6 \\
\hline Lenguaje de programación & 4,4 & 3,1 & 5,3 & 1,8 & 9,4 & 7,7 \\
\hline Juegos & 61,0 & 46,0 & 49,4 & 40,4 & 67,9 & 63,7 \\
\hline Otro & 4,4 & 5,0 & 6,9 & 4,6 & 6,4 & 2,7 \\
\hline Total & 100 & 100 & 100 & 100 & 100 & 100 \\
\hline
\end{tabular}

Entre los usuarios de computadora, el universo femenino es inferior en todas las favelas.

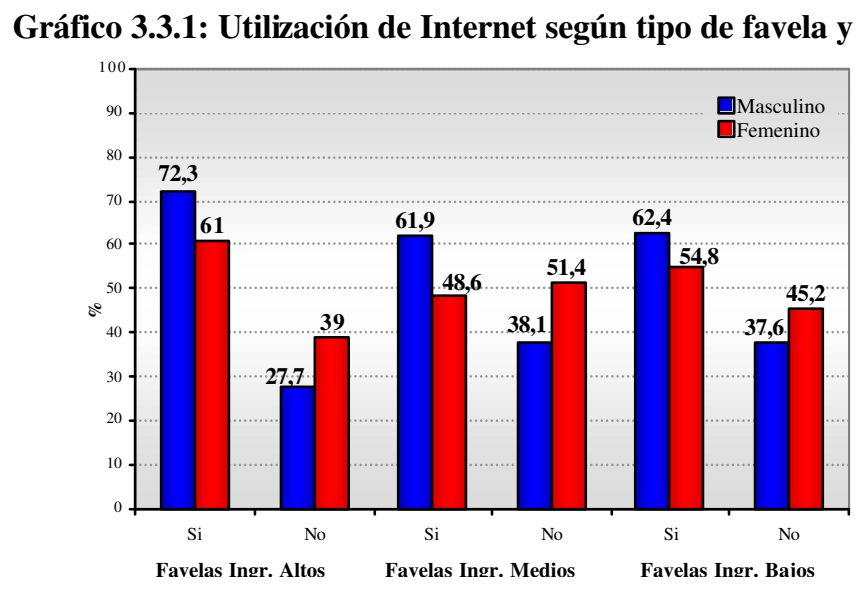

Los motivos por los cuales no entran en Internet, aducidos por los usuarios femeninos y masculinos, presentan diferencia de matices importantes. La importancia de la falta de local es bastante más alta para el público femenino que para el masculino, en las favelas de ingresos medios y altos. Dado que objetivamente no hay diferencias de localización de espacios de Internet para ambos géneros, la explicación se encuentra posiblemente en la percepción del espacio de circulación dentro o fuera de la favela, ya que las personas de género masculino presentan mayor movilidad y, en el caso de los menores de edad, son menos controlados por los padres. La falta de interés más señalada por los hombres merece ser investigada. 
Cuadro 3.3.4: Motivos para no entrar en Internet

\begin{tabular}{|c|c|c|c|c|c|c|}
\hline \multirow{4}{*}{$\begin{array}{l}\text { No tiene lugar dónde entrar } \\
\text { No tiene interés }\end{array}$} & \multicolumn{2}{|c|}{ Favelas Inar. Altos } & \multicolumn{2}{|c|}{ Favelas Inar. Medios } & \multicolumn{2}{|c|}{ Favelas Inar. Baios } \\
\hline & Masculino & Femenino & Masculino & Femenino & Masculino & Femenino \\
\hline & 58,7 & 73,4 & 60,4 & 66,2 & 62,5 & 60,2 \\
\hline & 14,3 & 9,4 & 13,4 & 10,3 & 11,5 & 7,2 \\
\hline Le parece muy dificil & 14,3 & 3,1 & 11,9 & 11,0 & 5,2 & 4,8 \\
\hline Caro & 4,8 & 3,1 & 5,2 & 5,5 & 10,4 & 12,0 \\
\hline No tiene tiempo & 7,9 & 10,9 & 9,0 & 6,9 & 10,4 & 15,7 \\
\hline Total & 100 & 100 & 100 & 100 & 100 & 100 \\
\hline
\end{tabular}

Si sumamos los que acceden una vez por día o más, los usuarios masculinos presentan un porcentaje mayor, en particular en las favelas de remuneración medias y bajas.

Cuadro 3.3.5: Con qué frecuencia entra en Internet

\begin{tabular}{|c|c|c|c|c|c|c|}
\hline & \multicolumn{2}{|c|}{ Favelas Inar. Altos } & \multicolumn{2}{|c|}{ Favelas Inar. Medios } & \multicolumn{2}{|c|}{ Favelas Inar. Baios } \\
\hline & Masculino & Femenino & Masculino & $\begin{array}{l}\text { Femenino } \\
\end{array}$ & Masculino & Femenino \\
\hline Más de una vez por día & 9,1 & 13,1 & 24,8 & 13,2 & 9,3 & 8,2 \\
\hline Una vez por día & 17,7 & 12,1 & 17,6 & 15,4 & 10,6 & 6,2 \\
\hline Más de una vez por semana & 22,6 & 25,3 & 24,3 & 17,6 & 32,9 & 29,9 \\
\hline Una vez por semana & 30,5 & 32,3 & 23,0 & 27,2 & 30,4 & 39,2 \\
\hline Una vez por mes & 20,1 & 17,2 & 10,4 & 26,5 & 16,8 & 16,5 \\
\hline Total & 100 & 100 & 100 & 100 & 100 & 100 \\
\hline
\end{tabular}

En el tipo de sitios visitado las diferencias entre los géneros son bastante sugerentes. Mientras los sitios de deporte se encuentran entre los más visitados por los hombres, son secundarios entre las mujeres. Los sitios de búsqueda/investigación, proveedores, periódicos y música, son tanto visitados por hombre como por mujeres. A excepción de las favelas altos ingresos, los sitios de utilidad pública son también bastante visitados, mientras que los portales de empresas con igualmente visitados en favelas de remuneración alta y media, pero en menor proporción por las mujeres de favelas baja remuneración. 
Cuadro 3.3.6: Tipos de sitio más visitados por sexo y tipo de favela

\begin{tabular}{|c|c|c|c|c|c|c|}
\hline & \multicolumn{2}{|c|}{ Favelas Inar. Altos } & \multicolumn{2}{|c|}{ Favelas Inar. Medios } & \multicolumn{2}{|c|}{ Favelas Inar. Baios } \\
\hline & Masculino & Femenino & Masculino & $\overline{\text { Femenino }}$ & Masculino & Femenino \\
\hline Webmail & 40,5 & 35,4 & 38,6 & 33,6 & 38,8 & 30,2 \\
\hline Cybercafés & 14,7 & 14,1 & 11,7 & 10,7 & 10,0 & 13,5 \\
\hline Sitios de los proveedores & 49,7 & 49,5 & 50,2 & 55,0 & 40,0 & 50,0 \\
\hline Sitios de búsqueda/ investigación & 78,5 & 66,7 & 61,0 & 68,6 & 68,8 & 69,8 \\
\hline Sitios de revistas & 25,8 & 45,5 & 32,7 & 30,0 & 23,1 & 28,1 \\
\hline Sitios de diarios & 40,5 & 36,4 & 41,7 & 35,0 & 42,5 & 33,3 \\
\hline Utilidad pública & 23,9 & 13,1 & 26,9 & 28,6 & 41,3 & 41,7 \\
\hline Sitios de empresas & 17,8 & 17,2 & 21,5 & 18,6 & 30,0 & 18,8 \\
\hline Sitios de música & 59,5 & 49,5 & 50,7 & 41,4 & 48,1 & 44,8 \\
\hline Sitios de deportes & 55,8 & 13,1 & 48,0 & 15,0 & 42,5 & 10,4 \\
\hline Sitios infantiles & 5,5 & 14,1 & 7,6 & 9,3 & 6,9 & 8,3 \\
\hline Otro tipo de sitios (específicos) & 11,7 & 12,1 & 20,6 & 13,6 & 3,1 & 6,3 \\
\hline $\begin{array}{c}\text { Total } \\
\end{array}$ & 100 & 100 & 100 & 100 & 100 & 100 \\
\hline
\end{tabular}

La predisposición para hacer cursos por Internet no es muy diferente entre los sexos:

Gráfico 3.3.2: Predisposición para la realización de cursos por Internet por sexo y tipo de favela

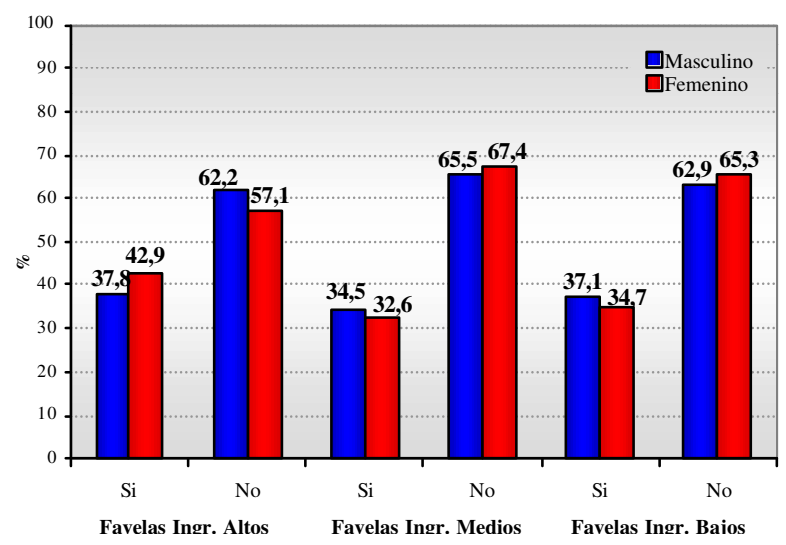

La utilización de Internet para hacer negocios es similar entre los sexos en las favelas de remuneración alta y va disminuyendo en las favelas remuneración media y baja, donde el porcentaje de mujeres es bastante inferior. 
Gráfico 3.3.3: Utilización de Internet para hacer negocios por sexo ye tipo de favela

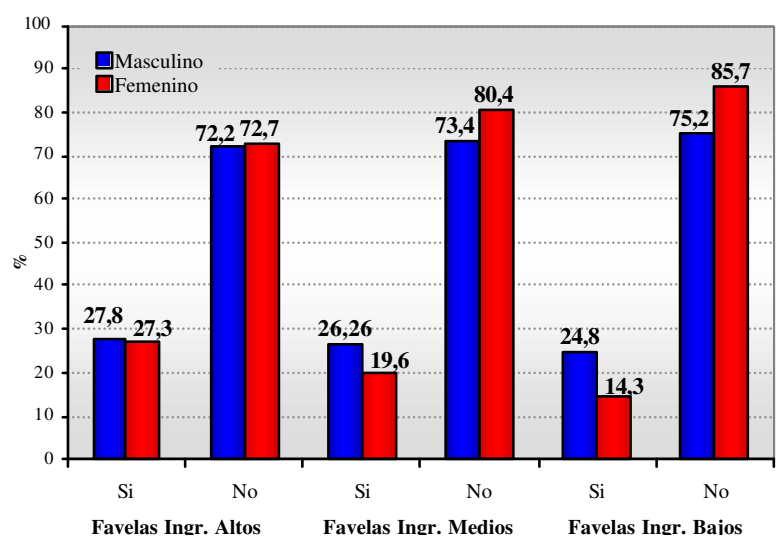

La principal diferencia en el uso de Internet para realizar negocios comunes a varios tipos de favela, es la gran utilización por parte de las mujeres para buscar precios.

Cuadro 3.3.7: Tipos de negocios realizados en Internet según sexo y tipo de favela

\begin{tabular}{|c|c|c|c|c|c|c|}
\hline \multirow[b]{3}{*}{ Compra } & \multicolumn{2}{|c|}{ Favelas Inar. Altos } & \multicolumn{2}{|c|}{ Favelas Inar. Medios } & \multicolumn{2}{|c|}{ Favelas Inar. Baios } \\
\hline & Masculino & Femenino & Masculino & Femenino & Masculino & Femenino \\
\hline & 30,4 & 25,9 & 45,8 & 42,3 & 50,0 & 42,9 \\
\hline Venta & 6,5 & 3,7 & 13,6 & 15,4 & 23,8 & - \\
\hline Información de precios & 32,6 & 40,7 & 13,6 & 23,1 & 28,6 & 35,7 \\
\hline Pago de cuentas & 32,6 & 22,2 & 28,8 & 34,6 & 28,6 & 21,4 \\
\hline Operaciones financieras & 21,7 & 22,2 & 32,2 & 30,8 & 26,2 & 28,6 \\
\hline Otros & 17,4 & 22,2 & 5,1 & 3,8 & 7,1 & 14,3 \\
\hline
\end{tabular}

Mientras en las favelas ingresos altos y medios los hombres visitan más portales en otros idiomas que las mujeres, en las favelas de ingresos bajos esta tendencia se revierte. 
Gráfico 3.3.4: Visita a sitios en otros idiomas según sexo y tipo de favela

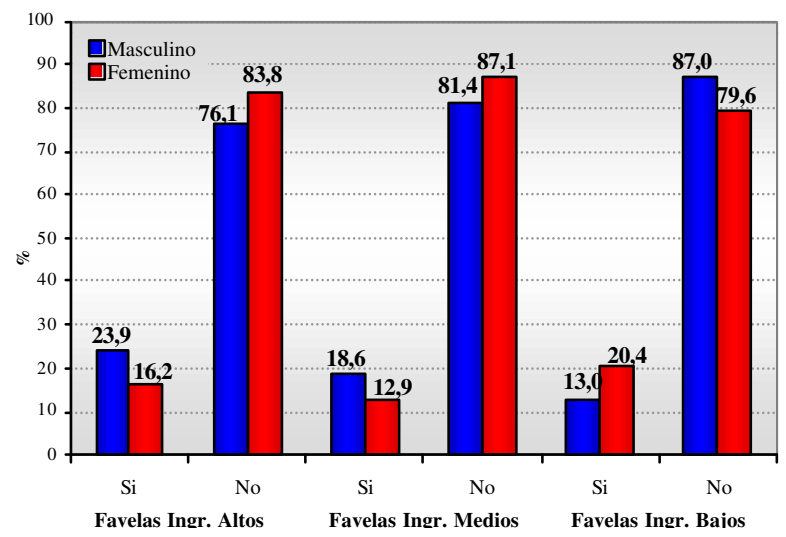

No hay diferencias significativas entre los sexos respecto al interés por entrar en contacto con personas de otros países.

Gráfico 3.3.5: Interés en tener contacto con barrios de otros países por sexo y tipo defavela

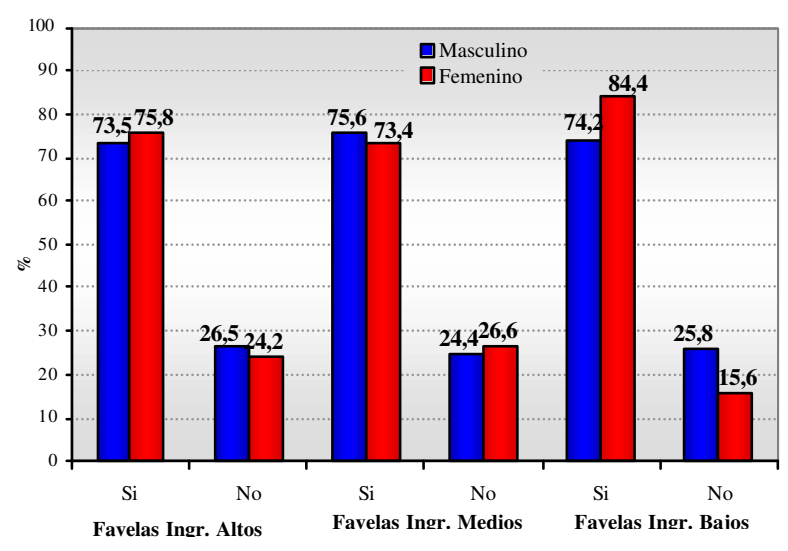

Entre los usuarios de Internet no hay diferencias significativas entre los sexos en el uso del e-mail. 
Gráfico 3.3.6: Utilización de e-mail por sexo y tipo de favela

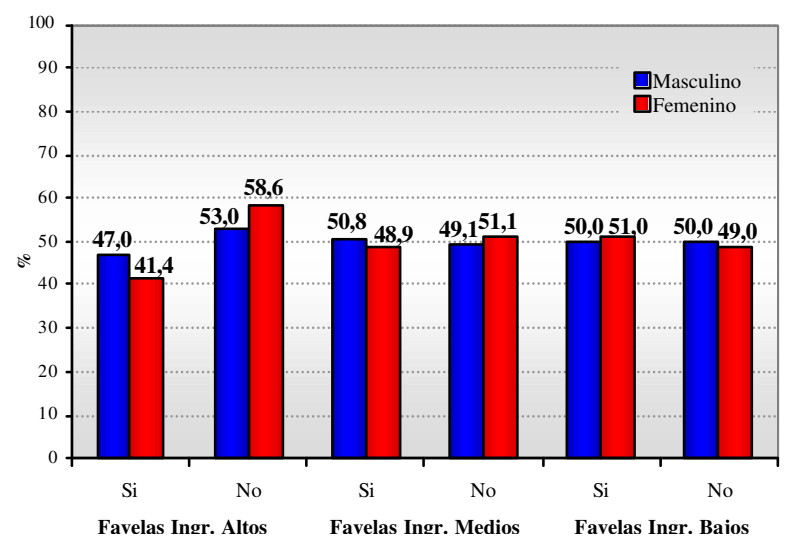

La frecuencia para revisar el e-mail es más intensa entre las mujeres en las favelas de altas remuneraciones y menor en las favelas de remuneraciones medias y bajas.

Cuadro 3.3.8: Frecuencia de utilización del e-mail por sexo y tipo defavela

\begin{tabular}{|c|c|c|c|c|c|c|}
\hline \multirow[b]{3}{*}{ Más de una vez por día } & \multicolumn{2}{|c|}{ Favelas Inar. Altos } & \multicolumn{2}{|c|}{ Favelas Inar. Medios } & \multicolumn{2}{|c|}{ Favelas Inar. Baios } \\
\hline & Masculino & $\begin{array}{l}\text { Femenino } \\
\end{array}$ & Masculino & Femenino & Masculino & Femenino \\
\hline & 16,9 & 19,5 & 33,3 & 22,1 & 17,1 & 14,0 \\
\hline Una vez por día & 15,6 & 17,1 & 24,6 & 11,8 & 7,3 & 10,0 \\
\hline Más de una vez por semana & 22,1 & 19,5 & 21,1 & 11,8 & 28,0 & 30,0 \\
\hline Una vez por semana & 31,2 & 22,0 & 14,0 & 27,9 & 34,1 & 28,0 \\
\hline Una vez por mes & 9,1 & 14,6 & 5,3 & 16,2 & 8,5 & 12,0 \\
\hline Nunca & 5,2 & 7,3 & 1,8 & 10,3 & 4,9 & 6,0 \\
\hline
\end{tabular}

El universo de personas contactadas por Internet es bastante inferior entre las mujeres. Esto puede ser debido al mayor control y vigilancia que se ejerce sobre el mundo femenino, sea por parte de los padres o los esposos. 
Gráfico 3.3.7: Número medio de personas que forman parte de la lista de usuarios de e-mail según sexo y tipo de favela

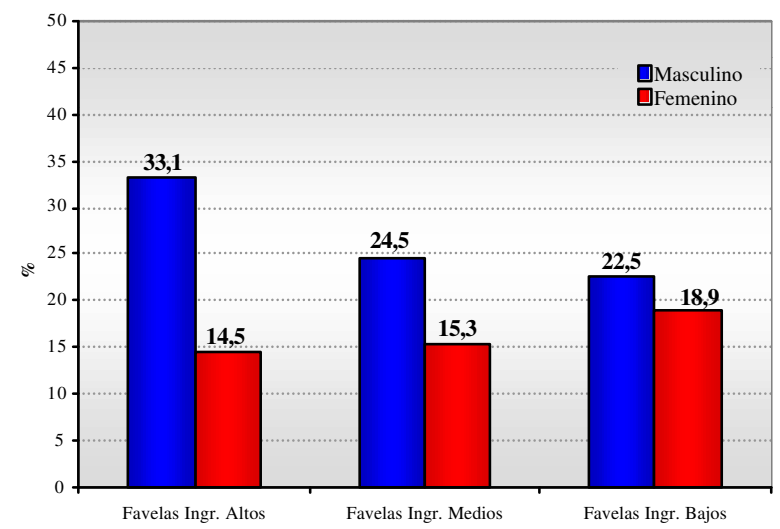

El uso de Internet, sin embargo, permite igualar el acceso a otras personas "virtuales", siendo que el porcentaje es bastante similar entre hombres y mujeres, particularmente en las favelas de remuneraciones medias y bajas.

Gráfico 3.3.8: Conocimiento de personas por Intemet por sexo y tipo de favela

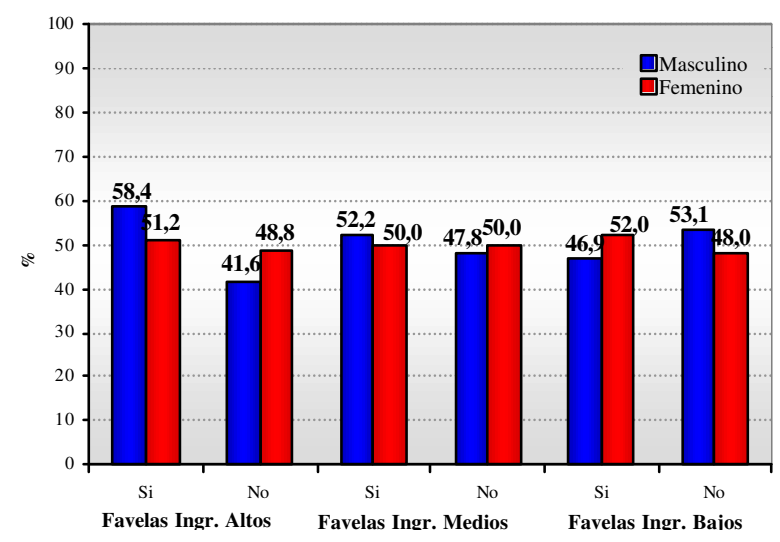

Generalmente, tanto hombres como mujeres encuentran en Internet personas con un nivel socioeconómico más alto o igual, a pesar de que en las favelas de bajos ingresos, $9.5 \%$ de las mujeres indican que encontraron personas con nivel inferior. 
Gráfico 3.3.9: Nivel socioeconómico de las personas que conoció por Internet, por sexo y tipo de favela

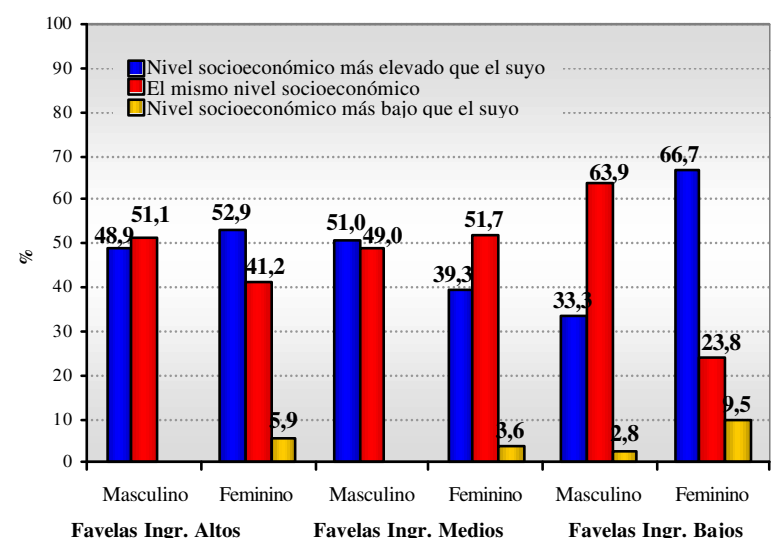

Generalmente las mujeres, mucho más que los hombres, no encontraron en estos contactos algún tipo de utilidad. En este sentido no hubo grandes diferencias entre los géneros.

Cuadro 3.3.9: Esas personas ya te ayudaron en:

\begin{tabular}{|c|c|c|c|c|c|c|}
\hline & \multicolumn{2}{|c|}{ Favelas Ingr. Altos } & \multicolumn{2}{|c|}{ Favelas Ingr. Medios } & \multicolumn{2}{|c|}{ Favelas Ingr. Bajos } \\
\hline & Masculino & Femenino & Masculino & Femenino & Masculino & Femenino \\
\hline Esas personas no me ayudaron & 41,9 & 60,0 & 50,8 & 61,8 & 32,4 & 52,2 \\
\hline No obtiene informaciones, no hay temas que le interesen & 39,5 & 35,0 & 28,8 & 26,5 & 50,0 & 39,1 \\
\hline Esas personas me ayudaron en otras cosas & 11,6 & - & 10,2 & 2,9 & 5,9 & 4,3 \\
\hline Recomendación de trabajo & 7,0 & 5,0 & 10,2 & 8,8 & 11,8 & 4,3 \\
\hline
\end{tabular}

Las mujeres tienen una tendencia un poco mayor a participar de los sitios/chateos que los hombres. 
Gráfico 3.3.10: Participación en chateos por sexo y tipo de favela

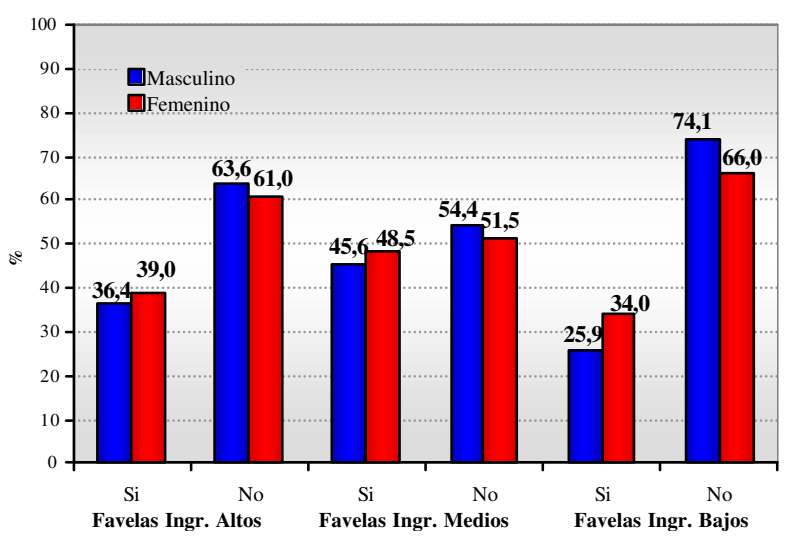

Particularmente en las favelas de bajos ingresos, y también en las favelas de ingresos altos, es mucho más elevado el número de mujeres que utilizan el e-mail solamente para el trabajo y en las favelas de ingresos medios, esta relación se invierte. Esto confirma la hipótesis de la primera parte de este libro, donde indicamos la importancia del trabajo en la discriminación de las mujeres en relación a los hombres.

Cuadro 3.3.10: Objetivo de la utilización del e-mail

\begin{tabular}{|c|c|c|c|c|c|c|}
\hline \multirow[b]{3}{*}{ Sólo para trabajar } & \multicolumn{2}{|c|}{ Favelas Inar. Altos } & \multicolumn{2}{|c|}{ Favelas Inar. Medios } & \multicolumn{2}{|c|}{ Favelas Inar. Baios } \\
\hline & Masculino & Femenino & Masculino & Femenino & Masculino & Femenino \\
\hline & 47,1 & 65,0 & 42,7 & 40,8 & 32,8 & 53,8 \\
\hline Más para trabajar que para divertirse & 19,6 & 15,0 & 24,0 & 28,6 & 17,2 & 20,5 \\
\hline Mitad para trabajar, mitad para divertirse & 17,6 & 10,0 & 9,3 & 16,3 & 32,8 & 2,6 \\
\hline Más para divertirse que para trabajar & 15,7 & 10,0 & 24,0 & 14,3 & 17,2 & 23,1 \\
\hline
\end{tabular}

Prácticamente la totalidad de los hombres y mujeres indican la importancia, en general, de saber computación para obtener un empleo. 
Gráfico 3.3.11: Opinión sobre el efecto de saber computación para conseguir empleo, por sexo y tipo de favela

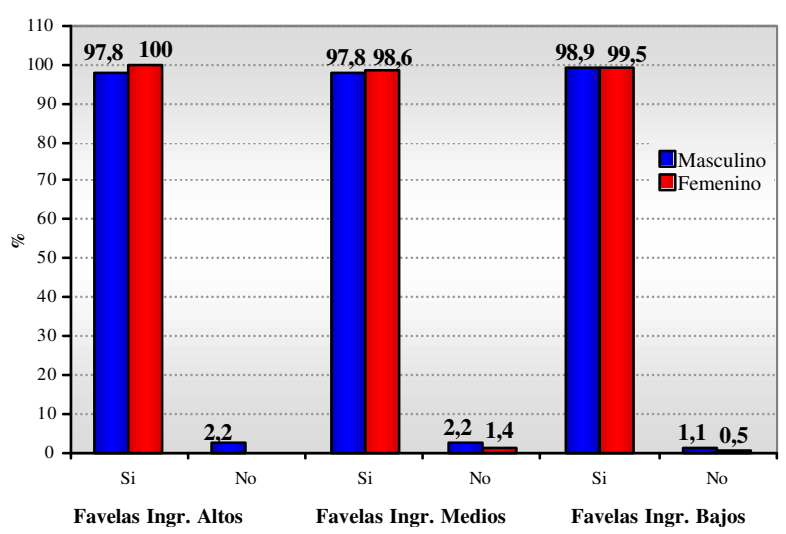

También es similar la respuesta sobre la importancia que tuvo saber computación para la persona entrevistada obtener empleo.

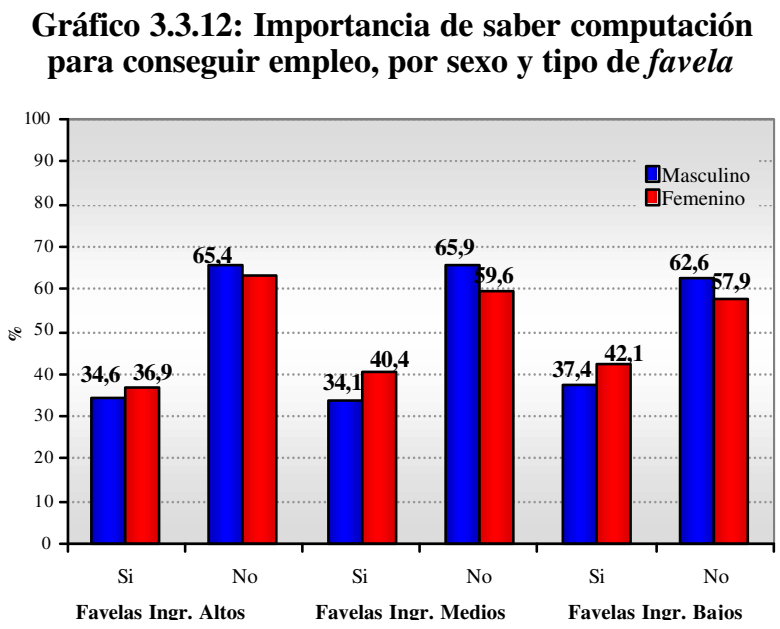

En el momento de obtener empleo, la exigencia de saber computación era más importante para los hombres que para las mujeres (posiblemente un porcentaje importante de estas realizan trabajos domésticos o de limpieza). 
Cuadro 3.3.11: Forma en que la computación ayudó a conseg uir empleo

\begin{tabular}{|c|c|c|c|c|c|c|}
\hline & \multicolumn{2}{|c|}{ Favelas Inar. Altos } & \multicolumn{2}{|c|}{ Favelas Inar. Medios } & \multicolumn{2}{|c|}{ Favelas Inar. Baios } \\
\hline & Masculino & Femenino & Masculino & Femenino & Masculino & Femenino \\
\hline A través de información & 10,9 & 24,1 & 13,8 & 15,9 & 12,4 & 12,3 \\
\hline En el momento de la entrevista & 28,1 & 16,7 & 15,6 & 21,5 & 27,0 & 39,7 \\
\hline Para cumplir, en el trabajo & 60,9 & 55,6 & 67,9 & 60,7 & 55,1 & 46,6 \\
\hline Otros motivos & - & 3,7 & 2,8 & 1,9 & 5,6 & 1,4 \\
\hline
\end{tabular}

Debido a los problemas de representación en la muestra (que impide un cierto nivel de detalle), trataremos los datos referentes al grupo de edad y a la raza del conjunto de las favelas.

\section{4 - Análisis según el grupo de edad ${ }^{11}$}

Aunque la muestra esté limitada por el pequeño número de usuarios con más de 45 años, constatamos que el número de usuarios por día es bastante similar, y el aumento del porcentaje con la edad posiblemente se debe a que los que deben hacer un uso más constante de la computadora son los usuarios adultos, que tienen acceso en su trabajo. Cuando se trata del grupo que usa una vez por semana (posiblemente un uso no relacionado al trabajo), la tendencia se revierte y son los más jóvenes los que presentan mayor frecuencia. Esto queda claro en el último grupo (de los que utilizan la computadora raramente), donde el grupo de más de 45 años está sobrerepresentado.

\footnotetext{
${ }^{11}$ Todos los cuadros de esta sección muestra porcentajes relativos al propio grupo.
} 
Cuadro 3.4.1: Frecuencia con que utiliza la computadora según grupo de edad

Todos los días

Por lo menos una vez por semana

Utiliza la computadora ocasionalmente

Utiliza la computadora raras veces

\begin{tabular}{|c|c|c|}
\hline Hasta 24 años & 25 a 44 añ & 45 y más años \\
\hline 26,8 & 32,6 & 33,3 \\
\hline 30,3 & 25,3 & 13,8 \\
\hline 14,7 & 12,0 & 10,3 \\
\hline 28,1 & 30,1 & 42,5 \\
\hline
\end{tabular}

En lo que se refiere al camino recorrido para usar computadora, la principal diferencia entre los grupos de edad reside en la importancia del local de trabajo, a medida que pasamos por los grupos de más edad, e inversamente cuando se trata del uso de cursos especializados.

Cuadro 3.4.2: Forma en que aprendió a utilizar la computadora según grupo de edad

\begin{tabular}{lccc}
\hline & & & \\
\hline \hline & Hasta 24 años & 25 a 44 años & 45 y más años \\
\cline { 2 - 4 } \cline { 3 - 3 } Sólo, intentando & 14,5 & 15,9 & 15,7 \\
Con orientación, en el trabajo & 1,2 & 2,3 & 3,4 \\
Con la ayuda de amigos & 3,1 & 11,6 & 16,9 \\
En cursos especializados & 12,1 & 11,4 & 15,7 \\
De otra forma & 64,3 & 55,3 & 44,9 \\
\hline
\end{tabular}

No existen grandes diferencias en relación al uso de programas entre los grupos de edad, a no ser en lo referente a los juegos e Internet. En ambos casos el uso aumenta a medida que pasamos de los grupos de más edad hacia los más jóvenes.

Cuadro 3.4.3: Tipos de programas más utilizados según grupos de edad

\begin{tabular}{lccc}
\hline & & & \\
\hline & Hasta 24 años & 25 a 44 años & 45 y más años \\
\cline { 2 - 4 } \cline { 2 - 3 } Procesadores de texto & 77,6 & 78,3 & 75,0 \\
Planillas electrónicas & 45,5 & 54,1 & 43,2 \\
Programas de presentación gráfica & 32,1 & 31,6 & 18,2 \\
Lenguaje de programación & 5,4 & 4,8 & 6,8 \\
Juegos & 64,5 & 42,9 & 34,1 \\
Otro & 4,0 & 7,0 & 5,7 \\
\hline
\end{tabular}


Cuadro 3.4.4: Utilización de Internet según grupos de edad

\begin{tabular}{|c|c|c|c|}
\hline & Hasta 24 años & 25 a 44 años & 45 y más años \\
\hline $\mathrm{Si}$ & 66,0 & 55,4 & 40,0 \\
\hline No & 34,0 & 44,6 & 60,0 \\
\hline
\end{tabular}

En relación a los motivos para no usar Internet, la falta de local de conexión es indicada como el factor más importante para todos los grupos, particularmente entre los más jóvenes. En los otros factores las diferencias porcentuales no llegan a tener gran relevancia, salvo el precio, que es considerado importante por el $14.8 \%$ de los mayores de 45 años, comparado con el 6.4\% de los menores de 24 años; posiblemente, el factor central sea de orden subjetivo, pues las personas de más edad “valorizan” más el dinero.

Cuadro 3.4.5: Motivos para no entrar en Internet según grupos de edad

\begin{tabular}{lcccc}
\hline \hline & & & & \\
\cline { 2 - 3 } No tiene lugara 24 años & & 25 a 44 años & & 45 y más años \\
\cline { 2 - 3 } No tiene interés & 61,7 & 67,3 & 51,9 \\
Le parece muy dificil & 12,4 & & 9,0 & 16,7 \\
Caro & 9,8 & & 8,3 & 7,4 \\
No tiene tiempo & 6,4 & 5,6 & 14,8 \\
\hline
\end{tabular}

Entre los usuarios de Internet, la frecuencia tiende a aumentar a medida que pasamos de un grupo de edad para otro. El factor explicativo debe estar basado en el hecho de que en estos grupos, el uso de Internet está asociado al trabajo cotidiano.

Cuadro 3.4.6: Frecuencia con que entra en Internet

\begin{tabular}{|c|c|c|c|}
\hline & Hasta 24 años & 25 a 44 años & 45 y más años \\
\hline Más de una vez por día & 11,5 & 17,9 & 20,6 \\
\hline Una vez por día & 14,0 & 14,0 & 14,7 \\
\hline Más de una vez por semana & 25,0 & 25,5 & 26,5 \\
\hline Una vez por semana & 31,5 & 26,4 & 20,6 \\
\hline Una vez por mes & 18,0 & 16,1 & 17,6 \\
\hline
\end{tabular}


En relación a los tipos de sitios, vemos que los sitios asociados a la utilidad/funcionalidad son, excepto los de los cybercafés, más utilizados por los grupos de más edad, mientras que los sitios de diversión/entretenimiento, lo son por los grupos de menor edad. El grupo de 25 a 44 años presenta índices altos de utilización en casi todos los grupos de edad.

Cuadro 3.4.7: Tipos de programas más utilizados según grupo de edad

\begin{tabular}{lcccc}
\hline & & & \\
\hline & Hasta 24 años & 25 a 44 años & 45 y más años \\
\cline { 2 - 3 } Cybercafés & 36,7 & 36,9 & 42,9 \\
Sitios de los proveedores & 10,7 & & 15,2 & 8,6 \\
Sitios de búsqueda/ investigación & 48,6 & 50,3 & 42,9 \\
Sitios de revistas & 69,6 & 67,1 & 65,7 \\
Sitios de diarios & 28,7 & 34,1 & 14,3 \\
Utilidad pública & 31,9 & 50,6 & 37,1 \\
Sitios de empresas & 20,7 & 42,7 & 37,1 \\
Sitios de música & 14,9 & 29,0 & 40,0 \\
Sitios de deportes & 55,3 & 43,6 & 20,0 \\
Sitios infantiles & 35,8 & 36,0 & 22,9 \\
Otro tipo de sitios (específicos) & 7,3 & 9,8 & 8,6 \\
\hline
\end{tabular}

En lo referente a la utilización de Internet para realizar cursos, las repuestas son prácticamente homogéneas entre todos los grupos de edad.

Cuadro 3.4.8: Predisposición para la realización de cursos por Internet,

según grupos de edad

\begin{tabular}{|c|c|c|c|}
\hline & Hasta 24 años & 25 a 44 años & 45 y más años \\
\hline $\mathrm{Si}$ & 37,0 & 35,3 & 38,2 \\
\hline No & 63,0 & 64,4 & 61,8 \\
\hline
\end{tabular}

En cuanto a la utilización de Internet para "hacer negocios" (cuya descripción aparece en la próxima pregunta), el porcentaje aumenta junto con el aumento en el grupo de edad. 
Cuadro 3.4.9: Utiliza Internet para hacer negocios?

\begin{tabular}{|c|c|c|c|}
\hline & Hasta 24 años & 25 a 44 años & 45 y más años \\
\hline $\mathrm{Si}$ & 16,5 & 34,2 & 40,0 \\
\hline No & 83,5 & 65,8 & 60,0 \\
\hline
\end{tabular}

Mientras que el grupo de edad de más de 45 años utiliza Internet sobre todo para hacer movimientos de cuenta bancaria y pagar cuentas, en el grupo de menor edad predominan las compras, la búsqueda de información de precios y el pago de cuentas. En el grupo intermedio, la distribución es más equilibrada, aunque la utilización para compras presenta mayor incidencia.

Cuadro 3.4.10: Tipo de negocio realizado por Internet según tipo de favela

\begin{tabular}{|c|c|c|c|}
\hline & Hasta 24 años & 25 a 44 años & 45 y más años \\
\hline Compra & 35,2 & 46,0 & 28,6 \\
\hline Venta & 14,8 & 10,6 & 7,1 \\
\hline Información de precios & 26,1 & 27,4 & 21,4 \\
\hline Pago de cuentas & 27,3 & 28,3 & 42,9 \\
\hline Operaciones financieras & 18,2 & 31,9 & 42,9 \\
\hline Otros & 13,6 & 8,0 & 14,3 \\
\hline
\end{tabular}

La visita a portales en otros idiomas presenta porcentajes similares entre el grupo más joven y el más viejo, mientras cae abruptamente en el grupo de 25 a 44 años. La explicación para esta tendencia es que el universo de los mayores de 45 años que utilizan Internet es pequeño y posiblemente mucho más calificado, dado que los jóvenes actualmente tienen más acceso a cursos de lenguas extranjeras, en particular de inglés.

Cuadro 3.4.11: Visita a portales de texto en otros idiomas

\begin{tabular}{|c|c|c|c|}
\hline & Hasta 24 años & 25 a 44 años & 45 y más años \\
\hline $\mathrm{Si}$ & 20,3 & 12,8 & 22,9 \\
\hline No & 79,7 & 87,2 & 77,1 \\
\hline
\end{tabular}


La anterior información se confirma conr el próximo cuadro, que indica la importancia de los cursos de idiomas (privados) que hoy están disponibles en todas las favelas, a precios competitivos (cuando anteriormente eran pocos y caros).

Cuadro 3.4.12: Local de aprendizaje de idiomas según grupo de edad

\begin{tabular}{lccc}
\hline & & & \\
\hline & Hasta 24 años & 25 a 44 años & 45 y más años \\
\cline { 2 - 4 } Curso & 42,4 & 48,7 & 25,0 \\
Institución de enseñanza & 38,0 & 23,1 & 37,5 \\
Sólo & 9,8 & 15,4 & 12,5 \\
En Internet & 4,3 & 7,7 & 0,0 \\
De otra forma & 5,4 & 5,1 & 25,0 \\
\hline
\end{tabular}

El uso de Internet como instrumento de contacto con otros países es alto en todos los grupos, particularmente entre los más jóvenes.

Cuadro 3.4.13: Interés en tener contacto con personas de otros países

\begin{tabular}{|c|c|c|c|}
\hline & Hasta 24 años & 25 a 44 años & 45 y más años \\
\hline Si & 81,3 & 66,6 & 77,1 \\
\hline No & 18,7 & 33,4 & 22,9 \\
\hline
\end{tabular}

Los tipos de temas son muy diversos, sin un claro predominio de un tema sobre otro.

Cuadro 3.4.14: Temas más citados según grupos de edad

\begin{tabular}{lcccc}
\hline & & & \\
\hline \hline & Hasta 24 años & 25 a 44 años & 45 y más años \\
\cline { 2 - 3 } Cómo viven, cómo es allá & 18,0 & & 13,4 & 12,5 \\
Cultura, actualidades, información & 23,6 & 29,7 & 20,8 \\
Chateo & 2,0 & 2,9 & - \\
Temas generales & 22,8 & 16,7 & 16,7 \\
Música, juegos, deporte, recreación & 10,4 & 3,3 & - \\
Investigación, educación, idiomas & 2,2 & & 5,3 & 4,2 \\
Religión & 1,4 & 5,3 & 4,2 \\
Política, economía, empleo & 10,7 & 13,9 & 4,2 \\
Turismo, seguridad & 2,5 & 3,8 & 8,3 \\
Sociedad, salud, pobreza & 8,7 & 12,0 & 4,2 \\
Informática, tecnología & 1,4 & 2,9 & 4,2 \\
Otras & 2,2 & 2,4 & 20,8 \\
\hline
\end{tabular}


Entre los usuarios de Internet el número de personas con e-mail aumenta junto con el grupo de edad, lo que nuevamente puede estar relacionado al uso en el trabajo.

Cuadro 3.4.15: Utilización del e-mail según grupos de edad

\begin{tabular}{|c|c|c|c|}
\hline & Hasta 24 años & 25 a 44 años & 45 y más años \\
\hline Si & 42,7 & 56,1 & 68,6 \\
\hline No & 57,3 & 43,9 & 31,4 \\
\hline
\end{tabular}

No existen diferencias de intensidad en el uso del email entre los diferentes grupos de edad, aunque el grupo de menos de 24 años presente menor intensidad de uso, posiblemente porque para este grupo el uso del e-mail tiene un costo relacionado, mientras que para parte de los grupo de edad más elevada existe la posibilidad de acceso en el trabajo.

Cuadro 3.4.16: Frecuencia de utilización del e-mail según grupo de edad

\begin{tabular}{|c|c|c|c|}
\hline & Hasta 24 años & 25 a 44 años & 45 y más años \\
\hline Más de una vez por día & 19,6 & 24,6 & 25,0 \\
\hline Una vez por día & 12,5 & 19,3 & 12,5 \\
\hline Más de una vez por semana & 23,2 & 20,3 & 20,8 \\
\hline Una vez por semana & 30,8 & 19,8 & 20,8 \\
\hline Una vez por mes & 10,7 & 8,6 & 12,5 \\
\hline Nunca & 3,1 & 7,5 & 8,3 \\
\hline
\end{tabular}

Los contactos con personas nuevas a través de Internet aumentan a medida que la edad disminuye. Naturalmente, los jóvenes están más abiertos y disponibles para nuevas relaciones.

Cuadro 3.4.17: Conocimiento de personas a través de Internet

\begin{tabular}{|c|c|c|c|}
\hline & Hasta 24 años & 25 a 44 años & 45 y más años \\
\hline Si & 64,1 & 41,0 & 25,0 \\
\hline No & 35,9 & 59,0 & 75,0 \\
\hline
\end{tabular}

Las personas conocidas a través de Internet, por todos los grupos, son del mismo nivel o de nivel socioeconómico superior. 
Cuadro 3.4.18: Nivel socioeconómico de las personas que conoció por Internet según grupos de edad

\begin{tabular}{lccc}
\hline \hline & & & \\
\cline { 2 - 4 } Nasta 24 años & $\frac{25 \text { a } 44 \text { años }}{42,7}$ & $\frac{45 \text { y más años }}{50,8}$ & 50,0 \\
El mismo nivel socioeconómico & 54,7 & 45,9 & 50,0 \\
Nivel socioeconómico más bajo que el suyo & 2,6 & 3,3 & - \\
\hline
\end{tabular}

Los contactos hechos por los jóvenes y los adultos de hasta 44 años, tienen como objetivo principal el intercambio de informaciones, mientras que para las personas de más de 50 años, el foco son las recomendaciones de trabajo. Dentro del grupo de más de 44 años, los contactos tienen mayoritariamente una funcionalidad, mientras que en los otros grupos es alto el porcentaje de encuentros sin utilidad.

Cuadro 3.4.19: De qué forma las personas que Usted conoció por Internet le ayudaron

\begin{tabular}{lcccc}
\hline & & & \\
& & Hasta 24 años & 25 a 44 años & 45 y más años \\
\cline { 2 - 4 } \cline { 4 - 4 } Recomendación de trabajo & 9,4 & 4,2 & 50,0 \\
No obtiene informaciones, no hay temas que le interesen & 31,2 & & 43,7 & 33,3 \\
Estas personas me ayudaron en otras cosas & 6,5 & 9,9 & 0,0 \\
Estas personas no me ayudaron & 52,9 & 42,3 & 16,7 \\
\hline
\end{tabular}

La participación en grupos de chateo es alta entre los jóvenes (51.4\%), decreciendo a medida que aumenta el grupo de edad.

Cuadro 3.4.20: Participación en chateos según grupos de edad

\begin{tabular}{|c|c|c|c|}
\hline & Hasta 24 años & 25 a 44 años & 45 y más años \\
\hline $\mathrm{Si}$ & 51,4 & 26,6 & 16,7 \\
\hline No & 48,6 & 73,4 & 83,3 \\
\hline
\end{tabular}


La importancia del e-mail como instrumento de trabajo aumenta junto con la edad:

Cuadro 3.4.21: Finalidad de la utilización del e-mail según grupos de edad:

Sólo para trabajar

Más para trabajar que para divertirse

Mitad para trabajar, mitad para divertirse

Más para divertirse que para trabajar

Sólo para divertirse

\begin{tabular}{ccc} 
Hasta 24 años & 25 a 44 años & 45 y más años \\
\cline { 2 - 3 } \cline { 3 - 3 } 5,9 & 15,6 & 29,2 \\
7,3 & 20,1 & 16,7 \\
18,6 & 34,1 & 29,2 \\
16,8 & 15,1 & 4,2 \\
41,4 & 15,1 & 20,8 \\
\hline
\end{tabular}

En todos los grupos de edad hay prácticamente consenso en relación al reconocimiento de la importancia de la computadora para la obtención de empleo:

Cuadro 3.4.22: Opinión sobre el efecto del conocimiento de informática en la obtención del empleo entre los habitantes que utilizan computadora según grupo de edad

\begin{tabular}{|c|c|c|c|}
\hline & Hasta 24 años & 25 a 44 años & 45 y más años \\
\hline $\mathrm{Si}$ & 98,7 & 98,3 & 98,9 \\
\hline No & 1,3 & 1,7 & 1,1 \\
\hline
\end{tabular}

El factor más importante para el uso de computadora fue la exigencia en el trabajo:

Cuadro 3.4.23: Forma en que la computación ayudó a obtener el empleo

\begin{tabular}{lccc}
\hline \hline & Hasta 24 años & 25 a 44 años & 45 y más años \\
\cline { 2 - 3 } A través de información & 14,5 & 13,3 & 26,1 \\
En el momento de la entrevista & 27,0 & 22,7 & 8,7 \\
Para cumplir, en el trabajo & 58,1 & 60,1 & 52,2 \\
Otros motivos & 0,4 & 3,9 & 13,0 \\
\hline
\end{tabular}




\section{5 - Análisis según raza ${ }^{12}$}

La utilización de la computadora es mucho más intensa entre los blancos. Existe también un diferencial entre los pardos y los negros, a favor de los pardos, pero menor al existente en relación a los blancos.

Cuadro 3.5.1:Frecuencia de utilización de la computadora según raza

\begin{tabular}{|c|c|c|c|}
\hline & Blanco & Negro & Pardo \\
\hline Todos los días & 33,8 & 23,0 & 27,3 \\
\hline Por lo menos una vez por semana & 25,3 & 28,7 & 29,2 \\
\hline Utiliza la computadora ocasionalmente & 16,3 & 11,1 & 11,1 \\
\hline Utiliza la computadora raras veces & 24,7 & 37,3 & 32,5 \\
\hline
\end{tabular}

No existen diferencias importantes entre los grupos de acuerdo a la raza, en relación al aprendizaje, siendo mayoritario el grupo que aprendió en cursos especializados.

Cuadro 3.5.2: Forma en que aprendió a usar la computadora según raza

\begin{tabular}{|c|c|c|c|}
\hline & Blanco & Negro & Pardo \\
\hline Sólo, intentando & 14,8 & 16,6 & 15,3 \\
\hline Sólo, ayudado por manuales & 2,0 & 1,2 & 1,8 \\
\hline Con orientación, en el trabajo & 7,9 & 4,0 & 7,6 \\
\hline Con la ayuda de amigos & 12,0 & 11,3 & 12,8 \\
\hline En cursos especializados & 60,7 & 62,8 & 56,4 \\
\hline De otra forma & 2,6 & 4,0 & 6,1 \\
\hline
\end{tabular}

No existen demasiadas diferencias entre los diferentes tipos de programas utilizados, salvo en relación al uso de Internet, donde los negros aparecen en menor proporción.

\footnotetext{
${ }^{12}$ Todos los cuadros de esta sección muestran porcentajes relativos al propio grupo.
} 
Cuadro 3.5.3: Tipos de programas más utilizados según raza

\begin{tabular}{|c|c|c|c|}
\hline & Blanco & Negro & Pardo \\
\hline Procesadores de texto & 76,8 & 77,6 & 78,3 \\
\hline Planillas electrónicas & 48,8 & 48,2 & 48,2 \\
\hline Programas de presentación gráfica & 32,2 & 27,3 & 30,8 \\
\hline Lenguaje de programación & 6,1 & 2,9 & 5,4 \\
\hline Juegos & 52,9 & 51,4 & 56,2 \\
\hline Otro & 6,7 & 4,1 & 3,7 \\
\hline
\end{tabular}

El gráfico anterior es confirmado por el próximo, que indica que los negros hacen menos uso de Internet que los pardos y los blancos (la diferencia percentual entre los gráficos se debe al hecho de que los entrevistados posiblemente no identifiquen en todos los casos Internet como un "programa" específico).

Cuadro 3.5.4: Utilización de Internet según raza

\begin{tabular}{|c|c|c|c|}
\hline & Blanco & Negro & Pardo \\
\hline Si & 62,4 & 52,0 & 60,9 \\
\hline No & 37,6 & 48,0 & 39,1 \\
\hline
\end{tabular}

Entre los no usuarios de Internet que son usuarios de computadora, las explicaciones presentadas entre los diferentes grupos de raza son bastante similares, siendo factor fundamental la falta de local de conexión.

Cuadro 3.5.5: Motivos para no conectarse a Internet según raza

\begin{tabular}{|c|c|c|c|}
\hline & Blanco & Negro & Pardo \\
\hline No tiene lugar dónde entrar & 66,9 & 66,1 & 58,3 \\
\hline No tiene interés & 10,9 & 6,1 & 14,7 \\
\hline Le parece muy dificil & 8,8 & 13,0 & 6,2 \\
\hline Caro & 4,2 & 5,2 & 10,4 \\
\hline No tiene tiempo & 9,2 & 9,6 & 10,4 \\
\hline
\end{tabular}

La intensidad de uso es bastante similar entre los blancos y los pardos, y es relativamente inferior entre los negros: 
Cuadro 3.5.6: Frecuencia de conexión a Internet según raza

\begin{tabular}{|c|c|c|c|}
\hline & Blanco & Negro & Pardo \\
\hline Más de una vez por día & 14,8 & 11,5 & 14,4 \\
\hline Una vez por día & 14,5 & 10,7 & 15,3 \\
\hline Más de una vez por semana & 27,1 & 23,8 & 23,9 \\
\hline Una vez por semana & 28,1 & 30,3 & 29,4 \\
\hline Una vez por mes & 15,5 & 23,8 & 17,1 \\
\hline
\end{tabular}

En relación al tipo de portal visitado no existen diferencias relevantes entre los diferentes grupos:

Cuadro 3.5.7: Tipos de portales más visitados según raza

\begin{tabular}{lcccc}
\hline & & & \\
\cline { 2 - 2 } Webmail & Blanco & & Negro & Pardo \\
\cline { 2 - 3 } Cybercafés & 39,8 & & 34,4 & 33,7 \\
Sitios de los proveedores & 11,0 & & 9,0 & 14,3 \\
Sitios de búsqueda/ investigación & 56,9 & & 46,7 & 37,7 \\
Sitios de revistas & 73,7 & & 66,4 & 62,3 \\
Sitios de diarios & 31,3 & & 27,0 & 28,6 \\
Utilidad pública & 41,9 & & 32,8 & 38,0 \\
Sitios de empresas & 28,6 & & 33,6 & 29,2 \\
Sitios de música & 24,1 & & 18,9 & 18,5 \\
Sitios de deportes & 51,1 & & 52,5 & 46,5 \\
Sitios infantiles & 36,8 & & 34,4 & 34,7 \\
Otro tipo de sitios (específicos) & 8,0 & & 6,6 & 9,4 \\
& 13,5 & 11,5 & 10,0 \\
\hline
\end{tabular}

Esta tendencia se repite en relación al uso de Internet para realizar cursos:

Cuadro 3.5.8: Predisposición para realizar cursos por Internet entre los Habitantes que utilizan computadora, según raza

\begin{tabular}{|c|c|c|c|}
\hline & Blanco & Negro & Pardo \\
\hline $\mathrm{Si}$ & 34,6 & 38,2 & 37,6 \\
\hline No & 65,4 & 61,8 & 62,4 \\
\hline
\end{tabular}


El uso de Internet para realizar negocios presenta diferencias importantes de acuerdo al grupo, siendo de $29.9 \%$ entre los blancos, de $21.5 \%$ entre los pardos y de $13.7 \%$ entre los negros.

Cuadro 3.5.9: Utilización de Internet para hacer negocios entre los habitantes que utilizan computadora, según raza

\begin{tabular}{|c|c|c|c|}
\hline & Blanco & Negro & Pardo \\
\hline Si & 29,9 & 13,7 & 21,5 \\
\hline No & 70,1 & 86,3 & 78,5 \\
\hline
\end{tabular}

El tipo de negocio realizado tiene características similares entre los grupos:

Cuadro 3.5.10: Tipo de negocio realizado en Internet según raza

\begin{tabular}{|c|c|c|c|}
\hline & Blanco & Negro & Pardo \\
\hline Compra & 39,7 & 50,0 & 37,7 \\
\hline Venta & 10,7 & 5,6 & 17,4 \\
\hline Información de precios & 28,1 & 27,8 & 24,6 \\
\hline Pago de cuentas & 31,4 & 50,0 & 18,8 \\
\hline Operaciones financieras & 33,9 & 22,2 & 14,5 \\
\hline Otros & 9,9 & 5,6 & 14,5 \\
\hline
\end{tabular}

El uso de portales en otros idiomas es más alto entre los blancos, seguido por los pardos y negros. Esto posiblemente sea resultado de las diferencias de nivel educativo y de ingresos (posibilidades de pagar cursos privados):

Cuadro 3.5.11: Visitas a portales de texto en otros idiomas entre los habitantes que utilizan computadora, según raza

\begin{tabular}{|c|c|c|c|}
\hline & Blanco & Negro & Pardo \\
\hline $\mathrm{Si}$ & 19,4 & 12,9 & 17,0 \\
\hline No & 80,6 & 87,1 & 83,0 \\
\hline
\end{tabular}


Como lo muestra el siguiente gráfico, la anterior hipótesis se confirma: mientras que los blancos aprenden idiomas mayoritariamente en cursos, los pardos y negros dependen de la institución de enseñanza.

Cuadro 3.5.12: Local de aprendizaje de idiomas según raza

\begin{tabular}{|c|c|c|c|}
\hline & Blanco & Negro & Pardo \\
\hline Curso & 52,2 & 35,7 & 34,0 \\
\hline Institución de enseñanza & 24,6 & 57,1 & 38,0 \\
\hline Sólo & 8,7 & 7,1 & 16,0 \\
\hline En Internet & 7,2 & - & 4,0 \\
\hline De otra forma & 7,2 & - & 8,0 \\
\hline
\end{tabular}

El interés en tener contacto con barrios de otros países es similar entre los diferentes grupos:

Cuadro 3.5.13: Interés en tener contacto con otros países entre habitantes que utilizan la computadora, según raza

\begin{tabular}{|c|c|c|c|}
\hline & Blanco & Negro & Pardo \\
\hline $\mathrm{Si}$ & 72,3 & 83,9 & 76,9 \\
\hline No & 27,7 & 16,1 & 23,1 \\
\hline
\end{tabular}

Esto es válido para los temas en los cuales hay interés de hacer intercambio:

Cuadro 3.5.14: Tipos de temas más citados, según raza

\begin{tabular}{|c|c|c|c|}
\hline & Blanco & Negro & Pardo \\
\hline Cómo viven, cómo es allá & 14,8 & 19,1 & 16,3 \\
\hline Cultura, actualidades, información & 24,0 & 24,7 & 26,4 \\
\hline Chateo & 2,8 & 0,0 & 1,8 \\
\hline Temas generales & 21,2 & 19,1 & 21,6 \\
\hline Música, juegos, deporte, recreación & 8,0 & 10,1 & 6,2 \\
\hline Investigación, educación, idiomas & 3,2 & 4,5 & 3,1 \\
\hline Religión & 3,6 & 4,5 & 1,3 \\
\hline Política, economía, empleo & 12,4 & 4,5 & 13,2 \\
\hline Turismo, seguridad & 3,2 & 2,2 & 3,5 \\
\hline Sociedad, salud, pobreza & 10,4 & 7,9 & 10,6 \\
\hline Informática, tecnología & 0,8 & 5,6 & 1,8 \\
\hline Otras & 4,0 & 4,5 & 1,8 \\
\hline
\end{tabular}


En relación al uso de e-mail por aquellos que tienen acceso a Internet, todos los grupos presentan un porcentaje similar (cerca del 50\%):

Cuadro 3.5.15: Utilización de e-mail, según raza

\begin{tabular}{|c|c|c|c|}
\hline & Blanco & Negro & Pardo \\
\hline $\mathrm{Si}$ & 49,4 & 48,0 & 49,2 \\
\hline No & 50,6 & 52,0 & 50,8 \\
\hline
\end{tabular}

No existen diferencias significativas en la utilización del e-mail de acuerdo con la raza de los usuarios. Una posible hipótesis es que siendo, el lugar de trabajo, el principal local de conexión de los negros, existe un incentivo al uso del e mail, con lo cual se eliminan parcialmente las diferencias entre este grupo racial y los demás.

Cuadro 3.5.16: Frecuencia con que abre el e-mail, según raza

\begin{tabular}{|c|c|c|c|}
\hline & Blanco & Negro & Pardo \\
\hline Más de una vez por día & 26,5 & 24,6 & 15,9 \\
\hline Una vez por día & 15,8 & 13,1 & 15,9 \\
\hline Más de una vez por semana & 24,0 & 16,4 & 21,3 \\
\hline Una vez por semana & 24,0 & 23,0 & 27,4 \\
\hline Una vez por mes & 6,6 & 13,1 & 12,8 \\
\hline Nunca & 3,1 & 9,8 & 6,7 \\
\hline
\end{tabular}

La importancia de Internet para conocer personas es la misma entre los diferentes grupos raciales:

Cuadro 3.5.17: Conocimiento de personas por al Internet, según raza

\begin{tabular}{|c|c|c|c|}
\hline & Blanco & Negro & Pardo \\
\hline Si & 53,1 & 50,8 & 51,8 \\
\hline No & 46,9 & 49,2 & 48,2 \\
\hline
\end{tabular}


Como es de esperarse, los negros generalmente tienen menores ingresos y conocen más personas de ingresos más altos, disminuyendo este porcentaje entre los pardos y mucho más todavía entre los blancos. Se repite nuevamente la tendencia de un bajo porcentaje de contacto con personas de nivel económico inferior.

Cuadro 3.5.18: Nivel socioeconómico de las personas que conoción por Internet, según raza

\begin{tabular}{|c|c|c|c|}
\hline & Blanco & Negro & Pardo \\
\hline Nivel socioeconómico más elevado que el suyo & 41,5 & 59,1 & 46,1 \\
\hline El mismo nivel socioeconómico & 57,3 & 40,9 & 48,7 \\
\hline Nivel socioeconómico más bajo que el suyo & 1,2 & 0,0 & 5,3 \\
\hline
\end{tabular}

No existen grandes diferencias en relación al tipo de ayuda que es brindada por estos contactos.

Cuadro 3.5.19: De qué forma las personas que Usted conoció por Internet le ayudaron, según raza

\begin{tabular}{|c|c|c|c|}
\hline & Blanco & Nearo & Pardo \\
\hline Recomendación de trabajo & 6,1 & 6,9 & 8,6 \\
\hline No obtiene informaciones, no hay temas que le interesen & 42,4 & 31,0 & 29,6 \\
\hline Estas personas me ayudaron en otras cosas & 6,1 & 10,3 & 8,6 \\
\hline Estas personas no me ayudaron en nada & 45,5 & 51,7 & 53,1 \\
\hline
\end{tabular}

Aunque no exista una diferencia técnica importante en relación a participar en grupos de chateo, es sorprendente el porcentaje más elevado de los negros:

Cuadro 3.5.20: Participación en chateos según raza

\begin{tabular}{|c|c|c|c|}
\hline & Blanco & Negro & Pardo \\
\hline $\mathrm{Si}$ & 39,3 & 43,3 & 36,0 \\
\hline No & 60,7 & 56,7 & 64,0 \\
\hline
\end{tabular}


La importancia del e-mail para el trabajo, en el caso de los negros, confirma en cierta medida la hipótesis anterior sobre el local de trabajo como la principal fuente de conexión para este grupo:

Cuadro 3.5.21: Objetivo de la utilización del e-mail según raza

\begin{tabular}{lccccc}
\hline & & & & \\
\hline \hline & Blanco & & Negro & & Pardo \\
\cline { 2 - 2 } \cline { 5 - 6 } Sólo para trabajar & 8,9 & & 12,1 & & 13,7 \\
Más para trabajar que para divertirse & 14,1 & & 17,2 & & 11,2 \\
Mitad para trabajar, mitad para divertirse & 37,2 & & 25,9 & & 26,7 \\
Más para divertirse que para trabajar & 14,1 & & 17,2 & & 13,7 \\
Sólo para divertirse & 25,7 & & 27,6 & & 34,8 \\
\hline
\end{tabular}

Nuevamente es consensual la importancia de saber computación para obtener un empleo:

Cuadro 3.5.22: Opinión sobre efecto de saber informática en la obtención del empleo, entre los habitantes que utilizan computadora, según raza

\begin{tabular}{|c|c|c|c|}
\hline & Blanco & Negro & Pardo \\
\hline $\mathrm{Si}$ & 98,9 & 98,8 & 98,0 \\
\hline No & 1,1 & 1,2 & 2,0 \\
\hline
\end{tabular}

La percepción de la importancia de saber computación es diferente entre los diferentes grupos:

Cuadro 3.5.23: Forma en que el saber computación ayudó a la obtención del empleo, según raza

\begin{tabular}{|c|c|c|c|}
\hline & Blanco & Negro & Pardo \\
\hline A través de información & 13,6 & 10,8 & 17,2 \\
\hline En el momento de la entrevista & 17,3 & 24,3 & 31,2 \\
\hline Para cumplir, en el trabajo & 66,4 & 62,2 & 48,9 \\
\hline Otros motivos & 2,7 & 2,7 & 2,7 \\
\hline
\end{tabular}




\section{6 - Análisis según nivel de ingreso ${ }^{13}$}

Como era previsible, a medida que el ingreso aumenta, la intensidad del uso de la computadora también aumenta:

Cuadro 3.6.1: Frecuencia de utilización el la computadora por nivel de ingreso (grupos

\begin{tabular}{|c|c|c|c|c|c|c|c|c|}
\hline & \multicolumn{2}{|c|}{ Hasta 240 Reales } & \multicolumn{2}{|c|}{ De 241 a 720 Reales } & \multicolumn{2}{|c|}{ De 721 a 1200 Reales } & \multicolumn{2}{|c|}{ Más de 1200 Reales } \\
\hline & $\begin{array}{c}\text { Ingreso } \\
\text { Familiar } \\
\end{array}$ & $\begin{array}{c}\text { Ingreso } \\
\text { Individual }\end{array}$ & $\begin{array}{c}\text { Ingreso } \\
\text { Familiar } \\
\end{array}$ & $\begin{array}{c}\text { Ingreso } \\
\text { Individual }\end{array}$ & $\begin{array}{c}\text { Ingreso } \\
\text { Familiar }\end{array}$ & $\begin{array}{c}\text { Ingreso } \\
\text { Individual } \\
\end{array}$ & $\begin{array}{c}\text { Ingreso } \\
\text { Familiar }\end{array}$ & $\begin{array}{c}\text { Ingreso } \\
\text { Individual }\end{array}$ \\
\hline Todos los días & 18,0 & 18,8 & 20,8 & 34,2 & 32,1 & 40,0 & 42,9 & 52,6 \\
\hline Por lo menos una vez por semana & 27,9 & 33,6 & 28,5 & 18,8 & 26,3 & 23,3 & 24,1 & 18,4 \\
\hline Utiliza la computadora ocasionalmente & 13,1 & 14,8 & 15,3 & 14,5 & 13,9 & 16,7 & 15,0 & 10,5 \\
\hline Utiliza la computadora en raras ocasiones & 41,0 & 32,7 & 35,4 & 32,5 & 27,7 & 20,0 & 18,0 & 18,4 \\
\hline
\end{tabular}

A medida que el ingreso aumenta, aumenta también la forma de aprendizaje por intento, mientras que la utilización de cursos es mayor en los grupos de menor remuneración. Esto es posible pues para los grupos de mayores ingresos es más alta la probabilidad de tener computadora, por lo tanto, de aprender practicando en el hogar.

Cuadro 3.6.2: Forma en que aprendió a usar la computadora, según nivel de ingreso (grupo)

\begin{tabular}{|c|c|c|c|c|c|c|c|c|}
\hline & \multicolumn{2}{|c|}{ Hasta 240 Reales } & \multicolumn{2}{|c|}{ De 241 a 720 Reales } & \multicolumn{2}{|c|}{ De 721 a 1200 Reales } & \multicolumn{2}{|c|}{ Más de 1200 Reales } \\
\hline & $\begin{array}{c}\text { Ingreso } \\
\text { Familiar } \\
\end{array}$ & $\begin{array}{c}\text { Ingreso } \\
\text { Individual } \\
\end{array}$ & $\begin{array}{c}\text { Ingreso } \\
\text { Familiar } \\
\end{array}$ & $\begin{array}{c}\text { Ingreso } \\
\text { Individual } \\
\end{array}$ & $\begin{array}{c}\text { Ingreso } \\
\text { Familiar } \\
\end{array}$ & $\begin{array}{c}\text { Ingreso } \\
\text { Individual } \\
\end{array}$ & $\begin{array}{c}\text { Ingreso } \\
\text { Familiar } \\
\end{array}$ & $\begin{array}{c}\text { Ingreso } \\
\text { Individual } \\
\end{array}$ \\
\hline Sólo, intentando & 8,2 & 12,9 & 14,5 & 16,1 & 12,3 & 7,9 & 12,9 & 15,4 \\
\hline Sólo, ayudado por manuales & 0,0 & 1,2 & 0,7 & 1,7 & 2,2 & 0,0 & 0,8 & 2,6 \\
\hline Con orientación, en el trabajo & 9,8 & 3,3 & 5,5 & 16,9 & 13,0 & 20,6 & 12,9 & 10,3 \\
\hline Con la ayuda de amigos & 8,2 & 12,4 & 9,7 & 5,9 & 9,4 & 7,9 & 7,6 & 5,1 \\
\hline En cursos especializados & 68,9 & 63,1 & 61,4 & 55,1 & 60,1 & 58,7 & 59,1 & 59,0 \\
\hline De otra forma & 4,9 & 7,0 & 8,3 & 4,2 & 2,9 & 4,8 & 6,8 & 7,7 \\
\hline
\end{tabular}

A medida que pasamos a los grupos de mayores ingresos, hay una tendencia de aumento de la diversificación de los tipos de programas utilizados:

\footnotetext{
${ }^{13}$ Todos los cuadros de esta sección muestran los porcentajes relativos al propio grupo
} 
Cuadro 3.6.3: Tipos de programas más utilizados, según grupo de ingreso

\begin{tabular}{|c|c|c|c|c|c|c|c|c|}
\hline & \multicolumn{2}{|c|}{ Hasta 240 Reales } & \multicolumn{2}{|c|}{ De 241 a 720 Reales } & \multicolumn{2}{|c|}{ De 721 a 1200 Reales } & \multicolumn{2}{|c|}{ Más de 1200 Reales } \\
\hline & $\begin{array}{l}\text { Ingreso } \\
\text { Familiar }\end{array}$ & $\begin{array}{c}\text { Ingreso } \\
\text { Individual }\end{array}$ & $\begin{array}{l}\text { Ingreso } \\
\text { Familiar }\end{array}$ & $\begin{array}{c}\text { Ingreso } \\
\text { Individual }\end{array}$ & $\begin{array}{l}\text { Ingreso } \\
\text { Familiar }\end{array}$ & $\begin{array}{c}\text { Ingreso } \\
\text { Individual }\end{array}$ & $\begin{array}{l}\text { Ingreso } \\
\text { Familiar }\end{array}$ & $\begin{array}{c}\text { Ingreso } \\
\text { Individual } \\
\end{array}$ \\
\hline Procesadores de texto & 83,6 & 80,0 & 78,2 & 81,7 & 81,9 & 83,3 & 79,1 & 79,5 \\
\hline Planillas electrónicas & 52,5 & 47,7 & 57,0 & 64,2 & 55,8 & 61,7 & 62,0 & 61,5 \\
\hline Programas de presentación gráfica & 31,1 & 32,1 & 34,5 & 30,8 & 37,7 & 45,0 & 35,7 & 33,3 \\
\hline Lenguaje de programación & 3,3 & 3,3 & 2,8 & 7,5 & 8,0 & 10,0 & 9,3 & 17,9 \\
\hline Juegos & 62,3 & 66,0 & 62,0 & 58,3 & 54,3 & 53,3 & 59,7 & 46,2 \\
\hline Otro & 3,3 & 3,8 & 3,5 & 5,8 & 5,8 & 8,3 & 7,0 & 10,3 \\
\hline
\end{tabular}

Sólo en los grupos de más altos ingresos encontramos un diferencial de uso (el uso es más elevado también) de Internet.

Cuadro 3.6.4: Utilización de Internet según grupo de ingreso

\begin{tabular}{|c|c|c|c|c|c|c|c|c|}
\hline & \multicolumn{2}{|c|}{ Hasta 240 Reales } & \multicolumn{2}{|c|}{ De 241 a 720 Reales } & \multicolumn{2}{|c|}{ De 721 a 1200 Reales } & \multicolumn{2}{|c|}{ Más de 1200 Reales } \\
\hline & $\begin{array}{l}\text { Ingreso } \\
\text { Familiar }\end{array}$ & $\begin{array}{c}\text { Ingreso } \\
\text { Individual } \\
\end{array}$ & $\begin{array}{c}\text { Ingreso } \\
\text { Familiar } \\
\end{array}$ & $\begin{array}{c}\text { Ingreso } \\
\text { Individual }\end{array}$ & $\begin{array}{c}\text { Ingreso } \\
\text { Familiar } \\
\end{array}$ & $\begin{array}{c}\text { Ingreso } \\
\text { Individual }\end{array}$ & $\begin{array}{c}\text { Ingreso } \\
\text { Familiar } \\
\end{array}$ & $\begin{array}{c}\text { Ingreso } \\
\text { Individual }\end{array}$ \\
\hline $\mathrm{Si}$ & 57,4 & 59,3 & 57,4 & 59,3 & 58,6 & 60,9 & 69,4 & 60,5 \\
\hline No & 42,6 & 40,7 & 42,6 & 40,7 & 41,4 & 39,1 & 30,6 & 39,5 \\
\hline
\end{tabular}

Cuadro 3.6.5: Motivos para no entrar en Internet según grupos de ingreso

\begin{tabular}{|c|c|c|c|c|c|c|c|c|}
\hline & \multicolumn{2}{|c|}{ Hasta 240 Reales } & \multicolumn{2}{|c|}{ De 241 a 720 Reales } & \multicolumn{2}{|c|}{ De 721 a 1200 Reales } & \multicolumn{2}{|c|}{ Más de 1200 Reales } \\
\hline & $\begin{array}{l}\text { Ingreso } \\
\text { Familiar }\end{array}$ & $\begin{array}{c}\text { Ingreso } \\
\text { Individual }\end{array}$ & $\begin{array}{l}\text { Ingreso } \\
\text { Familiar }\end{array}$ & $\begin{array}{c}\text { Ingreso } \\
\text { Individual }\end{array}$ & $\begin{array}{l}\text { Ingreso } \\
\text { Familiar }\end{array}$ & $\begin{array}{c}\text { Ingreso } \\
\text { Individual }\end{array}$ & $\begin{array}{l}\text { Ingreso } \\
\text { Familiar }\end{array}$ & $\begin{array}{c}\text { Ingreso } \\
\text { Individual }\end{array}$ \\
\hline No tiene lugar dónde entrar & 76,0 & 62,7 & 66,1 & 54,3 & 59,6 & 48,0 & 51,2 & 46,7 \\
\hline No tiene interés & 8,0 & 12,4 & 7,1 & 10,9 & 17,5 & 20,0 & 12,2 & 20,0 \\
\hline Le parece muy dificil & 4,0 & 8,9 & 12,5 & 2,2 & 0,0 & 0,0 & 7,3 & 6,7 \\
\hline Caro & 8,0 & 7,7 & 3,6 & 13,0 & 10,5 & 16,0 & 14,6 & 20,0 \\
\hline No tiene tiempo & 4,0 & 8,3 & 10,7 & 19,6 & 12,3 & 16,0 & 14,6 & 6,7 \\
\hline
\end{tabular}


Cuanto mayor el ingreso, mayor la intensidad de uso:

Cuadro 3.6.6: Frecuencia de entrada en Internet según grupo de ingreso

\begin{tabular}{|c|c|c|c|c|c|c|c|c|}
\hline & \multicolumn{2}{|c|}{ Hasta 240 Reales } & \multicolumn{2}{|c|}{ De 241 a 720 Reales } & \multicolumn{2}{|c|}{ De 721 a 1200 Reales } & \multicolumn{2}{|c|}{ Más de 1200 Reales } \\
\hline & $\begin{array}{l}\text { Ingreso } \\
\text { Familiar } \\
\end{array}$ & $\begin{array}{c}\text { Ingreso } \\
\text { Individual } \\
\end{array}$ & $\begin{array}{l}\text { Ingreso } \\
\text { Familiar } \\
\end{array}$ & $\begin{array}{c}\text { Ingreso } \\
\text { Individual } \\
\end{array}$ & $\begin{array}{l}\text { Ingreso } \\
\text { Familiar } \\
\end{array}$ & $\begin{array}{c}\text { Ingreso } \\
\text { Individual } \\
\end{array}$ & $\begin{array}{c}\text { Ingreso } \\
\text { Familiar } \\
\end{array}$ & $\begin{array}{c}\text { Ingreso } \\
\text { Individual }\end{array}$ \\
\hline Más de una vez por día & 5,9 & 5,2 & 6,8 & 15,3 & 14,8 & 20,5 & 24,7 & 34,8 \\
\hline Una vez por día & 23,5 & 11,6 & 12,5 & 18,1 & 11,1 & 25,6 & 25,8 & 26,1 \\
\hline Más de una vez por semana & 17,6 & 25,5 & 21,6 & 13,9 & 23,5 & 15,4 & 15,1 & 13,0 \\
\hline Una vez por semana & 35,3 & 35,9 & 35,2 & 31,9 & 35,8 & 25,6 & 21,5 & 21,7 \\
\hline Una vez por mes & 17,6 & 21,9 & 23,9 & 20,8 & 14,8 & 12,8 & 12,9 & 4,3 \\
\hline
\end{tabular}

No existen diferencias significativas entre los tipos de portales visitados:

Cuadro 3.6.7: Tipos de portales más visitados según grupo de ingreso

\begin{tabular}{|c|c|c|c|c|c|c|c|c|}
\hline & \multicolumn{2}{|c|}{ Hasta 240 Reales } & \multicolumn{2}{|c|}{ De 241 a 720 Reales } & \multicolumn{2}{|c|}{ De 721 a 1200 Reales } & \multicolumn{2}{|c|}{ Más de 1200 Reales } \\
\hline & $\begin{array}{c}\text { Ingreso } \\
\text { Familiar }\end{array}$ & $\begin{array}{c}\text { Ingreso } \\
\text { Individual }\end{array}$ & $\begin{array}{l}\text { Ingreso } \\
\text { Familiar }\end{array}$ & $\begin{array}{c}\text { Ingreso } \\
\text { Individual }\end{array}$ & $\begin{array}{c}\text { Ingreso } \\
\text { Familiar }\end{array}$ & $\begin{array}{c}\text { Ingreso } \\
\text { Individual }\end{array}$ & $\begin{array}{c}\text { Ingreso } \\
\text { Familiar }\end{array}$ & $\begin{array}{c}\text { Ingreso } \\
\text { Individual }\end{array}$ \\
\hline Webmail & 50,0 & 39,3 & 41,6 & 52,8 & 46,9 & 56,4 & 42,4 & 52,2 \\
\hline Cybercafés & 11,8 & 11,1 & 19,1 & 15,3 & 17,3 & 12,8 & 15,2 & 17,4 \\
\hline Sitios de los proveedores & 55,9 & 49,2 & 46,1 & 62,5 & 45,7 & 64,1 & 57,6 & 69,6 \\
\hline Sitios de búsqueda/ investigación & 67,6 & 70,2 & 70,8 & 72,2 & 63,0 & 71,8 & 71,7 & 73,9 \\
\hline Sitios de revistas & 41,2 & 32,1 & 34,8 & 33,3 & 35,8 & 25,6 & 30,4 & 26,1 \\
\hline Sitios de diarios & 44,1 & 29,8 & 38,2 & 61,1 & 45,7 & 43,6 & 44,6 & 52,2 \\
\hline Utilidad pública & 32,4 & 25,4 & 33,7 & 45,8 & 33,3 & 61,5 & 34,8 & 39,1 \\
\hline Sitios de empresas & 14,7 & 10,3 & 19,1 & 33,3 & 25,9 & 35,9 & 23,9 & 26,1 \\
\hline Sitios de música & 47,1 & 56,0 & 55,1 & 50,0 & 51,9 & 56,4 & 53,3 & 26,1 \\
\hline Sitios de deportes & 38,2 & 37,3 & 41,6 & 38,9 & 30,9 & 30,8 & 38,0 & 43,5 \\
\hline Sitios infantiles & 20,6 & 11,5 & 9,0 & 6,9 & 4,9 & 2,6 & 12,0 & 8,7 \\
\hline Otro tipo de sitios (específicos) & 8,8 & 8,7 & 4,5 & 8,3 & 16,0 & 12,8 & 9,8 & 8,7 \\
\hline
\end{tabular}

Con el aumento del ingreso, disminuye la expectativa de hacer cursos por Internet. O sea, cuanto menor es el ingreso, mayor es la expectativa de poder hacer algún curso por interés, pues en este caso no posee recursos para hacer cursos presenciales.

Cuador 3.6.8: Predisposición para la realización de cursos por Internet entre los habitantes que utilizan compudadora, según grupo de ingreso

\begin{tabular}{|c|c|c|c|c|c|c|c|c|}
\hline & \multicolumn{2}{|c|}{ Hasta 240 Reales } & \multicolumn{2}{|c|}{ De 241 a 720 Reales } & \multicolumn{2}{|c|}{ De 721 a 1200 Reales } & \multicolumn{2}{|c|}{ Más de 1200 Reales } \\
\hline & $\begin{array}{c}\text { Ingreso } \\
\text { Familiar }\end{array}$ & $\begin{array}{c}\text { Ingreso } \\
\text { Individual }\end{array}$ & $\begin{array}{l}\text { Ingreso } \\
\text { Familiar }\end{array}$ & $\begin{array}{c}\text { Ingreso } \\
\text { Individual }\end{array}$ & $\begin{array}{l}\text { Ingreso } \\
\text { Familiar }\end{array}$ & $\begin{array}{c}\text { Ingreso } \\
\text { Individual }\end{array}$ & $\begin{array}{c}\text { Ingreso } \\
\text { Familiar } \\
\end{array}$ & $\begin{array}{c}\text { Ingreso } \\
\text { Individual }\end{array}$ \\
\hline $\mathrm{Si}$ & 42,4 & 35,5 & 39,8 & 31,5 & 39,0 & 48,7 & 27,2 & 21,7 \\
\hline No & 57,6 & 64,5 & 60,2 & 68,5 & 61,0 & 51,3 & 72,8 & 78,3 \\
\hline
\end{tabular}


Como se suponía, cuanto mayor es el ingreso, mayor es también la utlización de Internet para hacer negocios:

Cuadro 3.6.9: Utilización de Internet para hacer negocios entre los habitantes que utilizan computadora, según grupo de ingreso

\begin{tabular}{|c|c|c|c|c|c|c|c|c|}
\hline & \multicolumn{2}{|c|}{ Hasta 240 Reales } & \multicolumn{2}{|c|}{ De 241 a 720 Reales } & \multicolumn{2}{|c|}{ De 721 a 1200 Reales } & \multicolumn{2}{|c|}{ Más de 1200 Reales } \\
\hline & $\begin{array}{c}\text { Ingreso } \\
\text { Familiar }\end{array}$ & $\begin{array}{c}\text { Ingreso } \\
\text { Individual }\end{array}$ & $\begin{array}{l}\text { Ingreso } \\
\text { Familiar } \\
\end{array}$ & $\begin{array}{c}\text { Ingreso } \\
\text { Individual }\end{array}$ & $\begin{array}{l}\text { Ingreso } \\
\text { Familiar } \\
\end{array}$ & $\begin{array}{c}\text { Ingreso } \\
\text { Individual }\end{array}$ & $\begin{array}{c}\text { Ingreso } \\
\text { Familiar }\end{array}$ & $\begin{array}{c}\text { Ingreso } \\
\text { Individual } \\
\end{array}$ \\
\hline $\mathrm{Si}$ & 17,6 & 13,5 & 15,9 & 27,4 & 26,8 & 35,9 & 35,9 & 52,2 \\
\hline No & 82,4 & 86,5 & 84,1 & 72,6 & 73,2 & 64,1 & 64,1 & 47,8 \\
\hline
\end{tabular}

De la misma forma, a medida que aumenta el ingreso, es mayor el uso de Internet para hacer operaciones bancarias y compras.

Cuadro 3.6.10: Tipo de negocio realizado en Internet según el grupo de ingreso

\begin{tabular}{|c|c|c|c|c|c|c|c|c|}
\hline & \multicolumn{2}{|c|}{ Hasta 240 Reales } & \multicolumn{2}{|c|}{ De 241 a 720 Reales } & \multicolumn{2}{|c|}{ De 721 a 1200 Reales } & \multicolumn{2}{|c|}{ Más de 1200 Reales } \\
\hline & $\begin{array}{l}\text { Ingreso } \\
\text { Familiar } \\
\end{array}$ & $\begin{array}{c}\text { Ingreso } \\
\text { Individual }\end{array}$ & $\begin{array}{l}\text { Ingreso } \\
\text { Familiar } \\
\end{array}$ & $\begin{array}{c}\text { Ingreso } \\
\text { Individual } \\
\end{array}$ & $\begin{array}{l}\text { Ingreso } \\
\text { Familiar } \\
\end{array}$ & $\begin{array}{c}\text { Ingreso } \\
\text { Individual }\end{array}$ & $\begin{array}{l}\text { Ingreso } \\
\text { Familiar } \\
\end{array}$ & $\begin{array}{c}\text { Ingreso } \\
\text { Individual } \\
\end{array}$ \\
\hline Compra & 33,3 & 35,3 & 7,7 & 10,5 & 27,3 & 35,7 & 43,8 & 53,8 \\
\hline Venta & - & 8,8 & 7,7 & 15,8 & 22,7 & 14,3 & 6,3 & 15,4 \\
\hline Información de precios & 16,7 & 32,4 & 46,2 & 21,1 & 22,7 & 7,1 & 31,3 & 23,1 \\
\hline Pago de cuentas & 33,3 & 29,4 & 46,2 & 15,8 & 13,6 & 57,1 & 34,4 & 38,5 \\
\hline Operaciones financieras & 50 & 17,6 & 23,1 & 42,1 & 27,3 & 42,9 & 53,1 & 38,5 \\
\hline Otros & 33,3 & 14,7 & - & 10,5 & 13,6 & 7,1 & 6,3 & 7,7 \\
\hline
\end{tabular}

Como era previsible, para los grupos de ingreso más alto es mayor la visita de portales en otros idiomas, ya que generalmente el ingreso tiene una fuerte correlación con la escolaridad: 
Cuadro 3.6.11: Visita a portales de texto en otros idiomas entre los habitantes que utilizan computadora según grupo de ingreso

\begin{tabular}{|c|c|c|c|c|c|c|c|c|}
\hline & \multicolumn{2}{|c|}{ Hasta 240 Reales } & \multicolumn{2}{|c|}{ De 241 a 720 Reales } & \multicolumn{2}{|c|}{ De 721 a 1200 Reales } & \multicolumn{2}{|c|}{ Más de 1200 Reales } \\
\hline & $\begin{array}{c}\text { Ingreso } \\
\text { Familiar } \\
\end{array}$ & $\begin{array}{c}\text { Ingreso } \\
\text { Individual }\end{array}$ & $\begin{array}{l}\text { Ingreso } \\
\text { Familiar }\end{array}$ & $\begin{array}{c}\text { Ingreso } \\
\text { Individual }\end{array}$ & $\begin{array}{l}\text { Ingreso } \\
\text { Familiar }\end{array}$ & $\begin{array}{c}\text { Ingreso } \\
\text { Individual }\end{array}$ & $\begin{array}{l}\text { Ingreso } \\
\text { Familiar }\end{array}$ & $\begin{array}{c}\text { Ingreso } \\
\text { Individual }\end{array}$ \\
\hline $\mathrm{Si}$ & 11,8 & 19,8 & 15,9 & 9,6 & 19,5 & 25,6 & 22,8 & 13,0 \\
\hline No & 88,2 & 80,2 & 84,1 & 90,4 & 80,5 & 74,4 & 77,2 & 87,0 \\
\hline
\end{tabular}

Como lo vemos en el próximo gráfico, el aprendizaje de otros idiomas en cursos privados es mayor en los grupos de ingresos más altos (la muestra de familias con ingreso de más de $\mathrm{R} \$ 1.200,00$, no es representativa de este indicador, lo que posiblemente produce un desvío en la tendencia).

Cuadro 3.6.12: Local de aprendizaje de idiomas según grupo de ingreso

\begin{tabular}{|c|c|c|c|c|}
\hline & $\begin{array}{c}\text { Hasta } 240 \\
\text { Reales }\end{array}$ & $\begin{array}{c}\text { De } 241 \text { a } \\
720 \text { Reales }\end{array}$ & $\begin{array}{c}\text { De } 721 \text { a } \\
1200 \text { Reales }\end{array}$ & $\begin{array}{c}\text { Más de } 1200 \\
\text { Reales }\end{array}$ \\
\hline Curso & 25,0 & 33,3 & 46,7 & 47,4 \\
\hline Institución de enseñanza & 75,0 & 33,3 & 26,7 & 31,6 \\
\hline Sólo & - & 16,7 & 13,3 & 10,5 \\
\hline En Internet & - & 8,3 & 6,7 & 5,3 \\
\hline De otra forma & - & 8,3 & 6,7 & 5,3 \\
\hline
\end{tabular}

En los sectores de ingresos más elevados, el uso de e-mail presenta un claro aumento.

Cuadro 3.6.13: Interés en tener contacto con otros países entre los habitantes que utilizan computadora según grupo de ingreso

\begin{tabular}{|c|c|c|c|c|c|c|c|c|}
\hline & \multicolumn{2}{|c|}{ Hasta 240 Reales } & \multicolumn{2}{|c|}{ De 241 a 720 Reales } & \multicolumn{2}{|c|}{ De 721 a 1200 Reales } & \multicolumn{2}{|c|}{ Más de 1200 Reales } \\
\hline & $\begin{array}{c}\text { Ingreso } \\
\text { Familiar }\end{array}$ & $\begin{array}{c}\text { Ingreso } \\
\text { Individual } \\
\end{array}$ & $\begin{array}{l}\text { Ingreso } \\
\text { Familiar }\end{array}$ & $\begin{array}{c}\text { Ingreso } \\
\text { Individual }\end{array}$ & $\begin{array}{l}\text { Ingreso } \\
\text { Familiar }\end{array}$ & $\begin{array}{c}\text { Ingreso } \\
\text { Individual }\end{array}$ & $\begin{array}{c}\text { Ingreso } \\
\text { Familiar }\end{array}$ & $\begin{array}{c}\text { Ingreso } \\
\text { Individual }\end{array}$ \\
\hline $\mathrm{Si}$ & 41,2 & 38,1 & 36,4 & 41,1 & 54,9 & 64,1 & 62,0 & 78,3 \\
\hline No & 58,8 & 61,9 & 63,6 & 58,9 & 45,1 & 35,9 & 38,0 & 21,7 \\
\hline
\end{tabular}


Teniendo en cuenta que el e-mail está asociado al trabajo, consideramos el ingreso individual, ya que la tendencia en la frecuencia de uso del e-mail aumenta junto con el aumento del ingreso individual:

Cuadro 3.6.15: Utilización del e-mail según grupo de ingreso

\begin{tabular}{lccccc}
\hline \hline & & & & \\
\hline & Hasta 240 & De 241 a & & De 721 a & Más de 1200 \\
& Reales & 720 Reales & & 1200 Reales & Reales \\
\cline { 2 - 3 } \cline { 5 - 6 } Más de una vez por día & 20,8 & 30,0 & & 24,0 & 42,1 \\
Una vez por día & 8,3 & 13,3 & & 20,0 & 21,1 \\
Más de una vez por semana & 22,9 & 16,7 & & 12,0 & 10,5 \\
Una vez por semana & 29,2 & 33,3 & & 32,0 & 15,8 \\
Una vez por mes & 12,5 & 6,7 & & 8,0 & 5,3 \\
Nunca & 6,3 & - & & 4,0 & 5,3 \\
\hline
\end{tabular}

Cuanto mayor es el nivel de ingreso, más el uso del e-mail está asociado al trabajo:

Cuadro 3.6.16: Objetivo de la utilización del e-mail según grupo de ingreso

\begin{tabular}{|c|c|c|c|c|c|c|c|c|}
\hline & \multicolumn{2}{|c|}{ Hasta 240 Reales } & \multicolumn{2}{|c|}{ De 241 a 720 Reales } & \multicolumn{2}{|c|}{ De 721 a 1200 Reales } & \multicolumn{2}{|c|}{ Más de 1200 Reales } \\
\hline & $\begin{array}{c}\text { Ingreso } \\
\text { Familiar }\end{array}$ & $\begin{array}{c}\text { Ingreso } \\
\text { Individual } \\
\end{array}$ & $\begin{array}{c}\text { Ingreso } \\
\text { Familiar }\end{array}$ & $\begin{array}{c}\text { Ingreso } \\
\text { Individual }\end{array}$ & $\begin{array}{c}\text { Ingreso } \\
\text { Familiar }\end{array}$ & $\begin{array}{c}\text { Ingreso } \\
\text { Individual } \\
\end{array}$ & $\begin{array}{c}\text { Ingreso } \\
\text { Familiar }\end{array}$ & $\begin{array}{c}\text { Ingreso } \\
\text { Individual }\end{array}$ \\
\hline Sólo para trabajar & 7,1 & 5,3 & 9,4 & 13,3 & 9,1 & 12,0 & 10,9 & 15,8 \\
\hline Más para trabajar que para divertirse & 7,1 & 8,5 & 12,5 & 10,0 & 11,4 & 20,0 & 12,7 & 15,8 \\
\hline Mitad para trabajar, mitad para divertirse & 42,9 & 28,7 & 21,9 & 26,7 & 27,3 & 48,0 & 36,4 & 36,8 \\
\hline Más para divertirse que para trabajar & 7,1 & 13,8 & 12,5 & 23,3 & 27,3 & 12,0 & 14,5 & 10,5 \\
\hline Sólo para divertirse & 35,7 & 43,6 & 43,8 & 26,7 & 25,0 & 8,0 & 25,5 & 21,1 \\
\hline
\end{tabular}

Una vez más es consensual la importancia del conocimiento de informática para la obtención de empleo:

Cuadro 3.6.17: Opinión sobre el efecto del conocimiento de informática para la obtención de empleo entre los habitantes que utilizan computadora, según grupo de ingreso

\begin{tabular}{|c|c|c|c|c|c|c|c|c|}
\hline & \multicolumn{2}{|c|}{ Hasta 240 Reales } & \multicolumn{2}{|c|}{ De 241 a 720 Reales } & \multicolumn{2}{|c|}{ De 721 a 1200 Reales } & \multicolumn{2}{|c|}{ Más de 1200 Reales } \\
\hline & $\begin{array}{c}\text { Ingreso } \\
\text { Familiar } \\
\end{array}$ & $\begin{array}{c}\text { Ingreso } \\
\text { Individual } \\
\end{array}$ & $\begin{array}{c}\text { Ingreso } \\
\text { Familiar } \\
\end{array}$ & $\begin{array}{c}\text { Ingreso } \\
\text { Individual } \\
\end{array}$ & $\begin{array}{c}\text { Ingreso } \\
\text { Familiar } \\
\end{array}$ & $\begin{array}{c}\text { Ingreso } \\
\text { Individual }\end{array}$ & $\begin{array}{c}\text { Ingreso } \\
\text { Familiar } \\
\end{array}$ & $\begin{array}{c}\text { Ingreso } \\
\text { Individual } \\
\end{array}$ \\
\hline $\mathrm{Si}$ & 95,1 & 99,1 & 97,9 & 99,2 & 100,0 & 100,0 & 98,5 & 94,9 \\
\hline No & 4,9 & 0,9 & 2,1 & 0,8 & - & - & 1,5 & 5,1 \\
\hline
\end{tabular}




\section{7 - Análisis según el nivel de instrucción ${ }^{14}$}

En los datos estadísticos que surgen a continuación, fueron tenidos en cuenta los individuos de más de 20 años, como forma de eliminar el factor de edad. Igualmente se unificaron los grupos del ciclo universitario completo e incompleto para obtener un grupo estadísticamente representativo.

Como lo muestra el próximo gráfico, el hecho de que el entrevistado posea secundaria completa o si inclusive cursó un curso universitario, significa una diferencia importante en términos de intensidad de uso de la computadora:

Cuadro3.7.1: Frecuencia de utilización de la computadora según nivel de instrucción

\begin{tabular}{|c|c|c|c|c|c|}
\hline & $\begin{array}{l}\text { Primaria } \\
\text { incompleta }\end{array}$ & $\begin{array}{l}\text { Primaria } \\
\text { completa }\end{array}$ & $\begin{array}{l}\text { Secundaria } \\
\text { incompleta }\end{array}$ & $\begin{array}{l}\text { Secundaria } \\
\text { completa }\end{array}$ & $\begin{array}{c}\text { Universidad } \\
\text { incompleta/ } \\
\text { completa }\end{array}$ \\
\hline Todos los días & 22,3 & 21,6 & 27,9 & 36,5 & 62,1 \\
\hline Por lo menos una vez por semana & 21,2 & 22,2 & 25,9 & 27,2 & 19,0 \\
\hline Utiliza la computadora ocasionalmente & 13,4 & 9,9 & 13,6 & 13,0 & 6,9 \\
\hline Utiliza la computadora raras veces & 43,0 & 46,3 & 32,7 & 23,3 & 12,1 \\
\hline
\end{tabular}

No hay un modelo claro para saber cómo diferentes grupos de ingreso aprendieron a usar la computadora:

Cuadro 3.7.2: Forma en que aprendió a usar la computadora según nivel de instrucción

\begin{tabular}{|c|c|c|c|c|c|}
\hline & $\begin{array}{c}\text { Primaria } \\
\text { incompleta }\end{array}$ & $\begin{array}{l}\text { Primaria } \\
\text { completa }\end{array}$ & $\begin{array}{l}\text { Secundaria } \\
\text { incompleta }\end{array}$ & $\begin{array}{l}\text { Secundaria } \\
\text { completa }\end{array}$ & $\begin{array}{c}\text { Universidad } \\
\text { incompleta/ } \\
\text { completa } \\
\end{array}$ \\
\hline Sólo, intentando & 17,6 & 15,9 & 14,9 & 11,8 & 20,7 \\
\hline Sólo, ayudado por manuales & 2,7 & 1,2 & 1,4 & 2,5 & 1,7 \\
\hline Con orientación, en el trabajo & 14,8 & 7,9 & 9,5 & 10,3 & 10,3 \\
\hline Con la ayuda de amigos & 18,7 & 16,5 & 7,4 & 7,6 & 6,9 \\
\hline En cursos especializados & 41,8 & 55,5 & 62,8 & 64,9 & 58,6 \\
\hline De otra forma & 4,4 & 3,0 & 4,1 & 2,9 & 1,7 \\
\hline
\end{tabular}

\footnotetext{
${ }^{14}$ Todos los cuadros de esta sección muestran porcentajes relativos al propio grupo
} 
A mayor nivel de educación, más amplio y diversificado es el número de programas utilizado:

Cuadro 3.7.3: Tipos de programas más utilizados según nivel de instrucción

\begin{tabular}{|c|c|c|c|c|c|}
\hline & $\begin{array}{c}\text { Primaria } \\
\text { incompleta }\end{array}$ & $\begin{array}{l}\text { Primaria } \\
\text { completa }\end{array}$ & $\begin{array}{l}\text { Secundaria } \\
\text { incompleta }\end{array}$ & $\begin{array}{c}\text { Secundaria } \\
\text { completa }\end{array}$ & $\begin{array}{c}\text { Universidad } \\
\text { incompleta/ } \\
\text { completa }\end{array}$ \\
\hline Procesadores de texto & 58,4 & 75,8 & 81,1 & 84,8 & 91,4 \\
\hline Planillas electrónicas & 41,6 & 48,4 & 43,9 & 61,3 & 74,1 \\
\hline Programas de presentación gráfica & 12,9 & 24,2 & 29,7 & 41,4 & 51,7 \\
\hline Lenguaje de programación & 1,7 & 5,0 & 5,4 & 7,1 & 13,8 \\
\hline Juegos & 49,4 & 47,8 & 48,6 & 44,6 & 36,2 \\
\hline Otro & 9,0 & 7,5 & 8,8 & 4,7 & 10,3 \\
\hline
\end{tabular}

Igualmente, a mayor nivel de educación, mayores son las posibilidades de que el usuario de computadora use Internet, pues los que hicieron cursos superiores están próximos al cien por ciento en relación a este ítem:

Cuadro 3.7.4: Utilización de Internet según nivel de instrucción

\begin{tabular}{|c|c|c|c|c|c|}
\hline & $\begin{array}{c}\text { Primaria } \\
\text { incompleta }\end{array}$ & $\begin{array}{l}\text { Primaria } \\
\text { completa }\end{array}$ & $\begin{array}{l}\text { Secundaria } \\
\text { incompleta }\end{array}$ & $\begin{array}{c}\text { Secundaria } \\
\text { completa }\end{array}$ & $\begin{array}{c}\text { Universidad } \\
\text { incompleta/ } \\
\text { completa }\end{array}$ \\
\hline $\mathrm{Si}$ & 39,1 & 46,6 & 50,7 & 67,8 & 84,2 \\
\hline No & 60,9 & 53,4 & 49,3 & 32,2 & 15,8 \\
\hline
\end{tabular}

La falta de local de cone xión es el principal motivo por el cual algunos grupos no entran en Internet.

Cuadro 3.7.5: Motivos para no entrar en Internet según nivel de instrucción 


\begin{tabular}{|c|c|c|c|c|c|}
\hline & $\begin{array}{l}\text { Primaria } \\
\text { incompleta }\end{array}$ & $\begin{array}{l}\text { Primaria } \\
\text { completa }\end{array}$ & $\begin{array}{l}\text { Secundaria } \\
\text { incompleta }\end{array}$ & $\begin{array}{l}\text { Secundaria } \\
\text { completa }\end{array}$ & $\begin{array}{c}\text { Universidad } \\
\text { incompleta/ } \\
\text { completa }\end{array}$ \\
\hline No tiene lugar dónde entrar & 61,8 & 63,1 & 68,1 & 71,0 & 77,8 \\
\hline No tiene interés & 5,5 & 13,1 & 12,5 & 9,9 & - \\
\hline Le parece muy dificil & 14,5 & 9,5 & 5,6 & 3,8 & - \\
\hline Caro & 4,5 & 7,1 & 9,7 & 6,9 & - \\
\hline No tiene tiempo & 13,6 & 7,1 & 4,2 & 8,4 & 22,2 \\
\hline
\end{tabular}

La frecuencia de conexión a Internet aumenta con el nivel de escolaridad:

Cuadro 3.7.6: Frecuencia de conexión a Internet según nivel de instrucción

\begin{tabular}{|c|c|c|c|c|c|}
\hline & $\begin{array}{c}\text { Primaria } \\
\text { incompleta }\end{array}$ & $\begin{array}{l}\text { Primaria } \\
\text { completa }\end{array}$ & $\begin{array}{l}\text { Secundaria } \\
\text { incompleta }\end{array}$ & $\begin{array}{l}\text { Secundaria } \\
\text { completa }\end{array}$ & $\begin{array}{c}\text { Universidad } \\
\text { incompleta/ } \\
\text { completa }\end{array}$ \\
\hline Más de una vez por día & 16,2 & 5,3 & 12,5 & 18,7 & 33,3 \\
\hline Una vez por día & 11,8 & 15,8 & 12,5 & 11,7 & 25,0 \\
\hline Más de una vez por semana & 17,6 & 19,7 & 27,8 & 27,5 & 25,0 \\
\hline Una vez por semana & 33,8 & 27,6 & 27,8 & 24,5 & 12,5 \\
\hline Una vez por mes & 20,6 & 31,6 & 19,4 & 17,6 & 4,2 \\
\hline
\end{tabular}

Con el aumento del nivel de escolaridad, los portales de búsqueda de "utilidad pública" y “empresas", tienden a ser más visitados. Para los otros portales no hay tendencias significativas. 
Cuadro 3.7.7: Tipos de portales más visitados según nivel de instrucción

\begin{tabular}{|c|c|c|c|c|c|}
\hline & $\begin{array}{l}\text { Primaria } \\
\text { incompleta }\end{array}$ & $\begin{array}{l}\text { Primaria } \\
\text { completa }\end{array}$ & $\begin{array}{l}\text { Secundaria } \\
\text { incompleta }\end{array}$ & $\begin{array}{l}\text { Secundaria } \\
\text { completa }\end{array}$ & $\begin{array}{c}\text { Universidad } \\
\text { incompleta/ } \\
\text { completa }\end{array}$ \\
\hline Webmail & 34,3 & 23,7 & 36,0 & 37,3 & 57,4 \\
\hline Cybercafés & 13,4 & 17,1 & 17,3 & 14,0 & 14,9 \\
\hline Sitios de los proveedores & 46,3 & 47,4 & 53,3 & 46,5 & 68,1 \\
\hline Sitios de búsqueda/investigación & 55,2 & 63,2 & 70,7 & 69,7 & 78,7 \\
\hline Sitios de revistas & 29,9 & 38,2 & 37,3 & 31,7 & 25,5 \\
\hline Sitios de diarios & 38,8 & 48,7 & 50,7 & 49,1 & 44,7 \\
\hline Utilidad pública & 22,4 & 25,0 & 32,0 & 44,3 & 59,6 \\
\hline Sitios de empresas & 23,9 & 21,1 & 24,0 & 30,3 & 44,7 \\
\hline Sitios de música & 44,8 & 57,9 & 48,0 & 42,4 & 29,8 \\
\hline Sitios de deportes & 23,9 & 39,5 & 40,0 & 32,8 & 36,2 \\
\hline Sitios infantiles & 4,5 & 13,2 & 5,3 & 7,4 & 8,5 \\
\hline Otro tipo de sitios (específicos) & 10,4 & 11,8 & 16,0 & 10,3 & 17,0 \\
\hline
\end{tabular}

De la misma forma, no hay diferencias significativas en la referido a la utilización de Internet para la realización de cursos.

Cuadro 3.7.8: Predisposición para la realización de arsos por Internet entre los habitantes que utilizan computadora, según nivel de instrucción

\begin{tabular}{|c|c|c|c|c|c|}
\hline & $\begin{array}{c}\text { Primaria } \\
\text { incompleta }\end{array}$ & $\begin{array}{l}\text { Primaria } \\
\text { completa }\end{array}$ & $\begin{array}{l}\text { Secundaria } \\
\text { incompleta }\end{array}$ & $\begin{array}{l}\text { Secundaria } \\
\text { completa }\end{array}$ & $\begin{array}{c}\text { Universidad } \\
\text { incompleta/ } \\
\text { completa } \\
\end{array}$ \\
\hline $\mathrm{Si}$ & 39,7 & 35,5 & 45,2 & 32,4 & 39,6 \\
\hline No & 60,3 & 64,5 & 54,8 & 67,6 & 60,4 \\
\hline
\end{tabular}

La utilización de Internet para realizar negocios aumenta significativamente en relación directa al aumento del nivel de escolaridad:

Cuadro 3.7.9: Utilización de Internet para hacer negocios entre los habitantes que utilizan computadora, según nivel de instrucción

\begin{tabular}{|c|c|c|c|c|c|}
\hline & $\begin{array}{l}\text { Primaria } \\
\text { incompleta }\end{array}$ & $\begin{array}{l}\text { Primaria } \\
\text { completa }\end{array}$ & $\begin{array}{l}\text { Secundaria } \\
\text { incompleta }\end{array}$ & $\begin{array}{l}\text { Secundaria } \\
\text { completa }\end{array}$ & $\begin{array}{c}\text { Universidad } \\
\text { incompleta/ } \\
\text { completa }\end{array}$ \\
\hline $\mathrm{Si}$ & 22,4 & 29,3 & 35,1 & 33,7 & 47,9 \\
\hline No & 77,6 & 70,7 & 64,9 & 66,3 & 52,1 \\
\hline
\end{tabular}


La principal diferencia en la utilización comercial de Internet se refiere a las operaciones bancarias, que aumentan significativamente en los niveles más altos de escolaridad.

Cuadro 3.7.10: Tipo de negocio realizado en Internet según el nivel de instrucción

\begin{tabular}{|c|c|c|c|c|c|}
\hline & $\begin{array}{l}\text { Primaria } \\
\text { incompleta }\end{array}$ & $\begin{array}{l}\text { Primaria } \\
\text { completa }\end{array}$ & $\begin{array}{l}\text { Secundaria } \\
\text { incompleta }\end{array}$ & $\begin{array}{l}\text { Secundaria } \\
\text { completa }\end{array}$ & $\begin{array}{c}\text { Universidad } \\
\text { incompleta/ } \\
\text { completa }\end{array}$ \\
\hline Compra & 46,7 & 30,4 & 26,9 & 47,3 & 50,0 \\
\hline Venta & 13,3 & 17,4 & 15,4 & 8,6 & 12,5 \\
\hline Información de precios & 20,0 & 30,4 & 46,2 & 25,8 & 16,7 \\
\hline Pago de cuentas & 33,3 & 34,8 & 30,8 & 28,0 & 29,2 \\
\hline Operaciones financieras & 13,3 & 26,1 & 38,5 & 20,4 & 62,5 \\
\hline Otros & 20,0 & 13,0 & 3,8 & 7,5 & 12,5 \\
\hline
\end{tabular}

La utilización de portales en otros idiomas, muestra cambios bastante significativos en los niveles más altos de escolaridad:

Cuadro 3.7.11: Visita a portales de texto en otros idiomas entre los habitantes que utilizan Computadora, según nivel de instrucción

\begin{tabular}{|c|c|c|c|c|c|}
\hline & $\begin{array}{l}\text { Primaria } \\
\text { incompleta }\end{array}$ & $\begin{array}{l}\text { Primaria } \\
\text { completa }\end{array}$ & $\begin{array}{l}\text { Secundaria } \\
\text { incompleta }\end{array}$ & $\begin{array}{l}\text { Secundaria } \\
\text { completa }\end{array}$ & $\begin{array}{c}\text { Universidad } \\
\text { incompleta/ } \\
\text { completa }\end{array}$ \\
\hline $\mathrm{Si}$ & 8,8 & 8,0 & 10,8 & 17,6 & 37,5 \\
\hline
\end{tabular}

El interés en tener contacto con otros barrios es bastante parecido entre los diferentes niveles de escolaridad:

Cuadro 3.7.12: Interés en tener contacto con otros países entre los habitantes que utilizan computadora, según nivel de instrucción

\begin{tabular}{|c|c|c|c|c|c|}
\hline & $\begin{array}{l}\text { Primaria } \\
\text { incompleta }\end{array}$ & $\begin{array}{l}\text { Primaria } \\
\text { completa }\end{array}$ & $\begin{array}{l}\text { Secundaria } \\
\text { incompleta }\end{array}$ & $\begin{array}{l}\text { Secundaria } \\
\text { completa }\end{array}$ & $\begin{array}{c}\text { Universidad } \\
\text { incompleta/ } \\
\text { completa }\end{array}$ \\
\hline Si & 65,7 & 71,2 & 69,9 & 73,2 & 81,3 \\
\hline No & 34,3 & 28,8 & 30,1 & 26,8 & 18,8 \\
\hline
\end{tabular}


Los temas de interés no presentan una clara definición de tendencia:

Cuadro 3.7.13: Tipos de temas más citados según nivel de instrucción

\begin{tabular}{|c|c|c|c|c|c|}
\hline & $\begin{array}{c}\text { Primaria } \\
\text { incompleta }\end{array}$ & $\begin{array}{l}\text { Primaria } \\
\text { completa }\end{array}$ & $\begin{array}{l}\text { Secundaria } \\
\text { incompleta }\end{array}$ & $\begin{array}{c}\text { Secundaria } \\
\text { completa }\end{array}$ & $\begin{array}{c}\text { Universidad } \\
\text { incompleta/ } \\
\text { completa }\end{array}$ \\
\hline Cómo viven, cómo es allá & 13,9 & 15,7 & 12,8 & 10,5 & 5,3 \\
\hline Cultura, actualidades, información & 27,8 & 11,8 & 29,8 & 27,4 & 34,2 \\
\hline Chateo & - & 3,9 & - & 2,1 & 2,6 \\
\hline Temas generales & 25,0 & 17,6 & 12,8 & 21,6 & 13,2 \\
\hline Música, juegos, deporte, recreación & 8,3 & 2,0 & 2,1 & 3,7 & 2,6 \\
\hline Investigación, educación, idiomas & 5,6 & 2,0 & 4,3 & 3,2 & 5,3 \\
\hline Religión & 2,8 & 2,0 & 4,3 & 3,2 & 5,3 \\
\hline Política, economía, empleo & 8,3 & 15,7 & 19,1 & 13,2 & 5,3 \\
\hline Turismo, seguridad & 5,6 & 3,9 & 2,1 & 2,1 & 2,6 \\
\hline Sociedad, salud, pobreza & - & 15,7 & $\overrightarrow{6}, 4$ & 8,9 & 13,2 \\
\hline Informática, tecnología & - & 5,9 & 6,4 & 0,5 & 7,9 \\
\hline Otras & 2,8 & 3,9 & - & 3,7 & 2,6 \\
\hline
\end{tabular}

El uso de e-mail aumenta con el aumento del nivel de escolaridad:

Cuadro 3.7.14: Utilización de e-mail según nivel de instrucción

\begin{tabular}{|c|c|c|c|c|c|}
\hline & $\begin{array}{l}\text { Primaria } \\
\text { incompleta }\end{array}$ & $\begin{array}{l}\text { Primaria } \\
\text { completa }\end{array}$ & $\begin{array}{l}\text { Secundaria } \\
\text { incompleta }\end{array}$ & $\begin{array}{c}\text { Secundaria } \\
\text { completa }\end{array}$ & $\begin{array}{c}\text { Universidad } \\
\text { incompleta/ } \\
\text { completa }\end{array}$ \\
\hline $\mathrm{Si}$ & 38,2 & 47,4 & 48,6 & 58,7 & $\begin{array}{l}81,3 \\
188\end{array}$ \\
\hline No & 61,8 & 52,6 & 51,4 & 41,3 & 18,8 \\
\hline
\end{tabular}

Por otro lado, la intensidad para entrar en el e-mail no tiene un modelo definido: 
Cuadro 3.7.15: Frecuencia con que entra en el e-mail según nivel de instrucción

\begin{tabular}{|c|c|c|c|c|c|}
\hline & $\begin{array}{l}\text { Primaria } \\
\text { incompleta }\end{array}$ & $\begin{array}{l}\text { Primaria } \\
\text { completa }\end{array}$ & $\begin{array}{l}\text { Secundaria } \\
\text { incompleta }\end{array}$ & $\begin{array}{c}\text { Secundaria } \\
\text { completa }\end{array}$ & $\begin{array}{c}\text { Universidad } \\
\text { incompleta/ } \\
\text { completa }\end{array}$ \\
\hline Más de una vez por día & 26,9 & 16,2 & 34,3 & 18,6 & 27,5 \\
\hline Una vez por día & 23,1 & 18,9 & 14,3 & 15,5 & 25,0 \\
\hline Más de una vez por semana & 15,4 & 16,2 & 20 & 24,2 & 20,0 \\
\hline Una vez por semana & 23,1 & 21,6 & 17,1 & 25,5 & 17,5 \\
\hline Una vez por mes & 7,7 & 16,2 & 8,6 & 9,9 & 5,0 \\
\hline Nunca & 3,8 & 10,8 & 5,7 & 6,2 & 5,0 \\
\hline
\end{tabular}

Esto también es válido para el uso de Internet con la intención de conocer personas:

Cuadro 3.7.16: Conocimiento de personas por Internet según nivel de instrucción

\begin{tabular}{|c|c|c|c|c|c|}
\hline & $\begin{array}{l}\text { Primaria } \\
\text { incompleta }\end{array}$ & $\begin{array}{l}\text { Primaria } \\
\text { completa }\end{array}$ & $\begin{array}{l}\text { Secundaria } \\
\text { incompleta }\end{array}$ & $\begin{array}{l}\text { Secundaria } \\
\text { completa }\end{array}$ & $\begin{array}{c}\text { Universidad } \\
\text { incompleta/ } \\
\text { completa }\end{array}$ \\
\hline $\begin{array}{l}\text { Si } \\
\text { No }\end{array}$ & $\begin{array}{l}30,8 \\
69,2\end{array}$ & $\begin{array}{l}43,2 \\
56,8 \\
\end{array}$ & $\begin{array}{l}48,6 \\
51,4\end{array}$ & $\begin{array}{l}48,4 \\
51,6 \\
\end{array}$ & $\begin{array}{l}32,5 \\
67,5 \\
\end{array}$ \\
\hline
\end{tabular}

O para el nivel socioeconómico y la utilidad del contacto:

Cuadro 3.7.17: Nivel socioeconómico de las personas que conoció por Internet y nivel de instrucción

\begin{tabular}{|c|c|c|c|c|c|}
\hline & $\begin{array}{l}\text { Primaria } \\
\text { incompleta }\end{array}$ & $\begin{array}{l}\text { Primaria } \\
\text { completa }\end{array}$ & $\begin{array}{l}\text { Secundaria } \\
\text { incompleta }\end{array}$ & $\begin{array}{l}\text { Secundaria } \\
\text { completa }\end{array}$ & $\begin{array}{c}\text { Universidad } \\
\text { incompleta/ } \\
\text { completa }\end{array}$ \\
\hline Nivel socioeconómico más elevado que el suyo & 33,3 & 60,0 & 50,0 & 49,3 & 40,0 \\
\hline El mismo nivel socioeconómico & 66,7 & 30,0 & 42,9 & 49,3 & 50,0 \\
\hline Nivel socioeconómico más bajo que el suyo & - & 10,0 & 7,1 & 1,4 & 10,0 \\
\hline
\end{tabular}


Cuadro 3.7.18: De qué forma las personas que Ud. conoce por Internet lo ayudaron, según nivel de instrucción

\begin{tabular}{|c|c|c|c|c|c|}
\hline & $\begin{array}{c}\text { Primaria } \\
\text { incompleta }\end{array}$ & $\begin{array}{l}\text { Primaria } \\
\text { completa }\end{array}$ & $\begin{array}{l}\text { Secundaria } \\
\text { incompleta }\end{array}$ & $\begin{array}{c}\text { Secundaria } \\
\text { completa }\end{array}$ & $\begin{array}{c}\text { Universidad } \\
\text { incompleta/ } \\
\text { completa }\end{array}$ \\
\hline Recomendación para trabajo & 12,5 & - & 13,3 & 8,2 & 18,2 \\
\hline No obtiene informaciones, no hay temas que le interesen & 37,5 & 43,8 & 40,0 & 42,5 & 36,4 \\
\hline Estas personas me ayudaron en otras cosas & - & 12,5 & 20,0 & 5,5 & 18,2 \\
\hline Estas personas no me ayudaron en nada & 50,0 & 43,8 & 43,8 & 43,8 & 27,3 \\
\hline
\end{tabular}

En lo que se refiere a participación en grupos de chateos, las personas de nivel de instrucción superior participan menos:

Cuadro 3.7.19: Participación en chateos según nivel de instrucción

\begin{tabular}{|c|c|c|c|c|c|}
\hline & $\begin{array}{l}\text { Primaria } \\
\text { incompleta }\end{array}$ & $\begin{array}{l}\text { Primaria } \\
\text { completa }\end{array}$ & $\begin{array}{l}\text { Secundaria } \\
\text { incompleta }\end{array}$ & $\begin{array}{l}\text { Secundaria } \\
\text { completa }\end{array}$ & $\begin{array}{c}\text { Universidad } \\
\text { incompleta/ } \\
\text { completa }\end{array}$ \\
\hline $\begin{array}{l}\mathrm{Si} \\
\text { No }\end{array}$ & $\begin{array}{l}34,6 \\
65,4\end{array}$ & $\begin{array}{l}32,4 \\
67,6\end{array}$ & $\begin{array}{l}34,3 \\
65,7\end{array}$ & $\begin{array}{l}31,1 \\
68,9\end{array}$ & $\begin{array}{l}22,5 \\
77,5\end{array}$ \\
\hline
\end{tabular}

A mayor nivel de escolaridad aumenta la utilización de e-mail para el trabajo, pero lo sigue inmediatamente el nivel del escolaridad más bajo. En este último caso vemos que el contacto con Internet y con el e-mail se dan en función del trabajo. Por otro lado, el gráfico indica una clara tendencia decreciente entre el nivel de escolaridad y el uso del e-mail para la recreación (entre los que lo usan sólo para la recreación, la mayoría tiene bajo nivel de escolaridad): 
Cuadro 3.7.20: Objetivo de la utilización de email según nível de instrucción

\begin{tabular}{|c|c|c|c|c|c|}
\hline & $\begin{array}{c}\text { Primaria } \\
\text { incompleta }\end{array}$ & $\begin{array}{l}\text { Primaria } \\
\text { completa }\end{array}$ & $\begin{array}{l}\text { Secundaria } \\
\text { incompleta }\end{array}$ & $\begin{array}{c}\text { Secundaria } \\
\text { completa }\end{array}$ & $\begin{array}{c}\text { Universidad } \\
\text { incompleta/ } \\
\text { completa }\end{array}$ \\
\hline Sólo para trabajar & 16,0 & 11,4 & 12,1 & 12,8 & 23,1 \\
\hline Más para trabajar que para divertirse & 20,0 & 14,3 & 6,1 & 17,9 & 23,1 \\
\hline Mitad para trabajar, mitad para divertirse & 16,0 & 34,3 & 24,2 & 37,8 & 43,6 \\
\hline Más para divertirse que para trabajar & 12,0 & 8,6 & 30,3 & 16,7 & 2,6 \\
\hline Sólo para divertirse & 36,0 & 31,4 & 27,3 & 14,7 & 7,7 \\
\hline
\end{tabular}

Nuevamente es consensual la importancia del conocimiento de computación para la obtención de empleo:

Cuadro 3.7.21: Opinión sobre el efecto del conocimiento de informática en la obtención de empleo entre los habitantes que utilizan computadora, según nivel de instrucción

\begin{tabular}{|c|c|c|c|c|c|}
\hline & $\begin{array}{c}\text { Primaria } \\
\text { incompleta }\end{array}$ & $\begin{array}{l}\text { Primaria } \\
\text { completa }\end{array}$ & $\begin{array}{l}\text { Secundaria } \\
\text { incompleta }\end{array}$ & $\begin{array}{l}\text { Secundaria } \\
\text { completa }\end{array}$ & $\begin{array}{c}\text { Universidac } \\
\text { incompleta } \\
\text { completa }\end{array}$ \\
\hline $\mathrm{Si}$ & 98,9 & $\begin{array}{c}97,5 \\
2,5\end{array}$ & 100,0 & 99,0 & $\begin{array}{c}98,2 \\
18\end{array}$ \\
\hline
\end{tabular}

En los niveles más altos de escolaridad, es normal el uso de computadora, pero también representa una exigencia para más de la mitad dentro de los otros niveles de escolaridad:

Cuadro 3.7.22: Forma en que el conocimiento de computación ayudó a la obtención del empleo, según nivel de instrucción

\begin{tabular}{|c|c|c|c|c|c|}
\hline & $\begin{array}{c}\text { Primaria } \\
\text { incompleta }\end{array}$ & $\begin{array}{l}\text { Primaria } \\
\text { completa }\end{array}$ & $\begin{array}{l}\text { Secundaria } \\
\text { incompleta }\end{array}$ & $\begin{array}{l}\text { Secundaria } \\
\text { completa }\end{array}$ & $\begin{array}{c}\text { Universidad } \\
\text { incompleta/ } \\
\text { completa } \\
\end{array}$ \\
\hline A través de información & 9,1 & 18,6 & 20,4 & 13,4 & 2,9 \\
\hline En el momento de la entrevista & 29,5 & 20,9 & 20,4 & 23,9 & 20,6 \\
\hline Para cumplir, en el trabajo & 56,8 & 53,5 & 57,4 & 60,2 & 73,5 \\
\hline Otros motivos & 4,5 & 7,0 & 1,9 & 2,5 & 2,9 \\
\hline
\end{tabular}


Entre los entrevistados de menos de 20 años de edad, 50\% de los que frecuentan instituciones privadas usan computadora diariamente. Este número se reduce a la mitad, cuando se trata de los que frecuentan instituciones públicas. Por otro lado, entre los que usan la computadora de vez en cuando, $8.3 \%$ frecuentan instituciones de enseñanza privadas y $25.1 \%$ instituciones de enseñanza públicas:

\section{8 - Análisis según tipo de institución de enseñanza}

El análisis a continuación, tiene como parámetros, el tipo de institución educativa (pública o privada) y tomamos como referencia solamente el público entrevistado con hasta 20 años de edad.

Cuadro 3.8.1: Frecuencia de utilización de computadora, según tipo de institución de enseñanza

\begin{tabular}{lccc}
\hline & & \\
\cline { 2 - 2 } Todos los días & Pública & Privada \\
\cline { 2 - 3 } Por lo menos una vez por semana & 24,1 & 50,0 \\
Utiliza la computadora ocasionalmente & 34,2 & 30,6 \\
Utiliza la computadora raras veces & 16,6 & 11,1 \\
\hline
\end{tabular}

Como vemos, existe correlación entre el tipo de institución de enseñanza a la que se asiste, la remuneración y la tenencia de computadora en casa.

Cuadro 3.8.2: Nivel de ingreso según tipo de institución de enseñanza

\begin{tabular}{lccc}
\hline & & \\
\cline { 2 - 2 } Hasta 240 Reales & Pública & & Privada \\
\cline { 2 - 2 } De 241 a 720 Reales & 15,0 & 5,9 \\
De 721 a 1.200 Reales & 39,4 & & 23,5 \\
Más de 1.200 Reales & 30,7 & & 17,6 \\
\hline
\end{tabular}


Cuadro 3.8.3: Posesión de computadora según tipo de institución de enseñanza

\begin{tabular}{|c|c|c|}
\hline & Pública & Privada \\
\hline Tener computadora en el hogar & 25,8 & 60,0 \\
\hline No tener computadora en el hogar & 74,2 & 40,0 \\
\hline
\end{tabular}

No hay grandes diferencias en relación a los caminos seguidos para aprender computación, aunque entre los que van a la institución de enseñanza pública la realización de cursos especializados muestra el menor porcentaje de individuos con computadora en casa:

Cuadro 3.8.4: Forma en que aprendió a usar la computadora, según tipo de institución de enseñanza

\begin{tabular}{|c|c|c|}
\hline & Pública & Privada \\
\hline Sólo, intentando & 16,6 & 19,4 \\
\hline Sólo, con la ayuda de manuales & 1,0 & 2,8 \\
\hline Con orientación, en el trabajo & 0,5 & - \\
\hline Con la ayuda de amigos & 12,4 & 16,7 \\
\hline En cursos especializados & 64,5 & 52,8 \\
\hline De otra forma & 5,0 & 8,3 \\
\hline
\end{tabular}

Los que frecuentan la institución de enseñanza privada presentan mayor diversidad e intensidad en el uso de programas de computación:

Cuadro 3.8.5: Tipos de programas más utilizados según tipo de institución de enseñanza

\begin{tabular}{lccc}
\hline & & \\
\cline { 2 - 2 } & & Pública & Privada \\
\cline { 2 - 2 } Procesadores de texto & 76,7 & 97,2 \\
Planillas electrónicas & 40,4 & 58,3 \\
Programas de presentación gráfica & 28,0 & 50,0 \\
Lenguaje de programación & 2,7 & 13,9 \\
Juegos & 68,0 & 72,2 \\
Otros & 2,7 & 2,8 \\
\hline
\end{tabular}

La diferencia entre los que usan Internet es muy grande, favorable a los que cursan en instituciones de enseñanza privadas: 
Cuadro 3.8.6: Utilización de Internet según tipo de institución de enseñanza

\begin{tabular}{|c|c|c|}
\hline & Pública & Privada \\
\hline Si & 65,3 & 91,7 \\
\hline No & 34,7 & 8,3 \\
\hline
\end{tabular}

El próximo gráfico muestra muy poco en relación a los usuarios de Internet de las instituciones de enseñanza privadas, pues representa un universo muy pequeño. Entre los alumnos de las instituciones de enseñanza públicas, la falta de lugar para conectarse, es considerado el principal motivo:

Cuadro 3.8.7: Motivos para no conectarse a Internet según tipo de institución de enseñanza

\begin{tabular}{lcc}
\hline & & \\
\cline { 2 - 2 } No posee local donde pueda entrar & Pública & Privada \\
\cline { 2 - 2 } No tiene interés & 59,4 & 33,3 \\
Le parece muy dificil & 13,0 & - \\
Caro & 10,1 & - \\
No tiene tiempo & 7,2 & 33,3 \\
Nota: El universo de alumnos de instituciones de ensenanza privadas que no entrarn en Internet es muy
\end{tabular}

pequeño.

La frecuencia de los que usan Internet es más intensa entre los alumnos de instituciones de enseñanza privadas:

Cuadro 38.8: Frecuencia de entrada en Internet según tipo de institución de enseñanza

\begin{tabular}{|c|c|c|}
\hline & Pública & Privada \\
\hline Más de una vez por día & 8,8 & 6,1 \\
\hline Una vez por día & 15,0 & 24,2 \\
\hline Más de una vez por semana & 25,0 & 33,3 \\
\hline Una vez por semana & 36,9 & 30,3 \\
\hline Una vez por mes & 14,2 & 6,1 \\
\hline
\end{tabular}


Los portales de búsqueda e informaciones son los más utilizados por los alumnos de las instituciones de enseñanza privadas:

Cuadro 3.8.9: Tipos de portales más visitados según tipo de institución de enseñanza

\begin{tabular}{lccc}
\hline & & \\
\cline { 2 - 2 } Webmail & Pública & Privada \\
\cline { 2 - 2 } Cybercafés & 39,3 & 33,3 \\
Sitios de proveedor & 7,6 & & 12,1 \\
Sitios de búsqueda / investigación & 49,2 & & 48,5 \\
Sitios de revista & 70,6 & & 81,8 \\
Sitios de diarios & 25,6 & 33,3 \\
Utilidades públicas & 24,4 & 36,4 \\
Sitios de empresas & 14,5 & 12,1 \\
Sitios de música & 6,1 & 15,2 \\
Sitios de deportes & 60,3 & 57,6 \\
Sitios infantiles & 41,2 & 24,2 \\
Otros tipos de sitios (específicos) & 9,5 & 12,1 \\
& 11,8 & 3,0 \\
\hline
\end{tabular}

Los alumnos de instituciones de enseñanza públicas tienen una expectativa mayor de hacer cursos por Internet:

Cuadro 3.8.10: Predisposición para la realización de cursos por Internet entre Los habitantes que utilizan computadora, según tipo de institución de enseñanza

\begin{tabular}{|c|c|c|}
\hline & Pública & Privada \\
\hline $\mathrm{Si}$ & 39,2 & 27,3 \\
\hline No & 60,8 & 72,7 \\
\hline
\end{tabular}

Dado que los alumnos de las instituciones de enseñanza privadas son los que tienen mayor remuneración, se espera que un mayor porcentaje de éstos indiquen que hicieron algún negocio por Internet:

Cuadro 3.8.11: Utilización de Internet para hacer negocios, entre los habitantes qe utilizan computadora, según tipo de institución de enseñanza

\begin{tabular}{|c|c|c|}
\hline & Pública & Privada \\
\hline $\mathrm{Si}$ & 7,7 & 18,2 \\
\hline No & 92,3 & 81,8 \\
\hline
\end{tabular}

Los alumnos de instituciones de enseñanza privadas usan más los instrumentos de negocios por Internet: 
Cuadro 3.8.12: Tipo de negocio realizado en Internet, según el tipo de institución de enseñanza

\begin{tabular}{lccc}
\hline & & \\
\cline { 2 - 2 } Compra & Pública & & Privada \\
\cline { 2 - 2 } Venta & 25,0 & & 33,3 \\
Información de precios & 20,0 & & 16,7 \\
Pago de cuentas & 20,0 & & 50,0 \\
Operaciones financieras & 35,0 & & - \\
Otros & 15,0 & & 16,7 \\
\hline
\end{tabular}

El doble de alumnos de instituciones de enseñanza privadas, en relación a los de las instituciones de enseñanza públicas, visitan portales en otros idiomas:

Cuadro 3.8.13: Visita a portales de texto en otros idiomas, entre los habitantes que utilizan computadora, según tipo de institución de enseñanza

\begin{tabular}{|c|c|c|}
\hline & Pública & Privada \\
\hline Si & 19,2 & 39,4 \\
\hline No & 80,8 & 60,6 \\
\hline
\end{tabular}

Es mayor el porcentaje de alumnos de instituciones de enseñanza privadas que van a cursos especializados, lo que probablemente es reflejo de la mayor capacidad adquisitiva de este grupo:

Cuadro 3.8.14: Local de aprendizaje de idiomas según tipo de institución de enseñanza

\begin{tabular}{|c|c|c|}
\hline & Pública & Privada \\
\hline Curso & 32,5 & 46,2 \\
\hline Institución Escolar & 55,0 & 46,2 \\
\hline Sólo & 7,5 & - \\
\hline En Internet & 2,5 & - \\
\hline De otra forma & 2,5 & 7,7 \\
\hline
\end{tabular}

Es grande la diferencia entre los que cursan instituciones de enseñanza privadas y públicas, en relación al uso del e-mail: 
Cuadro 3.8.15: Utilización del e-mail según tipo de institución de enseñanza

\begin{tabular}{|c|c|c|}
\hline & Pública & Privada \\
\hline $\mathrm{Si}$ & 36,6 & 60,6 \\
\hline No & 63,4 & 39,4 \\
\hline
\end{tabular}

Sin embargo, la intensidad es similar:

Cuadro 3.8.16: Frecuencia con que entra en el e-mail según tipo de institución de enseñanza

\begin{tabular}{|c|c|c|}
\hline & Pública & Privada \\
\hline Una vez por día & 22,9 & 20,0 \\
\hline Más de una vez por día & 9,4 & 10,0 \\
\hline Más de una vez por semana & 22,9 & 30,0 \\
\hline Una vez por semana & 32,3 & 25,0 \\
\hline Una vez por mes & 8,3 & 15,0 \\
\hline Nunca & 4,2 & - \\
\hline
\end{tabular}

Sucede lo mismo en relación al conocimiento de personas por Internet:

Cuadro 3.8.17: Conocimiento de personas por Internet según tipo de institución de enseñanza

\begin{tabular}{lccc} 
& & & \\
\cline { 2 - 3 } Si & Pública & & Privada \\
\cline { 2 - 3 } & 68,8 & & 70,0 \\
No & 31,3 & & 30,0 \\
\hline
\end{tabular}

Los alumnos de instituciones de enseñanza públicas (generalmente con menor remuneración), al usar Internet naturalmente tienden a establecer contactos con personas de ingresos más elevados o equivalentes, tendencia que disminuye en el caso de los alumnos de instituciones de enseñanza privadas:

Cuadro 3.8.18: Nivel socioeconómi co de las personas que conoció por Internet, según tipo de institución de enseñanza

\begin{tabular}{lccc}
\hline & & & \\
\cline { 2 - 3 } Nivel socioeconómico más elevado que el propio & Privada \\
Mismo nivel socioeconómico & 42,3 & & 36,4 \\
Nivel socioeconómico más bajo que el propio & 55,8 & 63,6 \\
\hline
\end{tabular}


Como se vio anteriormente, en general, cuando el nivel de ingresos aumenta, la participación en grupos de chateo disminuye, lo que se ve reflejado entre los que cursan en instituciones de enseñanza privadas y públicas:

Cuadro 3.8.19: Participación en chateos según tipo de institución de enseñanza

\begin{tabular}{|c|c|c|}
\hline & Pública & Privada \\
\hline $\mathrm{Si}$ & 61,1 & 40,0 \\
\hline No & 38,9 & 60,0 \\
\hline
\end{tabular}

La expectativa de que la computación ayuda en el trabajo, es casi un consenso:

Cuadro 3.8.20: Opinión sobre efecto del conocimiento de informática en la obtención del empleo entre habitantes que utilizan computadora según tipo de institución de enseñanza

\begin{tabular}{|c|c|c|}
\hline & Pública & Privada \\
\hline $\mathrm{Si}$ & 99,0 & 94,4 \\
\hline No & 1,0 & 5,6 \\
\hline
\end{tabular}

\section{9 - Estación Futuro}

Como se indicó anteriormente, las Estaciones Futuro son telecentros instalados por la ONG Viva Rio en diversas favelas de Rio de Janeiro. Con una media de 25 computadoras por cada Estación, éstas ofrecen conexión de alta velocidad, cursos de informática y varios servicios para el barrio.

A continuación analizamos los datos de dos favelas que poseen Estación Futuro, con el objetivo de conocer la importancia que éstas tienen para el universo de usuarios de computadora.

Del total de usuarios de computadora, prácticamente tres cuartos conocen las Estaciones Futuro: 


\section{Gráfico 3.9.1: Nivel de conocimiento de la Estación Futuro}

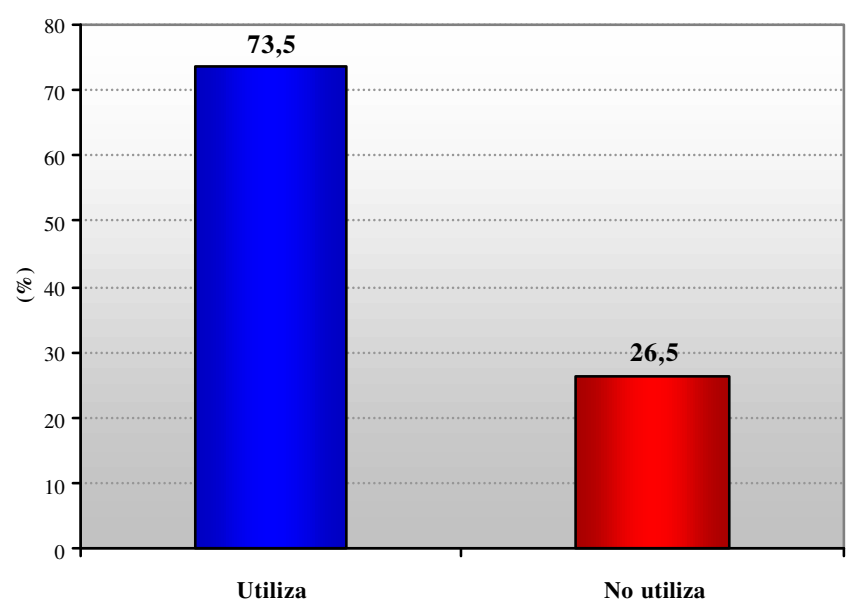

En el caso de la Favela de Rocinha, el número de personas que conocen la Estación Futuro es bastante más grande que en el caso de la Favela de Maré, lo que se debe al hecho de que la Favela de Maré es más grande (en realidad es un conjunto de favelas), espacialmente más dispersa (se encuentra en un territorio plano mientras que Rocinha está en una montaña) y está dividida internamente por el tráfico de drogas que no permite la libre circulación interna dentro de la propia área de la favela.

Cuadro 3.9.2: Porcentaje de personas que conocen la Estación Futuro, por favela

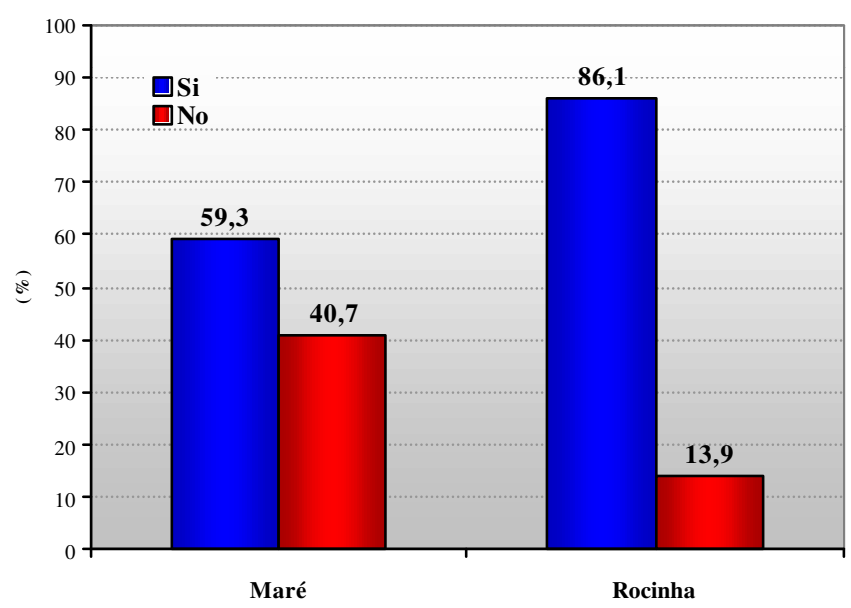


Del total de usuarios, $60 \%$ utilizan la Estación Futuro.

Cuadro 3.9.3: Nivel de utilización de la Estación Futuro

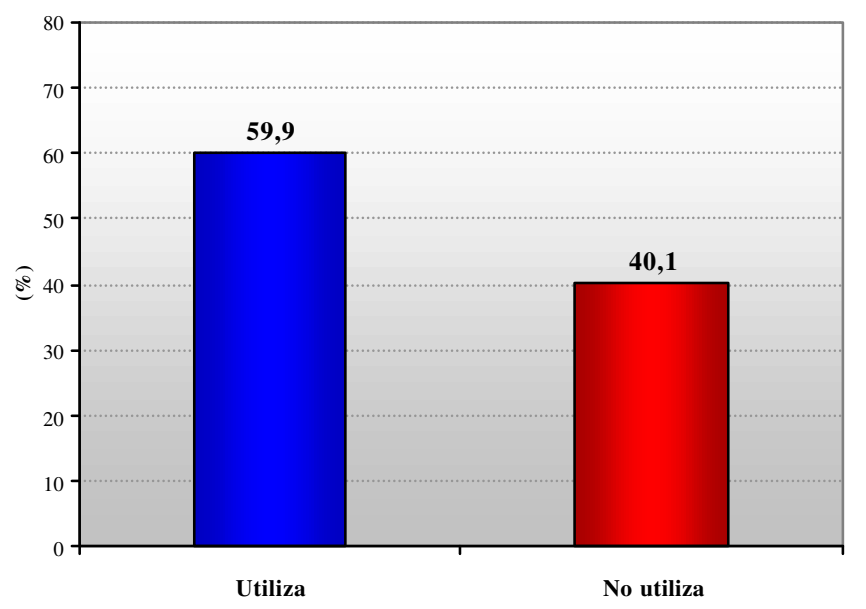

Nuevamente en la favela de Rocinha el porcentaje de usuarios de la Estación Futuro es superior:

Cuadro 3.9.4: Porcentaje de personas que utilizan la Estación Futuro por favela

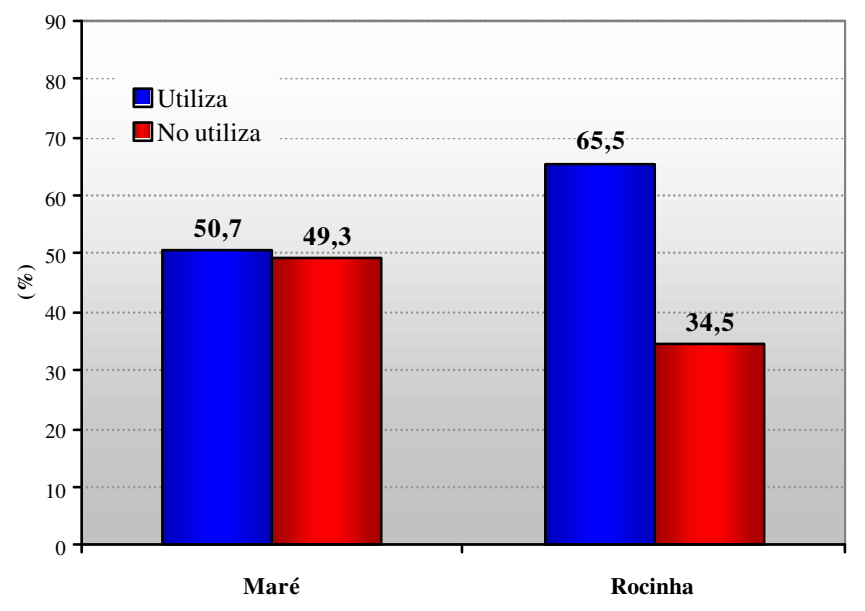

El uso de las Estaciones Futuro presenta las mismas diferencias entre sexos que encontramos en general en el universo de usuarios. Esto refleja la distribución general de los usuarios así como también indica la una dificultad por parte de las Estaciones Futuro de cambiar esa tendencia general: 


\section{Gráfico 3.9.5: Porcentaje de personas que utilizan computadora y}

la Estación Futuro según el sexo

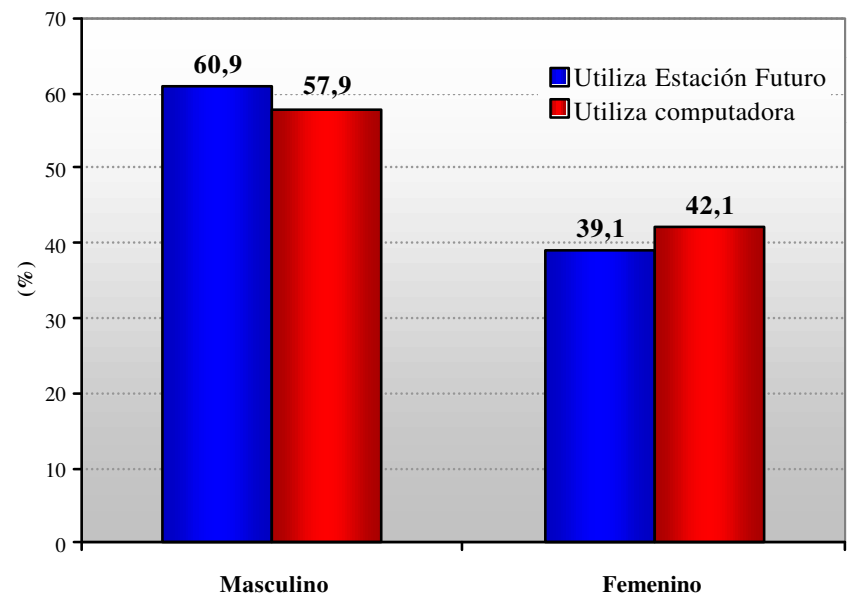

Nota: el univeso es el total de los usuarios de la Estación Futuro

Esto equivale para la población negra, que teniendo un nivel de ingreso medio más bajo, tiene dificultades para pagar los costos del uso de la Estación Futuro:

\section{Gráfico 3.9.6: Porcentaje de personas que utilizan computadora y la Estación Futuro, según la raza}

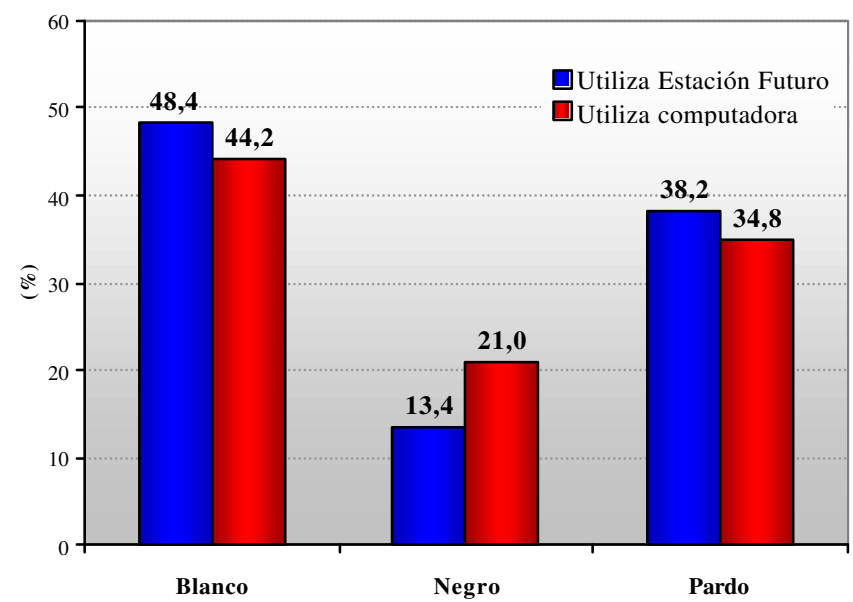

En relación al grupo de edad, las Estaciones Futuro atraen principalmente a los más jóvenes: 


\section{Gráfico 3.9.7: Porcentaje de personas que utilizan computadora y la}

Estación Futuro, según el grupo de edad

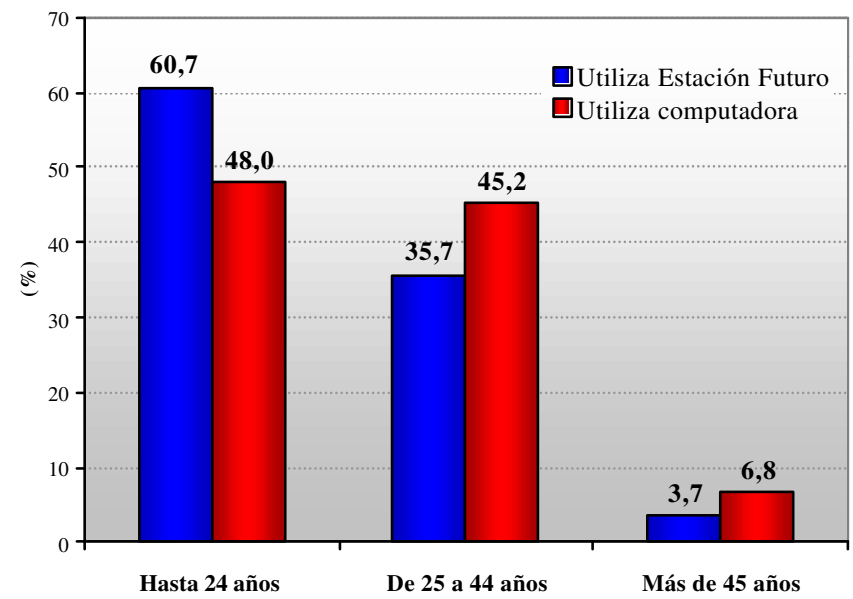

Estas jóvenes generalmente son dependientes, y probablemente muchos de ellos no trabajan:

\section{Gráfico 3.9.8: Porcentaje de personas que utilizan computadora y la Estación Futuro según la posición en el hogar}

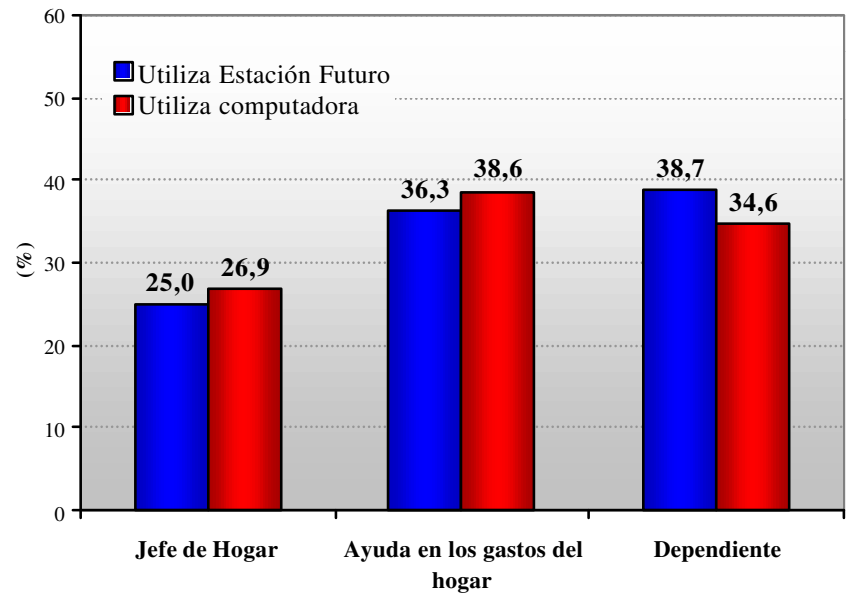

Los usuarios de la Estación Futuro tienen un ingreso familiar similar al del usuario medio de computación. En otros términos, las Estaciones Futuro expanden la disponibilidad de conexión, pero no cambian el perfil de remuneración de los usuarios: 


\section{Gráfico 3.9.9: Porcentaje de personas que utilizan computadora y la}

Estación Futuro según el ingreso familiar

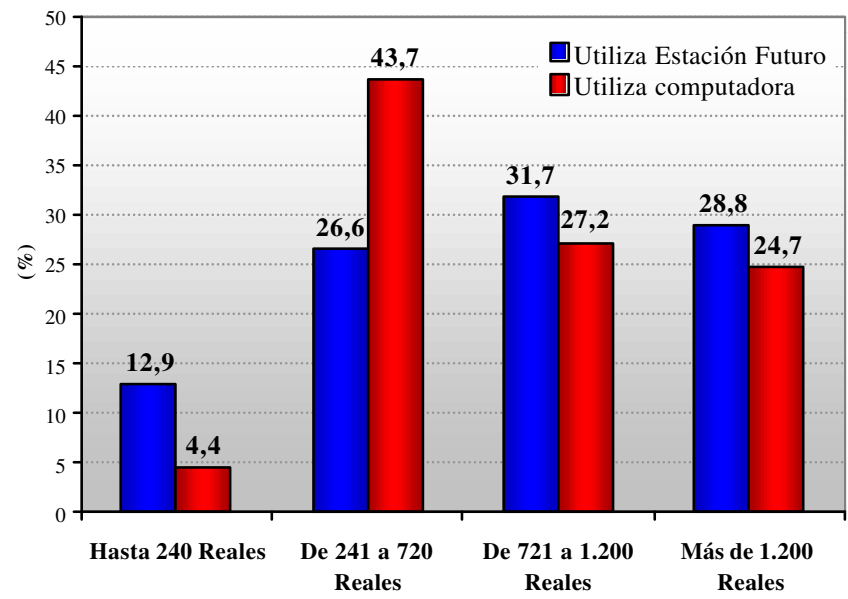

Como lo muestran los dos próximos gráficos, el número de usuarios de las Estación Futuro que poseen computadora o conexión a Internet es menor que la media general, pero continúa siendo un porcentaje importante. Inclusive el propietario de computadora usa la Estación Futuro por causa de la calidad de la conexión a Internet y la disponibilidad de impresora.

Gráfico 3.9.10: Porcentaje de personas que utilizan computadora y la Estación Futuro según posesión de computadora en el hogar

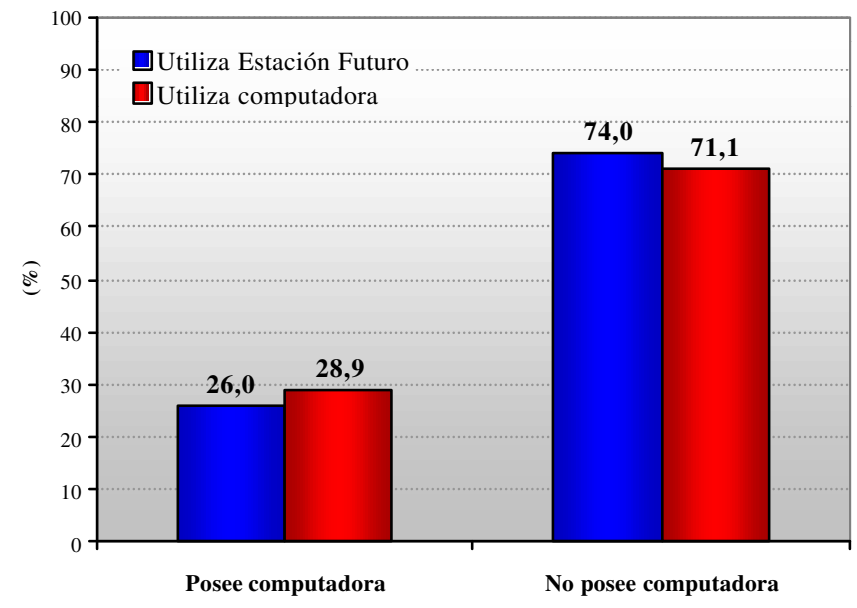


Gráfico 3.9.11: Porcentaje de personas que utilizan computadora y la Estación Futuro según posesión de Internet en el hogar

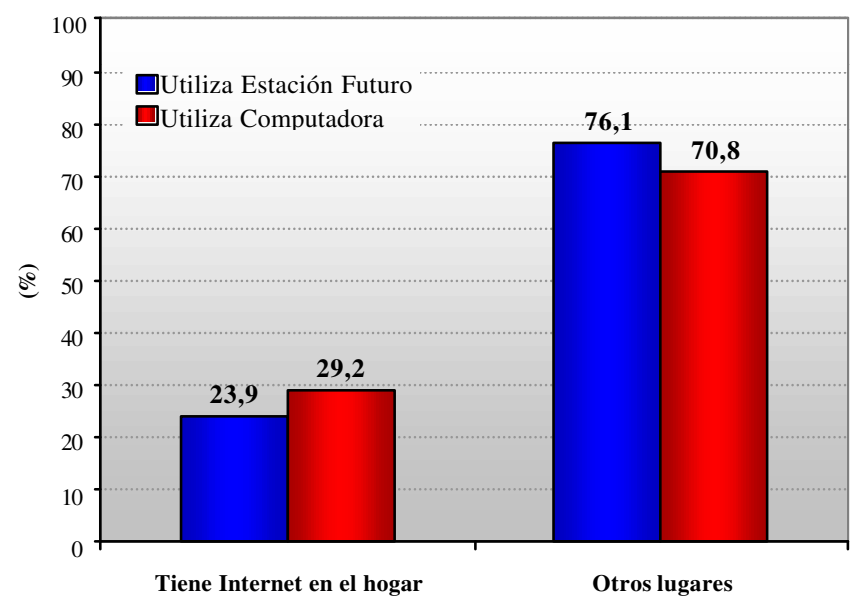

En síntesis, las Estaciones Futuro aumentan el universo de los que se conectan pero no modifican el perfil de los usuarios. 


\section{4 - Conclusiones: Políticas públicas e inclusión digital}

Teniendo en cuenta los resultados de esta investigación y la bibliografía internacional especializada en este tema de la exclusión digital, algunas conclusiones sobre los objetivos de la universalización del acceso a Internet y a la democratización de la información son importantes de destacar. Es conveniente recordar que al subrayar las limitaciones para democratizar la información, esto no significa que se esté destacando la importancia de las políticas de universalización de acceso. Por el contrario, universalizar el conocimiento básico sobre el uso de la computadora y de Internet es fundamental para limitar el impacto negativo que pueden traer para los sectores más pobres. Actualmente, los conocimientos básicos de computación e Internet son cada vez más una precondición para la obtención de empleo.

Las políticas de universalización del acceso deben de contraponerse a las complejidades asociadas a la apropiación efectiva de las TICs por los sectores más pobres de la población:

1. El valor efectivo de la información depende de la capacidad de los usuarios de cuestionarla. La información sólo existe en la forma de conocimiento, y el conocimiento depende de un largo proceso de socialización y de prácticas que crean una capacidad analítica capaz de transformar bits en conocimiento. Por lo tanto, cuestionar la exclusión escolar.

2. Las políticas de universalización del acceso a Internet en los países en desarrollo serán una quimera si no están asociados a otras políticas sociales, en particular a las de formación escolar. No habrá universalización del acceso a las nuevas tecnologías de la información y de la comunicación sin universalización de otros bienes sociales. En los países en desarrollo, donde las tasas de analfabetismo funcional son muy altas (en Brasil son aproximadamente el $30 \%$ ), la lucha contra las diferentes dificultades de acceso a los servicios públicos (educación, saneamiento, seguridad, salud, servicios jurídicos), exige una visión 
compleja de la lucha contra la exclusión digital. Seguramente, esto no significa que se deba esperar a que llegue a erradicarse el analfabetismo para desarrollar políticas de inclusión digital. No podemos olvidar que la lucha por la inclusión digital es una lucha contra el tiempo. Las nuevas tecnologías de la información aumentan la desigualdad social, de tal forma que in universalización del acceso no es sino la lucha por renivelar las condiciones de acceso al mercado del trabajo. Las exigencias de la economía y los nuevos empleos hacen necesaria la convivencia de políticas públicas que trabajen junto a diferentes sectores sociales y ritmos desiguales de universalización de los servicios públicos. Sin embargo, no se puede dejar de reconocer la imbricación de las políticas sociales, y que el éxito final de éstas depende de un programa integrado de universalización de varios servicios públicos. A corto plazo, las políticas de inclusión digital, que tendrán necesariamente un impacto sobre sólo parte de la población más pobre, deben definir claramente cuáles son el público prioritario al cual están dirigidas.

3. Como fue indicado anteriormente, es fundamental definir las prioridades de los públicos objeto de las políticas. Como lo indica la investigación, inicialmente, los tele-centros de los barrios pobres son utilizados por los sectores del barrio que ya poseen un nivel básico de escolaridad y un nivel de ingreso más alto. Una política de universalización del acceso a Internet debe de tener como objetivo fundamental cubrir la red escolar, único lugar donde pude ser efectivamente alcanzado el conjunto de la población. Como también lo indica la investigación, el local de trabajo es un factor importante de inclusión digital, y las políticas de inclusión digital deberían crear incentivos para aumentar el número de empresas que son usuarias de informática e Internet y ofrecen cursos de computación e Internet para todos sus empleados.

4. Las instituciones educativas son instrumentos centrales para socializar a las nuevas generaciones en Internet. Esto no implica: a) transformar la telemática en un instrumentos privilegiado del sistema educativo, ni b) realizar una 
inversión exagerada de computadoras por institución educativa. Los resultados de esta investigación, acerca del impacto del uso de informática e Internet en las instituciones de enseñanza, son contradictorios. La adaptación de los profesores a este nuevo instrumento es un proceso largo que no puede estar disociado del mejoramiento de la capacitación profesional. El desarrollo de softwares adecuados, la readaptación del sistema pedagógico y el desarrollo de disciplinas de educación crítica del uso de la telemática, serán, para la mayoría de los países en desarrollo, un proceso obligatoriamente de larga duración. Hasta que llegue ese momento, el papel de los laboratorios educativos de telemática, debe ser el de introducir a los alumnos en el uso de estos instrumentos, capacitándolos dentro para el conocimiento de los programas básicos, de tal forma que facilite la futura inserción de éstos en el mercado de trabajo y los motive para el uso de nuevas tecnologías. En este caso, es suficiente ofrecer cursos de telemática durante un sólo año, en la enseñanza primaria, y, eventualmente, de nuevo en secundaria.

5. Similar perspectiva debe ser aplicada en relación al objetivo de democratización de la información. El valor efectivo de la información depende de la capacidad de interpretación del usuario. Un nivel más elevados de educación es fundamental para maximizar el potencial ofrecido por Internet. La promoción de portales con contenidos específicos a los habitantes de bajos ingresos, o en los idiomas nativos, puede desempeñar un importante papel para compensar las dificultades de acceder a contenidos producidos para los públicos de la clase media o que conocen otros idiomas. Pero, en este sentido, a pesar de que los problemas han sido reconocidos por organismos dedicados a la inclusión digital, los avances han sido bastante limitados. Actualmente, la financiación de la mayor parte de los nuevos contenidos disponibles en Internet, es realizada por capital de riesgo, el cual requiere de ganancia por su inversión. Gran parte del mercado al cual están dirigidos los contenidos, son las clases medias. 
6. El desarrollo de los tele-centros, o sea, los locales de acceso público a Internet, es algo importante para cualquier política de universalización de los servicios.

A pesar de los esfuerzos de las ONGs por desarrollar los tele-centros comunitarios, estas iniciativas han tenido un impacto cuantitativo casi residual, aunque cumplan con la importante función de efecto de demostración y puedan tener, a veces, un rol importante en los barrios donde actúan. Pero la universalización del acceso para fundamentalmente por las políticas públicas relacionadas al sector privado y por los incentivos al mercado. El sector privado ha tenido un rol importante para la creación de los tele-centros, sobre todo cuando se usa equipamiento de bajo costo, programas piratas y éstos son administrados por la familia propietaria, como lo indica el ejemplo peruano. ${ }^{15}$ Pero las políticas públicas son fundamentales para llegar a una escala que las iniciativas voluntarias no tienen condiciones de alcanzar. Las políticas públicas de universalización del acceso exigen soluciones creativas de licitación de los servicios para los barrios más pobres, con servicios subsidiados, realizados por empresas privadas o asociaciones comunitarias e/u ONGs.

\footnotetext{
15 - Cf., F. J. Proenza, R. Bastidas-Buch, G, Montero, "Telecenters for Socioeconomic and Rural Development in Latin America and the Caribbean", FAO/ITU/IADB, Washington, D.C., May, 2001, http://www.iadb.org/ict4dev/telecenters/fullrep.pdf
} 


\section{Anexo 1: Representatividad del universo de investigación}

La estrategia de recolección de datos de investigación incluyó dos encuestas con objetivos y estrategias de construcción de muestreo también diferentes. La primera encuesta, cuyo principal objetivo era verificar el nivel de exclusión digital en los barrios pobres del municipio de Rio de Janeiro, se concentró en cuatro dimensiones básicas: posesión de computadoras, utilización de computadoras, utilización de Internet y utilización de e-mail. Otro objetivo que debería ser alcanzado por la primera encuesta, sería el de mostrar el impacto de la presencia de la Estación Futuro sobre la inclusión digital local. De esta forma, se definió que el universo de investigación serían los habitantes de las favelas del municipio de Rio de Janeiro, que tenían entre 15 y 65 años de edad.

Para alcanzar estos objetivos, se creó una muestra capaz de proporcionar una visión general de la exclusión digital en el conjunto de las favelas del municipio de Rio de Janeiro, con la posibilidad de que se obtuvieran indicadores para dos tipos de favelas: las que tienen Estación Futuro y las que no tienen Estación Futuro. De esta forma, fueron seleccionadas dos favelas que poseen Estación Futuro: la favela de Rocinha y la favela de Maré, ésta última representada por ocho grandes barrios (Parque Maré, Nova Holanda, Baixa do Sapateiro, Parque União, Rubens Vaz, Morro do Timbau, Praia de Ramos, Roquete Pinto), y dieciocho favelas que no tienen Estaciones Futuro: Alto da Bela Vista, Canal do Anil, Mangueira, Fazenda Coqueiro, Formiga, Favela do Jacaré (Santíssimo), Jacarezinho, Joaquim Queiroz, Morro da União, Nova Brasília, Parque Alegria, Parque Royal, Parque São Jorge, Pavão-Pavãozinho, Vila Cruzeiro, Vila Rica de Irajá, Vila São Jorge, Vila Vintém.

Las favelas seleccionadas para la muestra responden a criterios de localización, tamaño de la población y promedio de ingresos, para que todos los tipos de favelas fueran parte de la selección. La muestra total para esta encuesta fue de 1.510 entrevistados habitantes de los barrios mencionados anteriormente, y las entrevistas fueron realizadas en las entradas y en las salidas de las favelas para que el proceso de obtención de la información fuera más rápido. Esta encuesta es representativa del conjunto de favelas del municipio de Rio de 
Janeiro, y, por extensión, de la población pobre del municipio. Sin embargo, no es representativa ni del área metropolitana ni del Estado de Rio de Janeiro.

La segunda encuesta tuvo un objetivo complementario. La investigación debería definir con más precisión que la encuesta anterior, el perfil de utilización del acceso a Internet y de utilización del e-mail. Por lo tanto, se definió que el universo de la investigación serían los habitantes de las favelas del municipio de Rio de Janeiro, que tuvieran entre 10 y 65 años de edad, y que utilizan computadora.

El objetivo de esta segunda encuesta también era el de crear condiciones para que los resultados permitieran diferenciar por segmentos entre las favelas. Para esto, fueron aplicadas técnicas de investigación en seis favelas, una con un promedio de ingresos más alto, tres con promedio de ingresos intermedio y dos con promedio de ingresos bajos, utilizando un cuestionario más detallado. En el primer caso, se incluyó la favela de Rocinha, en el segundo caso la favela de Maré (un conjunto de favelas representadas por las mismas ocho favelas de la primera encuesta, muchas de ellas segmentadas por el tráfico de drogas, con sectores internos bastante diferenciados en términos de ingresos), Rio das Pedras y Morro Dona Marta, y en el tercer caso, fueron elegidas las favelas de Jacarezinho y Jacaré (Senador Camará).

El diseño de muestreo, permite una lectura de los datos para el conjunto de favelas, de forma agregada. La muestra total para esta encuesta también fue de 1.510 entrevistados habitantes de los barrios anteriormente mencionadas, que utilizan computadora, y las entrevistas también fueron realizadas en las entradas y salidas de las favelas para que el proceso de obtención de información fuera más rápido. Esta encuesta es representativa de la población de usuarios de computadora de las favelas del municipio de Rio de Janeiro. 


\section{Anexo 2 - Perfil de los grupos motivacionales}

Fueron realizados ocho Grupos Motivacionales en los barrios de Rocinha y Favela da Maré: cuatro con habitantes de Rocinha, tres con habitantes de Maré y uno con líderes comunitarios $^{16}$ de ambas. Los grupos se reunieron en el periodo del 10 al 14 de noviembre de 2003 y fueron planificados previamente de acuerdo con el grupo de edad y el sexo, excepto el grupo de los líderes comunitarios. En el próximo cuadro, está indicada la configuración de cada grupo:

\begin{tabular}{ccccc}
\hline Grupos & Faixa Etária & Sexo & Comunidade & Tipo \\
\hline \hline 1 & 12 a 16 anos & Homens e Mulheres & Rocinha & Usuários de Internet \\
2 & 16 a 22 anos & Homens e Mulheres & Maré & Usuários de Internet \\
3 & 22 a 35 anos & Homens & Rocinha & Usuários de Internet \\
4 & 22 a 35 anos & Mulheres & Rocinha & Usuários de Internet \\
5 & mais de 35 anos & Homens & Maré & Usuários de Internet \\
6 & mais de 35 anos & Mulheres & Rocinha & Usuários de Internet \\
7 & 18 a 25 anos & Homens e Mulheres & Maré & Não usuários de Internet \\
8 & - & - & Maré e Rocinha & Liderancas \\
\hline
\end{tabular}

$37 \%$ del total de los participantes del los grupos poseen computadora en su propia casa. Entre los del grupo de mujeres con más de 35 años de edad y del de los jóvenes no usuarios de Internet, hay una disminución de la adquisición de computadora. En el grupo de mujeres sólo $22 \%$ poseen equipamiento y ninguno de los jóvenes no usuarios tiene computadora:

\footnotetext{
${ }^{16}$ La expresión "lideres comunitarios" se refiere a las personas que trabajan en instituciones dedicadas a mejorar la calidad de vida en el barrio y está referida a los representantes de este barrio, en general a las asociaciones de vecinos, como a las organizaciones no gubernamentales e instituciones comunitarias sin fines de lucro.
} 


\section{Personas que participaron de las discusiones en grupo}

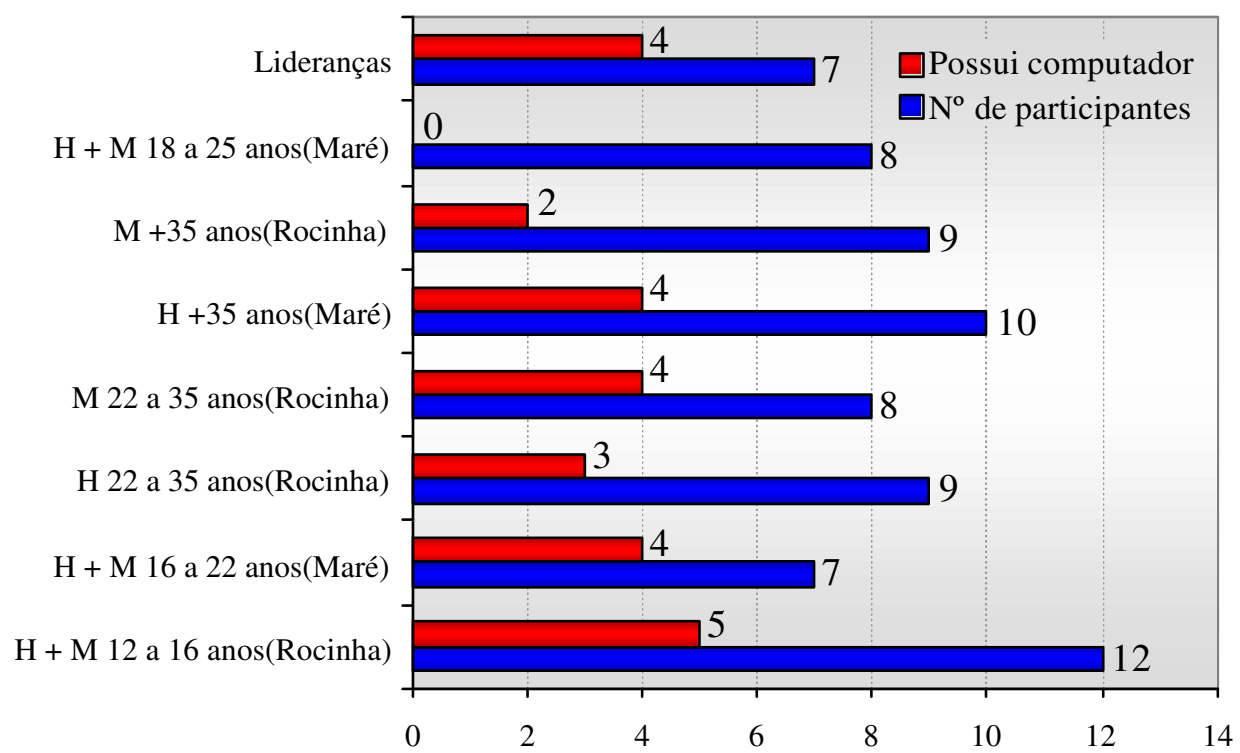

Cada grupo contó con la participación de siete a doce integrantes, que fueron invitados personalmente o a través de contacto telefónico realizado a partir del registro de usuarios de la Estación Futuro. Los grupos de Rocinha se reunieron en la Asociación de Vecinos (AMABB), localizada en la Travessa Palmas, 193 , dentro del propio barrio. Los grupos de Maré, en la Congregación Presbiteriana de Bonsucesso, localizada en la calle General Galiene, $n^{0}$ 122, Bonsucesso, y el grupo con los líderes se reunió en la sede de Viva Rio, en Glória.

Se esperó a los participantes durante 20 minutos, para después comenzar los grupos, para dar tiempo a los participantes de llegar y evitar la entrada de personas que llegaran tarde a la reunión. Primero fue realizada la presentación del equipo y del objetivo del trabajo. 